\title{
Genetic improvement of feed intake and methane emissions of cattle
}

Coralia I. V. Manzanilla Pech 


\section{Thesis committee}

\section{Promotor}

Prof. Dr R. F. Veerkamp

Professor of Numerical Genetics and Genomics

Wageningen University and Research

\section{Co-promotor}

Dr Y. de Haas

Senior researcher, Animal Breeding and Genomics

Wageningen University and Research

\section{Other members}

Prof. Dr W. H. Hendriks, Wageningen University and Research

Dr J. Lassen, Aarhus University, Tjele, Denmark

Prof. Dr E. Wall, SRUC, Midlothian, UK

Dr F. Ruiz, INIFAP, Queretaro, México

This research was conducted under the auspices of the Graduate School of Wageningen Institute of Animal Sciences (WIAS). 


\title{
Genetic improvement of feed intake and methane emissions of cattle
}

\author{
Coralia I. V. Manzanilla Pech
}

\author{
Thesis \\ submitted in fulfillment of the requirements for the degree of doctor \\ at Wageningen University \\ by the authority of the Rector Magnificus, \\ Prof. Dr A. P. J. Mol, \\ in the presence of the \\ Thesis Committee appointed by the Academic Board \\ to be defended in public \\ on Wednesday March 22, 2017 \\ at 4 p.m. in the Aula
}


Manzanilla Pech, C. I. V.

Genetic improvement of feed intake and methane emissions of cattle, 200 pages.

PhD thesis, Wageningen University, Wageningen, the Netherlands (2017) With references, with summary in English

ISBN 978-94-6343-069-2

DOI: $10.18174 / 403342$ 


\begin{abstract}
Manzanilla Pech, C. I. V. (2017). Genetic improvement of feed intake and methane emissions of cattle. PhD thesis, Wageningen University, the Netherlands
\end{abstract}

Feed costs represent half of the total costs of dairy production. One way to increase profitability of dairy production is to reduce feed costs by improving feed efficiency. As DMI is a trait that varies significantly during and across lactations, it is imperative to understand the underlying genetic architecture of DMI across lactation. Moreover, phenotypes of DMI are scarce, due to the difficulty of recording them (expensive and labor-intensive). Some predictor traits have been suggested to predict DMI. Examples of these predictor traits are those related to production (milk yield (MY) or milk content) or to the maintenance of the cow (body weight (BW) or conformation traits). The ability to determine when predictor traits ideally should be measured in order to achieve an accurate prediction of DMI throughout the whole lactation period is thus important. Recently, with the use of information of single nucleotide polymorphism (SNP) markers, together with phenotypic data and pedigree, genomically estimated breeding values (GEBV) of scarcely recorded traits, such as DMI, have become easier to accurately predict. This approach, combined with predictor traits, could contribute to an increased accuracy of predictions of GEBV of DMI. Methane $\left(\mathrm{CH}_{4}\right)$ is the second important greenhouse gas, and enteric $\mathrm{CH}_{4}$ is the largest source of anthropogenic $\mathrm{CH}_{4}$, representing $17 \%$ of global $\mathrm{CH}_{4}$ emissions. Furthermore, methane emissions represent $2-12 \%$ of feed energy losses. Selecting for lower $\mathrm{CH}_{4}$ emitting animals and more feed-efficient animals would aid in mitigating global $\mathrm{CH}_{4}$ emissions. To identify the impact on $\mathrm{CH}_{4}$ emissions of selecting for lower DMI animals, it is important to determine the correlations between $\mathrm{DMI}$ and $\mathrm{CH}_{4}$ and to identify whether the same genes that control DMI affect $\mathrm{CH}_{4}$. Therefore, the general objectives of this thesis were to (1) explore the genetic architecture of DMI during lactation, (2) study the relationship of DMI to conformation, production and other related traits, (3) investigate the correlations between DMI and methane traits, and determine the SNP in common between $\mathrm{DMI}$ and $\mathrm{CH}_{4}$ through a genome-wide association study (GWAS), and (4) investigate the accuracy of predictions of DMI using predictor traits combined with genomic data. 



\section{Contents}

$\begin{array}{ll}\text { Abstract } & 5\end{array}$

$\begin{array}{lll}\text { Chapter } 1 \text { General introduction } & 9\end{array}$

Chapter 2 Genetic parameters across lactation for feed 27

intake, fat and protein corrected milk and live

weight in first parity Holstein cattle

Chapter 3 Genetic parameters between feed intake-related

traits and conformation in two separate dairy

populations: the Netherlands and United States

Chapter 4 Genome-wide association study of methane emissions

89

in Angus beef cattle with validation in dairy cattle

Chapter 5 Accuracies of genomic breeding values for dry matter intake in Holstein cattle using different methods and scenarios

Chapter 6 General discussion

Summary

Curriculum vitae

Training and Supervision plan 192

Acknowledgments 



\section{Chapter 1}

General Introduction 



\subsection{Importance of feed efficiency and methane}

Feed costs represent a large proportion of the total costs of dairy farming and, therefore, there is major interest in improving the feed efficiency of dairy cattle. Reducing feed intake, while maintaining production, should improve feed efficiency and hence farmer profit. In dairy cattle, feed efficiency can be defined either as the ratio of the kilograms of milk produced to the kilograms of dry matter intake (DMI) (Veerkamp and Emmans, 1995), or as the difference between actual and predicted intake, or residual feed intake (RFI). For both definitions, DMI is a required component for calculating feed efficiency (Berry and Crowley, 2013). However, interest in DMI extends beyond improving feed efficiency alone, as DMI is also related to energy balance (EB) (Villagodoy et al., 1988), which is defined as the difference between the energy a cow expends for lactation, maintenance, growth and reproduction and the energy a cow gains from the intake of nutrients (Liinamo et al., 2012). Several studies have reported the unfavorable effects of negative EB on health and fertility (Pryce et al., 1998; Berry et al., 2003; Friggens, 2003). Thus, including DMI in the breeding goal could aid in avoiding negative EB in cows. Moreover, improving feed efficiency in cattle is also expected to help lower methane emissions (Hegarty et al., 2007; De Haas et al., 2011), which could have implications for greenhouse gases mitigation (Wall et al., 2010).

Methane $\left(\mathrm{CH}_{4}\right)$ contributes substantially to global warming, being the second most important greenhouse gas after carbon dioxide $\left(\mathrm{CO}_{2}\right)$ (Knapp et al., 2014). The livestock sector is a major contributor to $\mathrm{CH}_{4}$ emissions, representing $18 \%$ of total global anthropogenic greenhouse emissions. Methane is a sub-product of the enteric (microbial) fermentation of carbohydrates in the reticulum-rumen of farm animals (Gray et al., 1951), and represents 2-12\% of feed energy losses (Johnson et al., 1994). Reducing enteric emissions will thus lower these losses, thereby improving the cow's efficiency. Moreover, given that $\mathrm{CH}_{4}$ is a complex trait involving several biological processes in the rumen, including the ruminal microorganisms present, type of diet, the amount of feed intake and the size of the animal, among others, the goal of mitigating $\mathrm{CH}_{4}$ should be approached as a combined, interdisciplinary effort. Over the past decade, the scientific community in this field has been investigating means by which to reduce $\mathrm{CH}_{4}$ emissions, encompassing various scientific disciplines, such as animal nutrition, physiology, management and genetics (Alford et al., 2006; Hegarty et al., 2007; De Haas et al., 2011; Waghorn and Hegarty, 2011; Garnsworthy et al., 2012; Ross et al., 2013). As a result, several nutritional and genetic approaches have been proposed to reduce 
$\mathrm{CH}_{4}$ (Hegarty et al., 2007; Beauchemin et al., 2008; Grainger et al., 2008; McGinn et al., 2009). In this thesis, some genetic advances suggested to mitigate methane emissions will be discussed.

\subsection{History of genetic research regarding DMI and methane}

Dry matter intake has been the subject of research for over two decades (Korver, 1988; Van Arendonk et al., 1991; Kennedy et al., 1993; Veerkamp et al., 1994a; Veerkamp et al., 1994b; Veerkamp et al., 1995), providing the groundwork for our basic knowledge about DMI and genetics: 1) DMI is heritable, 2) it varies across lactation periods, and 3 ) it is highly correlated with production and maintenance traits. Despite this generated knowledge regarding $\mathrm{DMI}$, it has been impossible to include DMI in breeding programs thus far, for two main reasons. Firstly, most of these studies used relatively small data sets, making it difficult to estimate accurate genetic parameters for DMI. Accurate genetic correlations with other economic traits are needed to establish the correct breeding goal, and to utilize predictor traits to estimate breeding values for DMI. Secondly, the available method for obtaining the estimated breeding value (EBV) for bulls was, until recently, the best linear unbiased prediction (BLUP) (Henderson, 1984). To estimate accurate EBV thus required large databases of phenotypic records and the pedigrees of animals and/or their offspring. In dairy cattle, most economically important traits are measured in females, while major genetic progress arises from bull selection. Hence, selection has been primarily based on progeny testing of the performance of bulls' daughters in commercial herds, requiring at least 100 daughters per sire/bull to estimate accurate EBV (Schaeffer, 2006), assuming a moderate heritability of the trait. Measuring individual DMI in commercial herds was not practical, and therefore direct selection for DMI was impossible until recent times.

In the last decade, the availability of genotyping platforms, together with cost reductions in genotyping and improvements in computing capacity, has modified the concept of animal breeding. Single nucleotide polymorphisms (SNP) across the genome, together with phenotypic data, are used to predict genomic EBV (GEBV). For classical traits, the benefits of genomic selection are reducing the generation interval and increasing the accuracy of EBV for females, which increases the genetic gain per year (Schaeffer, 2006; Konig and Swalve, 2009). A young animal's GEBV can be predicted accurately very early in life, and this GEBV can be 
used as a selection criterion for candidates to become sires, even without known phenotypic information of offspring. However, genomic selection also has an important advantage for scarcely recorded traits, because genomic selection relaxes the requirement of having DMI records on many progeny for each bull. This has stimulated research in DMI (Veerkamp et al., 2012; Yao et al., 2013; Pryce et al., 2014b; VandeHaar et al., 2016), and genomic predictions for DMI have thus been investigated over the past five years (De Haas et al., 2012; Berry et al., 2014; Pryce et al., 2015). However, more phenotypes of DMI are still required in the reference population than those available in each single country, in order to estimate accurate GEBV (Daetwyler et al., 2010). Therefore, research has focused on combining data sets across countries and populations through international projects (Berry et al., 2014; De Haas et al., 2015).

Methane is a relatively newly studied trait in animal breeding. Over the last five years, few genetic studies on $\mathrm{CH}_{4}$ have been published on actual $\mathrm{CH}_{4}$ emissions in beef (Donoghue et al., 2016b; Hayes et al., 2016) and dairy (Difford et al., 2016; Lassen and Lovendahl, 2016), as most data sets on $\mathrm{CH}_{4}$ are currently small in size. Additionally, there are some studies published on the genetic analyses of predicted methane emissions, either from milk yield and feed intake, or from milk fatty acids and methyl-coenzyme M (De Haas et al., 2011; Aguinaga Casanas et al., 2015; Pickering et al., 2015; Van Engelen et al., 2015; Yin et al., 2015). Furthermore, more research regarding methane in sheep has been developed (Pinares-Patino et al., 2013; Robinson et al., 2014; Shi et al., 2014; Rose et al., 2016), which could be used to measure and analyze methane, given that it is easier to record methane in the field in sheep than in cows. Finally, all these studies show that methane in ruminants is a trait with moderate heritability and genetic selection can be used to reduce $\mathrm{CH}_{4}$ emissions. However, to select for lower $\mathrm{CH}_{4}$ emitting animals, accurate genetic parameters and EBV are required. Therefore, given the actual limitation of small databases, several studies are ongoing in a number of countries (the Netherlands, Australia and Denmark, among others) in order to record $\mathrm{CH}_{4}$ emissions for a wider population of cattle.

\subsection{Genetics of DMI and methane}

To understand the genetics of the feed utilization complex, and to include feed efficiency in breeding goals, accurately estimated genetic parameters for DMI are needed. Several studies have reported heritabilities for DMI in dairy cattle between 0.1 and 0.4 (Veerkamp and Brotherstone, 1997; Vallimont et al., 2010), 
demonstrating that genetic selection for feed efficiency is possible. For beef cattle, the heritabilities ranged between 0.3 and 0.7 (Herd and Bishop, 2000; Arthur et al., 2001; Crowley et al., 2010). Since DMI is influenced by several biological processes that vary across lactation periods (e.g., milk yield and pregnancy), it is likely that DMI shows different genetic variations and heritabilities at different stages of lactation (Koenen and Veerkamp, 1998; Veerkamp and Thompson, 1999; Spurlock et al., 2012; Tetens et al., 2014). Some studies have also shown a negative genetic correlation between DMI in early and mid lactation (Koenen and Veerkamp, 1998; Huttmann et al., 2009; Buttchereit et al., 2011), and highly positive genetic correlations between DMI in mid and late lactation (Huttmann et al., 2009). Having different genetic correlations within DMI at different stages of lactation could mean that the trait changes genetically from one lactation stage to another, making it difficult to predict DMI for the entire lactation period with only a few records. Additionally, the responses when selecting DMI depend on when DMI is measured. Currently, there is no evidence that major genes with large effects on DMI exist; however, a couple of genes on chromosome 27 could be potential candidate genes for DMI in dairy cattle (Veerkamp et al., 2012). Likewise, in beef cattle, genomic regions associated with feed intake and feed efficiency have been identified (Santana et al., 2014; Yao et al., 2015).

Despite the limited amount of $\mathrm{CH}_{4}$ data for cattle, there are some genetic studies that have presented genetic parameters for $\mathrm{CH}_{4}$ (Donoghue et al., 2016a; Hayes et al., 2016; Lassen and Lovendahl, 2016). These studies have reported moderate heritabilities for $\mathrm{CH}_{4}$ - between 0.2 and 0.3 - higher than those previously reported in sheep, at around 0.1 (Pinares-Patino et al., 2013; Rose et al., 2016). Additionally, thus far, there has been little evidence of genes with large effects on $\mathrm{CH}_{4}$, though chromosome 12 seems to explain $8 \%$ of the variation in $\mathrm{CH}_{4}$ in growing beef cattle (Hayes et al., 2016). Therefore, given the existing genetic variation in $\mathrm{CH}_{4}$, there is potential to reduce $\mathrm{CH}_{4}$ through (genomic) selection, but this requires further investigation.

\subsubsection{Predictor traits}

In the absence of direct records on the trait of interest, indirect measures for this trait can be used to assess its genetic variation. A predictor trait must meet several requirements: it must be easily recordable, preferably routinely recorded, inexpensive to measure, heritable and, most importantly, genetically correlated with the trait of interest. Using a predictor trait results in faster and cheaper improvements of the trait of interest when the accuracy of the EBV for the 
predictor trait multiplied by the genetic correlation outweighs the accuracy for the EBV for DMI when measured directly.

Body weight and selected conformation traits (e.g., body size, stature, chest width, body depth, angularity, rump width) have shown to be useful predictors of milk production, DMI and feed efficiency in Holsteins (Parke et al., 1999; Veerkamp and Brotherstone, 1997). Production traits, such as milk yield and milk contents, are also considered to be good predictors of DMI as they are genetically highly correlated with $\mathrm{DMI}$, and relatively easy and cheap to record on a large, national scale (Korver, 1988; Van Arendonk, 1991; Veerkamp and Brotherstone, 1997; Veerkamp, 1998; Liinamo et al., 2012). As it has been shown that DMI changes genetically across different lactation stages (Koenen and Veerkamp, 1998; Karacaoren et al., 2006; Huttmann et al., 2009; Buttchereit et al., 2011), it is important to consider genetic correlations between predictor traits and DMI across lactation periods.

Finally, combining predictor traits and genomic information seems to be an approach by which predictor traits could provide more data for the genomic evaluation and help to explain some of the variance of DMI together with genomic information (Pszczola et al., 2013). Moreover, genomic predictions of DMI can be used to indicate the additional differences in DMI between two animals that share the same predictor trait values. Using genomic information in combination with predictor traits is expected to enable us to better differentiate between individual cows and, therefore, to predict more accurate breeding values for DMI.

\subsubsection{Combining data sets}

Even though genomic selection relaxes the requirements of recording phenotypes on progeny, the number of cows recorded for the trait of interest (in this case $\mathrm{DMI}$ or $\mathrm{CH}_{4}$ ) might still be too low within each country to achieve accurate national GEBV (Pszczola et al., 2012b). Several authors have shown that the accuracy of GEBV can be improved by increasing the number of animals in the reference population, by sampling animals within families relevant for selection, by increasing marker density, and by increasing heritability (Daetwyler et al., 2008; Goddard, 2009; Calus, 2010; Pszczola et al., 2012a). For DMI, the most viable option for increasing the accuracy of GEBV is to enlarge the number of animals in the reference population by exchanging phenotypes and genotypes among countries (Banos et al., 2012; Pintus et al., 2012). This helps to increase the accuracy of breeding values, as well as having sufficient numbers of animals and records increases the accuracy of estimated genetic parameters, and (co)variance components. In addition, a multi-country data set provides a pool of records that 
can be used as a reference population in genomic studies, contributing to the facilitation of genomic selection. A slightly different approach to increasing the size of the reference population of animals with scarcely recorded traits (e.g., RFI) is to combine data from different dairy and beef cattle breeds, attempting to increase the accuracy of prediction of the trait (Khansefid et al., 2014; Wientjes et al., 2016).

Challenges when combining phenotypes from several countries include the genotype by environment interaction, and the possible differences in trait definition between countries. A multi-trait model can handle traits that are measured in different environments as separate traits (Calus and Veerkamp, 2011; De Haas et al., 2012), thereby appropriately treating both the genotype by environment interaction and differences in trait definitions. An example of international collaboration is the global Dry Matter Initiative (gDMI), which combines 15 partners from 10 countries with the aim of building one reference population of genotyped Holstein animals and DMI records (Veerkamp et al., 2013). Several studies have already been published as a result of this gDMI project (Berry et al., 2014; Pryce et al., 2014a; De Haas et al., 2015). Similar initiatives include a dairy feed efficiency consortium in the US (VandeHaar, 2014) the Genome Canada project (Genome Canada, 2016), collaborations between Australia and New Zealand (Pryce et al., 2012), and Scandinavian country partnerships (FUNC, 2016) Another example of combining Holstein reference populations is that reported by Lund et al. (2011), with a reference population of 4000 bulls from four different countries (France, Denmark, Germany and the Netherlands) through their respective breeding organizations. These initiatives have demonstrated the value of combining data to increase reference populations and increase the accuracy of predictions of several traits in cattle.

Nowadays, accuracies of predictions of GEBV for DMI have been estimated at between 0.30 and 0.39, as reported by Pryce et al. (2014b) and De Haas et al. (2012), showing that there is still a need for improvement. Merging databases to increase the reference population seems to be the quickest way by which to increase the accuracies of predictions of GEBV for DMI. Likewise, predictions of GEBV for $\mathrm{CH}_{4}$ have been reported in the literature with accuracies between 0.37 and 0.43 in sheep (Rowe et al., 2014), and between 0.32 and 0.38 in Angus beef cattle (Hayes et al., 2016). However, it is necessary to increase the reference population of Angus with methane phenotypes to achieve more accurate GEBV. 


\subsection{This thesis}

The objectives of this thesis are to (1) explore the genetic architecture of DMI during lactation, (2) study the relationship of DMI to conformation, production and other related traits, (3) investigate the correlations between DMI and methane traits, and determine the SNP in common between DMI and $\mathrm{CH}_{4}$ through a genome-wide association study (GWAS), and (4) investigate the accuracy of predictions of DMI using predictor traits combined with genomic data. This thesis provides information about the genetic architecture of $\mathrm{DMI}$ and $\mathrm{CH}_{4}$, together with related traits, such as fat and protein corrected milk (FPCM) and body weight (BW), and conformation traits that can be used as predictor traits - whether together with genomic prediction or otherwise. In Chapter 2, genetic parameters are estimated for DMI, FPCM and BW in Holstein Friesian cows during the entire first lactation period using random regression, in order to determine whether those traits are genetically correlated to one another, and whether such correlation varies across lactation periods. The database used was a combination of a number of historical nutritional experiments in the Netherlands, resulting in a large amount of data. In Chapter 3, genetic correlations are estimated between six feed intakerelated traits - DMI, RFI, milk yield (MY), milk energy (MilkE), BW and metabolic BW (MBW) - and seven conformation traits, reflecting body conditions and sizes of Holstein cows from two different countries: the Netherlands and the United States. These genetic correlations are used to determine whether these 13 traits are the same in both countries and to calculate the accuracies of predictions of DMI, RFI and MBW with selection index theory using different predictor traits. In Chapter 4, GWAS are performed to identify SNP associated with $\mathrm{CH}_{4}$ traits - methane production (MeP), methane yield (MeY) and methane intensity (MI) - as well as $\mathrm{DMI}$ and BW in Australian Angus beef cattle, to validate, a posteriori, the significant SNP found in beef (for all traits) in two Holstein population. Additionally, two different residual methane traits are evaluated and it is determined whether SNP associated with $\mathrm{CH}_{4}$ also play a role in controlling residual methane traits. In Chapter 5, accuracies of GEBV for DMI from three methods (GBLUP, SSGBLUP and SSRRBLUP) and several different scenarios (using information from one or three lactations; using FPCM and BW as predictor traits or not) are compared in order to determine which method and scenario provides the most accurate GEBV. In Chapter 6 (General Discussion), two main points are discussed in detail: 1) what is needed in order to include feed efficiency in the breeding goal for dairy cattle, and 2) how to optimize the recording of feed intake and its predictors. 


\subsection{References}

Aguinaga Casanas, M. A., N. Rangkasenee, N. Krattenmacher, G. Thaller, C. C. Metges and B. Kuhla. 2015. Methyl-coenzyme $M$ reductase $A$ as an indicator to estimate methane production from dairy cows. J. Dairy Sci. 98(6):4074-4083.

Alford, A. R., R. S. Hegarty, P. F. Parnell, O. J. Cacho, R. M. Herd and G. R. Griffith. 2006. The impact of breeding to reduce residual feed intake on enteric methane emissions from the Australian beef industry. Aust. J. Exp. Agr. 46(6-7):813-820.

Arthur, P. F., J. A. Archer, D. J. Johnston, R. M. Herd, E. C. Richardson and P. F. Parnell. 2001. Genetic and phenotypic variance and covariance components for feed intake, feed efficiency, and other postweaning traits in Angus cattle. J. Anim. Sci. 79(11):2805-2811.

Beauchemin, K. A., M. Kreuzer, F. O'Mara and T. A. McAllister. 2008. Nutritional management for enteric methane abatement: a review. Aust. J. Exp. Agr. 48(12):21-27.

Berry, D. P., F. Buckley, P. Dillon, R. D. Evans, M. Rath and R. F. Veerkamp. 2003. Genetic relationships among body condition score, body weight, milk yield, and fertility in dairy cows. J. Dairy Sci. 86(6):2193-2204.

Berry, D. P., M. P. Coffey, J. E. Pryce, Y. De Haas, P. Lovendahl, N. Krattenmacher, J. J. Crowley, Z. Wang, D. Spurlock, K. Weigel, K. Macdonald and R. F. Veerkamp. 2014. International genetic evaluations for feed intake in dairy cattle through the collation of data from multiple sources. J. Dairy Sci. 97(6):3894-3905.

Berry, D. P. and J. J. Crowley. 2013. Cell Biology Symposium: genetics of feed efficiency in dairy and beef cattle. J. Anim. Sci. 91(4):1594-1613.

Buttchereit, N., E. Stamer, W. Junge and G. Thaller. 2011. Short communication: genetic relationships among daily energy balance, feed intake, body condition score, and fat to protein ratio of milk in dairy cows. J. Dairy Sci. 94(3):1586-1591.

Calus, M. P. L. 2010. Genomic breeding value prediction: methods and procedures. Animal 4(2):157-164.

Calus, M. P. L. and R. F. Veerkamp. 2011. Accuracy of multi-trait genomic selection using different methods. Genet. Sel. Evol. 43.

Crowley, J. J., M. McGee, D. A. Kenny, D. H. Crews, R. D. Evans and D. P. Berry. 2010. Phenotypic and genetic parameters for different measures of feed efficiency in different breeds of Irish performance-tested beef bulls. J. Anim. Sci. $88(3): 885-894$. 
Daetwyler, H. D., R. Pong-Wong, B. Villanueva and J. A. Woolliams. 2010. The impact of genetic architecture on genome-wide evaluation methods. Genetics 185(3):1021-1031.

Daetwyler, H. D., B. Villanueva and J. A. Woolliams. 2008. Accuracy of predicting the genetic risk of disease using a genome-wide approach. Plos One 3(10).

De Haas, Y., M. P. L. Calus, R. F. Veerkamp, E. Wall, M. P. Coffey, H. D. Daetwyler, B. J. Hayes and J. E. Pryce. 2012. Improved accuracy of genomic prediction for dry matter intake of dairy cattle from combined European and Australian data sets. J. Dairy Sci. 95(10):6103-6112.

De Haas, Y., J. E. Pryce, M. P. L. Calus, E. Wall, D. P. Berry, P. Lovendahl, N. Krattenmacher, F. Miglior, K. Weigel, D. Spurlock, K. A. Macdonald, B. Hulsegge and R. F. Veerkamp. 2015. Genomic prediction of dry matter intake in dairy cattle from an international data set consisting of research herds in Europe, North America, and Australasia. J. Dairy Sci. 98(9):6522-6534.

De Haas, Y., J. J. Windig, M. P. L. Calus, J. Dijkstra, M. De Haan, A. Bannink and R. F. Veerkamp. 2011. Genetic parameters for predicted methane production and potential for reducing enteric emissions through genomic selection. J. Dairy Sci. 94(12):6122-6134.

Difford, G. F., J. Lassen and P. Lovendahl. 2016. Interchangeability between methane measurements in dairy cows assessed by comparing precision and agreement of two non-invasive infrared methods. Comput. Electron Agr. 124:220-226.

Donoghue, K. A., T. Bird-Gardiner, P. F. Arthur, R. M. Herd and R. F. Hegarty. 2016a. Genetic and phenotypic variance and covariance components for methane emission and postweaning traits in Angus cattle. J. Anim. Sci. 94(4):1438-1445.

Donoghue, K. A., T. Bird-Gardiner, P. F. Arthur, R. M. Herd and R. F. Hegarty. 2016b. Genetic and phenotypic variance and covariance components for methane emission and postweaning traits in Angus cattle. J. Anim. Sci. (in press).

Friggens, N. C. 2003. Body lipid reserves and the reproductive cycle: towards a better understanding. Livest. Prod. Sci. 83(2-3):219-236.

FUNC. Feed utilization in Nordic cattle. http://projects.au.dk/func/. Accessed: December 2, 2016.

Garnsworthy, P. C., J. Craigon, J. H. Hernandez-Medrano and N. Saunders. 2012. Variation among individual dairy cows in methane measurements made on farm during milking. J. Dairy Sci. 95(6):3181-3189.

Genome Canada. 2016. https://www.genomecanada.ca/en/increasing-feedefficiency-and-reducing-methane-emissions-through-genomics-new-promisinggoal. Accessed: November 22, 2016. 
Goddard, M. 2009. Genomic selection: prediction of accuracy and maximisation of long term response. Genetica 136(2):245-257.

Grainger, C., M. J. Auldist, T. Clarke, K. A. Beauchemin, S. M. McGinn, M. C. Hannah, R. J. Eckard and L. B. Lowe. 2008. Use of monensin controlled-release capsules to reduce methane emissions and improve milk production of dairy cows offered pasture supplemented with grain. J. Dairy Sci. 91(3):1159-1165.

Gray, F. V., A. F. Pilgrim and R. A. Weller. 1951. Fermentation in the rumen of the sheep: the production of volatile fatty acids and methane during the fermentation of wheaten hay and lucerne hay in vitro by micro-organisms from the rumen. J. Exp. Biol. 28(1):74-82.

Hayes, B. J., K. A. Donoghue, C. M. Reich, B. A. Mason, T. Bird-Gardiner, R. M. Herd and P. F. Arthur. 2016. Genomic heritabilities and genomic estimated breeding values for methane traits in Angus cattle. J. Anim. Sci. 94(1):1-7.

Hegarty, R. S., J. P. Goopy, R. M. Herd and B. McCorkell. 2007. Cattle selected for lower residual feed intake have reduced daily methane production. J. Anim. Sci. 85(6):1479-1486.

Henderson, C. R. 1984. Estimation of variances and covariances under multiple trait models. J. Dairy Sci. 67(7):1581-1589.

Herd, R. M. and S. C. Bishop. 2000. Genetic variation in residual feed intake and its association with other production traits in British Hereford cattle. Livest. Prod. Sci. 63(2):111-119.

Huttmann, H., E. Stamer, W. Junge, G. Thaller and E. Kalm. 2009. Analysis of feed intake and energy balance of high-yielding first lactating Holstein cows with fixed and random regression models. Animal 3(2):181-188.

Johnson, K., M. Huyler, H. Westberg, B. Lamb and P. Zimmerman. 1994. Measurement of methane emissions from ruminant livestock using a sulfur hexafluoride tracer technique. Environ. Sci. Technol. 28(2):359-362.

Karacaoren, B., F. Jaffrezic and H. N. Kadarmideen. 2006. Genetic parameters for functional traits in dairy cattle from daily random regression models. J. Dairy Sci. 89(2):791-798.

Kennedy, B. W., J. H. J. Vanderwerf and T. H. E. Meuwissen. 1993. Genetic and statistical properties of residual feed intake. J. Anim. Sci. 71(12):3239-3250.

Khansefid, M., J. E. Pryce, S. Bolormaa, S. P. Miller, Z. Wang, C. Li and M. E. Goddard. 2014. Estimation of genomic breeding values for residual feed intake in a multibreed cattle population. J. Anim. Sci. 92(8):3270-3283.

Knapp, J. R., G. L. Laur, P. A. Vadas, W. P. Weiss and J. M. Tricarico. 2014. Invited review: enteric methane in dairy cattle production: quantifying the opportunities and impact of reducing emissions. J. Dairy Sci. 97(6):3231-3261. 
Koenen, E. P. C. and R. F. Veerkamp. 1998. Genetic covariance functions for live weight, condition score, and dry-matter intake measured at different lactation stages of Holstein Friesian heifers. Livest. Prod. Sci. 57(1):67-77.

Konig, S. and H. H. Swalve. 2009. Application of selection index calculations to determine selection strategies in genomic breeding programs. J. Dairy Sci. 92(10):5292-5303.

Korver, S. 1988. Genetic aspects of feed intake and feed efficiency in dairy cattle: a review. Livest. Prod. Sci. 20(1):1-13.

Lassen, J. and P. Lovendahl. 2016. Heritability estimates for enteric methane emissions from Holstein cattle measured using noninvasive methods. J. Dairy Sci. 99(3):1959-1967.

Liinamo, A. E., P. Mantysaari and E. A. Mantysaari. 2012. Short communication: genetic parameters for feed intake, production, and extent of negative energy balance in Nordic Red dairy cattle. J. Dairy Sci. 95(11):6788-6794.

Lu, Y., M. J. VandeHaar, D. M. Spurlock, K. A. Weigel, L. E. Armentano, C. R. Staples, E. E. Connor, Z. Wang, N. M. Bello and R. J. Tempelman. 2015. An alternative approach to modeling genetic merit of feed efficiency in dairy cattle. J. Dairy Sci. 98(9):6535-6551.

Lund, M. S., A. P. W. De Roos, A. G. De Vries, T. Druet, V. Ducrocq, S. Fritz, F. Guillaume, B. Guldbrandtsen, Z. T. Liu, R. Reents, C. Schrooten, F. Seefried and G. S. Su. 2011. A common reference population from four European Holstein populations increases reliability of genomic predictions. Genet. Sel. Evol. 43.

McGinn, S. M., Y. H. Chung, K. A. Beauchemin, A. D. Iwaasa and C. Grainger. 2009. Use of corn distillers' dried grains to reduce enteric methane loss from beef cattle. Can. J. Anim. Sci. 89(3):409-413.

Parke, P., B. W. Kennedy, J. C. M. Dekkers, R. K. Moore and L. Jairath. 1999. Genetic and phenotypic parameter estimates between production, feed intake, feed efficiency, body weight and linear type traits in first lactation Holsteins. Can. J. Anim. Sci. 79(4):425-431.

Pickering, N. K., M. G. Chagunda, G. Banos, R. Mrode, J. C. McEwan and E. Wall. 2015. Genetic parameters for predicted methane production and laser methane detector measurements. J. Anim. Sci. 93(1):11-20.

Pinares-Patino, C. S., S. M. Hickey, E. A. Young, K. G. Dodds, S. MacLean, G. Molano, E. Sandoval, H. Kjestrup, R. Harland, C. Hunt, N. K. Pickering and J. C. McEwan. 2013. Heritability estimates of methane emissions from sheep. Animal 7:316-321.

Pintus, M. A., G. Gaspa, E. L. Nicolazzi, D. Vicario, A. Rossoni, P. Ajmone-Marsan, A. Nardone, C. Dimauro, and N. P. P. Macciotta. 2012. Prediction of genomic 
breeding values for dairy traits in Italian Brown and Simmental bulls using a principal component approach. J. Dairy Sci. 95(6):3390-3400.

Pryce, J. E., J. Arias, P. J. Bowman, S. R. Davis, K. A. Macdonald, G. C. Waghorn, W. J. Wales, Y. J. Williams, R. J. Spelman and B. J. Hayes. 2012. Accuracy of genomic predictions of residual feed intake and 250-day body weight in growing heifers using 625,000 single nucleotide polymorphism markers. J. Dairy Sci. 95(4):21082119.

Pryce, J. E., R. J. Esslemont, R. Thompson, R. F. Veerkamp, M. A. Kossaibati and G. Simm. 1998. Estimation of genetic parameters using health, fertility and production data from a management recording system for dairy cattle. Animal Science 66:577-584.

Pryce, J. E., O. Gonzalez-Recio, G. Nieuwhof, W. J. Wales, M. P. Coffey, B. J. Hayes and M. E. Goddard. 2015. Hot topic: definition and implementation of a breeding value for feed efficiency in dairy cows. J. Dairy Sci. 98(10):7340-7350.

Pryce, J. E., O. Gonzalez-Recio, J. B. Thornhill, L. C. Marett, W. J. Wales, M. P. Coffey, Y. De Haas, R. F. Veerkamp and B. J. Hayes. 2014a. Short communication: validation of genomic breeding value predictions for feed intake and feed efficiency traits. J. Dairy Sci. 97(1):537-542.

Pryce, J. E., W. J. Wales, Y. De Haas, R. F. Veerkamp and B. J. Hayes. 2014b. Genomic selection for feed efficiency in dairy cattle. Animal 8(1):1-10.

Pszczola, M., T. Strabel, H. A. Mulder and M. P. L. Calus. 2012a. Reliability of direct genomic values for animals with different relationships within and to the reference population. J. Dairy Sci. 95(1):389-400.

Pszczola, M., T. Strabel, J. A. M. Van Arendonk and M. P. L. Calus. 2012b. The impact of genotyping different groups of animals on accuracy when moving from traditional to genomic selection. J. Dairy Sci. 95(9):5412-5421.

Pszczola, M., R. F. Veerkamp, Y. De Haas, E. Wall, T. Strabel and M. P. L. Calus. 2013. Effect of predictor traits on accuracy of genomic breeding values for feed intake based on a limited cow reference population. Animal 7(11):1759-1768.

Robinson, D. L., J. P. Goopy, R. S. Hegarty, V. H. Oddy, A. N. Thompson, A. F. Toovey, C. A. Macleay, J. R. Briegal, R. T. Woodgate, A. J. Donaldson and P. E. Vercoe. 2014. Genetic and environmental variation in methane emissions of sheep at pasture. J. Anim. Sci. 92(10):4349-4363.

Rose, G., B. Paganoni and A. N. Thompson. 2016. Breeding for feed efficiency does not decrease methane production in growing lambs. p.451, Proceedings, Annual meeting of the European Federation of Animal Science. Wageningen Academy Publishers, Belfast, United Kingdom. 
Ross, E. M., P. J. Moate, L. Marett, B. G. Cocks and B. J. Hayes. 2013. Investigating the effect of two methane-mitigating diets on the rumen microbiome using massively parallel sequencing. J. Dairy Sci. 96(9):6030-6046.

Rowe, S., J. C. McEwan, S. Hickey, R. A. Anderson, D. L. Hyndman and E. A. Young. 2014. Genomic selection as a tool to decrease greenhouse gas emission from dual purpose New Zealand sheep. p. 43, Proceedings, 10th World Congress of Genetics Applied to Livestock Production, Vancouver, Canada.

Santana, M. H. A., G. A. Oliveira, R. C. Gomes, S. L. Silva, P. R. Leme, T. R. Stella, E. C. Mattos, P. Rossi, F. S. Baldi, J. P. Eler and J. B. S. Ferraz. 2014. Genetic parameter estimates for feed efficiency and dry matter intake and their association with growth and carcass traits in Nellore cattle. Livest. Sci. 167:80-85.

Schaeffer, L. R. 2006. Strategy for applying genome-wide selection in dairy cattle. J. Anim. Breed. Genet. 123(4):218-223.

Shi, W. B., C. D. Moon, S. C. Leahy, D. W. Kang, J. Froula, S. Kittelmann, C. Fan, S. Deutsch, D. Gagic, H. Seedorf, W. J. Kelly, R. Atua, C. Sang, P. Soni, D. Li, C. S. Pinares-Patino, J. C. McEwan, P. H. Janssen, F. Chen, A. Visel, Z. Wang, G. T. Attwood and E. M. Rubin. 2014. Methane yield phenotypes linked to differential gene expression in the sheep rumen microbiome. Genome Res. 24(9):1517-1525.

Spurlock, D. M., J. C. M. Dekkers, R. Fernando, D. A. Koltes and A. Wolc. 2012. Genetic parameters for energy balance, feed efficiency, and related traits in Holstein cattle. J. Dairy Sci. 95(9):5393-5402.

Tetens, J., G. Thaller and N. Krattenmacher. 2014. Genetic and genomic dissection of dry matter intake at different lactation stages in primiparous Holstein cows. J. Dairy Sci. (0).

Vallimont, J. E., C. D. Dechow, J. M. Daubert, M. W. Dekleva, J. W. Blum, C. M. Barlieb, W. Liu, G. A. Varga, A. J. Heinrichs and C. R. Baumrucker. 2010. Genetic parameters of feed intake, production, body weight, body condition score, and selected type traits of Holstein cows in commercial tie-stall barns. J. Dairy Sci. 93(10):4892-4901.

Van Arendonk, J. A. M. 1991. Use of profit equations to determine relative economic value of dairy-cattle herd life and production from field data. J. Dairy Sci. 74(3):1101-1107.

Van Arendonk, J. A. M., G. J. Nieuwhof, H. Vos and S. Korver. 1991. Genetic aspects of feed intake and efficiency in lactating dairy heifers. Livest. Prod. Sci. 29(4):263275.

Van Engelen, S., H. Bovenhuis, J. Dijkstra, J. A. Van Arendonk and M. H. Visker. 2015. Short communication: genetic study of methane production predicted from milk fat composition in dairy cows. J. Dairy Sci. 98(11):8223-8226. 
VandeHaar, M.J. 2014. Feeding and breeding for a more efficient cow. Advances in Dairy Technology (2014) Volume 26: 17 - 30.

VandeHaar, M. J., L. E. Armentano, K. Weigel, D. M. Spurlock, R. J. Tempelman and R. Veerkamp. 2016. Harnessing the genetics of the modern dairy cow to continue improvements in feed efficiency. J. Dairy Sci. 99(6):4941-4954.

Veerkamp, R. F. 1998. Selection for economic efficiency of dairy cattle using information on live weight and feed intake: a review. J. Dairy Sci. 81(4):11091119.

Veerkamp, R. F. and S. Brotherstone. 1997. Genetic correlations between linear type traits, food intake, live weight and condition score in Holstein Friesian dairy cattle. Animal Science 64:385-392.

Veerkamp, R. F., M. P. Coffey, D. P. Berry, Y. De Haas, E. Strandberg, H. Bovenhuis, M. P. L. Calus and E. Wall. 2012. Genome-wide associations for feed utilisation complex in primiparous Holstein-Friesian dairy cows from experimental research herds in four European countries. Animal 6(11):1738-1749.

Veerkamp, R. F. and G. C. Emmans. 1995. Sources of genetic variation in energetic efficiency of dairy cows. Livest. Prod. Sci. 44(2):87-97.

Veerkamp, R. F., G. C. Emmans, A. R. Cromie and G. Simm. 1995. Variance components for residual feed intake in dairy cows. Livest. Prod. Sci. 41(2):111120.

Veerkamp, R. F., J. E. Pryce, D. Spurlock, D. P. Berry, M. P. Coffey, P. Lovendahl, R. Van Der Linde, J. Bryant, F. Miglior, Z. Wang, M. Winters, N. Krattenmacher, N. Charfeddine, J. Pedersen and Y. De Haas. 2013. Selection of feed intake of feed efficiency: a position paper from gDMI breeding goal discussions. pp.15-22. Proc. Interbull Bulletin No.47, Nantes, France.

Veerkamp, R. F., G. Simm and J. D. Oldham. 1994a. Effects of interaction between genotype and feeding system on milk-production, feed-intake, efficiency and body tissue mobilization in dairy-cows. Livest. Prod. Sci. 39(3):229-241.

Veerkamp, R. F., G. Simm and P. Persaud. 1994b. Potential value of linear type traits for the prediction of intake, efficiency and economic margins in dairycattle. Livest. Prod. Sci. 38(3):179-189.

Veerkamp, R. F. and R. Thompson. 1999. A covariance function for feed intake, live weight, and milk yield estimated using a random regression model. J. Dairy Sci. 82(7):1565-1573.

Villagodoy, A., T. L. Hughes, R. S. Emery, L. T. Chapin and R. L. Fogwell. 1988. Association between energy balance and luteal function in lactating dairy cows J. Dairy Sci. 71(4):1063-1072. 
Waghorn, G. C. and R. S. Hegarty. 2011. Lowering ruminant methane emissions through improved feed conversion efficiency. Anim. Feed Sci. Tech. 166(67):291301.

Wall, E., G. Simm and D. Moran. 2010. Developing breeding schemes to assist mitigation of greenhouse gas emissions. Animal 4(3):366-376.

Wientjes, Y. C. J., P. Bijma, R. F. Veerkamp and M. P. L. Calus. 2016. An equation to predict the accuracy of genomic values by combining data from multiple traits, populations, or environments. Genetics 202(2):799-823.

Yao, C., L. E. Armentano, M. J. VandeHaar and K. A. Weigel. 2015. Short communication: use of single nucleotide polymorphism genotypes and health history to predict future phenotypes for milk production, dry matter intake, body weight, and residual feed intake in dairy cattle. J. Dairy Sci. 98(3):2027-2032.

Yao, C., D. M. Spurlock, L. E. Armentano, C. D. Page, Jr., M. J. VandeHaar, D. M. Bickhart and K. A. Weigel. 2013. Random forests approach for identifying additive and epistatic single nucleotide polymorphisms associated with residual feed intake in dairy cattle. J. Dairy Sci. 96(10):6716-6729.

Yin, T., T. Pinent, K. Brugemann, H. Simianer and S. Konig. 2015. Simulation, prediction, and genetic analyses of daily methane emissions in dairy cattle. J. Dairy Sci. 98(8):5748-5762. 



\section{Chapter 2}

\section{Genetic parameters across lactation for feed intake, fat and protein corrected milk and live weight in first parity Holstein cattle}

C. I. V. Manzanilla Pech ${ }^{1,2,3}$, R. F. Veerkamp ${ }^{1,2}$, M. P. L. Calus ${ }^{1}$, R. Zom ${ }^{4}$, A. van Knegsel $^{5}$, J. E. Pryce ${ }^{6}$, Y. De Haas ${ }^{1}$

\footnotetext{
${ }^{1}$ Animal Breeding and Genomics Centre, Wageningen UR Livestock Research, 8200 AB Lelystad, the Netherlands; ${ }^{2}$ Animal Breeding and Genomics Centre, Wageningen University, $6700 \mathrm{AH}$ Wageningen, the Netherlands; ${ }^{3}$ Mococha Research Station, National Research Institute of Forestry, Agriculture and Livestock, 97454 Mococha, Yucatan, Mexico ${ }^{4}$ Animal Nutrition Group, Wageningen UR Livestock Research, 8200 AB Lelystad, the Netherlands; ${ }^{5}$ Adaptation Physiology, Wageningen University, $6700 \mathrm{AH}$ Wageningen, the Netherlands; ${ }^{6}$ Biosciences Research Division, Department of Environment and Primary Industries Victoria, 5 Ring Road, Bundoora, VIC 3083, Australia
} 


\section{Abstract}

Breeding values for DMI are important to optimize dairy cattle breeding goals for feed efficiency. However, generally, only small data sets are available for feed intake, due to the cost and difficulty of measuring DMI, which makes understanding the genetic associations between traits across lactation difficult, let alone the possibility for selection of breeding animals. However, estimating national breeding values through cheaper and easier measured correlated traits, such as milk yield and live weight (LW), could be a first step to predict DMI. Combining DMI data across historical nutritional experiments might help to expand the datasets. Therefore, the objective was to estimate genetic parameters for DMI, fat and protein corrected milk (FPCM), and LW across the entire first lactation using a relatively large dataset combining experimental data across the Netherlands. A total of 30,483 weekly records for DMI, 49,977 for FPCM, and 31,956 for LW were available from 2,283 Dutch Holstein-Friesian first-parity cows between 1990 and 2011. Heritabilities, covariance components, and genetic correlations were estimated using a multivariate random regression model in ASReml. The model included an effect for year-season of calving, and polynomials for age of cow at calving and days in milk (DIM). The random effects were: experimental treatment, year-month of measurement, and the additive genetic, permanent environmental and residual term. Additive genetic and permanent environmental effects were modeled using a third-order orthogonal polynomial. Estimated heritabilities ranged from 0.21 to 0.40 for DMI, from 0.20 to 0.43 for FPCM, and from 0.25 to 0.48 for LW across DIM. Genetic correlations between DMI at different DIM were relatively low during early and late lactation, compared with mid lactation. The genetic correlations between DMI and FPCM varied across DIM. This correlation was negative (up to -0.5 ) between FPCM in early lactation and DMI across the entire lactation, but highly positive (above 0.8 ) when both traits were in mid lactation. The correlation between DMI and LW was 0.6 during early lactation, but reduced to 0.4 during mid lactation. The highest correlations between FPCM and LW (0.3-0.5) were estimated during mid-lactation. However, the genetic correlations between DMI and either FPCM or LW were not symmetric across DIM, and differed depending on which trait was measured first. The results of our study are useful to understand the genetic relationship of DMI, FPCM, and LW on specific days across lactation.

Key words: feed intake, milk yield, live weight, genetic correlation, random regression 


\subsection{Introduction}

Feed costs represent above $50 \%$ of the total costs of dairy production (EU, 2011), so reducing costs by improving dairy cow feed efficiency is a way to increase profitability (Veerkamp, 1998; de Haas et al., 2012; Veerkamp et al., 2012). However, feed efficiency is a complex trait, with many definitions (Korver, 1988) of which some also include nutrition, health and reproduction factors (Berry and Crowley, 2013). The most classic definition is the ratio between kilograms of milk produced and kilograms of dry matter intake (DMI) (Veerkamp and Emmans, 1995). This trait shows that to be able to define feed efficiency in dairy cattle breeding goals, accurate estimates of genetic parameters for DMI are needed. However, DMI is not recorded in commercial herds and therefore, in most studies, the number of DMI records is small and estimates of genetic parameters have large sampling errors. Besides, in most of those studies, DMI was only recorded until 150 or 180 DIM, and not through the entire lactation (Veerkamp, 1998; Berry and Crowley, 2013).

The difficulty of recording hinders direct selection for feed intake, since no records are available on daughters of progeny tested bulls. This difficulty might be overcome with the introduction of genomic selection (Pryce et al., 2012), but still the number of available records in the genomic reference population has to be $>10,000$ to obtain accurate breeding values (Calus et al., 2013). Additionally, indirect selection through moderate to highly correlated traits, which can be easier measured, might be viable (Pszczola et al., 2013). Milk yield traits and live weight (LW) could be useful predictors of DMI, because they would allow proper accounting for the amount of feed required for production and maintenance, respectively, and consequently allow an approximation of net feed efficiency (Kennedy et al., 1993; Veerkamp, 1998). These traits are relatively easy and cheap to measure on a large scale, especially when LW is predicted using linear type traits (Veerkamp and Brotherstone, 1997; Parke et al., 1999; Banos et al., 2012; Liinamo et al., 2012). However, estimates of genetic parameters are required to evaluate the benefit of using LW and milk yield in addition to genomic prediction.

Dry matter intake is influenced by several biological processes that change during the course of lactation, and therefore DMI could have a different genetic background at different lactation stages (Koenen and Veerkamp, 1998). In fact, estimated heritabilities of DMI change during lactation (Koenen and Veerkamp, 1998; Berry et al., 2007; Buttchereit et al., 2011), and low genetic correlations were estimated between DMI recorded in early and late lactation (Koenen and 
Veerkamp, 1998; Liinamo et al., 2012). Similarly, LW and milk yield may not be genetically the same trait across lactation, and genetic correlations between them may also change across lactation. Therefore, the objective of this study was to estimate genetic parameters for DMI, fat and protein corrected milk (FPCM), and LW across the entire first lactation. By combining data from historical nutritional experiments in the Netherlands, a unique large dataset was created, which makes this probably the largest study of its kind currently available.

\subsection{Material and methods}

\subsubsection{Data collection}

A total of 307,007 daily records on DMI, FPCM or LW were available from 2,977 Holstein-Friesian that calved between 1990 and 2011. These cows participated in nutritional experiments conducted on several farms in Netherlands, e.g. Aver Heino, Heino; Bosma Zathe, Ureterp; Cranendonck, Soerendonk; 't Gen, Lelystad; Minderhoudhoeve, Swifterbant; Waiboerhoeve Dairy Unit 2, 3, Lelystad; Zegveld farm, Zegveld; Hoorn, Lelystad; and New Wairboerhoeve, Lelystad. A description of the methodology of most experiments has been summarized previously (Veerkamp et al., 2000; Beerda et al., 2007; Zom et al., 2012; Van Knegsel et al., 2014), and an overview is given in Table 2.1. All cows were kept indoors in conventional cubicle housings, were offered complete mixed diets ad libitum, and were milked twice a day, except half of the cows at Bosma Zathe $(n=50)$ that were milked three times per day.

\subsubsection{Traits}

Dry matter intake was, depending on the experiment, recorded one, two, three or five times per week (Beerda et al., 2007; Zom et al., 2012). Feed intake was recorded using computer controlled access gates (Calan feeding system) at the experimental farms Bosma Zathe, Ureterp; Zegveld, Zegveld; Aver Heino; Heino; Waiboerhoeve Dairy Unit 3, Lelystad. Offered feed was recorded automatically, but feed refusals were weighed manually. Data from these historical nutritional experiments were combined from four separate datasets, and an overview is shown in Table 2.1. In the nutritional experiments described by Zom et al. (2012), fresh forage mixtures were offered once or twice daily and the refusals were weighed and removed daily. To ensure ad libitum intake of forage (mixtures), the quantities offered were such that the feed refusals were at least $10 \%$ of the amount offered. At the other experimental farms, automated feed intake units were used, where feed was provided via a roughage intake control (RIC) system, 
which allowed monitoring the daily total mixed ration per individual. The RIC system (Insentec, Marknesse, the Netherlands) consists of a feeding gate that controls access via neck collars. The visit time is registered, as well as the amount of feed that a cow ate during the visit.

Weighing platforms were used to automatically monitor LW three times a week or daily depending on the experiment. To represent milk yield and its components, FPCM was calculated, where the milk yield is corrected for its fat and protein content to a standard of $4.0 \%$ fat and $3.3 \%$ protein (FAO, 2010). Fat and protein contents in milk were measured weekly, and they were used to calculate FPCM according to the following formula (FAO, 2010):

$$
\mathrm{FPCM}(\mathrm{kg})=(0.337 * \text { raw milk } \mathrm{kg})+(11.6 * \text { fat content } \mathrm{kg})+
$$

(5.999* protein content $\mathrm{kg}$ )

Table 2.1 Description of available phenotypic records of dry matter intake (DMI), fat and protein corrected milk (FPCM), and live weight (LW) for four datasets with first parity Holstein Friesian cows.

\begin{tabular}{|c|c|c|c|c|}
\hline & \multicolumn{4}{|c|}{ Dataset } \\
\hline & 1 & 2 & 3 & 4 \\
\hline \# of experiment & 4 & 1 & 39 & 51 \\
\hline \# of sites & 1 & 1 & 9 & 2 \\
\hline \multicolumn{5}{|l|}{ \# of cows with } \\
\hline DMI & 99 & 682 & 367 & 149 \\
\hline FPCM & 99 & 714 & 647 & 825 \\
\hline LW & 99 & 701 & 367 & 194 \\
\hline Total & 99 & 714 & 647 & 826 \\
\hline \multicolumn{5}{|l|}{ \# of weekly } \\
\hline \multicolumn{5}{|l|}{ records for } \\
\hline DMI & 1462 & 19365 & 8233 & 1423 \\
\hline FPCM & 2167 & 25130 & 14015 & 8665 \\
\hline LW & 1456 & 20183 & 8318 & 1999 \\
\hline Total & 2220 & 25576 & 14131 & 9517 \\
\hline $\begin{array}{l}\text { DMI recording } \\
\text { period (DIM) }\end{array}$ & 104 & 294 & 324 & 324 \\
\hline Years interval & 2003-2005 & 1990-1998 & 1990-2001 & 1995-2011 \\
\hline Published in & $\begin{array}{l}\text { Beerda et } \\
\text { al. (2007) }\end{array}$ & $\begin{array}{r}\text { Veerkamp et } \\
\text { al. (2000) }\end{array}$ & $\begin{array}{r}\text { Zom et al. } \\
(2012)\end{array}$ & unpublished \\
\hline
\end{tabular}




\subsubsection{Data Editing}

The raw data consisted of 307,007 records from 2,977 animals. All records from animals without information on pedigree, parity number, calving date or date of measurement were removed, and only DMI records in the first 324 DIM (46 weeks) were retained. These edits resulted in a dataset with 299,338 records from 2,651 animals from parity 1 to 14 . Weekly means of daily DMI and LW records were calculated, so that the phenotypes were consistent for each experimental treatment. This resulted in a dataset with 195,810 records from 2,651 cows.

Finally, only first lactation records were kept and cows with less than $75 \%$ of Holstein Friesian genes were deleted. This resulted in a dataset consisting of 30,483 records for DMI on 1,297 animals; 49,977 records for FPCM on 2,285 animals, and 31,956 records for LW on 1,361 animals. Descriptive information of phenotypic records of DMI, FPCM, and LW for the four datasets is shown in Table 2.1. Total number of experimental treatments was 95, but varied from 1 to 51 through the four datasets, and the total number of cows ranged between 99 and 826 per dataset. The total number of weekly records per dataset ranged from 2,220 to 25,576 . The number of cows with FPCM records was twice the number of cows with DMI records in dataset 3 , and three times as much in dataset 4 . This is because in those experiments the period of interest for DMI recording was late first lactation and early second lactation, whereas milk production was measured during the entire lactation (Van Knegsel et al., 2014). The pedigree was traced back for 18 generations and included 10,226 animals.

\subsubsection{Statistical Analysis}

A trivariate analysis of DMI, FPCM and LW was performed to estimate the variance and covariance components between these three traits for each day of lactation, with a test-day random regression model using ASReml (Gilmour et al., 2009). The model included random effects for experimental treatment (EXP), yearmonth of measurement (YM), and the additive genetic, permanent environmental, and residual term. The fixed effects in the model were year by season of calving (YSC, with 4 classes: Jan-Mar, Apr-Jun, Jul-Sep, Oct-Dec), age of cow at calving (ACC, in days) and days in milk (DIM). Age of cow at calving and DIM were modeled with third and fourth order Legendre orthogonal polynomials, respectively. Additive genetic and permanent environmental covariance functions were modeled using Legendre orthogonal polynomials of third order. This implies that the covariance structure depends on a set of orthogonal polynomials, as a function of the lactation stage (Van der Werf et al., 1998). 
The model used was:

$$
\begin{aligned}
& \mathbf{y}_{\mathrm{ijklmno}}=\mu+\mathrm{YSC}_{\mathrm{i}}+\sum_{\mathrm{j}=0}^{3} \mathrm{C}_{\mathrm{j}} \boldsymbol{\beta}_{\mathrm{j}}+\sum_{\mathrm{k}=\mathbf{0}}^{4} \mathrm{D}_{\mathrm{k}} \Phi_{\mathrm{k}}+\sum_{\mathrm{k}=0}^{3} \mathrm{a}_{\mathrm{kl}} \boldsymbol{\Phi}_{\mathrm{kl}}+\sum_{\mathrm{k}=0}^{3} \mathrm{pe}_{\mathrm{kl}} \boldsymbol{\Phi}_{\mathrm{kl}} \\
& +\mathbf{E X P}_{\mathbf{m}}+\mathbf{Y M}_{\mathbf{n}}+\mathbf{e}_{\mathrm{ijklmno}}
\end{aligned}
$$

Where yijklmno is phenotype for DMI, FPCM and LW; $\mu$ is the mean; YSC is the fixed effect of year-season of calving ( $i=1$ to 83 ); $\mathrm{Cj}$ is the fixed regression coefficient for ACC; $\beta$ j is the term of the 3rd order Legendre polynomial for ACC; $D k$ is the fixed regression coefficient of DIM; $\Phi_{k}$ is the term of 4 th order Legendre polynomial for DIM; akl is the kth regression coefficient of the Legendre polynomial for the additive genetic effect of the Ith cow; pekl is the kth regression coefficient of the Legendre polynomial for the permanent environmental effect of the lth cow; $\Phi_{\mathrm{kl}}$ is the term of 3rd order Legendre polynomial for a and pe, where the time variable was DIM; EXPm is the random effect of the $m$ th experimental treatment $(n=94) ; Y M n$ is the random effect of the year-month of measurement $(n=257)$ and eijklmno is the residual error. Residual errors were assumed to have heterogeneous variances and were divided into 4 classes according to the distribution of DMI records $(1=1$ to $48 d, 2=49$ to $97 d, 3=98$ to $160 d$ and $4=161$ to 324 DIM). Residual covariances between traits at same DIM were estimated, but residual covariances within the same trait at different DIM were assumed to be zero as well as the residual covariances between traits at different DIM. Estimated (co)variance components of the random regression were used, together with the Legendre polynomials to calculate heritabilities, genetic and permanent environmental covariances, and correlations for each DIM using the methodology of Fischer et al. (2004):

$$
\begin{aligned}
& \mathbf{G}=\boldsymbol{\Phi} \mathbf{K} \boldsymbol{\Phi}^{\prime} \\
& \mathbf{P E}=\boldsymbol{\Phi К P E} \Phi^{\prime}
\end{aligned}
$$

Where $\mathbf{G}$ is the genetic variance-covariance matrix across traits and DIM, $\boldsymbol{\Phi}$ is the matrix of order $\mathrm{t} x \mathrm{n}$, which contains 4 orthogonal polynomial coefficients from DMI, FPCM yield and LW through 324 DIM, then $t=12$ (3*4), and $n=972$ $\left(3^{*} 324\right)$; and $\mathbf{K}$ is the matrix of order $\mathrm{n} \times \mathrm{n}$ which contains the estimated covariance function describing the genetic variance components for the random regression coefficients. Likewise, $\mathrm{PE}$ is the permanent environmental variance-covariance 
matrix, and KPE is the matrix of order $\mathrm{n} \times \mathrm{n}$ which contains the covariance function for the permanent environmental variance components. At the same time, experimental treatment, year-month and residual components of (co)variances were used to calculate the phenotypic variance-covariance matrix (P). Standard errors of (co)variances, correlations, heritabilities and permanent environmental ratio were approximated by an automated procedure in $\mathrm{R}$ to produce the input files (pin) required by ASReml to calculate them.

Additionally, genetic and permanent environmental variances for the entire lactation were calculated by summing $\boldsymbol{\Phi}$ through 324 days, and multiplying this with $\mathrm{K}$ (Liu et al., 2000). Experimental treatment, year-month and residual matrices were also formed, using the sum of those variances, to calculate total lactation phenotypic variances, heritability and permanent environmental ratio $\left(c^{2}\right)$.

To have a better overview of what is happening with the genetic correlations when the distance in days increases independently of the time when they were recorded during lactation, average genetic correlations within a trait were calculated. This helped to show if DMI, FPCM and LW were in fact different traits at different DIMs. Therefore, average genetic correlations within DMI, FPCM, and LW were calculated taking all correlations when the difference in recording was $10,20, \ldots, 300$ days and calculating the average of those correlations. It is important to mention that the number of correlations is larger when the difference in recording is shorter (i.e., the average genetic correlation when the difference was $10 \mathrm{~d}$ was calculated from 314 different genetic correlations, whereas, the average genetic correlation when the difference was $200 \mathrm{~d}$ was calculated from 124 different genetic correlations).

\subsection{Results}

The number of records for DMI, FPCM, and LW were constant for the first 100 DIM, with more weekly records available for FPCM, than for DMI and LW (Figure 2.1). After 100 DIM the number of records decreased until the end of lactation (324 d), mainly because the experimental treatments in dataset 1 and 2 had a target of recording DMI for at least the first 100 DIM, and did not necessarily contain measurements throughout the entire lactation. Descriptive statistics of DMI, FPCM and LW for the four datasets are shown in Table 2.2. The averages varied between datasets, from 15.7 to $19.9 \mathrm{~kg}$ DMI per day, from 24.8 to $29.1 \mathrm{~kg}$ FPCM per day, and from 521.6 to $571.2 \mathrm{~kg} \mathrm{LW}$. Dataset 1 had a lower DMI, FPCM, and LW than the other datasets, but a similar standard deviation. The lower 
average of FPCM and DMI in dataset 1 was because one of experimental treatments included cows with a low genetic merit for milk yield, half of them with a low energy density diet (Beerda et al., 2007).

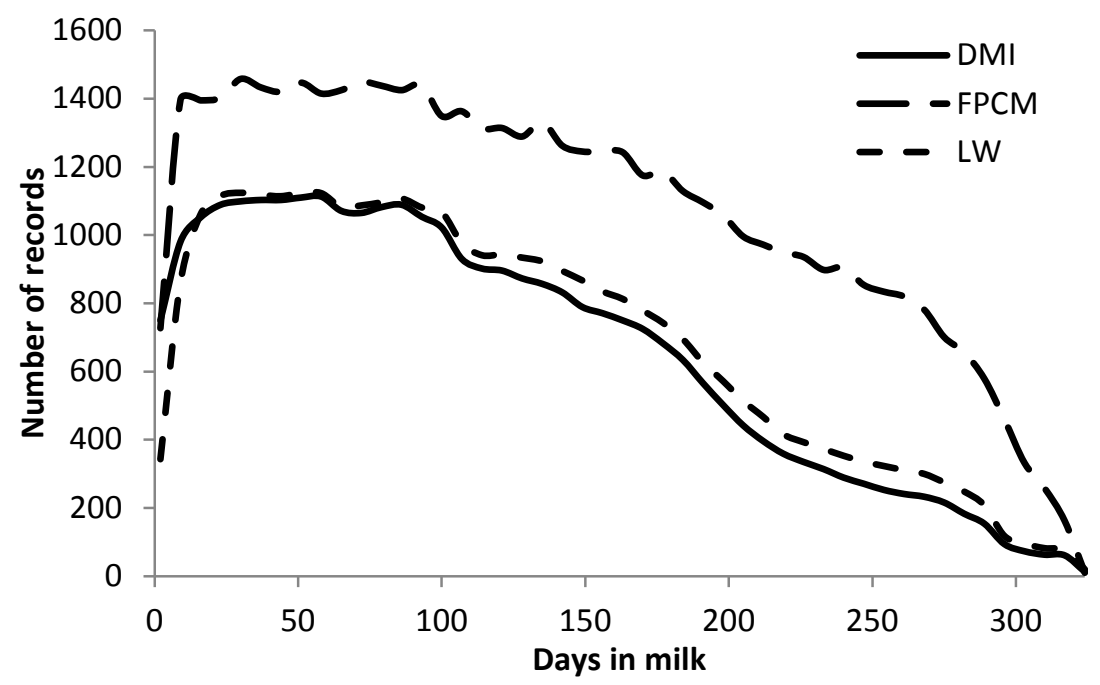

Figure 2.1 Frequency distribution of the number of records for dry matter intake (DMI), fat and protein corrected milk (FPCM) and live weight (LW) per days in milk.

\subsubsection{Entire Lactation Parameters and Experimental Effects}

The estimated heritabilities of the entire lactation were 0.46 for DMI and FPCM, and 0.38 for LW (Table 2.3). The estimated permanent environmental ratios $\left(c^{2}\right)$ of the entire lactation were 0.23 for DMI, 0.41 for FPCM, and 0.60 for LW. The estimated entire lactation genetic correlation between DMI and FPCM was 0.86, whereas the corresponding phenotypic correlation was 0.62 . The estimated entire lactation genetic correlation between DMI and LW was 0.45 , and 0.06 between FPCM and LW. The corresponding phenotypic correlations were 0.33 and -0.01 , respectively (Table 2.3 ).

Estimated variance components for the effects of experimental treatment and year-month showed that experimental treatment was more important than year-month (after adjusting for the other fixed effects in the model) for DMI and FPCM, but not for LW (Table 2.3). The ratios of experimental treatment variance over entire lactation phenotypic variance were 0.19 for DMI, $0.10 \mathrm{FPCM}$, and 0.00 for LW; and the ratios of year-month variance over entire lactation phenotypic variance were 0.12 for DMI, 0.04 for FPCM and 0.01 for LW. 
Table 2.2 Descriptive statistics (mean value with standard deviation (SD), minimum (min) and maximum (max) value) of dry matter intake (DMI), fat and protein corrected milk (FPCM), and live weight (LW) for four datasets with first parity Holstein Friesian cows.

\begin{tabular}{lrrrrr}
\hline & \multicolumn{5}{c}{ Dataset } \\
\cline { 2 - 6 } & $\mathbf{1}$ & $\mathbf{2}$ & $\mathbf{3}$ & $\mathbf{4}$ & \multicolumn{1}{c}{ All $^{\mathbf{1}}$} \\
\hline DMI (kg/d) & & & & & \\
Mean & 15.7 & 19.9 & 18.7 & 16.7 & 19.2 \\
SD & 3.2 & 3.2 & 2.7 & 3.4 & 3.3 \\
Min & 5.4 & 1.0 & 6.9 & 7.5 & 1.0 \\
Max & 24.6 & 33.4 & 35.8 & 27.8 & 35.8 \\
FPCM (kg/d) & & & & & \\
Mean & 24.8 & 28.2 & 26.2 & 29.1 & 27.7 \\
SD & 5.7 & 5.2 & 5.2 & 5.2 & 5.4 \\
Min & 3.4 & 2.0 & 8.4 & 2.0 & 2.0 \\
Max & 41.7 & 53.9 & 45.1 & 53.3 & 53.9 \\
LW (kg) & & & & & \\
Mean & 521.6 & 549.6 & 568.2 & 571.2 & 554.5 \\
SD & 41.9 & 53.8 & 59.1 & 52.9 & 55.9 \\
Min & 412.5 & 387.0 & 420.0 & 450.0 & 387.0 \\
Max & 655.2 & 793.0 & 963.0 & 751.5 & 963.0 \\
\hline Alldatabases & & & & &
\end{tabular}

${ }^{1}$ All databases

Table 2.3 Entire lactation heritability $\left(h^{2}\right)$, permanent environmental ratio $\left(c^{2}\right)$, experiment variance ratio $\left(\sigma_{\text {exp }}^{2} / \sigma_{p}^{2}\right)$, year-month variance ratio $\left(\sigma_{y m}^{2} / \sigma_{p}^{2}\right)$, genetic (below) and phenotypic correlations (above), experiment (below) and year-month (above) correlations between dry matter intake (DMI), fat and protein corrected milk (FPCM) and live weight (LW).

\begin{tabular}{lcccccccccc}
\hline Traits & & & Ratios & & $\begin{array}{l}\text { Genetic and } \\
\text { phenotypic } \\
\text { correlations }\end{array}$ & \multicolumn{3}{l}{$\begin{array}{l}\text { Experiment and year- } \\
\text { month correlations }\end{array}$} \\
\hline & $\mathbf{h}^{2}$ & $\mathbf{c}^{2}$ & $\begin{array}{c}\sigma^{2}{ }_{\text {exp }} \\
/ \sigma_{p}^{2}\end{array}$ & $\begin{array}{l}\sigma_{\text {ym }}^{2} \\
/ \sigma_{p}^{2}\end{array}$ & DMI & FPCM & LW & DMI & FPCM & LW \\
\hline DMI & 0.46 & 0.23 & 0.19 & 0.12 & & 0.62 & 0.33 & & 0.23 & 0.00 \\
FPCM & 0.46 & 0.41 & 0.10 & 0.04 & 0.86 & & -0.01 & 0.20 & & 0.14 \\
LW & 0.38 & 0.60 & 0.00 & 0.01 & 0.45 & 0.06 & & 0.81 & 0.25 & \\
\hline
\end{tabular}

These ratios were smaller than the estimated $h^{2}$ and $c^{2}$, indicating that the contribution of those variances to the phenotypic variance was small. Experimental treatments that had a positive effect on DMI also had a positive effect on LW, as 
reflected by the high positive correlation (0.81) between DMI and LW for experimental treatment. However, the estimated correlation between DMI and LW for year-month was zero. The correlations between DMI and FPCM for experimental treatment and year-month were 0.20 and 0.23 , respectively, and the corresponding correlations between FPCM and LW were 0.25 and 0.14 , respectively (Table 2.3 ).

Estimated residual variances for DMI, FPCM and LW were smallest between 49 and 97 DIM for all three traits, and highest for DMI and LW after 161 DIM, and highest for FPCM between 1 and 48 DIM (results not shown). Moderate residual correlations were estimated between DMI and FPCM (ranging between 0.24 and 0.37 ), which was consistent between all periods. The estimated residual correlations between DMI and LW ranged from 0.08 to 0.20 , and the residual correlations between FPCM and LW ranged from 0.01 to 0.11 .

\subsubsection{Estimated Heritabilities within Lactation}

Estimated daily heritabilities of DMI ranged from 0.21 to 0.40 across lactation (Figure 2.2), which is lower than the entire lactation heritability. Heritability of DMI was lowest (0.21) in early lactation (31 DIM) with a subsequent increase to 0.40 at $138 \mathrm{DIM}$, followed by a decrease in late lactation (to 0.34 at 223 DIM). Overall, the estimated daily heritabilities were highest between 80 and 205 DIM.

Estimated daily heritabilities for FPCM showed a similar pattern as the heritability for DMI, showing the lowest value of 0.22 in early lactation at 26 DIM, followed by an increase reaching its maximum heritability of 0.43 at 165 DIM (Figure 2.2). Estimated daily heritabilities for LW presented a different trend (sigmoid curve) with highest values at early lactation (0.48 at 49 DIM) followed by a decrease to 0.25 until 215 DIM (Figure 2.2).

Estimated daily permanent environmental ratios $\left(c^{2}\right)$ were highest for LW and lowest for DMI (Figure 2.3). Daily $c^{2}$ for DMI decreased from 0.38 to 0.16 in the first 111 DIM, followed by an increase to 0.60 until end of lactation, whereas daily $c^{2}$ for LW showed the lowest point at 35 DIM (0.43) and the highest point at 220 DIM (0.69). Together, the $h^{2}$ with $c^{2}$, determines the repeatability of feed intake records during lactation. 


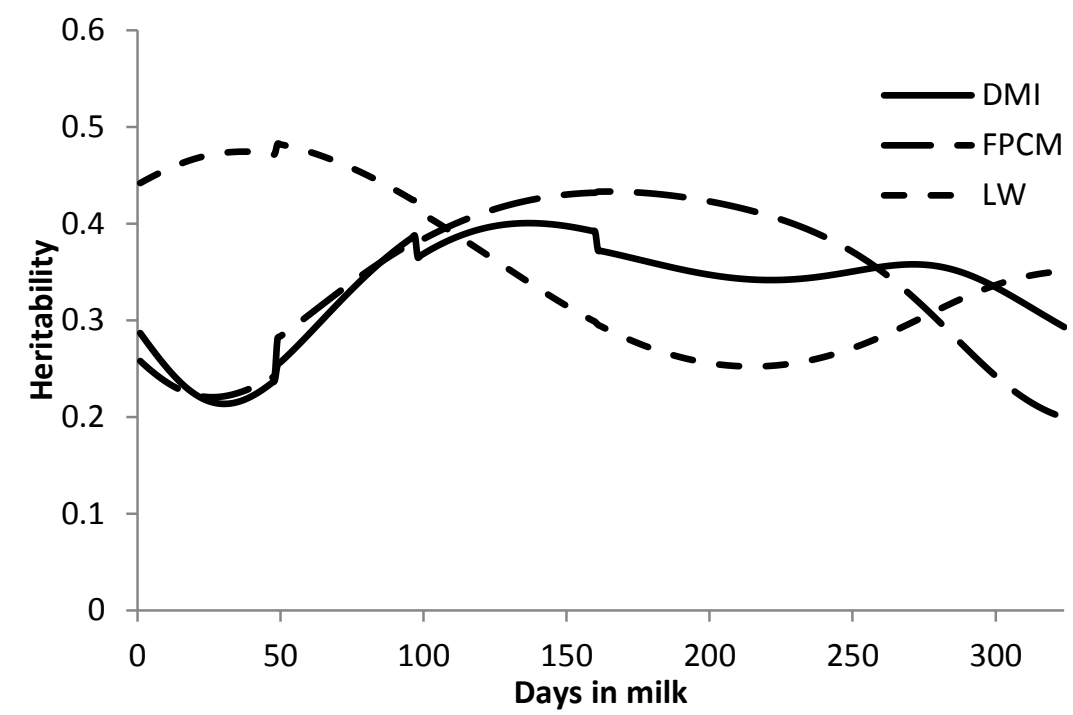

Figure 2.2 Estimated daily heritabilities from 1 to 324 days in milk (DIM) for a) dry matter intake (DMI, SE of median $=0.05$, of $3^{\text {rd }}$ quartile $=0.05$ ), b) fat and protein corrected milk (FPCM, SE of median=0.04, of $3^{\text {rd }}$ quartile $=0.04$ ), and c) live weight (LW, SE of median=0.07, of $3^{\text {rd }}$ quartile $=0.07$ ).

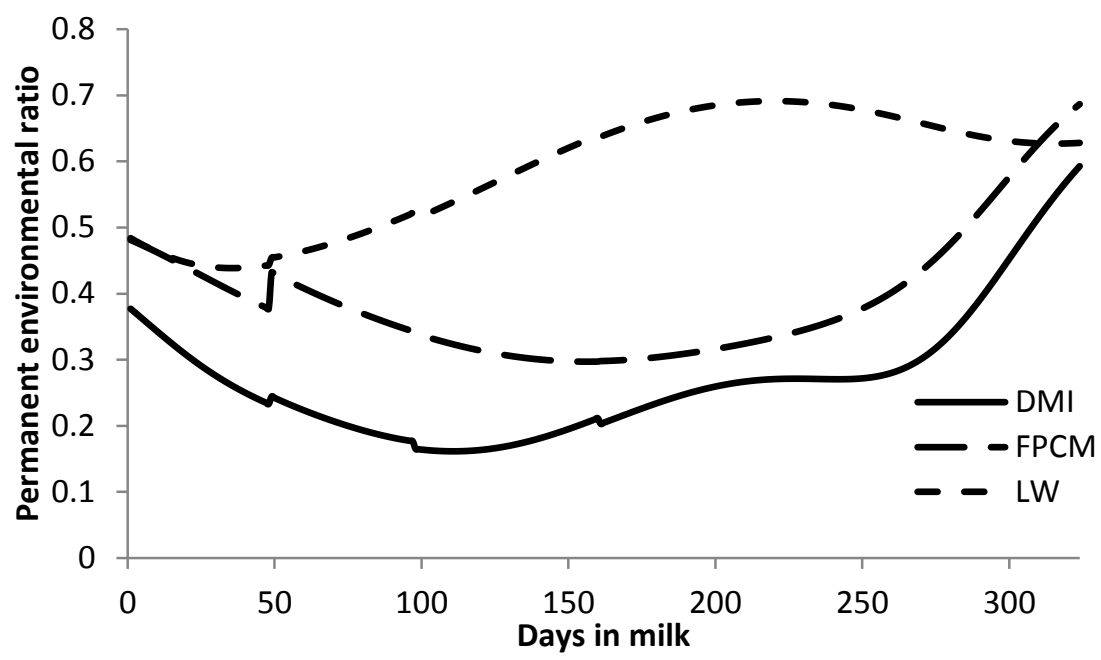

Figure 2.3 Estimated daily permanent environmental ratio from 1 to 324 days in milk (DIM) for a) dry matter intake (DMI, SE of median $=0.04$, of $3^{\text {rd }}$ quartile $=0.05$ ), b) fat and protein corrected milk (FPCM, SE of median $=0.04$, of $3^{\text {rd }}$ quartile $=0.04$ ), and c) live weight $(L W, S E$ of median $=0.04$, of $3^{\text {rd }}$ quartile $=0.04$ ). 


\subsubsection{Genetic Correlations within Traits across Lactation}

Genetic correlations within DMI, FPCM and LW across lactation are shown in Figure 2.4a-c. For DMI, genetic correlations between DMI on different DIMs were positive for the majority of the lactation, and were highest during mid lactation (> 0.80 (SE 0.07)). Genetic correlations were slightly negative (a minimum of -0.2 ) between DMI recorded in early lactation (before 50 DIM) and DMI recorded in the rest of the lactation. Genetic correlations between FPCM on different DIMs showed the same trend as DMI, showing positive correlations throughout the majority of the lactation (above 0.80), with an average SE of 0.02 . The only negative correlations were estimated between FPCM recorded in early lactation and FPCM recorded in very late lactation (i.e., before 50 DIM and after 300 DIM).

In order to get an overview of the strength of the correlations between the same trait measured at increasing days apart, the average of genetic correlations within DMI, FPCM or LW was calculated when the difference between two recordings was $10,20, \ldots, 310$ DIM (Figure 2.5). The average genetic correlation decreased faster for DMI than for FPCM and LW. For DMI, the average genetic correlation between all records of DMI taken 10 days apart was 0.99 , and this average correlation decreased to $0.67,0.44$ and 0.27 when the records were taken 100, 200 or 300 days apart, respectively. For FPCM, the average genetic correlation decreased from 0.99 to $0.86,0.77$ and 0.19 , respectively. For LW, the average genetic correlation decreased from 0.99 to $0.90,0.84$ and 0.69 , respectively.

\subsubsection{Genetic Correlations between Traits at same DIM}

Genetic correlations between DMI and FPCM at the same DIM (Figure 2.6) were negative before 38 DIM (-0.55) and positive from 60 DIM until the end of lactation (> 0.7), presenting the highest correlation at 195 DIM (0.91). Genetic correlations between DMI and LW were positive across lactation, ranging between 0.29 and 0.56 , reaching its maximum value at 34 DIM and its minimum at 153 DIM. Genetic correlations between FPCM and LW were slightly negative (until -0.06) in early lactation and at the end of the lactation.

\subsubsection{Genetic Correlations between Traits across Lactation}

Pairwise genetic correlations between DMI, FPCM and LW at different DIMs are shown in Figure 2.7a-c. Genetic correlations between DMI and FPCM were positive ( $>0.8$ ) when both traits were recorded during mid lactation (between 110 and 230 DIM for DMI, and between 140 and 260 DIM for FPCM). Negative 


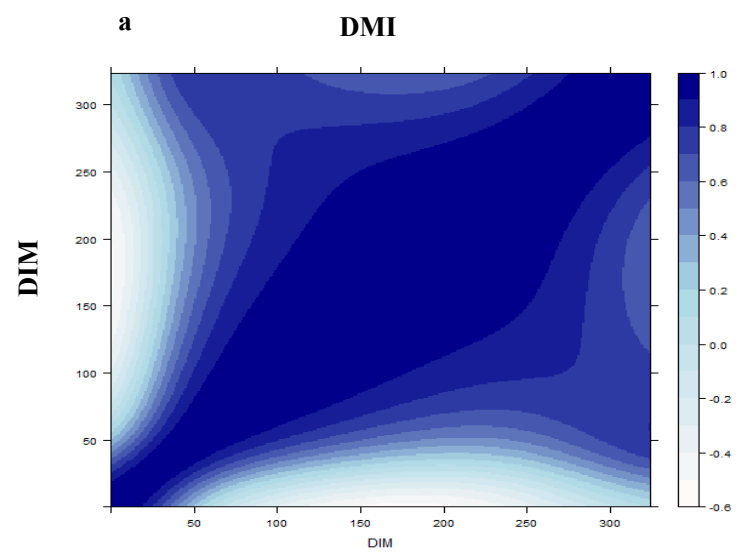

b

FPCM

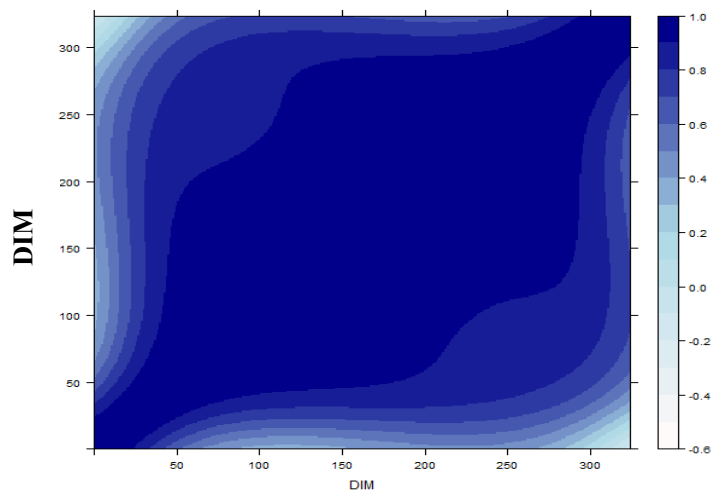

c

$\mathbf{L W}$

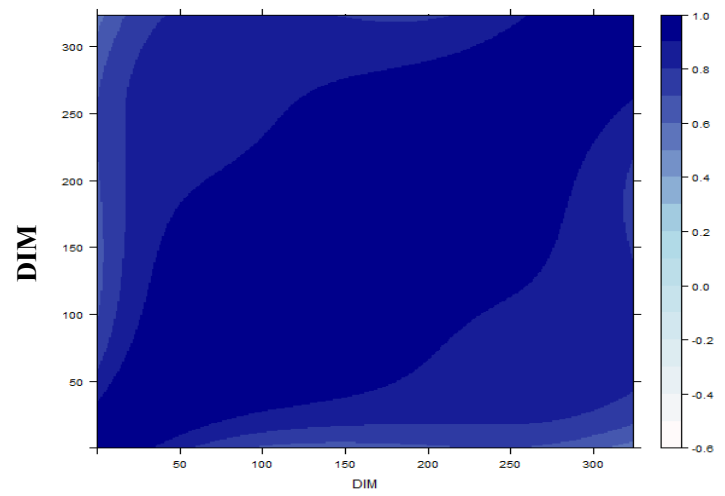

Figure 2.4 Estimated genetic correlations within same trait recorded from 1 to 324 days in milk DIM for a) dry matter intake (DMI, SE of median $=0.07$, of $3^{\text {rd }}$ quartile $=0.11$ ), b) fat and protein corrected milk (FPCM, SE of median $=0.02$, of $3^{\text {rd }}$ quartile $\left.=0.06\right)$, and $c$ ) live weight (LW, SE of median=0.04, of $3^{\text {rd }}$ quartile $=0.06$ ). 


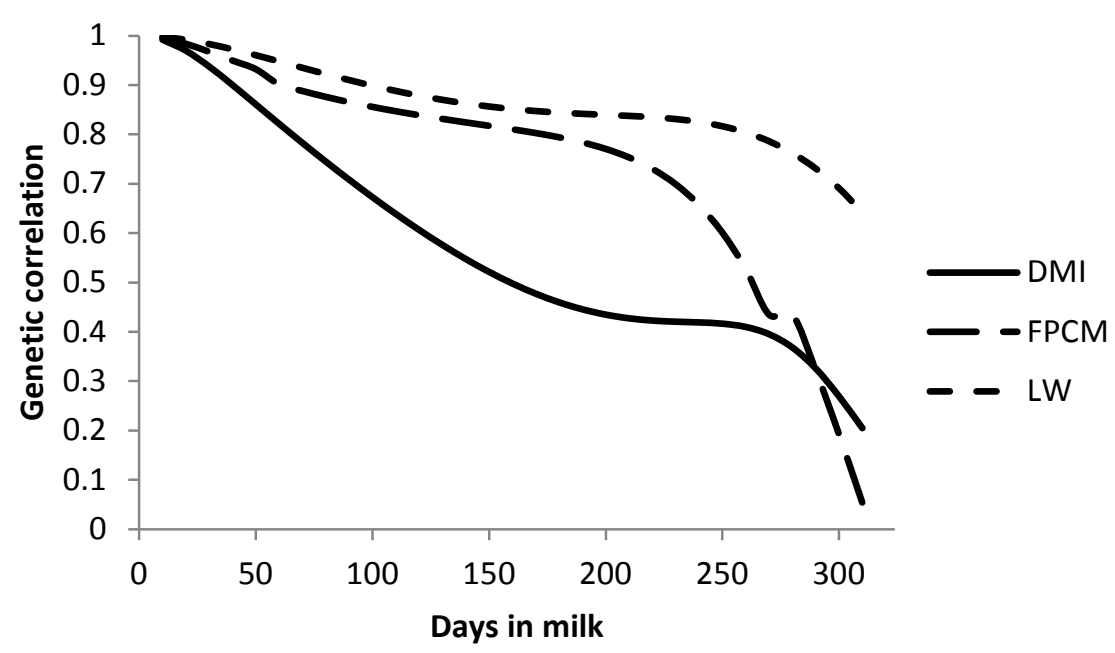

Figure 2.5 Calculated average of estimated genetic correlations within dry matter intake (DMI), fat and protein corrected milk (FPCM), and live weight (LW) when the difference between two recordings is $10,20, \ldots, 310$ days in milk (DIM).

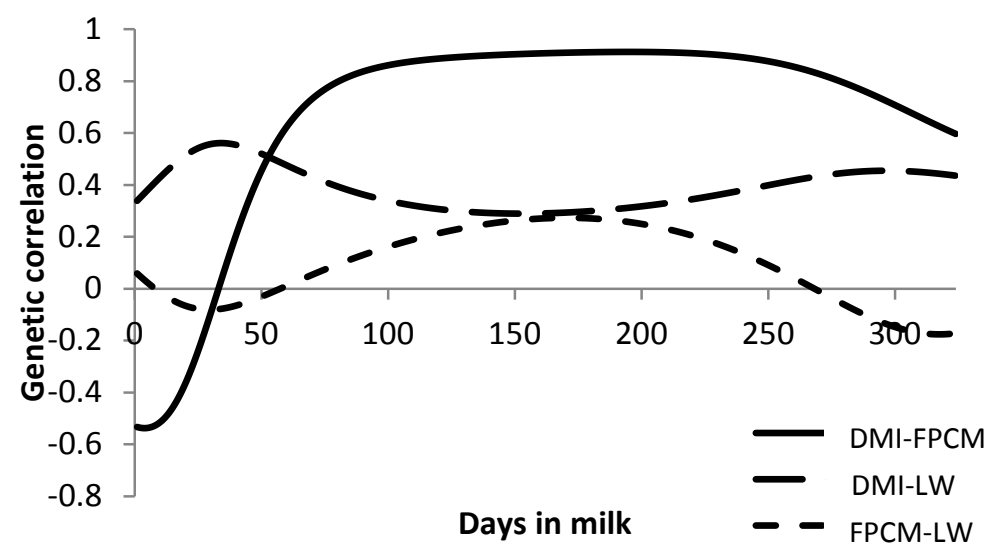

Figure 2.6 Pairwise genetic correlations when two traits are measured on the same day from 1 to 324 days in milk (DIM) between 1 . dry matter intake and fat and protein corrected milk (DMI-FPCM, SE of median=0.06, of $3^{\text {rd }}$ quartile=0.09), 2 . dry matter intake and live weight (DMI-LW, SE of median $=0.11$, of $3^{\text {rd }}$ quartile $=0.10$ ), and 3 . fat and protein corrected milk and live weight (FPCM-LW, SE of median $=0.12$, of $3^{\text {rd }}$ quartile $=0.13$ ). 

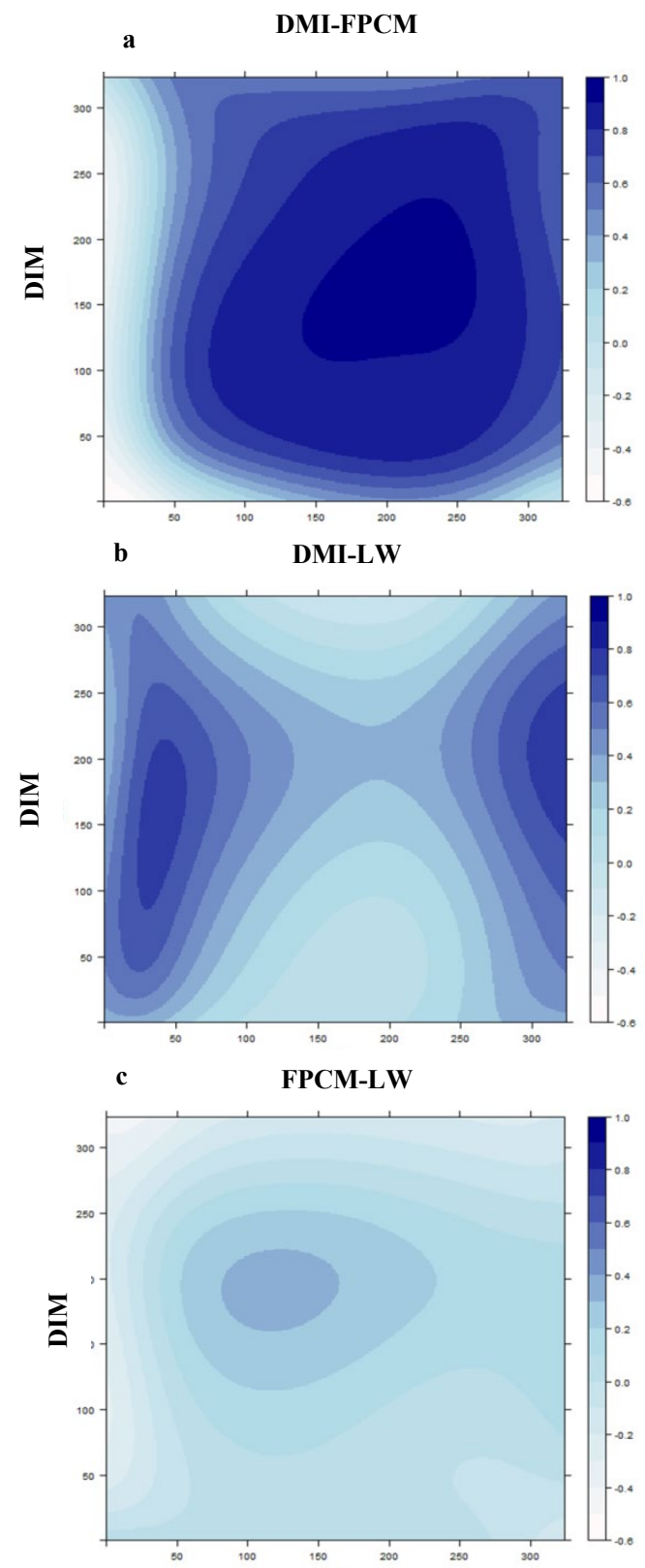

Figure 2.7 Pairwise genetic correlations when two traits are measured on different days between 1 to 324 days in milk (DIM) between a) dry matter intake and fat and protein corrected milk (DMI-FPCM, SE of median=0.07, of 3rd quartile=0.10), b) dry matter intake and live weight (DMI-LW, SE of median=0.12, of 3rd quartile=0.13), and $\mathrm{C}$ ) fat and protein corrected milk and live weight (FPCM-LW, SE of median=0.12, of 3rd quartile=0.14). 
genetic correlations (up to -0.5 ) were estimated between FPCM recorded during the first 50 DIM, and DMI recorded in the entire lactation.

Positive genetic correlations (> 0.6) were estimated when DMI and LW were both recorded during early $(<100$ DIM), or when LW was recorded in late lactation (from 260 to 300 DIM), and DMI was recorded in mid lactation. Lowest genetic correlations ( $\sim 0.2$ ) were estimated when both traits were recorded during mid lactation. Negative correlations (up to -0.2) were estimated when LW was recorded in mid lactation and DMI in early or late lactation.

The highest genetic correlations between FPCM and LW (0.3 to 0.5) were estimated when LW was recorded between 50 and 230 DIM, and FPCM was recorded between 110 and 250 DIM.

In order to get an overview of the strength of the correlations between different traits measured at increasing days apart, the average of genetic correlations between DMI, FPCM and LW was calculated when the difference between two recordings was 50, 100, ..., 250 DIM. It turned out that this calculated average of estimated genetic correlations between DMI and FPCM differed depending on which trait was measured first (results not shown). The calculated average of the genetic correlations between DMI and FPCM was much higher when DMI was measured first (i.e., 0.76 and 0.60 when records were taken 50 or 250 days apart, respectively), than when FPCM was measured first ( 0.70 to 0.18 , respectively). The calculated averaged of the estimated genetic correlations between DMI and LW did not vary much when the distance increased (from 0.28 to 0.38 for 50 to 250 days apart). When LW was measured before DMI, the calculated average was always 0.40 , independent of the distance between two recordings.

\subsection{Discussion}

\subsubsection{Genetics of DMI an LW during Lactation}

\subsubsection{Heritability}

Estimated heritabilities for DMI and LW have been reported widely, but most studies included either only records until 150 or 180 DIM (Veerkamp and Brotherstone, 1997; Koenen and Veerkamp, 1998; Huttmann et al., 2009; Buttchereit et al., 2011; Spurlock et al., 2012), or used smaller datasets with 320 up to 970 cows (Karacaoren et al., 2006; Berry et al., 2007; Vallimont et al., 2010). Estimated daily heritabilities of DMI in this study were between 0.21 to 0.40 , and were within the range (0.12 to 0.54 ) published in previous studies (Veerkamp and Brotherstone, 1997; Koenen and Veerkamp, 1998; Veerkamp and Thompson, 1999; Karacaoren et al., 2006; Berry et al., 2007; Vallimont et al., 2010; Spurlock et al., 
2012; Tetens et al., 2014). Estimated entire lactation heritabilities were slightly higher than estimated daily heritabilities, which is due to the fact that the genetic covariances are higher than permanent environmental and residual covariances.

Although the estimated daily heritabilities were within the range of previous studies, the trajectory of the heritability during lactation in our study was different compared to several other studies (Karacaoren et al., 2006; Berry et al., 2007; Spurlock et al., 2012; Tetens et al., 2014). In the current study, highest daily heritabilities were estimated during mid lactation, which is similar to the findings of Spurlock et al. (2012) when they also analyzed only the data of primiparous cows. However, when they analyzed the data of both primiparous and multiparous cows, the highest daily heritabilities (above 0.25 ) were estimated during early lactation (between 15 and 30 DIM). Tetens et al. (2014), however, estimated highest daily heritabilities ( 0.40) in early (10 DIM) and mid lactation (180 DIM), showing a curve which is opposite to the one reported in this study. Karacaoren et al. (2006) presented a sigmoid curve for the entire lactation (until 305) with the highest estimated daily heritabilities ( 0.3) between 77 and 96 DIM and at end of lactation (305 DIM) with SE of 0.20 during the entire lactation. Overall, all studies showed that the heritability of DMI differed across lactation, but curvature for the daily heritability of DMI were different in shape across studies. One explanation for these different curves might be that different recording practices or different feeding systems affected the residual variance, but the most likely explanation is that the limited data has hindered accurate estimates of daily heritabilities of DMI in the entire lactation.

Estimated daily heritabilities for LW in the current study ( 0.25 to 0.48 ) were within the range of estimated daily heritabilities published in previous studies (0.22 to 0.74 (Koenen and Veerkamp, 1998; Karacaoren et al., 2006; Huttmann et al., 2009; Spurlock et al., 2012). The recording periods of these studies differed from the recording period of the current study. Therefore, at first sight it might seem that some studies have published higher estimated daily heritabilities (e.g., from 0.43 to 0.56 (Koenen and Veerkamp, 1998) or from 0.57 to 0.74 (Spurlock et al., 2012)), but their included recording period corresponds with the period where the highest daily heritabilities were estimated in the current study. In the current study, the lactation curve of estimated daily heritabilities for LW presented a sigmoidal curve (i.e., highest at early lactation and lowest 200 DIM), which was different to the one presented by Karacaoren et al. (2006), with a shape of a decreasing line from early lactation to late lactation. 


\subsubsection{Genetic Correlations within DMI and LW across Lactation}

Genetic correlations within traits across lactation are important when judging how these traits differ through early, mid, and late lactation. Several studies have shown that DMI is a different trait in early and mid lactation (Koenen and Veerkamp, 1998; Karacaoren et al., 2006; Huttmann et al., 2009; Liinamo et al., 2012). Generally, the genetic correlations between DMI recorded in early and in mid lactation were negative when records were taken far ( 150 days) apart, and positive when records were taken less far ( $<50$ days) apart. All studies agreed that genetic correlations within DMI across lactation decreased faster than the genetic correlations within FPCM and LW across lactation (Figure 2.5). In some cases, the genetic correlation between DMI recorded at separate lactation stages even became negative (Koenen and Veerkamp, 1998; Karacaoren et al., 2006), whereas in other cases, the correlation decreased slower and stayed positive across the entire lactation (Huttmann et al., 2009; Liinamo et al., 2012).

Genetic correlations between LW recorded at separate DIM are consistently positive in the entire lactation (Koenen and Veerkamp, 1998; Liinamo et al., 2012; Veerkamp and Thompson, 1999). Most of these studies reported genetic correlations above 0.76 through lactation, which is similar to the genetic correlations estimated in the current study (i.e., above 0.60 for most of the lactation). This performance was similar in milk yield, where genetic correlations within lactation did not drop below 0.70 during most of the lactation in the current study, and not below 0.73 according to Huttmann et al. (2009) and not below 0.62 according to Veerkamp and Thompson (1999).

Overall, compared with FPCM and LW, DMI showed more variation in estimated daily heritabilities and in genetic correlations within DMI across lactation, and also showed more negative correlations during early and late lactation. These results suggest that genetics of DMI is more variable during lactation than of, for example, milk yield and live weight, which is important to take into account when measuring during DMI in a breeding program.

\subsubsection{Correlations between DMI, FPCM and LW during Lactation}

To our knowledge, there are not many studies that presented genetic correlations between DMI, FPCM and LW throughout the entire lactation. However, several studies have presented correlations between DMI and milk yield over a fixed period (Veerkamp and Brotherstone, 1997; Veerkamp and Thompson, 1999; Karacaoren et al., 2006; Huttmann et al., 2009; Vallimont et al., 2010), and also between DMI and LW (Veerkamp and Brotherstone, 1997; Veerkamp and 
Thompson, 1999; Karacaoren et al., 2006; Huttmann et al., 2009; Vallimont et al., 2010; Liinamo et al., 2012; Spurlock et al. 2012).

When weekly FPCM information throughout the entire lactation (1-46 weeks) was used in a selection index to predict DMI in the entire lactation, the accuracy of selection was 0.66 . If this was done for LW, an accuracy of 0.36 was calculated. However, if FPCM and LW were used together to predict DMI, an accuracy of up to 0.73 was calculated. This high accuracy based on phenotypic data justifies the estimation of genetic parameters for these traits with the aim to construct a national selection index.

In the current study, negative (up to -0.54) genetic correlations were estimated between DMI recorded in the entire lactation and FPCM recorded during first 50 DIM. However, for the majority of lactation, positive genetic correlations between DMI and FPCM were estimated in the current study (above 0.70 and up to 0.92). These values above 0.70 were higher than the correlations reported by Vallimont et al. (2010) (0.52), Veerkamp and Brotherstone (1997) (0.34) and Van Elzakker and Van Arendonk (1993) (0.46). Due to the high positive genetic correlations estimated in this study (above 0.7 ) of DMI with FPCM during most of the lactation, selection for milk yield is also expected to increase DMI. The estimated genetic correlations of $>0.7$ indicate that $>49 \%$ of the genetic variation in DMI can be explained by milk yield.

The low genetic correlations between FPCM recorded in early lactation (first 50 DIM) and DMI recorded during the entire lactation can be explained by a larger increase in milk production, than in feed intake during early lactation, according to Tamminga et al. (1997). That means that after calving both DMI and milk yield increase, but at different rates (Grummer, 2007). Milk yield will first increase sharply, followed by a slow increase in DMI. As a result, in the first 5-7 weeks post calving, a cow will get part of her energy from the mobilization of body tissue, rather than from her diet (Grummer, 2007). It has been shown that some of the genes involved in the high producing cows, are also related to a larger capacity to mobilize muscle protein and fat reserves (Veerkamp et al., 2003; Friggens et al., 2013). As a consequence, selecting for high producing cows is also a selection for higher capacity of tissue mobilization (Wathes et al., 2007).

Besides, the asymmetry in the genetic correlations between DMI and FPCM across lactation (Figure 2.7a), indicates that is also affected by which of the two traits was measured first. For example, when DMI was measured first, the average genetic correlation was above 0.7 when recording was up to 220 days apart, but when FPCM was measured first, the corresponding genetic correlation was $\sim 27$. 
Genetic correlations between DMI and LW have been previously reported (Veerkamp and Thompson, 1999; Karacaoren et al., 2006; Huttmann et al., 2009; Spurlock et al., 2012). In the current study, at same DIM, low to moderate genetic correlations were estimated between DMI and LW. Huttmann et al. (2009) estimated a genetic correlation of 0.03 when both DMI and LW were recorded between 31 to $60 \mathrm{DIM}$, and a correlation of 0.42 when both traits were recorded between 121 to 180 DIM. Karacaoren et al. (2006) estimated mainly negative genetic correlations between DMI and LW (-0.89 to 0.29) across lactation. However, the highest positive correlations estimated in the current study (above 0.6) between DMI and LW are in line with those reported by Veerkamp and Thompson (1999) and by Spurlock et al. (2012). The low correlations (-0.2 to 0.2) between LW recorded in mid lactation and DMI recorded in either early or late lactation indicate that the amount of feed that a cow eats during early lactation is not necessary according to her weight at mid lactation. The cow experiences a negative energy balance during the first 5-7 weeks post calving with a consequent fat and protein mobilization from the body reserves to be used for the milk production (Tamminga et al., 1997). Therefore, even when a cow is consuming a considerable amount of feed, she can still be losing weight due to the tissue mobilization. The body mobilization can vary considerably from one individual to another (i.e. from 15 to $60 \mathrm{~kg}$ ) (Tamminga et al., 1997). A trait that is reflecting the body mobilization is body condition score (BCS), which reflects the adiposity of the cow and can be used as an indicator of the energy status and fat mobilization (Roche et al., 2009). The genetic correlations between DMI and LW can therefore be a result of the relation of DMI with body energy, where body energy is supplying the energy for milk production (FPCM) instead DMI. The heritability of BCS is, however, somewhat lower than the heritability of LW (0.26; Battagin et al., 2012).

Vallimont et al. (2010) showed that a decrease in LW during the first weeks of lactation (3-6 weeks), is followed by a decrease in BCS in subsequent weeks (9-12 weeks). Therefore, LW seems to show the changes more instantly than BCS.

The genetic correlations between DMI and LW are asymmetric, indicating that the genetic correlations between DMI and LW depend on which trait was measured first. Veerkamp and Thompson (1999) also reported some asymmetry for DMI and LW, and they concluded that the correlation between DMI and LW appeared to be less affected by lactation stage than the correlation between LW and DMI.

Genetic correlations between FPCM and LW presented in this study (-0.4 to 0.6) were similar to those reported by Karacaoren et al. (2006) between milk yield and LW (-0.60 to 0.54). However, Huttmann et al. (2009) presented negative 
correlations of -0.41 to -0.04 between milk yield and LW until 180 DIM. The slightly negative correlation estimated in the current study between LW in early lactation and FPCM during the entire lactation indicates that a heavier cow in early lactation does not necessarily produces more milk than a lighter cow. This can be explained by the body tissue mobilization of high producing cows during some parts of lactation, affecting their LW in this way (Veerkamp and Brotherstone, 1997). Moderate genetic correlations between LW and FPCM are estimated during mid lactation, indicating that the milk production of a cow during mid lactation is proportional to her weight in mid lactation. The wide range of the genetic correlations between DMI, FPCM and LW across the entire lactation showed how the genetics of those traits differ per lactation stage, and this study provides important information about the genetic relationships within and between traits that should be taken into account when constructing a national selection index.

\subsection{Conclusions}

The heritabilities, genetic variances and genetic correlations of DMI, FPCM and LW changed across the different stages of lactation, mainly differing during early and late lactation in comparison with mid lactation. These parameters suggest that genetics of DMI varies across lactation. The average genetic correlation decreased faster for DMI than for FPCM and LW when two recordings of the same trait were taken more days apart. For the majority of the lactation, DMI and FPCM do not genetically correlate differently when recorded on the same day; only in early lactation different genetic correlations were estimated. Dry matter intake and LW, however, do genetically correlate differently during lactation; highest genetic correlations were estimated when both traits were recorded in either early or late lactation, and lowest when both traits were recorded in mid lactation. When DMI and LW were not recorded on the same day, the lowest genetic correlations were estimated when LW was recorded in mid lactation, and DMI was recorded in either early or late lactation. However, the genetic correlations between DMI and FPCM or LW were not symmetric in time, indicating that the genetic correlation depends both on the distance between two recordings, and on which trait was measured first. The results of our study are useful to understand the genetic relationship of DMI, FPCM, and LW on specific days across lactation, and should be taken into account when constructing a national selection index. 


\subsection{Acknowledgements}

This research is financed by the Dutch Dairy Board (Zoetermeer, the Netherlands), the Dutch Product Board Animal Feed (Zoetermeer, the Netherlands), and CRV (Arnhem, the Netherlands). The first author thanks CONACYT (National Council on Science and Technology of Mexico) for its financial support for a PhD-study at Wageningen University, and to INIFAP-Mexico (National Research Institute of Forestry, Agriculture and Livestock) to promote the professional development of the researchers. Piter Bijma (Wageningen University, Wageningen, the Netherlands) is kindly acknowledged for his helpful comments to this paper. 


\subsection{References}

Banos, G., M. P. Coffey, R. F. Veerkamp, D. P. Berry, and E. Wall. 2012. Merging and characterising phenotypic data on conventional and rare traits from dairy cattle experimental resources in three countries. Animal 6:1040-1048.

Battagin, M., F. Forabosco, J. H. Jakobsen, M. Penasa, T. J. Lawlor, and M. Cassandro. 2012. International genetic evaluation of Holstein bulls for overall type traits and body condition score. J. Dairy Sci. 95:4721-4731.

Beerda, B., W. Ouweltjes, L. B. J. Sebek, J. J. Windig, and R. F. Veerkamp. 2007. Effects of genotype by environment interactions on milk yield, energy balance, and protein balance. J. Dairy Sci. 90:219-228.

Berry, D. P. and J. J. Crowley. 2013. Cell Biology Symposium: genetics of feed efficiency in dairy and beef cattle. J. Anim. Sci. 91:1594-1613.

Berry, D. P., B. Horan, M. O'Donovan, F. Buckley, E. Kennedy, M. McEvoy, and P. Dillon. 2007. Genetics of grass dry matter intake, energy balance, and digestibility in grazing Irish dairy cows. J. Dairy Sci. 90:4835-4845.

Buttchereit, N., E. Stamer, W. Junge, and G. Thaller. 2011. Short communication: Genetic relationships among daily energy balance, feed intake, body condition score, and fat to protein ratio of milk in dairy cows. J. Dairy Sci. 94:1586-1591.

Calus, M. P. L., Y. de Haas, M. Pszczola, and R. F. Veerkamp. 2013. Predicted accuracy of and response to genomic selection for new traits in dairy cattle. Animal 7:183-191.

de Haas, Y., M. P. L. Calus, R. F. Veerkamp, E. Wall, M. P. Coffey, H. D. Daetwyler, B. J. Hayes, and J. E. Pryce. 2012. Improved accuracy of genomic prediction for dry matter intake of dairy cattle from combined European and Australian data sets. J. Dairy Sci. 95:6103-6112.

EC. European Commision of Agricultural and Rural Development. 2011. Farm Economics Brief. No. 2 Production costs overview. Accessed July 1, 2013. http://ec.europa.eu/agriculture/rica/pdf/Brief201102.pdf.

FAO. 2010. Food and agriculture organization of the United Nations. Greenhouse gas emissions from the dairy sector. Accessed July 8, 2013. http://agw156.aeadmin.com/assets/import/files/k7930e00.pdf

Fischer, T. M., A. R. Gilmour, and J. H. J. van der Werf. 2004. Computing approximate standard errors for genetic parameters derived from random regression models fitted by average information REML. Genet. Sel. Evol. 36:363369. 
Friggens, N. C., L. Brun-Lafleur, P. Faverdin, D. Sauvant, and O. Martin. 2013. Advances in predicting nutrient partitioning in the dairy cow: recognizing the central role of genotype and its expression through time. Animal 7:89-101.

Gilmour, A. R., B. J. Gogel, B. R. Cullis, and R. Thompson. 2009. ASREML User Guide Release 3.0 VSN International Ltd, Hemel Hempstead, UK.

Grummer, R. R. 2007. Strategies to improve fertility of high yielding dairy farms: Management of the dry period. Theriogenology 68:S281-S288.

Hüttmann, H., E. Stamer, W. Junge, G. Thaller, and E. Kalm. 2009. Analysis of feed intake and energy balance of high-yielding first lactating Holstein cows with fixed and random regression models. Animal 3:181-188.

Karacaören, B., F. Jaffrezic, and H. N. Kadarmideen. 2006. Genetic parameters for functional traits in dairy cattle from daily random regression models. J. Dairy Sci. 89:791-798.

Kennedy, B. W., J. H. J. Vanderwerf, and T. H. E. Meuwissen. 1993. Genetic and statistical properties of Residual Feed Intake. J. Anim. Sci. 71:3239-3250.

Koenen, E. P. C. and R. F. Veerkamp. 1998. Genetic covariance functions for live weight, condition score, and dry-matter intake measured at different lactation stages of Holstein Friesian heifers. Livest. Prod. Sci. 57:67-77.

Korver, S. 1988. Genetic aspects of feed intake and feed efficiency in dairy cattle: A review. Livest. Prod. Sci. 20:1-13.

Liinamo, A. E., P. Mantysaari, and E. A. Mantysaari. 2012. Short communication: Genetic parameters for feed intake, production, and extent of negative energy balance in Nordic Red dairy cattle. J. Dairy Sci. 95:6788-6794.

Liu, Z., F. Reinhardt, and R. Reents. 2000. Parameter estimates of a random regression test day model for first three lactation somatic cell scores. Pages pp. 61-66 in Interbull Bulletin Vol. 26.

Parke, P., B. W. Kennedy, J. C. M. Dekkers, R. K. Moore, and L. Jairath. 1999. Genetic and phenotypic parameter estimates between production, feed intake, feed efficiency, body weight and linear type traits in first lactation Holsteins. Can. J. Anim. Sci. 79:425-431.

Pryce, J. E., B. J. Hayes, and M. E. Goddard. 2012. Novel strategies to minimize progeny inbreeding while maximizing genetic gain using genomic information. J. Dairy Sci. 95:377-388.

Pszczola, M., R. F. Veerkamp, Y. de Haas, E. Wall, T. Strabel, and M. P. L. Calus. 2013. Effect of predictor traits on accuracy of genomic breeding values for feed intake based on a limited cow reference population. Animal 7:1759-1768. 
Roche, J. R., N. C. Friggens, J. K. Kay, M. W. Fisher, K. J. Stafford, and D. P. Berry. 2009. Body condition score and its association with dairy cow productivity, health, and welfare. J. Dairy Sci. 92:5769-5801.

Spurlock, D. M., J. C. M. Dekkers, R. Fernando, D. A. Koltes, and A. Wolc. 2012. Genetic parameters for energy balance, feed efficiency, and related traits in Holstein cattle. J. Dairy Sci. 95:5393-5402.

Tamminga, S., P. A. Luteijn, and R. G. M. Meijer. 1997. Changes in composition and energy content of liveweight loss in daily cows with time after parturition. Livest. Prod. Sci. 52(1):31-38.

Tetens, J., G. Thaller, and N. Krattenmacher. 2014. Genetic and genomic dissection of dry matter intake at different lactation stages in primiparous Holstein cows. J. Dairy Sci.97:1-12.

Vallimont, J. E., C. D. Dechow, J. M. Daubert, M. W. Dekleva, J. W. Blum, C. M. Barlieb, W. Liu, G. A. Varga, A. J. Heinrichs, and C. R. Baumrucker. 2010. Genetic parameters of feed intake, production, body weight, body condition score, and selected type traits of Holstein cows in commercial tie-stall barns. J. Dairy Sci. 93:4892-4901.

Van der Werf, J. H. J., M. E. Goddard, and K. Meyer. 1998. The use of covariance functions and random regressions for genetic evaluation of milk production based on test day records. J. Dairy Sci. 81:3300-3308.

Van Elzakker, P. J. M. and J. A. M. Van Arendonk. 1993. Feed intake, body weight and milk production: genetic anaysis of different measurements in lactating dairy heifers. Livest. Prod. Sci. 37:37-51.

Van Knegsel, A. T. M., G. J. Remmelink, S. Jorjong, V. Fievez, and B. Kemp. 2014. Effect of dry period length and dietary energy source on energy balance, milk yield, and cow composition of dairy cows. J. Dairy Sci. 97(3):1499-1512.

Veerkamp, R. F. 1998. Selection for economic efficiency of dairy cattle using information on live weight and feed intake: A review. J. Dairy Sci. 81:1109-1119.

Veerkamp, R. F., B. Beerda, and T. van der Lende. 2003. Effects of genetic selection for milk yield on energy balance, levels of hormones, and metabolites in lactating cattle, and possible links to reduced fertility's. Livest. Prod. Sci. 83(2-3):257-275.

Veerkamp, R. F. and S. Brotherstone. 1997. Genetic correlations between linear type traits, food intake, live weight and condition score in Holstein Friesian dairy cattle. Anim. Sci. 64:385-392.

Veerkamp, R. F., M. P. Coffey, D. P. Berry, Y. de Haas, E. Strandberg, H. Bovenhuis, M. P. L. Calus, and E. Wall. 2012. Genome-wide associations for feed utilisation complex in primiparous Holstein-Friesian dairy cows from experimental research herds in four European countries. Animal 6:1738-1749. 
Veerkamp, R. F., and G. C. Emmans. 1995. Sources of genetic variation in energetic efficiency of dairy cows. Livest. Prod. Sci. 44(2):87-97.

Veerkamp, R. F., J. K. Oldenbroek, H. J. Van Der Gaast, and J. H. J. Van Der Werf. 2000. Genetic correlation between days until start of luteal activity and milk yield, energy balance, and live weights. J. Dairy Sci. 83:577-583.

Veerkamp, R. F. and R. Thompson. 1999. A covariance function for feed intake, live weight, and milk yield estimated using a random regression model. J. Dairy Sci. 82:1565-1573.

Wathes, D. C., M. Fenwick, Z. Cheng, N. Bourne, S. Llewellyn, D. G. Morris, D. Kenny, J. Murphy, and R. Fitzpatrick. 2007. Influence of negative energy balance on cyclicity and fertility in the high producing dairy cow. Theriogenology 68:S232S241.

Zom, R. L. G., G. Andre, and A. M. van Vuuren. 2012. Development of a model for the prediction of feed intake by dairy cows: 1 . Prediction of feed intake. Livest. Sci. 143:43-57. 



\section{Chapter 3}

\section{Genetic parameters between feed intake- related traits and conformation in two separate dairy populations: the Netherlands and United States}

C. I. V. Manzanilla-Pech ${ }^{1,2,3}$, R. F. Veerkamp ${ }^{1,2}$, R. J. Tempelman ${ }^{4}$, M. L. van Pelt ${ }^{1,5}, K$. A. Weigel ${ }^{6}$, M. VandeHaar ${ }^{4}$, T. J. Lawlor ${ }^{7}$, D. M. Spurlock ${ }^{8}$, L. E. Armentano ${ }^{6}$, C. R. Staples $^{9}$, M. Hanigan ${ }^{10}$, Y. De Haas ${ }^{1}$

${ }^{1}$ Animal Breeding and Genomics Centre, Wageningen UR Livestock Research, P.O. Box 338, $6700 \mathrm{AH}$ Wageningen, the Netherlands; ${ }^{2}$ Animal Breeding and Genomics

Centre, Wageningen University, P.O. Box 338, 6700 AH Wageningen, the Netherlands; ${ }^{3}$ Mococha Research Station, National Institute of Forestry, Agriculture and Livestock Research, 97454 Mococha, Yucatan, Mexico; ${ }^{4}$ Department of Animal Science, Michigan State University, East Lansing, MI 48824; ${ }^{5}$ CRV BV, Animal Evaluation Unit, PO Box 454, 6800 AL Arnhem, The Netherlands; ${ }^{6}$ Department of Dairy Science, University of Wisconsin, Madison 53706; ${ }^{7}$ Holstein Association, Brattleboro, VT 05301; ${ }^{8}$ Department of Animal Science, lowa State University, Ames 50011; ${ }^{9}$ Department of Animal Sciences, University of Florida, 1 Gainesville 32611; ${ }^{10}$ Department of Dairy Science, Virginia Tech, Blacksburg, VA 24061 


\section{Abstract}

To include feed intake-related traits in the breeding goal, accurate estimates of genetic parameters of feed intake, and its correlations with other related traits (i.e. production, conformation) are required to compare different options. However, the correlations between feed intake and conformation traits can vary depending on the population. Therefore, the objective was to estimate genetic correlations between six feed intake-related traits and seven conformation traits within dairy cattle from two countries, the Netherlands (NL) and the United States (US). The feed intake-related traits were dry matter intake (DMI), residual feed intake (RFI), milk energy output (MilkE), milk yield (MY), body weight (BW) and metabolic body weight (MBW). The conformation traits were stature (ST), chest width (CW), body depth (BD), angularity (ANG), rump angle (RA), rump width (RW) and body condition score (BCS). Feed intake data were available for 1,665 cows in NL and for 1,920 cows in US, from 83 nutritional experiments (48 in NL and 35 in US) conducted between 1991 and 2011 in NL and between 2007 and 2013 in US. Additional conformation records from relatives of the animals with DMI records were added to the database giving a total of 37,241 cows in NL and 28,809 in the US with conformation trait information. Genetic parameters were estimated using bivariate animal model analyses. The model included the following fixed effects for feed intake-related traits: location by experiment-ration, age of cow at calving modelled with a 2 nd order polynomial by parity class, location by year-season, and days in milk, and these fixed effects for the conformation traits: herd by classification date, age of cow at classification and lactation stage at classification. Both models included additive genetic and residual random effects. The highest estimated genetic correlations involving $\mathrm{DMI}$ were with $\mathrm{CW}$ in both countries ( $\mathrm{NL}=0.45$ and $\mathrm{US}=0.61)$, followed by $\mathrm{ST}(\mathrm{NL}=0.33$ and $\mathrm{US}=0.57), \mathrm{BD}(\mathrm{NL}=0.26$ and $U S=0.49)$ and $B C S(N L=0.24$ and $U S=0.46)$. MilkE and MY were moderately correlated with ANG in both countries ( 0.33 and 0.47 in NL, and 0.36 and 0.48 in US). Finally, BW was highly correlated with CW ( 0.77 in NL and 0.84 in US) and with BCS (0.83 in NL and 0.85 in US). Feed intake-related traits were moderate to high genetically correlated with conformation traits (ST, CW, BD, and BCS) in both countries, making them potentially useful as predictors of DMI.

Key words: feed intake, conformation trait, genetic correlation 


\subsection{Introduction}

Feed intake accounts for approximately $50 \%$ of variable costs in dairy production in Europe (E.U., 2011). Including feed intake or feed efficiency in the selection index is worthwhile in order to reduce feed costs (Kennedy et al., 1993; de Haas et al., 2012; Veerkamp et al., 2012). Reducing feed intake, while increasing production in the breeding objective, should improve feed efficiency and hence farmer profit, provided that other economically important traits, such as fertility and health, are maintained. In order to be able to include feed intake in the selection index, specialized equipment is required to obtain individual dry matter intake (DMI) records. This equipment is expensive to buy and labor intensive to use. Therefore, it is unrealistic that large numbers of records will be obtained to allow accurate estimation of genetic parameters to predict breeding values in a progeny testing scheme.

Another option is to use other traits as predictors, like production traits (e.g., milk, fat, and protein content), that have been shown to have strong genetic correlations with DMI (Veerkamp and Emmans, 1995; Veerkamp and Brotherstone, 1997; Manzanilla-Pech et al., 2014). Other possible predictor traits are conformation traits or linear type traits, that describe a range of visual characteristics of an animal (Berry et al., 2004), or body condition score (BCS), which is an estimate of the fat storage (Waltner et al., 1993). Body condition score and chest width (CW) are highly correlated with body weight (BW) and have moderate to high heritabilities (Short and Lawlor, 1992). Several studies have already demonstrated that conformation traits are indeed useful as genetic predictors of DMI and feed efficiency in Holsteins (Veerkamp et al., 1994; Parke et al., 1999; Battagin et al., 2012).

Accurate estimates of genetic and residual correlations between feed intake-related traits and conformation traits are required to compare the different options of including the latter as predictor traits for DMI within a selection index. However, estimated genetic parameters can vary depending on the population they are estimated in (van Oers and Sinn, 2011). For instance, due to different selection history, genetic correlations between type and feed intake might differ. The objective of this study was to estimate genetic correlations between six feed intake-related traits and seven conformation traits for dairy cattle from two different countries: the Netherlands (NL) and United States (US). 


\subsection{Material and methods}

\subsubsection{Selection of the traits}

A careful selection of traits was conducted based on both nutritional and genetic perspectives. Some of the traits are obviously related, because of the trait definition; e.g., milk yield (MY) with milk energy (MilkE), and BW with metabolic body weight (MBW). Some other traits include part-whole relationships; e.g., DMI with residual feed intake (RFI), MilkeE with protein and fat content. The purpose of this paper was to estimate the genetic correlations between all feed intake-related traits (i.e., DMI, RFI, MY, MilkE, BW, MBW) and various conformation traits, in order to be able to determine which traits might be most useful to include in a selection index.

\subsubsection{Data Collection and Editing: Feed Intake Traits}

\subsubsection{The Netherlands}

Weekly data on MY, DMI and BW were available from 2,283 cows that participated in nutritional experiments that were conducted on several Dutch farms during 1986 to 2010. A description of the methodology of most experiments and of the content of the diets has been summarized previously (Veerkamp et al., 2000; Beerda et al., 2007; Zom et al., 2012). Diets primarily included grass silage, fresh grass, dehydrated grass, corn, corn silage, cereal, concentrates or beet pulp. Average DM of the diets was 53/100 g. All cows were kept indoors in conventional cubicle housing and they were offered completely mixed diets ad libitum. They were milked twice a day, except for half of the cows in one of the locations ( $n=50$ ) that were milked three times per day. Recording frequencies of the individual feed intake-related traits varied by experiment: DMI was recorded either 1, 2, 3 or 5 times per week (Veerkamp et al., 2000; Beerda et al., 2007; Zom et al., 2012), whereas BW was measured with weighing platforms 3 times per week or daily.

Additional feed intake-related traits were calculated: MilkE, MBW, and RFI. A full description of the data editing strategies can be found in Tempelman et al. (2015). Milk energy output is expressed in Mcal and was calculated from weekly MY plus the fat\% (FP), protein\% (PP) and lactose\% (LP), using the following formula according to National Research Dairy Council (2001):

MilkE $=(0.0929 * \mathrm{FP}+0.0563 * \mathrm{PP}+0.0395 * \mathrm{LP}) * \mathrm{MY} / 100$

Weekly MBW was computed as the weekly average BW0.75. Kleiber (1932) determined MBW to be proportional to the basal metabolic rate of animals 
and is representative of maintenance nutrient requirements for animals as a function of their BW. Residual feed intake is defined as the estimated residual from an energy sink model (Berry et al., (2014), whereby weekly DMI was modeled as a linear function of MilkE, MBW, and BW. The following six feed intake-related traits were analyzed: DMI, RFI, MilkE, MY, BW and MBW. Twenty eight day-average traits were calculated based on the records obtained in the first period of 28 days between 50 and 200 DIM (Tempelman et al., 2015). This restriction was imposed because BW changes are more stable in this interval, resulting in more robust RFI determinations, compared to determinations outside this DIM interval. Data from NL were on weekly basis, and in this case, four weekly records were used, taking the first observation after 7 weeks in lactation and the following 3 observations to calculate the $28 \mathrm{~d}$ average. Only data from the earliest parity of each animal was used, and only cows with at least $75 \%$ of Holstein genes were included. These editing steps resulted in a final dataset with 1,665 cows, sired by 372 bulls. Description of the data is shown in Table 3.1.

\subsubsection{United States}

Data for MY, DMI, and BW (2,276 records from 1,924 cows) were collected during 2007 to 2013 from seven different research stations in United States: University of Florida (FL), lowa State University (ISU), Michigan State University (MSU), the USDA-ARS Forage Research Center in Madison (USDFRC), the University of Wisconsin research herd (UW), Virginia Tech (VT) and the USDA Animal Genomics and Improvement Laboratory (AGIL) in Beltsville. Description of the methodology of some experiments, and of the content of the diets has been summarized previously; e.g., by Spurlock et al. (2012) and Yao et al. (2013) for ISU; by Ferraretto et al. (2011 and 2012) and He et al. (2012) for part of the data from UW, and by Potts et al. (2015) for MSU. The diets included corn silage, legume silage, wheat straw, soybean hulls, cottonseed, corn, and limestone. Average DM of the diets was 50/100 g. Dry matter intake and MY were recorded daily in all experiments, and data from a particular lactation was included just if at least 28 daily records on both traits were available. Body weight was recorded daily (FL, MSU, UW, and VT), weekly (ISU, MSU, USDFRC) or every two weeks (UW), depending on the experiment. Milk components (FP, PP, and LP) were recorded either daily (FL and VT), weekly (ISU, MSU, USDFRC, UW), or every two weeks (USDFRC). The six feed intake-related traits were derived in the same way as described above for the Dutch data. Averages from 1,921 cows were kept (from 478 sires). A description of the data is provided in Table 3.1. 


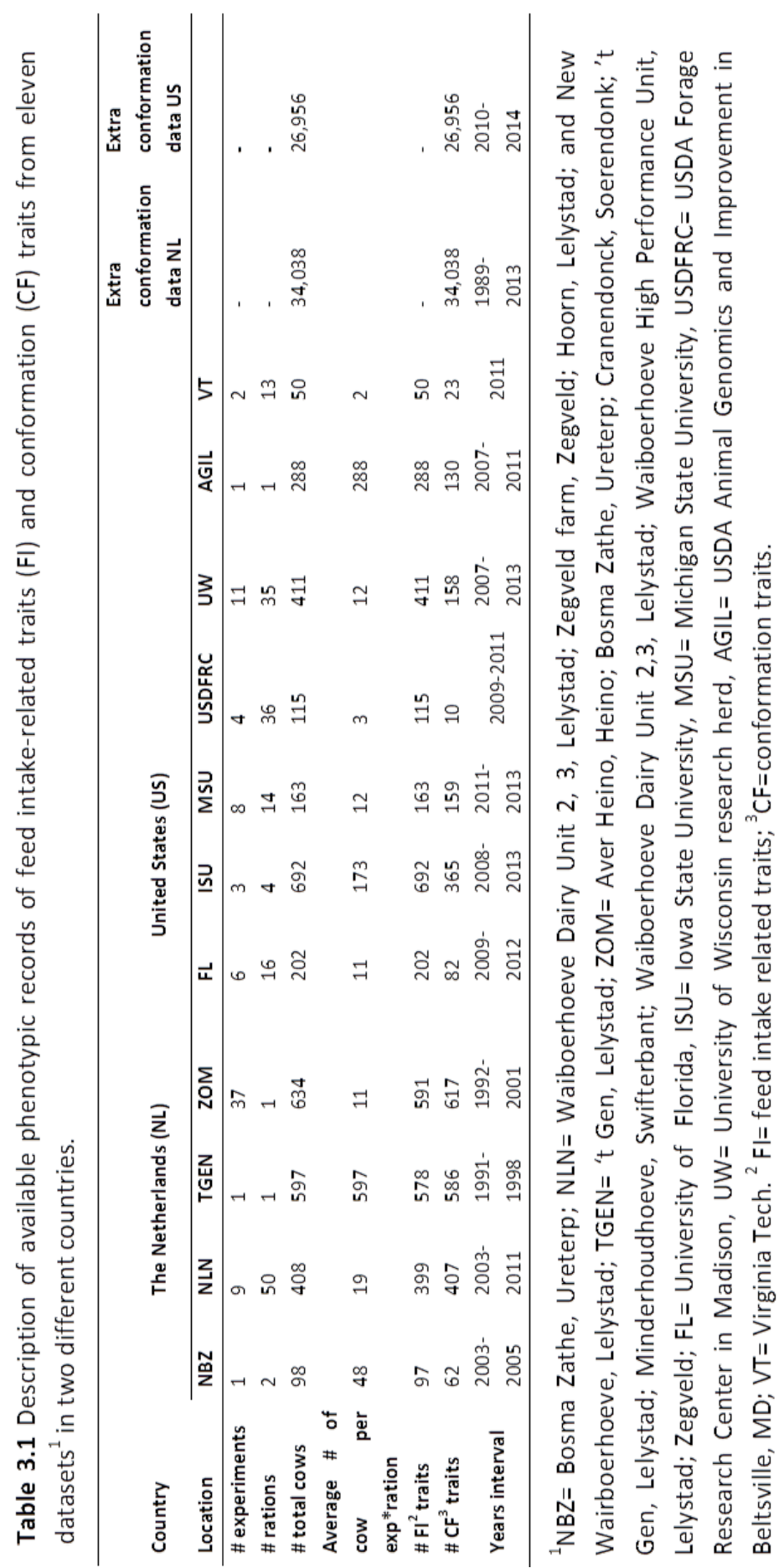




\subsubsection{Data Collection and Editing: Conformation Traits}

Data on seven conformation traits were available; stature (ST), CW, body depth (BD), angularity (ANG), rump angle (RA), rump width (RW), and BCS. Linear conformation traits were defined according to the World Holstein Friesian Federation (Holstein-USA, 2014; WHFF, 2014) and scored from i.e., 1 to 9 in NL, and from 1 to 50 in US. The different scale in both countries implies that the means cannot be compared between the two countries. However, the CV of the traits were similar, and the trait definition and the description to score them were visually equivalent for the extreme and intermediate values. For example, CW in NL was scored from narrow (1-3) to intermediate (4-6) to wide (7-9), whereas CW in US was scored from extremely narrow and frail (1-5), to intermediate (25) to extremely strong and wide (45-50) (Holstein-USA, 2014; WHFF, 2014). Similar, in both countries, BD is scored from shallow to deep, ANG is scored from lack of angularity to very angular, RA is scored from high pins to extreme slope, RW is scored from narrow to wide, and BCS is scored from poor to grossly fat. In the US, $\mathrm{CW}$ is called dairy strength, and ANG is called dairy form. Stature is measured in centimeters minus 100 in NL and classified from 1 to 50 in US going from short to tall.

\subsubsection{The Netherlands}

Most Dutch cows with feed intake-related information also had conformation recorded (1,603 of 1,665 ; Table 3.1$)$. Conformation traits were measured once in the lifetime of the cow, during the first lactation. In most cases, this is close to the time where nutritional experiment was performed. Conformation traits were recorded between 1989 and 2013.

Additional conformation data of progeny from the 372 sires were extracted from the Dutch national database from CRV (Dutch/Flemish cattle improvement cooperative, Arnhem, Netherlands.). This additional information was used for the bivariate analyses between feed intake-related and conformation traits within the Netherlands. The criterion to get extra conformation data from Dutch sires was to choose cows from herd-date classification groups with at least 5 cows coming from 5 different sires out of the 372 sires of our data. The final dataset included 34,038 extra Dutch cows with conformation data, plus the 1,603 cows with DMI recorded, resulting in a total of 35,641 cows with conformation data. 


\subsubsection{United States}

In total, 2,277 recordings of the seven conformation traits were available on 927 of the 1,921 cows with feed intake information. Only one conformation record per cow was kept, being the record taken during the nutritional experiments, or the nearest record to the time when feed intake-related traits were recorded. A summary of the distribution of records at each location is shown in Table 3.1.

Additional conformation data of progeny from the 478 sires were extracted from the USDA pedigree database. Accepting data with a classification date in 2010 or later resulted in 354,484 records. A second criterion was to select only contemporary groups (herd-year classes) with 200 or more records. This resulted in a total of 68 contemporary groups with records from the 478 sires. Selecting all records from those 68 groups resulted in a total of 32,186 additional conformation records. Even though some US cows had multiple records on conformation traits, only one record per cow was kept for this study. This left a total of 27,883 cows with conformation data, including 927 that also had feed intake information.

\subsubsection{Data Collection and Editing: Pedigrees}

\subsubsection{The Netherlands}

This pedigree was created from 35,641 individuals, of which 35,579 had conformation data and 1,665 had feed intake information. The complete pedigree contained 304,095 individuals, but was further cut at 4 generations, making sure that all sires and dams were identified $(n=152,314)$. After that, the pedigree was pruned by removing non-informative individuals; i.e., animals without any ancestral ties to phenotypes on other individuals, leaving a total of 144,489 animals in the pedigree.

\subsubsection{United States}

This pedigree was created from 28,877 individuals, of which 27,883 had conformation data and 1,921 had feed intake information. The full pedigree contained 120,485 individuals but was further cut at 4 generations ( $n=97,140$ ). After pruning, 94,405 animals remained.

\subsubsection{Statistical Analyses}

Univariate analyses were performed to estimate the variance components and the heritabilities for all 13 traits per country; i.e., six feed intake-related traits 
(DMI, RFI, MilkE, MY, BW and MBW) and seven conformation traits (ST, CW, BD, ANG, RA, RW and BCS). All the analyses were performed using ASReml 4.0 (Gilmour et al., 2009).

The model used for feed intake-related traits was as follows:

$$
\mathbf{y}=\mu+\mathbf{L E R}+\mathbf{P C}\left(\sum_{\mathbf{0}}^{2} \boldsymbol{\beta} \text { ACC }\right)+\text { LYS }+ \text { DIM }+\mathbf{a}+\mathbf{e}
$$

Here, $y$ is the phenotype for DMI, RFI, MilkE, MY, BW or MBW; LER is the fixed effect of location*experiment*ration; $A C C$ is the fixed regression coefficient for age of cow at calving in months nested in parity class (PC, two classes: primiparous (60\% in NL and 53\% in US) and multiparous); $\beta$ is the term of the 2 nd order Legendre polynomial for ACC; LYS is the fixed effect date of location*year*season of measurement; DIM is the fixed effect of the days in milk when the $28 \mathrm{~d}$ recording period started; $a$ is the additive genetic random effect of animal, and $\mathrm{e}$ is the residual term of $\mathrm{y}$. The classes for the fixed effects were: 112 classes for LER in NL and 132 in US, with on average 21 and 17 animals per class, respectively and 83 classes in NL and 115 classes in US had $>1$ cow. Age at calving ranged between 17 and 36 months in NL, with an average of 26, and between 21 and 127 in US, with an average of 36; LYS had 122 classes in NL and 99 in US, and 118 classes consisted of $>1$ cow in NL and all US classes had $>1$ cow. Days in milk when the recording period started ranged between 61 and 180 in NL, with an average of 31 cows recorded per day; and DIM ranged between 64 and 186 days in US, with an average of 16 cows recorded per day. In the Netherlands, on 53 days > 1 cow was recorded, and in US on 106 days > 1 cow was recorded. ASReml accounted for all classes with just 1 cow. Location was specified to interact with experiment and ration, as well as with year and season, to take into account that some experiments lasted for several years (especially in NL).

The model used for conformation traits was:

$$
\mathbf{y}=\mu+\mathbf{H D S}+\mathbf{A C C}+\mathbf{M L}+\mathbf{a}+\mathbf{e}
$$

Where $y$ is phenotype for ST, CW, BD, ANG, RA, RW, and BCS; HDS is the fixed effect of herd*classification date*classification standard for NL (6,585 classes) (where classification standard is black \& white, red \& white or dual purpose (CRV, 2014)), and of herd*classification date for US (3,402 classes); ACC is the fixed effect of age of cow at classification in months (35 classes in NL and 105 in US); ML is the fixed effect of lactation stage at classification in months (26 classes in NL and 83 in 
US), a is the random additive genetic effect of animal; and e is the residual term of y.

Four different sets of bivariate analyses were performed to obtain genetic correlation estimates; two sets of bivariate analyses between feed intake-related traits and conformation traits within a country (42 analyses per country, product of 6 feed intake-related traits times 7 conformation traits), and two sets of bivariate analyses within feed intake-related traits (15 per country, product of all possible combinations within feed intake-related traits). The estimated parameters from the univariate analyses were used as starting values for the bivariate analyses. Due to the lack of genetic links (4 sires) between the two populations, it was not possible to estimate genetic correlations between countries. Therefore, the genetic parameters that were estimated in this study were within each country between feed-intake related traits and conformation traits.

In order to know which combination of conformation traits is the best predictor of feed intake, selection index theory (Falconer and Mackay., 1996) was applied to calculate accuracies of breeding values. For this purpose, the genetic correlations between the conformation traits were estimated as well, using the model described above. Accuracies were calculated for predicting DMI, RFI and MBW for two cases: (1) for cows, when only single phenotypic records are available, and (2) for bulls. The bull case assumes that highly accurate breeding values from bulls are available for all predictors. The following formula was used to calculate the accuracy of the selection index $(\mathrm{rHI})$ :

$$
r_{H I}=\frac{\sigma_{H I}}{\sigma_{I}^{2} \sigma_{H}^{2}}=\sqrt{\frac{b^{\prime} G v}{v^{\prime} C v}}
$$

Where $\sigma_{-} \mathrm{HI}$ is the covariance between the breeding goal and the selection index, $\left.\sigma_{-}\right|^{\wedge} 2$ is the selection index variance, and $\sigma_{-} \mathrm{H}^{\wedge} 2$ is the breeding goal variance. Here $b$ is the index coefficient that is calculated as:

$$
b=P^{\wedge}(-1) \mathbf{G v}
$$

where $\mathbf{P}$ is the genetic variance-covariance matrix between the predictor traits (for the case of bulls) and the phenotypic variance-covariance matrix between the predictor traits (for the case of cows), $\mathbf{G}$ is the vector of genetic covariances between the predictor traits in the selection index and the breeding goal trait, and $v$ is the economic value. Since we are only interested in predicting one trait at the time (DMI, RFI or MBW), the value of $v$ is set arbitrarily to 1 , which means that all the weight is on one trait, as is the only trait in the breeding goal. 
Finally $C$ is the genetic variance-covariance matrix between the breeding goal trait(s). The $P$ variance-covariance matrix for the scenario with $B W, M i l k E, S T, C W$ and $\mathrm{BD}$ was bended to be positive definite.

\subsection{Results}

\subsubsection{Descriptive Statistics}

Descriptive statistics of feed intake-related and conformation traits for NL and US are shown in Table 3.2. The averages for feed intake-related traits were higher in US compared with NL cows; DMI was $20.7 \mathrm{~kg} / \mathrm{d}$ in NL and $24.1 \mathrm{~kg} / \mathrm{d}$ in US, whereas MY was $33.5 \mathrm{~kg} / \mathrm{d}$ in NL and $42.7 \mathrm{~kg} / \mathrm{d}$ in US, and BW was $575 \mathrm{~kg}$ in NL and $605 \mathrm{~kg}$ in US. The descriptive statistics for conformation traits for NL and US were not comparable with each other, because they are expressed using a different scale ( $\mathrm{NL}=1$ to 9 , except for ST recorded in centimeters and US = 1 to 50 for all traits). The averages for the conformation traits in NL were between 4.8 for ANG and 5.2 for $\mathrm{BD}$, and 44 centimeters for ST; whereas the averages for US were between 24.6 for RA and 26.9 for BD, and 33 units for ST.

\subsubsection{Genetic Parameters}

\subsubsection{Estimated Heritabilities.}

Estimated genetic variances and heritabilities for all traits for both countries are shown in Table 3.3. Estimated heritabilities for feed intake-related traits were moderate to high in both countries, varying from 0.18 for MilkE in US to 0.53 for $\mathrm{BW}$ and $\mathrm{MBW}$ in NL, with all SE ranging between 0.05 and 0.07 . Estimated heritabilities for DMI were 0.32 in NL and 0.29 in US. These heritabilities were higher than the estimated heritabilities for RFI; i.e., 0.25 and 0.22 , respectively. Estimated heritabilities for MY and MilkE were higher in NL than in US; i.e., 0.37 and 0.20 for MY, respectively, and 0.26 and 0.18 for MilkE. Finally, heritabilities for $\mathrm{BW}$ and MBW were both 0.53 in NL and 0.43 in US.

Since the scale of the conformation traits is different in both countries, the genetic and residual variances cannot be compared. However, in general, the heritabilities were higher in NL than in US. The heritabilities were within the range of 0.28 for CW and 0.60 for ST in NL and between 0.17 for BCS and 0.40 for ST in US; in both countries the SE were 0.02 for all traits. 


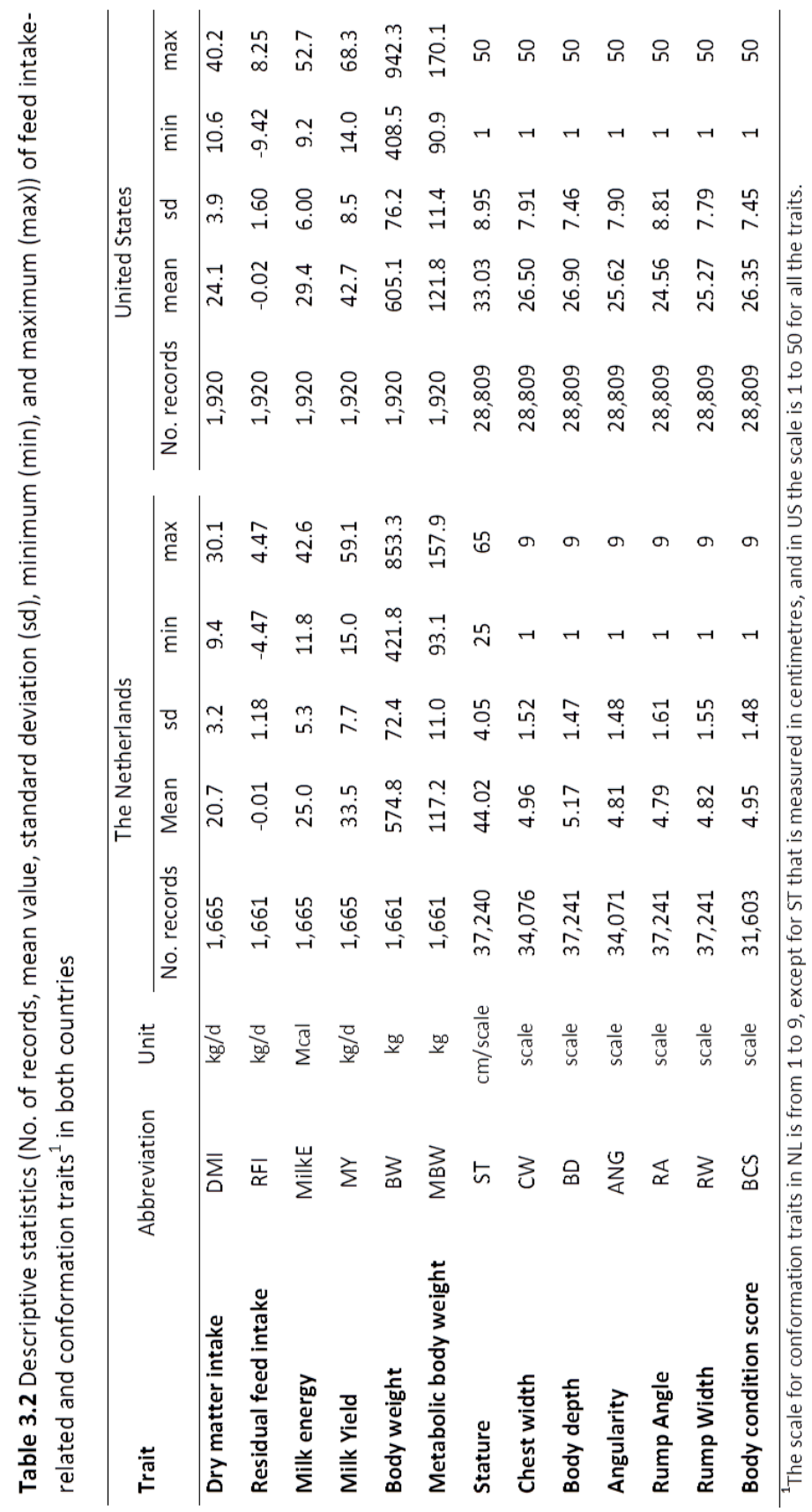


Table 3.3 Estimated genetic $\left(\sigma^{2} a\right)$ and error $\left(\sigma^{2} e\right)$ variances, and heritabilities $\left(h^{2}\right)$ with the corresponding standard error (se) from univariate analyses per trait and per country.

\begin{tabular}{lllllllll}
\hline \multirow{2}{*}{ Trait $^{1}$} & \multicolumn{5}{c}{ The Netherlands } & \multicolumn{5}{c}{ United States } \\
\cline { 2 - 9 } & $\boldsymbol{\sigma}^{2} \mathbf{a}$ & $\boldsymbol{\sigma}^{2} \mathbf{e}$ & $\mathbf{h}^{\mathbf{2}}$ & $\mathbf{s e}$ & $\boldsymbol{\sigma}^{2} \mathbf{a}$ & $\boldsymbol{\sigma}^{2} \mathbf{e}$ & $\mathbf{h}^{\mathbf{2}}$ & $\mathbf{s e}$ \\
\hline DMI & 0.99 & 2.12 & 0.32 & 0.07 & 1.85 & 4.43 & 0.29 & 0.06 \\
RFI & 0.38 & 1.12 & 0.25 & 0.07 & 0.61 & 2.11 & 0.22 & 0.06 \\
MilkE & 2.37 & 6.62 & 0.26 & 0.07 & 3.04 & 13.73 & 0.18 & 0.05 \\
MY & 8.21 & 14.03 & 0.37 & 0.07 & 7.02 & 27.82 & 0.20 & 0.05 \\
BW & 1244.49 & 1115.52 & 0.53 & 0.07 & 1158.08 & 1560.41 & 0.43 & 0.06 \\
MBW & 28.80 & 25.82 & 0.53 & 0.07 & 26.70 & 34.91 & 0.43 & 0.06 \\
ST & 8.16 & 5.31 & 0.60 & 0.02 & 26.61 & 40.11 & 0.40 & 0.02 \\
CW & 0.58 & 1.52 & 0.28 & 0.02 & 11.90 & 38.01 & 0.24 & 0.02 \\
BD & 0.66 & 1.38 & 0.32 & 0.02 & 12.13 & 31.08 & 0.28 & 0.02 \\
ANG & 0.53 & 1.60 & 0.25 & 0.02 & 11.06 & 40.84 & 0.21 & 0.02 \\
RA & 1.08 & 1.48 & 0.42 & 0.02 & 14.99 & 60.87 & 0.20 & 0.02 \\
RW & 0.76 & 1.48 & 0.34 & 0.02 & 9.36 & 42.50 & 0.18 & 0.02 \\
BCS & 0.70 & 1.35 & 0.34 & 0.03 & 8.68 & 41.27 & 0.17 & 0.02 \\
\hline
\end{tabular}

${ }^{1} \mathrm{DMI}=$ dry matter intake; $\mathrm{RFI}=$ residual feed intake; MilkE= milk energy; $\mathrm{MY}=$ milk yield; $\mathrm{BW}=$ body weight; $\mathrm{MBW}=$ metabolic body weight; $\mathrm{ST}=$ stature, $\mathrm{CW}=$ chest width, $\mathrm{BD}=$ body depth, $\mathrm{ANG}=$ angularity, $\mathrm{RA}=$ rump angle, $\mathrm{RW}=$ rump width, $\mathrm{BCS}=$ body condition score.

\subsubsection{Correlations within Feed Intake-related traits}

Genetic and phenotypic correlations within feed intake-related traits for both countries are presented in Table 3.4. Dry matter intake was genetically and phenotypically high correlated with RFI in both countries $(0.70$ and 0.72 , respectively, for NL, and 0.89 and 0.69 for US). This was expected, given that the $\mathrm{RFI}$ is the residual of DMI after adjusting for the energy sinks (MilkE and MBW). The genetic correlation between DMI and MY was, in both countries, lower than the correlation between DMI and MilkE. The genetic and phenotypic correlation of BW and MBW with DMI was the same in US (0.46), and almost the same in NL (0.55 and 0.56).

Residual feed intake was expected to have a zero phenotypic correlation with energy sinks, as it is feed intake adjusted for those energy sinks. This is also observed, and RFI also showed, in both countries, phenotypic correlations close to zero with MilkE, MY, BW, and MBW. Contrary, the genetic correlations between RFI and MilkE, MY, BW and MBW were different from zero, especially in US, ranging between 0.26 and 0.40 . 


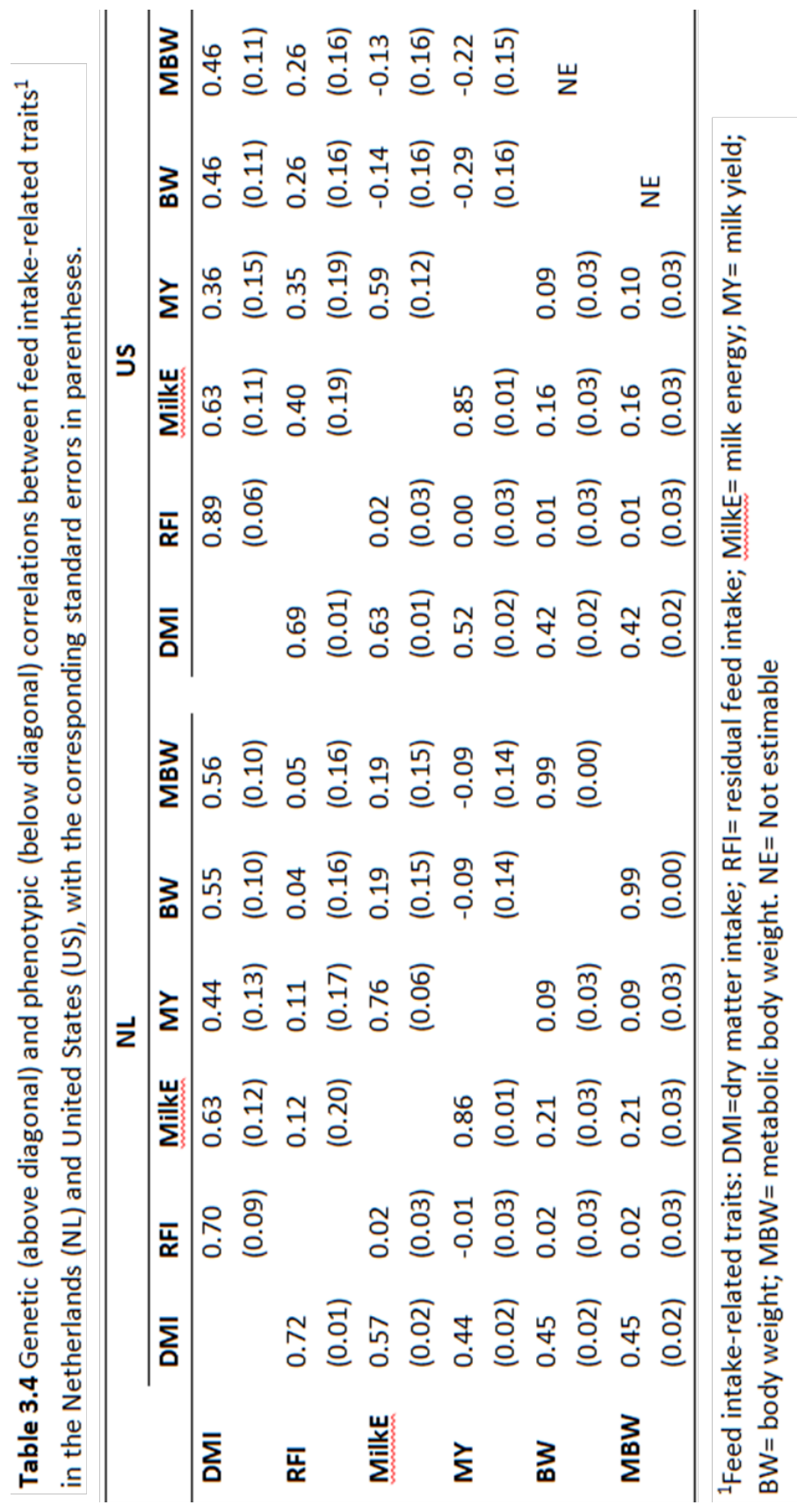




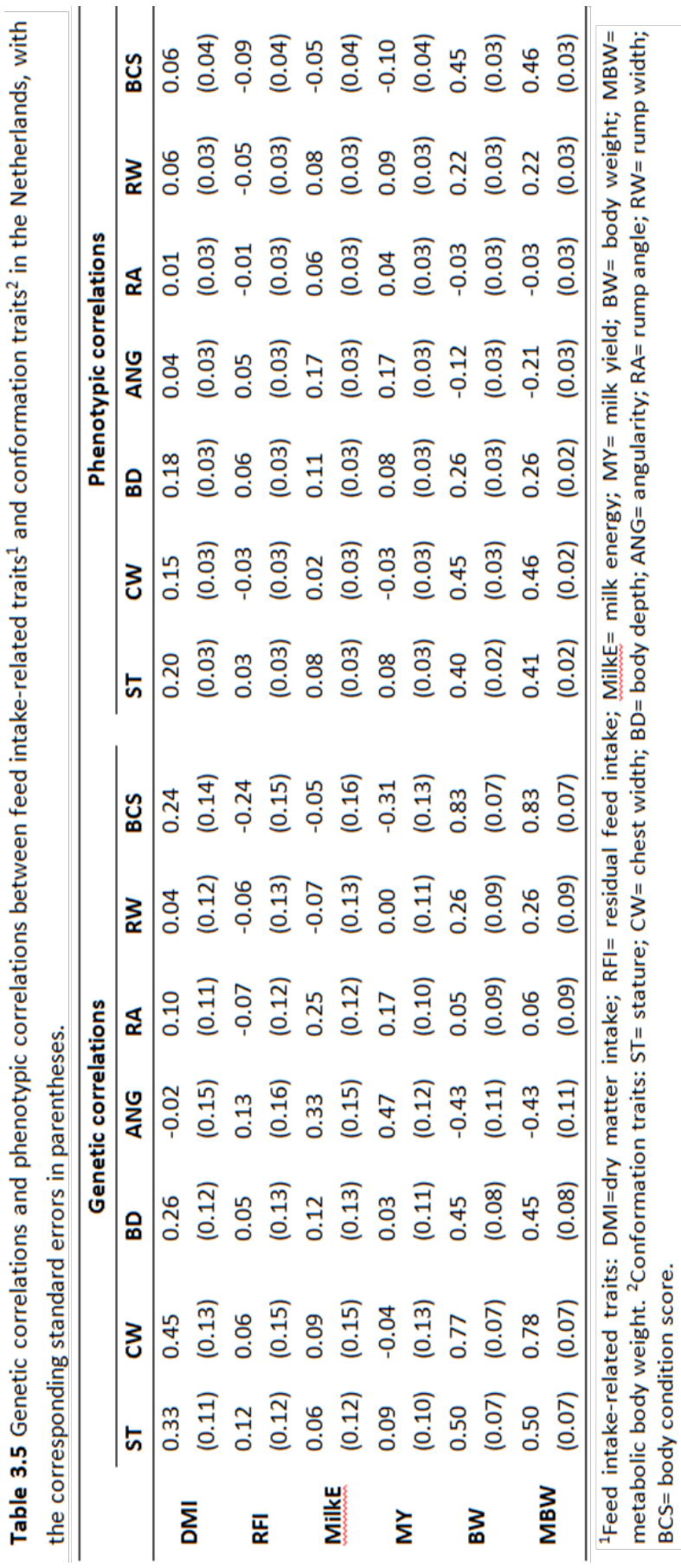


Based on the heritabilities and genetic correlations (Table 3.4), BW and MBW seem to have the same genetic background, which was expected because the transformation becomes close to linear within the scale of BW, even though MBW is a non-linear transformation of BW.

\subsubsection{Correlations between Feed Intake-related traits and Conformation} traits in NL

Genetic and phenotypic correlations between feed intake-related traits and conformation traits in NL, with their respective SE, are shown in Table 5 . The highest positive genetic correlation between DMI and the conformation traits was estimated between DMI and CW (0.45), and the phenotypic correlation between those two traits was 0.15 . For all other conformation traits, the estimated genetic correlations with DMI ranged between -0.02 (ANG) and 0.33 (ST), and the phenotypic correlations ranged between 0.01 (RA) and 0.20 (ST).

The highest positive correlation between RFI and conformation traits was estimated between RFI and ANG ( 0.13 for genetic and 0.05 for phenotypic), and the strongest negative correlation was estimated with BCS (-0.24 for genetic and -0.09 for phenotypic).

For $\mathrm{MY}$ and MilkE, the highest positive correlation was estimated with ANG (genetic and phenotypic correlation was 0.47 and 0.17 , respectively, for MY; and 0.33 and 0.17 for MilkE). Conversely, slightly negative genetic correlations were estimated between MY and CW (-0.04) and between MilkE and RW (-0.07). Finally, BW and MBW were highly positively correlated with CW (0.78 for genetic and 0.45 for phenotypic) and BCS (0.83 and 0.45 for genetic and phenotypic respectively).

\subsubsection{Correlations between Feed Intake-related traits and Conformation} traits in US

Estimated genetic and phenotypic correlations between feed intakerelated traits and conformation traits in US with their respective SE are presented in Table 3.6. Estimated genetic correlations of DMI with the conformation traits ranged from 0.13 for $\mathrm{RW}$ to 0.61 for $\mathrm{CW}$. Similar to the Dutch data, the highest positive genetic correlation for DMI with conformation in US was estimated with CW (0.61, compared with 0.45 in NL (Table 3.5)). The phenotypic correlation between $\mathrm{DMI}$ and all the conformation traits ranged between 0.03 (RA) and 0.28 (BD). 


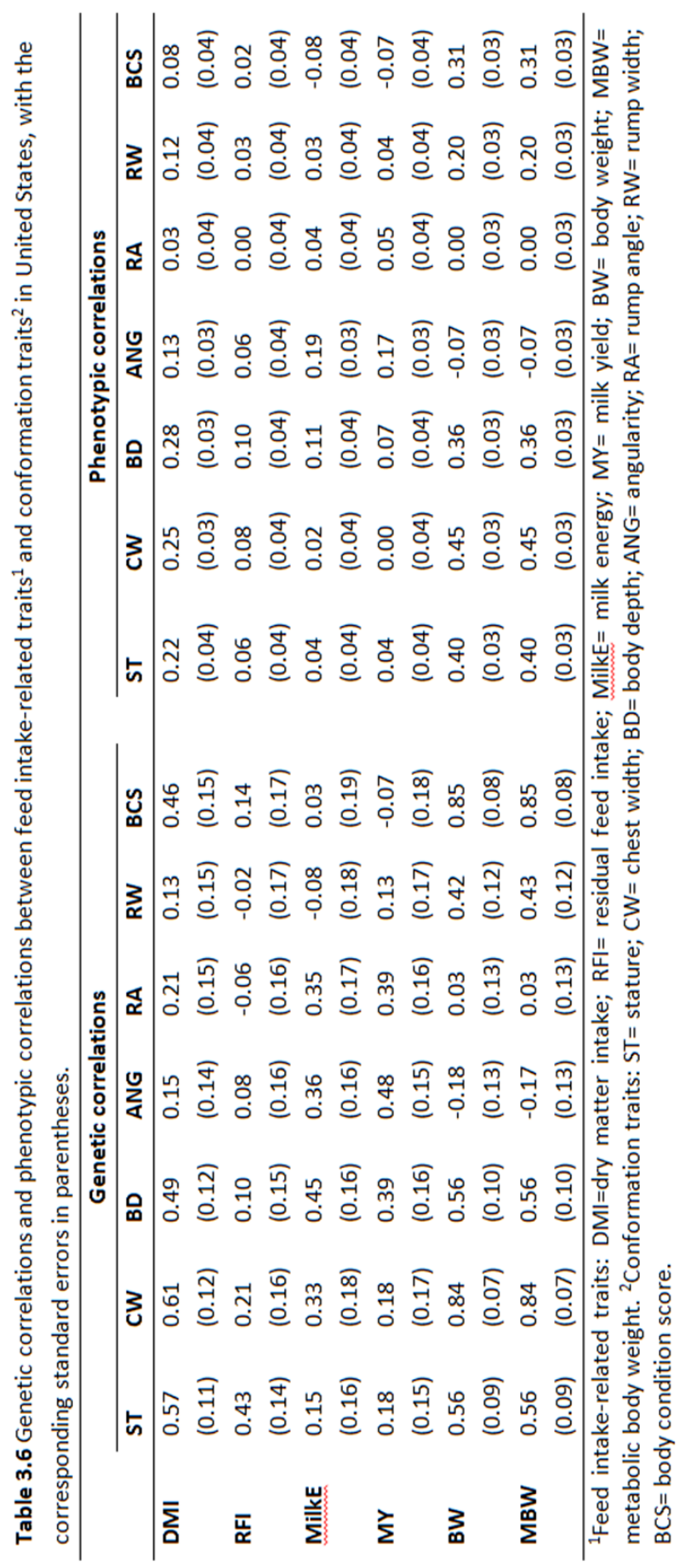


Estimated genetic correlations between RFI and the conformation traits ranged from -0.02 with $\mathrm{RW}$ and 0.43 for ST. The estimated genetic correlation between RFI and CW was 0.21 in US (and 0.06 in NL (Table 5)). This is lower than the genetic correlation between $\mathrm{DMI}$ and $\mathrm{CW}$ in both countries. For MilkE the highest estimated genetic correlation was with BD (0.45), whereas for MY the highest estimated genetic correlation was with ANG (0.48). Finally, BW (and MBW) had the highest estimated genetic correlations with CW (0.84) and BCS (0.85); this was similar to the genetic correlations estimated in NL between those traits (Table $5)$. Body weight had a negative genetic correlation (-0.18) estimated with ANG in US, albeit closer to zero than in NL (-0.43).

\subsubsection{Selection Index}

Based on the estimated parameters between feed intake-related and conformation traits, several selection indices were used to predict DMI, RFI and MBW (Table 3.7). Using a combination of type traits (ST, CW and BD), DMI was predicted for bulls with accuracies up to 0.43 in NL and 0.64 in US. When MilkE was added to the selection index, the accuracies increased to 0.74 in NL and 0.95 in US. Finally, when BW was also added to the index, the accuracies increased up to 0.79 in NL and 0.97 in US. These accuracies can be obtained when assuming that the genetic parameters are estimated without error.

Predicting RFI was not as accurate in NL as DMI could be predicted. The maximum accuracy was 0.17 for the combination of BW, MilkE, ST, CW and BD. In US a much higher accuracy of 0.97 was obtained. The difference in accuracies between NL and US is likely due to the low genetic correlations between RFI and all the predictor traits in NL compared to US. For example, the correlation between RFI and MilkE was 0.12 in NL and 0.40 in US, and the correlation between RFI and BW was 0.04 in NL and 0.26 in US. Similar comparisons can be made with the correlations involving RFI with ST, CW, and BD.

\subsection{Discussion}

The objective of this study was to estimate genetic correlations among six feed intake-related traits and seven conformation traits within cow populations from the NL and US, in order to determine if the correlations were different between the two countries and to analyse if these conformation traits have large enough heritabilities and genetic correlations to use them as predictors for feed intake-related traits. 
Table 3.7 Accuracies of prediction of dry matter intake (DMI), residual feed intake (RFI), and metabolic body weight (MBW) using different traits ${ }^{1}$ and their combination of in two different scenarios, cows, when just one phenotypic record is available, and for bulls, assuming that highly accurate breeding values are available for all predictors by country (the Netherlands (NL) and United States (US)).

\begin{tabular}{llccc}
\hline Predictor traits for DMI & \multicolumn{2}{c}{ NL } & \multicolumn{2}{c}{ US } \\
\hline & Bulls & Cows & Bulls & Cows \\
MilkE & 0.64 & 0.33 & 0.63 & 0.26 \\
BW & 0.58 & 0.42 & 0.47 & 0.30 \\
ST, CW, BD & 0.43 & 0.32 & 0.64 & 0.38 \\
MilkE + ST, CW, BD & 0.74 & 0.36 & 0.95 & 0.46 \\
BW + MilkE + ST, CW, BD & 0.79 & 0.50 & 0.97 & 0.48 \\
\hline Predictor traits for RFI & \multicolumn{3}{c}{ NL } & US \\
\hline & Bulls & Cows & Bulls & Cows \\
MilkE & 0.12 & 0.06 & 0.42 & 0.18 \\
BW & 0.04 & 0.03 & 0.26 & 0.17 \\
ST, CW, BD & 0.12 & 0.09 & 0.55 & 0.30 \\
MilkE + ST, CW, BD & 0.16 & 0.11 & 0.85 & 0.35 \\
BW + MilkE + ST, CW, BD & 0.17 & 0.11 & 0.96 & 0.36 \\
\hline Predictor traits for MBW & \multicolumn{3}{c}{ NL } & US \\
\hline & Bulls & Cows & Bulls & Cows \\
ST, CW, BD & 0.85 & 0.50 & 0.95 & 0.46 \\
BCS & 0.83 & 0.48 & 0.86 & 0.36 \\
ST, CW, BCS & 0.98 & 0.60 & 0.92 & 0.46 \\
ST, CW, BD, BCS & 0.98 & 0.60 & 0.96 & 0.50 \\
\hline I
\end{tabular}

${ }^{1}$ MilkE= Milk energy output; $\mathrm{BW}=$ body weight; $\mathrm{ST}=$ stature; $\mathrm{CW}=$ chest width; $\mathrm{BD}=$ body depth.

Many previous studies have estimated the genetic correlation between conformation traits and milk production traits, BW, fertility traits or longevity (Harris et al., 1992; Short and Lawlor, 1992; Brotherstone, 1994; Visscher and Goddard, 1995; Van Dorp et al., 1998; Berry et al., 2003a; Brotherstone et al., 2007; de la Fuente et al., 2011). Relatively few studies are available that link conformation traits and feed intake (Veerkamp et al., 1994; Veerkamp and Brotherstone, 1997), and comparisons between countries are non-existent.

\subsubsection{Mean differences between US and NL}

\subsubsection{Feed Intake-related traits}

The means of DMI, MY and BW were higher in US than in NL; in other words, cows in the US are bigger, eat more and therefore produce more milk. One 
of the experiments in NL included low energy rations, and even though this experiment involved only 50 animals, this could have contributed to the lower mean MY and DMI in NL in comparison with US. Perhaps one explanation to the higher MY, DMI and BW in US compared to NL is that the Dutch data was generally older compared to US data. During the last 25 years, total milk production per cow per year has increased $\sim 50 \%$ in the US (USDA, 2015), and therefore, it is likely that feed intake and body weight have also increased. In comparison, the total milk production per year per Dutch cow has increased by $35 \%$ in the past 25 years (CRV, 2015). Therefore, any country comparisons to be surmised from this study are partly confounded with genetic differences due to time trends in selection responses. Furthermore, the differences observed in DMI and MY between countries can be influenced by overall mean diet composition differences. Despite the differences in the phenotypic means between NL and US, the CV of the traits were similar in both countries; i.e., 0.15 and 0.16 for $\mathrm{DMI}$ in $\mathrm{NL}$ and US, respectively; 0.23 and 0.20 , respectively for $\mathrm{MY}$ and 0.13 for $\mathrm{BW}$ in both countries.

The average RFI was similar in both countries (-0.01 in NL and -0.02 in US), suggesting that on average the cows eat as much as is predicted to be needed for its maintenance and milk production. This was expected given that by definition the estimated residuals (RFI) should be zero. However, RFI was calculated separately for each location using separate regressions on the energy sinks (Tempelman et al., 2015). This was done to account for different diet composition across locations and experiments. The consequence of this calculation method is that RFI is expected to average zero within each location. Therefore, the average of location per country should also be zero.

The means of all conformation traits in $\mathrm{NL}$, except ST, are close to 5 , as suggested for linear type traits by Veerkamp et al. (Veerkamp et al., 2002), with a standard deviation of 1.6. These means for conformation traits in NL were within the range (4.58 to 6.06) previously reported by Brotherstone (1994), Kadarmideen and Wegmann (2003), Berry et al. (2004) and Zink et al. (2011). Moreover, the means of conformation traits in US were similar to those reported by Short and Lawlor (1992) and Tsuruta et al. (2005) that varied from 22.0 to 28.5 for all the traits.

\subsubsection{Variances and Heritabilities in NL and US}

\subsubsection{Feed Intake-related traits}

The genetic variances for DMI, RFI and MilkE were slightly larger in US than in NL, whereas the residual variances for DMI and RFI were two times larger in US 
than in NL, and around four times larger for MilkE and MY. This resulted in lower heritabilities in US than in NL for most feed intake-related traits. The exceptions were BW and MBW in US that had residual variances only $30 \%$ larger than the genetic variances.

The estimated genetic sd of DMI is nearly twice as large in the US (1.85 $\mathrm{kg} / \mathrm{d}$ ) than in $\mathrm{NL}(1 \mathrm{~kg} / \mathrm{d})$. The coefficient of genetic variation (ratio between genetic standard deviation and mean) was similar in both countries for DMI (0.05 in NL and 0.06 in US) and MY (0.08 and 0.06, respectively). So there is substantial genetic variation in DMI. After adjusting for the energy sinks (to derive RFI), 38\% of the genetic variation was left in NL, and $33 \%$ in the US. Thus, although the absolute genetic variance is larger in the US, the ratio between the genetic variance of DMI and of RFI is similar in both countries ( 3:1). Estimated heritability of DMI was 0.32 in NL and 0.29 in US, well within the range (0.17 to 0.56$)$ published in literature as reviewed by Berry and Crowley (2013). Estimated heritabilities for RFI were 0.25 in NL and 0.22 in US, Veerkamp et al. (1995) reported heritabilities for RFI between 0.01 and 0.69 including phenotypically and genetically calculated RFI.

The lower heritabilities for feed intake-related traits in US compared to NL can be due to some missing information in the fixed effects in the model or due to random noise in the measurement of the traits given that the US data cover only $1 / 5$ of the length of the Dutch data collection. The higher heritabilities in NL were seemingly caused by smaller estimated residual variances, because the experiments in NL lasted for 20 years and the methodology in the measurement of the traits was already standardized which reduced the residual variance.

The estimated genetic variances and heritabilities of MY were in the range reported in the literature (Veerkamp, 1998; Berry et al., 2003b; Kadarmideen and Wegmann, 2003; Muller et al., 2006; Nixon et al., 2009; Liinamo et al., 2012). The estimated heritabilities for BW were also in the range of literature from 0.43 to 0.65 (Veerkamp and Brotherstone, 1997; Koenen and Veerkamp, 1998; Berry et al., 2003b; Muller et al., 2006; Dechow et al., 2010). However, comparing heritability estimates across these studies is tricky. For example, in this study, the average of observations from $28 \mathrm{~d}$ was used, whereas other studies might have averages across fewer records or even more. Also, previous studies (Koenen and Veerkamp, 1998; Manzanilla-Pech et al., 2014; Tempelman et al., 2015) have shown that genetic parameters of feed intake-related traits vary depending on the stage of lactation. Therefore, it is also important to take the lactation stage of recording into account when comparing across studies. 


\subsubsection{Conformation traits}

Heritabilities and genetic correlations for conformation traits within and between countries (CRV, 2014; Holstein-USA, 2014; Interbull, 2014) are shown in Table 3.8. Most of the estimated heritabilities for conformation traits in NL were slightly higher than the reported national heritabilities from CRV (CRV, 2014), except for RW which was lower in this study, and for ANG where the estimated heritability was twice as large in this study. This can be due to changes in the definition of ANG which changed in 2008 in the Netherlands (CRV, 2014), noting that more than $66 \%$ of the records on ANG in this study are from before 2008 . The heritabilities estimated in this study for the Dutch conformation traits were also slightly higher than the heritabilities estimated by Veerkamp and Brotherstone (1997) that ranged from 0.23 (RW) to 0.50 (ST).

The estimated heritabilities for conformation traits in US were lower in this study than those reported by Holstein USA (Holstein-USA, 2014). Furthermore, Short and Lawlor (1992) estimated lower heritabilities for ST and CW compared with this study, a similar heritability for BD, and higher heritabilities for RA and RW. However their study was conducted 15 to 20 years prior to our study, and the genetic structure of the population could change such that it may have an effect on the estimation of the heritabilities.

\subsubsection{Correlations between Feed Intake-related traits}

Genetic correlation between DMI and RFI was high and positive in both countries (0.70 in NL and 0.89 in US). Kennedy et al. (1993) demonstrated how the genetic parameters for RFI can be predicted from the genetic parameters for the underlying traits. These authors predicted a correlation of 0.75 between RFI and DMI, based on heritabilities of 0.3 for DMI and production, a genetic and residual correlation of both 0.5 between DMI and production. This predicted correlation of 0.75 is close to the estimated correlation in our study; e.g., 0.70 in NL and 0.89 in the US. Similarly, these authors suggested that when RFI was phenotypically adjusted for the underlying traits, genetic correlations might still exist. This was also observed in the current study, and also by Veerkamp et al. (1995). The genetic correlations between RFI and MilkE, MY, MBW and BW (Table 3.4) were especially present in the US, albeit SE were still large. When estimated more precisely, these estimated genetic correlations should be taken into account when breeding objectives are defined, rather than assuming that RFI is independent of the underlying traits like milk production and BW (Kennedy et al., 1993; Veerkamp et al., 1995). 
Table 3.8 Heritabilities and genetic correlations for production and conformation traits within and between the Netherlands (NL) and United States (US; from Interbull, Holstein USA, and CRV)

\begin{tabular}{lccc}
\hline Trait & $\begin{array}{c}\mathbf{N L ~ h}^{\mathbf{2}} \\
\text { (CRV, 2014) }\end{array}$ & $\begin{array}{c}\text { US }^{2} \\
\text { (Holstein-USA, } \\
\text { 2014; Interbull, } \\
\text { 2014) }\end{array}$ & $\begin{array}{c}\text { NL-US genetic } \\
\text { correlations } \\
\text { (Interbull, } \\
\text { 2014) }\end{array}$ \\
\hline Milk & & 0.30 & 0.91 \\
Fat & 0.49 & 0.30 & 0.89 \\
Protein & 0.52 & 0.30 & 0.86 \\
Stature & 0.41 & 0.42 & 0.93 \\
Chest width & 0.52 & 0.31 & 0.82 \\
Body depth & 0.24 & 0.37 & 0.89 \\
Angularity & 0.31 & 0.29 & 0.69 \\
Rump Angle & 0.11 & 0.33 & 0.96 \\
Rump Width & 0.34 & 0.26 & 0.82 \\
Body condition score & 0.40 & 0.29 & 0.71 \\
\hline
\end{tabular}

\subsubsection{Predicting Feed Intake-related traits from Conformation traits}

\subsubsection{DMI and RFI}

The genetic correlations between DMI and ST, CW, and BD were moderate to high $(0.33,0.45$ and in NL, respectively and $0.57,0.61$ and 0.49 in US). The largest estimated genetic correlation was between DMI and CW in both countries. The correlations were larger than the correlations estimated by Veerkamp and Brotherstone (1997) in the UK-Langhill population for heifers and cows separately; i.e., $0.18,0.25$ and 0.20 , respectively for heifers, and $0.32,0.28$ and 0.34 for cows. Parke et al. (1999) reported negative genetic correlations between gross feed efficiency (fat corrected milk yield/total energy intake) and ST (-0.36) and RW (0.31 ), but these correlations cannot directly be compared with the genetic correlations with RFI estimated in our study.

RFI was also genetically negatively correlated with BCS $(-0.24)$ in NL. However in US, the genetic correlation between RFI and BCS was positive (0.14) but not different from zero due to the large SE (0.17). Therefore, it is unclear across the two countries what the effect of selection for RFI is on BCS.

The accuracies obtained in the selection indices were relatively high for the prediction of DMI; up to 0.74 in NL and 0.95 when accurate breeding values for conformation and yield are combined. For RFI the accuracy in the US was high, but 
low in NL. These high accuracies demonstrate the potential of using predictor traits to select the most efficient animals. However, the nature of the accuracy calculations is that they are probably overestimated, especially when SE of the estimated genetic parameters are large. Also taking into account that the energy sinks explain about $62 \%$ and $67 \%$ (100\% minus $38 \%$ and $33 \%$ respectively) of the variation in DMI in NL and US, it is unlikely that type traits will predict RFI so accurate. A possible explanation for the overestimated prediction accuracy might be the high SE (0.12 to 0.19) of the genetic correlations between the trait in the breeding goal and the predictor traits. Sales and Hill (1976) and Hill and Thompson (1978) have previously demonstrated that accuracies tend to be overestimated when genetic correlations have large SE. Therefore, it is too early to conclude that there is no need to record DMI or RFI anymore, even though the predictors gave an accuracy of 0.97. An important remaining question is how much of the genetic variation in DMI can be explained by easy to measure predictor traits.

\subsubsection{MY and MilkE}

Low negative genetic correlations between MY and BCS have been previously estimated by several authors (Veerkamp and Brotherstone, 1997; Veerkamp et al., 2001; Kadarmideen and Wegmann, 2003; Bastin and Gengler, 2013), ranging from -0.12 to -0.38 . On the other hand, the genetic correlations of MilkE and MY with ANG in NL ( 0.33 and 0.44 respectively), and between MilkE and BD (0.45) and between MY and ANG (0.48) in US were slightly higher than the ones reported by Zink et al. (2014) (0.19 between MY and BD and 0.32 between MY and ANG). The estimated correlations between MY and ANG in both countries should be interpreted carefully due to recent changes in the definition of ANG (CRV, 2014), and whether or not ANG is in fact the same trait in both countries.

\subsubsection{BW}

Body weight was highly genetically correlated with BCS in both countries ( 0.83 in NL and 0.85 in US). This correlation has been reported previously in the literature to range between 0.44 and 0.67 (Berry et al., 2003a; Muller et al., 2006; Vallimont et al., 2010). The correlations estimated in the current study were, therefore, higher than reported previously in literature. Chest width was also highly positively correlated with BW. Finally, BW was negatively correlated with ANG; this was expected due to the estimated negative genetic correlation between ANG and BCS ranging between -0.38 to -0.65 (Bastin and Gengler, 2013; Battagin et al., 2013). Veerkamp and Brotherstone, (1997) demonstrated how the correlations between conformation traits and BW changed depending on if BW was 
(genetically) adjusted to a common BCS or not. The correlation of BW with ANG and $\mathrm{CW}$ decreased considerably, and also the zero correlations between yield and BW became positive when BW was adjusted for BCS. Hence, this suggests that many components that contribute to variation in BW like gut fill, body fat, bones and muscle have differential nutritional requirements for maintenance. Therefore, linear conformation traits might be better as predictors of maintenance costs, since they allow for the separation of different body components, i.e. a fat small cow versus a thin tall cow that have the same weight.

\subsubsection{Implications}

Given that the heritability is an important factor for the calculation of the size of the reference population for genomic prediction (Daetwyler et al., 2008 and Daetwyler et al., 2010), the results from this study can be used to decide on the size of the reference population for DMI for separate countries. Based on a country-specific heritability for DMI of 0.32 in NL and 0.29 in US, and assuming the proportion of independent chromosome segments to be 0.75 , and assuming 1000 individuals in the effective size of the training population, the accuracy of genomic prediction of DMI would be 0.50 in NL and 0.48 in US, following Daetwyler et al. (2010). To reach an accuracy of 0.50 in the US as well, we would need 1104 animals with DMI recorded in the training set instead of 1000. This example shows the importance of accurate recording and of the heritability in the genome wide evaluation approach for novel traits.

Furthermore, the importance of the results of this study is beyond the use of conformation traits as predictor of feed intake-related traits, but also to understand how those traits are genetically correlated with each other. Estimated genetic correlations between feed intake-related traits and conformation traits can be used to estimate how the indirect selection would affect those traits (given that selection of one trait would affect all the traits correlated with it) and predict the correlated response. Also, the generated information can be used to be included in multiple traits selection index fitting several traits simultaneously.

\subsection{Conclusions}

Estimated heritabilities for feed intake-related traits and conformation traits were higher in NL than in US, and genetic correlations between feed intakerelated traits and conformation traits were higher in US than in NL. Despite these differences, the heritabilities and genetic correlations between feed intake-related 
traits and conformation traits showed the same pattern in both countries. Dry matter intake can be predicted with accuracies up to 0.43 in NL and 0.64 in US by a combination of conformation traits (ST, CW and BD), and up to 0.74 in NL and 0.95 in US when MilkE is added to the index. However, these accuracies should be taken with caution because they may be overestimated given the high SE of the estimated genetic correlations between the target and the predictor traits. Therefore, recording DMI continues to have a high priority.

\subsection{Acknowledgements}

The data collection was financed by the Dutch Dairy Board (Zoetermeer, the Netherlands), the Dutch Product Board Animal Feed (Zoetermeer, the Netherlands) and CRV (Arnhem, the Netherlands). Funding for this project was also provided by Agriculture and Food Research Initiative Competitive Grant \# 201168004-30340 from the USDA National Institute of Food and Agriculture. The first author thanks the National Council on Science and Technology of Mexico (CONACYT, Mexico) for its financial support for a PhD-study at Wageningen University, and to the National Research Institute of Forestry, Agriculture and Livestock (INIFAP, Mexico) to promote the professional development of the researchers. Mario Calus (Wageningen UR Livestock Research, Wageningen, the Netherlands) and Jennie Pryce (Department of Economic Development, Jobs, Transport \& Resources, Victoria, Australia) are kindly acknowledged for their helpful comments on this paper. 


\subsection{References}

Bastin, C., and N. Gengler. 2013. Genetics of body condition score as an indicator of dairy cattle fertility. A review. Biotechnol. Agron. Soc. 17(1):64-75.

Battagin, M., F. Forabosco, J. H. Jakobsen, M. Penasa, T. J. Lawlor, and M. Cassandro. 2012. International genetic evaluation of Holstein bulls for overall type traits and body condition score. J. Dairy Sci. 95(8):4721-4731.

Battagin, M., C. Sartori, S. Biffani, M. Penasa, and M. Cassandro. 2013. Genetic parameters for body condition score, locomotion, angularity, and production traits in Italian Holstein cattle. J. Dairy Sci. 96(8):5344-5351.

Beerda, B., W. Ouweltjes, L. B. J. Sebek, J. J. Windig, and R. F. Veerkamp. 2007. Effects of genotype by environment interactions on milk yield, energy balance, and protein balance. J. Dairy Sci. 90(1):219-228.

Berry, D. P., F. Buckley, P. Dillon, R. D. Evans, M. Rath, and R. F. Veerkamp. 2003a. Genetic parameters for body condition score, body weight, milk yield, and fertility estimated using random regression models. J. Dairy Sci. 86(11):37043717.

Berry, D. P., F. Buckley, P. Dillon, R. D. Evans, M. Rath, and R. F. Veerkamp. 2003b. Genetic relationships among body condition score, body weight, milk yield, and fertility in dairy cows. J. Dairy Sci. 86(6):2193-2204.

Berry, D. P., R. Buckley, P. Dillon, R. D. Evans, and R. R. Veerkamp. 2004. Genetic relationships among linear type traits, milk yield, body weight, fertility and somatic cell count in primiparous dairy cows. Irish J Agr Food Res 43(2):161-176.

Berry, D. P., M. P. Coffey, J. E. Pryce, Y. de Haas, P. Lovendahl, N. Krattenmacher, J. J. Crowley, Z. Wang, D. Spurlock, K. Weigel, K. Macdonald, and R. F. Veerkamp. 2014. International genetic evaluations for feed intake in dairy cattle through the collation of data from multiple sources. J. Dairy Sci. 97(6):3894-3905.

Berry, D. P., and J. J. Crowley. 2013. Cell Biology Symposium: genetics of feed efficiency in dairy and beef cattle. J. Anim. Sci. 91(4):1594-1613.

Brotherstone, S. 1994. Genetic and phenotypic correlations between linear type traits and production traits in Holstein-Friesian dairy cattle. Animal Production 59(02):183-187.

Brotherstone, S., M. P. Coffey, and G. Banos. 2007. Genetic parameters of growth in dairy cattle and associations between growth and health traits. J. Dairy Sci. $90(1): 444-450$. 
CRV. 2014. E-08. Breeding Value Estimation for Conformation Traits. https://global.crv4all.com/68143/67761/67689/e08conf. Accesed: February 18, 2015.

de Haas, Y., M. P. L. Calus, R. F. Veerkamp, E. Wall, M. P. Coffey, H. D. Daetwyler, B. J. Hayes, and J. E. Pryce. 2012. Improved accuracy of genomic prediction for dry matter intake of dairy cattle from combined European and Australian data sets. J. Dairy Sci. 95(10):6103-6112.

de la Fuente, L. F., C. Gonzalo, J. P. Sanchez, R. Rodriguez, J. A. Carriedo, and F. San Primitivo. 2011. Genetic parameters of the linear body conformation traits and genetic correlations with udder traits, milk yield and composition, and somatic cell count in dairy ewes. Can. J. Anim. Sci. 91(4):585-591.

Daetwyler, H. D., B. Villanueva, and J. A. Woolliams. 2008 Accuracy of predicting the genetic risk of disease using a genome-wide approach. PLoS ONE 3: e3395.

Daetwyler, H. D., R. Pong-Wong, B. Villanueva, and J. A. Woolliams. 2010. The impact of genetic architecture on genome-wide evaluation methods. Genetics 185: 1021-1031.

Dechow, C. D., J. Vallimont, M. D. Dekleva, J. M. Daubert, and J. W. Blum. 2010. Genetic correlations of gross feed efficiency with yield, body weight, body condition score, and energy balance in dairy cattle. J. Dairy Sci. 93:184-184.

E.U. 2011. European Commision of Agricultural and Rural Development. Farm Economics Brief. No. 2 Production costs overview. http://ec.europa.eu/agriculture/rica/pdf/Brief201102.pdf. Accesed: 25 April, 2015.

Falconer, D. S., and T. F. C. Mackay. 1996. Introduction to Quantitative Genetics. Vol. Fourth Edition. Pearson Prentice Hall.

Ferraretto, L. F., R. D. Shaver, and S. J. Bertics. 2012. Effect of dietary supplementation with live-cell yeast at two dosages on lactation performance, ruminal fermentation and total-tract nutrient digestibility in dairy cows. J. Dairy Sci. 95(7):4017-4028.

Ferraretto, L. F., R. D. Shaver, M. Espineira, H. Gencoglu, and S. J. Bertics. 2011. Influence of a reduced-starch diet with or without exogenous amylase on lactation performance by dairy cows. J. Dairy Sci. 94(3):1490-1499.

Gilmour, A. R., B. J. Gogel, B. R. Cullis, and R. Thompson. 2009. ASREML User Guide Release 3.0 VSN International Ltd, Hemel Hempstead, UK.

Harris, B. L., A. E. Freeman, and E. Metzger. 1992. Genetic and phenotypic parameters for type and production in Guernsey Dairy cows. J. Dairy Sci. 75(4):1147-1153. 
He, M., K. L. Perfield, H. B. Green, and L. E. Armentano. 2012. Effect of dietary fat blend enriched in oleic or linoleic acid and monensin supplementation on dairy cattle performance, milk fatty acid profiles, and milk fat depression. J. Dairy Sci. 95(3):1447-1461.

Hill, W. G., and Thompson, R. (1978). Probabilities of non-positive definite between-group or genetic covariance. Biometrics. 34 (3): 429-439

Holstein-USA. 2014.2 Linear type evaluations. http://www.holsteinusa.com/genetic_evaluations/ss_linear.html. Accesed: September 14, 2015.

Interbull. 2014. National genetic evaluation forms provided by countries. http://www.interbull.org/ib/geforms. Accesed: April 20, 2015.

Kadarmideen, H. N., and S. Wegmann. 2003. Genetic parameters for body condition score and its relationship with type and production traits in Swiss Holsteins. J. Dairy Sci. 86(11):3685-3693.

Kennedy, B. W., J. H. J. Vanderwerf, and T. H. E. Meuwissen. 1993. Genetic and statistical properties of Residual Feed Intake. J. Anim. Sci. 71(12):3239-3250.

Kleiber, M. 1932. Body Size and Metabolism. Hilgardia 6: 315-353.

Koenen, E. P. C., and R. F. Veerkamp. 1998. Genetic covariance functions for live weight, condition score, and dry-matter intake measured at different lactation stages of Holstein Friesian heifers. Livest. Prod. Sci. 57(1):67-77.

Liinamo, A. E., P. Mantysaari, and E. A. Mantysaari. 2012. Short communication: Genetic parameters for feed intake, production, and extent of negative energy balance in Nordic Red dairy cattle. J. Dairy Sci. 95(11):6788-6794.

Manzanilla-Pech, C. I. V., R. F. Veerkamp, M. P. L. Calus, R. Zom, A. van Knegsel, J. E. Pryce, and Y. De Haas. 2014. Genetic parameters across lactation for feed intake, fat-and protein-corrected milk, and liveweight in first-parity Holstein cattle. J. Dairy Sci. 97(9):5851-5862.

Muller, C. J. C., S. W. P. Cloete, J. J. Olivier, J. A. Botha, and H. de Waal. 2006. Heritability of live weight and condition score in a Holstein herd and correlations with milk traits - preliminary estimates. South African Journal of Animal Science 36(2):79-88.

National Research Dairy Council, N. R. D. 2001. Nutrient Requirements of Dairy Cattle. Natl. Acad. Press, Washington, D.C.

Nixon, M., J. Bohmanova, J. Jamrozik, L. R. Schaeffer, K. Hand, and F. Miglior. 2009. Genetic parameters of milking frequency and milk production traits in Canadian Holsteins milked by an automated milking system. J. Dairy Sci. 92(7):3422-3430.

Parke, P., B. W. Kennedy, J. C. M. Dekkers, R. K. Moore, and L. Jairath. 1999. Genetic and phenotypic parameter estimates between production, feed intake, 
feed efficiency, body weight and linear type traits in first lactation Holsteins. Can. J. Anim. Sci. 79(4):425-431.

Potts, S.B., J.P. Boerman, A.L. Lock, M.S. Allen, and M.J.VandeHaar. 2015. Residual feed intake is repeatable for lactating Holstein dairy cows fed high and low starch diets.J. Dairy Sci. 98:1-13.

Sales, J. and Hill, W. G. 1976. Effect of sampling errors on the efficiency of selection indices. 2. Use of information on associated traits for improvement of a single important trait. Animal Production 23: 1-14

Short, T. H., and T. J. Lawlor. 1992. Genetic Parameters of Conformation Traits, Milk-Yield, and Herd Life in Holsteins. J. Dairy Sci. 75(7):1987-1998.

Spurlock, D. M., J. C. M. Dekkers, R. Fernando, D. A. Koltes, and A. Wolc. 2012. Genetic parameters for energy balance, feed efficiency, and related traits in Holstein cattle. J. Dairy Sci. 95(9):5393-5402.

Tempelman, R., D. Spurlock, M. P. Coffey, R. F. Veerkamp, L. Armentano, K. Weigel, Y. de Haas, C. Staples, E. E. Connor, Y. Lu, and M. VandeHaar. 2015. Heterogeneity in genetic and non-genetic variation and energy sink relationships for residual feed intake across research stations and countries. J. Dairy Sci. Vol. 98(3):p2013-2026.

Tsuruta, S., I. Misztal, and T. J. Lawlor. 2005. Changing Definition of Productive Life in US Holsteins: Effect on Genetic Correlations. J. Dairy Sci. 88(3):11561165.USDA. 2015. http://www.ers.usda.gov/data-products/agriculturalproductivity-in-the-us.aspx\#28247. Accesed: May 10, 2015.

Vallimont, J. E., C. D. Dechow, J. M. Daubert, M. W. Dekleva, J. W. Blum, C. M. Barlieb, W. Liu, G. A. Varga, A. J. Heinrichs, and C. R. Baumrucker. 2010. Genetic parameters of feed intake, production, body weight, body condition score, and selected type traits of Holstein cows in commercial tie-stall barns. J. Dairy Sci. 93(10):4892-4901.

Van Dorp, T. E., J. C. M. Dekkers, S. W. Martin, and J. Noordhuizen. 1998. Genetic parameters of health disorders, and relationships with 305-day milk yield and conformation traits of registered Holstein cows. J. Dairy Sci. 81(8):2264-2270.

van Oers, K., and D. L. Sinn. From genes to Animal Behaviour: Social structures, personalities, communication by color. Page 171. Toward a basis for the phenotypic gambit: Advances in the evolutionary genetics of animal personality. Inoue-Murayama, M., S. Kawamura, A. Weiss. Springer. New York.

Veerkamp, R. F. 1998. Selection for economic efficiency of dairy cattle using information on live weight and feed intake: A review. J. Dairy Sci. 81(4):11091119. 
Veerkamp, R. F., and S. Brotherstone. 1997. Genetic correlations between linear type traits, food intake, live weight and condition score in Holstein Friesian dairy cattle. Animal Science 64:385-392.

Veerkamp, R. F., M. P. Coffey, D. P. Berry, Y. de Haas, E. Strandberg, H. Bovenhuis, M. Calus, and E. Wall. 2012. Genome-wide associations for feed utilisation complex in primiparous Holstein-Friesian dairy cows from experimental research herds in four European countries. Animal 11(6):1738-1749.

Veerkamp, R. F., and G. C. Emmans. 1995. Sources of genetic variation in energetic efficiency of dairy cows. Livest. Prod. Sci. 44(2):87-97.

Veerkamp, R. F., G. C. Emmans, A. R. Cromie, and G. Simm. 1995. Variance components for residual feed intake in dairy cows. Livest. Prod. Sci. 41(2):111120.

Veerkamp, R. F., C. L. M. Gerritsen, E. P. C. Koenen, A. Hamoen, and G. De Jong. 2002. Evaluation of Classifiers that Score Linear Type Traits and Body Condition Score Using Common Sires. J. Dairy Sci. 85(4):976-983.

Veerkamp, R. F., E. P. C. Koenen, and G. De Jong. 2001. Genetic correlations among body condition score, yield, and fertility in first-parity cows estimated by random regression models. J. Dairy Sci. 84(10):2327-2335.

Veerkamp, R. F., J. K. Oldenbroek, H. J. Van Der Gaast, and J. H. J. Van Der Werf. 2000. Genetic correlation between days until start of luteal activity and milk yield, energy balance, and live weights. J. Dairy Sci. 83(3):577-583.

Veerkamp, R. F., G. Simm, and P. Persaud. 1994. Potential Value of Linear Type Traits for the Prediction of Intake, Efficiency and Economic Margins in DairyCattle. Livest. Prod. Sci. 38(3):179-189.

Visscher, P. M., and M. E. Goddard. 1995. Genetic parameters for milk yield, survival, workability and type traits for Australian Dairy Cattle. J. Dairy Sci. 78(1):205-220.

Waltner, S. S., J. P. Mcnamara, and J. K. Hillers. 1993. Relationships of Body Condition Score to Production Variables in High Producing Holstein Dairy-Cattle. J. Dairy Sci. 76(11):3410-3419.

WHFF. 2014. World Holstein Friesian Federation. Progress of type harmonisation. doi:http://www.whff.info/documents/2014TypeHarmonisationReportandRecom mendations.pdf. Accessed: April 24, 2015.

Yao, C., D. M. Spurlock, L. E. Armentano, C. D. Page, Jr., M. J. VandeHaar, D. M. Bickhart, and K. A. Weigel. 2013. Random Forests approach for identifying additive and epistatic single nucleotide polymorphisms associated with residual feed intake in dairy cattle. J. Dairy Sci. 96(10):6716-6729. 
Zink, V., M. Stipkova, and J. Lassen. 2011. Genetic parameters for female fertility, locomotion, body condition score, and linear type traits in Czech Holstein cattle. J. Dairy Sci. 94(10):5176-5182.

Zink, V., L. Zavadilova, J. Lassen, M. Stipkova, M. Vacek, and L. Stolc. 2014. Analyses of genetic relationships between linear type traits, fat-to-protein ratio, milk production traits, and somatic cell count in first-parity Czech Holstein cows. Czech Journal of Animal Science 59(12):539-547.

Zom, R. L. G., G. Andre, and A. M. van Vuuren. 2012. Development of a model for the prediction of feed intake by dairy cows: 1 . Prediction of feed intake. Livest. Sci. 143(1):43-57. 




\title{
Chapter 4
}

\section{Genome-wide association study of methane emissions in Angus beef cattle with validation in dairy cattle}

\author{
C. I. V. Manzanilla-Pech ${ }^{1,2,3}$, Y. De Haas ${ }^{1}$, B. J. Hayes ${ }^{4}$, R. F. Veerkamp ${ }^{1,2}$, M. \\ Khansefid $^{4,5,6}$, K. A. Donoghue ${ }^{7}$, P. F. Arthur ${ }^{7}$, J. E. Pryce ${ }^{5,6}$
}

\begin{abstract}
${ }^{1}$ Animal Breeding and Genomics Centre, Wageningen UR Livestock Research, P.O. Box 338, $6700 \mathrm{AH}$ Wageningen, the Netherlands ${ }^{2}$ Animal Breeding and Genomics Centre, Wageningen University, P.O. Box 338, $6700 \mathrm{AH}$ Wageningen, the Netherlands ${ }^{3}$ Mococha Research Station, National Institute of Forestry, Agriculture and Livestock Research, 97454 Mococha, Yucatan, Mexico ${ }^{4}$ Department of Agriculture and Food Systems, Faculty of Veterinary and Agricultural Sciences, The University of Melbourne, Grattan Street, Parkville, VIC 3010, Australia ${ }^{5}$ Department of Economic Development, Jobs, Transport and Resources, AgriBio, 5 Ring Road, La Trobe University, Bundoora, Victoria 3086, Australia ${ }^{6}$ La Trobe University, AgriBio, 5 Ring Road, Bundoora, Victoria 3086, Australia ${ }^{7}$ Department of Primary Industries, Agricultural Research Centre, Trangie, NSW 2823, Australia
\end{abstract}




\begin{abstract}
Methane $\left(\mathrm{CH}_{4}\right)$ is a product of enteric fermentation in ruminants, and it represents around $17 \%$ of global $\mathrm{CH}_{4}$ emissions. There has been substantial effort from the livestock scientific community toward tools that can help to reduce this percentage. One approach is to select for lower emitting animals. To achieve this, accurate genetic parameters and identification of the genomic basis of $\mathrm{CH}_{4}$ traits are required. Thus, the objectives of this study were: 1) to perform a genome wide association study (GWAS) to identify SNP associated with several $\mathrm{CH}_{4}$ traits in Angus beef cattle (1,020 animals), and validate them in a lactating Holstein population (POP1; 205), 2) to validate significant SNP for DMI and WT from a second Holstein population, from a previous study (POP2; 903), in an Angus population, and 3) to evaluate two different residual $\mathrm{CH}_{4}$ traits and determine if the genes associated with $\mathrm{CH}_{4}$ also control residual $\mathrm{CH}_{4}$ traits. Phenotypes calculated for the genotyped Angus population included: $\mathrm{CH}_{4}$ production (MeP), $\mathrm{CH}_{4}$ yield ( $\mathrm{MeY}), \mathrm{CH}_{4}$ intensity (MI), DMI and weight at test (WT). The Holstein population (POP1) was multiparous, with phenotypes on $\mathrm{CH}_{4}$ traits (MeP, MeY and $\mathrm{MI}$ ) plus genotypes. Additionally, two $\mathrm{CH}_{4}$ traits: residual genetic $\mathrm{CH}_{4}(\mathrm{RGM})$ and residual phenotypic $\mathrm{CH}_{4}$ (RPM) were calculated by adjusting MeP for DMI and WT. Estimated heritabilities in Angus were $0.30,0.19$ and 0.15 for MeP, RGM and RPM respectively, and genetic correlations of MeP with DMI and WT were 0.83, and 0.80, respectively. Estimated heritabilities in Holstein POP1 were 0.23, 0.30 and 0.42 for MeP, MeY and MI, respectively. Strong associations with MeP were found on chromosomes $4,12,14,20$, and 30 at $P<0.001$, and those chromosomes also had significant SNP for DMI in Holstein POP1. In Angus, the number of significant SNP for MeP at $P<0.005$ was 3304, being 630 of those SNP also important for DMI and WT. When a set $(\sim 3,300)$ of significant SNP for DMI and WT in Angus was used to estimate genetic parameters for MeP and MeY in Holstein POP1, the genetic variance and consequently the heritability increased slightly, meaning that most of the genetic variation is largely captured by these SNP. Residual traits could be a good option to include in the breeding goal, as this would facilitate selection for lower emitting animals without compromising DMI and WT.
\end{abstract}

Key words: methane production, residual methane, feed intake 


\subsection{Introduction}

Methane emission $\left(\mathrm{CH}_{4}\right)$ is a complex trait that involves several biological processes in the rumen, including the ruminal microorganisms present, the type of diet, as well as the amount of feed intake (ration), and size of the animal. Given the complexity of $\mathrm{CH}_{4}$ and assuming that genetic variation is influenced by many genes with heterogeneous effects, there is currently a gap in knowledge on the genetic architecture of this new trait $\left(\mathrm{CH}_{4}\right)$. Additionally, as $\mathrm{CH}_{4}$ phenotypes are expensive to measure, it is also useful to know if information on specific genes in dairy cattle analyses could be applied to beef cattle (Pszczola et al., 2013; Khansefid et al., 2014), and vice versa, by identifying SNP that regulate $\mathrm{CH}_{4}$ in beef and dairy cattle. This knowledge could help to improve the accuracy of prediction of $\mathrm{CH}_{4}$ in dairy and beef cattle.

One of the challenges to selecting for reduced $\mathrm{CH}_{4}$ emissions is deciding on the breeding objective. Currently, there is no clear consensus on the best trait to change through selection and little knowledge of the underlying genetic architecture of different measures. Several definitions for $\mathrm{CH}_{4}$ have been proposed (Alcock and Hegarty, 2011; Herd et al., 2014a) including $\mathrm{CH}_{4}$ production (MeP), $\mathrm{CH}_{4}$ yield (MeY), $\mathrm{CH}_{4}$ intensity (MI) and residual $\mathrm{CH}_{4}$. MeP is defined as the daily $\mathrm{CH}_{4}$ production (g/d), MeY is the amount of $\mathrm{CH}_{4}$ produced per unit of input (DMI), and $\mathrm{Ml}$ is defined as $\mathrm{CH}_{4}$ produced per unit of product (milk or weight). There is also growing interest in residual $\mathrm{CH}_{4}$ traits, where $\mathrm{CH}_{4}$ is independent of feed intake, calculated as actual $\mathrm{CH}_{4}$ minus expected $\mathrm{CH}_{4}$ (Donoghue et al., 2013; Herd et al., 2014a).

The objectives of this study were 1 ) to perform a genome wide association study (GWAS) to identify SNP associated with several $\mathrm{CH}_{4}$ traits in Angus beef cattle, and validate them in a lactating Holstein population, 2) validate significant SNP for DMI and WT from a second Holstein population (from a previous study) in the Angus population, and 3 ) to evaluate two different residual $\mathrm{CH}_{4}$ traits and determine if the identified genes associated with $\mathrm{CH}_{4}$ also play a role in controlling residual $\mathrm{CH}_{4}$ traits.

\subsection{Material and methods}

For this study, data on 3 populations were available: one genotyped Angus population with phenotypes on MeP, MeY, MI, DMI, WT; one genotyped Holstein population (referred to as Holstein POP1) with phenotypes on MeP, MeY, and MI; 
and one list of significant SNP (from a previous study, Pryce et al., 2012) for DMI and WT on a second Holstein population (referred to as Holstein POP2). Information of the phenotypes and genotypes in Angus and Holstein POP1 are described below. Note that the GWAS on DMI and WT in Holstein POP2 has already been published by Pryce et al. (2012).

\subsubsection{Angus Phenotypes}

Methane production records, DMI and pre-test live weight (WT) were available for 1020 Angus animals. These animals took part in an experiment evaluating MeP and DMI at the Agricultural Research Centre, Trangie NSW, Australia. A full description of the animals and $\mathrm{CH} 4$ experiment is provided by Herd et al. (2014a). In brief, the animals (both sexes) were the offspring of 73 sires (14 progeny per sire on average), and were born in two groups: 2009 and 2011-2012. They were raised with their dams on pasture until weaning $(8 \mathrm{mo})$. The animals were managed as cohorts (by herd and sex) of 40 animals and within each cohort there were 4 random groups of 10 animals. Progeny of individual sires were stratified across groups and cohorts. For animals born in 2009, $\mathrm{CH}_{4}$ measurements were taken at $2 \mathrm{yr}$ of age, whereas, for animals born in 2011-2012, $\mathrm{CH}_{4}$ measurements were taken at $1 \mathrm{yr}$ of age. Animals had an acclimatization period of $10 \mathrm{~d}$ at the research center at Trangie, prior to the experiment. The test ration was a commercial alfalfa and oaten hay chaff. The mean nutritional values of the test ration over $3 \mathrm{yr}$ were $88 \% \mathrm{DM}, 14 \% \mathrm{CP}, 67 \%$ DM digestibility, and ME content of 9 $\mathrm{MJ} / \mathrm{kg}$ DM. The $\mathrm{CH}_{4}$ facility included 10 respiration chambers located at the University of New England, campus Armidale, NSW, Australia. Methane production was measured over $2 \mathrm{~d}$ (48 h), DMI was measured during to the $\mathrm{CH}_{4}$ measurement period, and the average was calculated. The weight of the feed was continuously recorded using load cells located below the feeder (Hegarty, 2013). Pre-test live weight was measured once after the preparation period and just before the start of the trial for measuring $\mathrm{CH}_{4}$. Two ratio traits were calculated: MeY as MeP divided by $\mathrm{DMI}$, and $\mathrm{MI}$ as MeP divided by WT.

Additionally, two residual $\mathrm{CH}_{4}$ traits were calculated, so that the $\mathrm{CH}_{4}$ traits were adjusted for DMI and WT. Those two traits were residual phenotypic methane (RPM) and residual genetic methane (RGM), and were calculated using the formula proposed by Kennedy et al. (1993) to calculate residual feed intake (RFI) based on phenotypic and genetic regressions on milk production and body weight. Thus, RPM and RGM were calculated based on the residual phenotypic and genetic regressions of a trivariate analysis of MeP, DMI and WT as follow: 


$$
\begin{aligned}
& \mathbf{R P M}=\mathbf{M e P}-\left[\left(\boldsymbol{\beta}_{\mathbf{p}} \times \mathbf{D M I}\right)+\left(\boldsymbol{\beta}_{\mathbf{p}} \mathbf{x} \mathbf{W T}\right)\right. \\
& \mathbf{R G M}=\mathbf{M e P}-\left[\left(\boldsymbol{\beta}_{\mathbf{g}} \times \mathbf{D M I}\right)+\left(\boldsymbol{\beta}_{\mathbf{g}} \times \mathbf{W T}\right)\right.
\end{aligned}
$$

The regression coefficients were calculated as

$$
\begin{array}{ll}
\boldsymbol{\beta}_{\mathbf{p}}=\mathbf{P}^{-\mathbf{1}} \mathbf{C}_{\mathrm{p}} & \text { for RPM (Eq. [1]), and } \\
\boldsymbol{\beta}_{\mathbf{g}}=\mathbf{G}^{-\mathbf{1}} \mathbf{C}_{\mathrm{g}} & \text { for RGM (Eq. [2]), }
\end{array}
$$

where $\mathbf{P}$ is the phenotypic variance-covariance matrix $(2 \times 2)$ between DMI and WT and $C_{p}$ is the vector $(2 \times 1)$ of phenotypic covariances between MeP and DMI and between MeP and WT; $\mathbf{G}$ is the genetic variance-covariance matrix $(2 \times 2)$ between $\mathrm{DMI}$ and $\mathrm{WT}$ and $\mathrm{C}_{\mathrm{g}}$ is the vector $(2 \times 1)$ of genetic covariance between MeP and DMI or between MeP and WT. The resulting coefficients are vectors, where a1 (first position) is the regression coefficient of $\mathrm{DMI}$, and a2 (second position) is the regression coefficient of WT.

\subsubsection{Holstein Phenotypes}

A total of $205 \mathrm{CH}_{4}$ records were available on Australian lactating Holstein cows (POP1) that were part of a 3 yr experiment, with preliminary results from 109 (2014) and 96 (2015) cows measured at DEDJTR Ellinbank (National Centre for Dairy Research and Development, Ellinbank, Victoria, Australia). Feed intake was measured on multiparous cows for $30 \mathrm{~d}$ (consecutive) in 3 batches per yr, within this period methane was measured for 3 to $5 \mathrm{~d}$ (consecutive). The cows were fed on a diet based on alfalfa supplemented with around $6 \mathrm{~kg}$ of crushed wheat per $\mathrm{d}$. The sulfur hexaflouride $\left(\mathrm{SF}_{6}\right)$ tracer technique (Grainger et al., 2007; Deighton et al., 2013) was used to measure $\mathrm{CH}_{4}$. The concordance correlation coefficient between $\mathrm{CH}_{4}$ emission the $\mathrm{SF}_{6}$ and the respiration chambers is reported to be 0.83 (Deighton et al., 2013). Methane yield was calculated using MeP divided by DMI, while MI was calculated using MeP divided by milk yield.

Pryce et al. (2012) described a population of 903 Australian Holstein heifer calves (POP2) with DMI and WT records taken at 56 to $70 \mathrm{~d}$ when the calves were 6 to $8 \mathrm{mo}$ old. These animals were part of a 2 yr experiment during 2009 and 2010 in Rutherglen, Victoria (Williams et al., 2011), and included 3 cohorts, two born in Spring and one in Autumn. The calves were fed a diet of alfalfa cubes ad libitum. Daily DMI was measured by electronic feed intake measuring devices (Gallagher Animal Management Systems). Body weight was measured and growth rates were 
calculated as a regression of weight on day of test and this was corrected to a weight corresponding to $250 \mathrm{~d}$ of age.

\subsubsection{Angus Genotypes}

Most animals (847) were genotyped using the 800K Illumina Bovine HD Array (777,962 SNP) and the remaining 173 were genotyped using the Illumina Bovine SNP50 (54,609 SNP) Illumina Inc., 9885 Towne Centre Drive, San Diego, CA 92121, USA. The SNP positions used were from bovine genome assembly UMD 3.1 (University of Maryland, College Park, MD). Monomorphic SNP and SNP with less than 5 observed copies of the rare allele were removed. After editing only genotypes with GenTrain score $(>0.6)$ were retained; we also removed mitochondrial, sex chromosome SNP, unmapped SNP, and SNP with duplicate or uncertain position. The final SNP dataset comprised of 632,003 SNP. Missing genotypes and animals genotyped with 50k were imputed using Beagle3 (Browning and Browning, 2009). Single nucleotide polymorphisms with duplicate positions given linkage disequilibrium with adjacent SNP and those with poor imputation accuracies were removed. A full description of the imputation and genotype editing is described by Hayes et al. (2016).

\subsubsection{Holstein Genotypes}

A total of 205 lactating cows in POP1 were genotyped with the Illumina Bovine SNP50 chip, with 50K SNP markers, and they were imputed to 632,003 SNP genotypes with Beagle3 software (Browning and Browning, 2009). The same quality control process, as described above was applied to the genotypes in the imputation process, so that the same SNP set was available for Angus and Holstein POP1.

The GWAS for Holstein POP2 was performed by Pryce et al. (2012). Pryce et al. (2012) described a total of 903 heifers were genotyped with the 800K Illumina Bovine HD Array (777,962 SNP). After the quality control process, 624,930 SNP remained. For the current study, a list of significant SNP for DMI and WT from the Pryce et al. (2012) study was used to validate in the Angus population, using only the SNP that correspond in each dataset, which was 603,002 SNP. Given that DMI and WT are highly correlated with $\mathrm{CH}_{4}$ traits and the fact that both populations were similar in age (growing animals), it was suggested that this could help with improving the accuracy of genomic prediction (Hayes et al., 2016; Khansefid et al., 2014). 


\subsubsection{Genetic Parameters Estimation}

Genetic parameters were estimated in both populations of Angus and Holstein POP1. In both cases, all 632,003 SNP were used to calculate the genomic relationship matrix (GRM) according to Yang et al. (2010), and this matrix was used in the estimation of genetic parameters using GREML as described below (Hayes and Goddard, 2008; Veerkamp et al., 2011). Analyses were performed using ASReml 3.0 (Gilmour et al., 2009).

First, in Angus population, a trivariate analysis between MeP, DMI and WT was performed to estimate genetic and phenotypic covariances between MeP and DMI and between MeP and WT, both were required to calculate RGM and RPM [1] and [2]. Second, 3 sets of trivariate analyses were performed between all the traits (MeP, MeY, MI, DMI, WT, RGM, RPM) to re-estimate and validate the genetic parameters. We used a series of trivariate analyses because there were difficulties in getting a 7-trait multivariate analysis with all traits to converge. The model used in the analyses was:

$$
\mathbf{y}_{\mathbf{i j k l}}=\mu+\mathbf{A G E}_{\mathbf{i}}+\mathbf{A D C}_{\mathbf{j}}+\mathbf{C G}_{\mathbf{k}}+\mathbf{g}_{\mathbf{l}}+\mathbf{e}_{\mathbf{i j k l}}
$$

Where $\mathrm{y}_{\mathrm{ijkl}}$ is the Angus phenotype for MeP, MeY, MI, DMI, WT, RGM or RPM, " $\mu$ " is the overall mean, $A_{G E}$ is the fixed effect of age of the animal at measurement in months as a covariate; $\mathrm{ADC}_{j}$ is the fixed effect of age of dam at calving in months as covariate, $\mathrm{CG}_{\mathrm{k}}$ is the fixed effect contemporary group that include cohort (by herd and sex), methane group and management group (114 classes); $g_{1}$ is the random additive genetic effect distributed as $N\left(0, G \sigma^{2}{ }_{a}\right)$ using genomic relationship matrix, and $e_{i j k l}$ is the residual term of $y_{i j k l}$ distributed as $N(0$, $\left(\sigma^{2}\right)$.

In Holstein POP1 univariate analyses for MeP, MeY, and $\mathrm{MI}$ in Holstein POP1 were run with the following model:

$$
\mathbf{y}_{\mathbf{i j k l}}=\mu+\mathbf{Y B}_{\mathbf{i}}+\mathbf{D I M}_{\mathbf{j}}+\mathbf{L N}_{\mathbf{k}}+\mathbf{g}_{\mathbf{l}}+\mathbf{e}_{\mathbf{i j k l}}
$$

Where $\mathrm{y}_{\mathrm{ijkl}}$ is the Holstein phenotype for MeP, MeY or MI, " $\mu$ " is the overall mean, $\mathrm{YB}_{\mathrm{i}}$ is the interaction $\mathrm{yr}^{*}$ batch (6 classes), $\mathrm{DIM}_{\mathrm{j}}$ is the days in milk as a deviation from the mean as covariate, $\mathrm{LN}_{\mathrm{k}}$ is the lactation number ( 7 classes), $\mathrm{g}_{\mathrm{l}}$ is the random additive genetic effect distributed as $\mathrm{N}\left(0, \mathrm{G}^{2}{ }_{\mathrm{a}}\right)$ using the genomic relationship estimated using the GRM matrix, and $e_{i j k l}$ is the residual term of $y_{i j k l}$ distributed as $N\left(0, \sigma^{2}{ }_{e}\right)$. 


\subsubsection{Genome Wide Association}

Genome wide association analyses were performed in the Angus population and Holstein POP1, to determine the association from each SNP with the analyzed traits (MeP, MeY, MI, RGM, RPM, DMI, WT in Angus and MeP, MeY, $\mathrm{MI}$ in Holstein POP1).

The model used in the GWAS for Angus and Holstein POP1 was:

$$
\mathbf{y}_{\mathrm{ijk}}=\mu+\mathbf{F E}_{\mathbf{i}}+\mathbf{S N P}_{\mathbf{j}}+\mathbf{g}_{\mathrm{k}}+\mathbf{e}_{\mathrm{ijk}}
$$

Where $\mathrm{y}_{\mathrm{ijk}}$ is the phenotype for MeP, MeY, MI, DMI, WT, RGM or RPM for Angus, and MeP, MeY and MI for Holstein, " $\mu$ " is the mean, $\mathrm{FE}_{\mathrm{i}}$ are the fixed effects, same as Eq. [3] for Angus and same as in Eq. [4] for Holstein, $\mathrm{SNP}_{\mathrm{j}}$ is the effect of each one of the SNP as fixed effects, $g_{k}$ is the random additive genetic effect distributed as $N\left(0, G \sigma^{2}{ }_{a}\right)$ using genomic relationship matrix, and $e_{i j k}$ is the residual term of $\mathrm{y}_{-} \mathrm{ijkl}$ distributed as $\mathrm{N}\left(0,1 \sigma^{2}{ }_{\mathrm{e}}\right)$. Analyses were also performed using ASReml 3.0 (Gilmour et al., 2009). Two different levels of significance were considered, $(P<0.001)$ and a more relaxed threshold $(P<0.005)$, the first one to find significant SNP, and the less stringent threshold to find significant SNP in common in both population.

Additionally, false discovery ratio (FDR; Bolormaa et al., 2011) was calculated for all the traits with the formula below:

$$
\mathrm{FDR}=\frac{\mathbf{p}(\mathbf{1}-\mathbf{s})}{\mathbf{s}(\mathbf{1}-\mathbf{p})}
$$

Where $p$ is the significant threshold ( $P$-value; $P<0.001$ and $P<0.005$ ) and $S$ is the proportion of significant SNP (number of significant SNP divided by number of total SNP) at that P-value.

\subsubsection{Validation with $\mathrm{X}^{2}$ test and Genome Wide Association Studies}

Using the results obtained from various single trait GWAS, significant SNP that were in common for all traits (MeP, MeY, MI, RPM, RGM, DMI, WT in Angus; MeP, MeY, MI in Holstein POP1 and DMI, WT in Holstein POP2) were identified. A total of 12 lists of SNP (one per trait) with associated P-value and positions (BP) were used in pairwise comparisons of significant SNP using the package "Chisquare \{stats\}" in R (R Core Team, 2013), to determine if a SNP in position I was significant at $P<0.001$ or $P<0.005$ in both traits. The degrees of freedom (DF) were 
calculated as the number of columns minus one $x$ number of rows minus one. For our data this gives $(2-1) \times(2-1)=1 \mathrm{DF}$. The $\mathrm{x}^{2}$ comparison test uses the data to calculate a test statistic (from a $\mathrm{X}^{2}$ distribution with 1 DF) that measures how far the observed data are from the null expectation (McDonald, 2014).

Additionally, those results from the pairwise comparisons $\left(X^{2}\right)$ were partially validated, using only significant SNP (obtained from the GWAS in Angus population) for MeP, MeY, MI, DMI, WT, RPM and RGM, in a second GWAS in Holstein POP1. For this, 14 different sets ( 7 traits by 2 different significant level $P<$ 0.001 and $P<0.005)$ of significant SNP in Angus were used to run a second GWAS in Holstein POP1for each trait (MeP, MeY and MI), and determine how many of those significant SNP in Angus were also significant in the Holstein POP1.

\subsubsection{Validation Based on Explained Genetic Variance}

\subsubsection{Using Holstein population 2 to validate in Angus population}

Significant SNP from Holstein POP2 were used to validate the Angus population through a genomic prediction method. Here, the GRM was built using only significant SNP for DMI and WT from Holstein POP2 to perform a univariate animal model for MeP, DMI and WT in Angus population. A total of seven scenarios were tested: 1 and 2$)$ using SNP $(\sim 2,000)$ with the largest effect $(P<0.001)$ on DMI and WT, 3 and 4) using significant SNP $(\sim 6,000)$ with $P<0.005$ in DMI and WT, 5) using the most significant SNP $(P<0.001)$ in common for both DMI and WT $(\sim 4,000)$, and 6 and 7$)$ using SNP with $P<0.01$ level of significance in DMI and WT $(\sim 12,000)$, respectively.

\subsubsection{Using Holstein population 2 for validation in Holstein population 1}

Significant SNP ( $<$ 0.005) for DMI and WT from Holstein POP2 were validated in Holstein POP1 through genomic prediction. Two lists of significant SNP were used to build 2 different GRM (DMI =6,559, WT =6,139), and each GRM was used to run an univariate animal model for each methane trait (MeP, MeY, and MI) in Holstein POP1. Genetic, residual, phenotypic variances, and heritabilities were compared with the base scenario, and log likelihood was used to determine the best set of significant SNP through an Akaike information criterion (AIC) test. This is a test that compares non-nested models based on the maximum value of the likelihood function for each model. 


\subsubsection{Using Angus population to validate in Holstein population 1}

Significant SNP ( $<$ 0.005) for MeP, RGM, RPM, DMI and WT from the Angus population were validated in Holstein POP1 through genomic prediction. A univariate animal model for each trait in Holstein (MeP, MeY, MI) was used to estimate genetic parameters, where different GRM that were built using only significant SNP for MeP, RGM, RPM, DMI and WT from Angus. From this we were able to determine how much of the genetic variance in Holsteins can be predicted by Angus significant SNP. Six GRM were built; the base scenario included all the SNP $(632,003)$, and then there was one set per trait for MeP $(3,304$ SNP), RGM (3,078 SNP), RPM (3,120 SNP), DMI (3,364 SNP), and WT (3,284 SNP). Genetic, residual, phenotypic variances, and heritabilities were compared with the base scenario, and log likelihood was used to determine the best set of significant SNP through an AIC test.

\subsection{Results}

\subsubsection{Descriptive Statistics}

Descriptive statistics for MeP (g/d), MeY (g/kg DMI), MI (g/kg WT), RPM, RGM (g/d), DMI ( $\mathrm{kg} / \mathrm{d})$ and WT at test $(\mathrm{kg})$ in beef cattle, and for DMI, WT, MeP, $\mathrm{MeY}$ and $\mathrm{Ml}$ (g/kg milk) in two populations of dairy cattle are presented in Table 4.1. The mean for MeP was $132.6 \mathrm{~g} / \mathrm{d}$ in Angus population and $110.5 \mathrm{~g} / \mathrm{d}$ in Holstein POP2, whereas, for MeY the mean was 21.9 in Angus and 17.5 in Holstein POP2. The average DMI was $6.1 \mathrm{~kg} / \mathrm{d}$ for Angus beef cattle, and the average WT was 357.7 kg. For growing Holstein calves (POP1), the average DMI was $8.3 \mathrm{~kg} / \mathrm{d}$, and the average WT was $215.7 \mathrm{~kg}$. Means for RPM and RGM were 4.93 and -30.3 , respectively.

\subsubsection{Estimated genetic parameters}

Estimated variances, heritabilities, genetic and phenotypic correlations for MeP, MeY, MI, RPM, RGM, DMI, and WT in the Angus populations are presented in Table 4.2. Estimated heritabilities for the $\mathrm{CH}_{4}$ traits MeP, MeY, MI, RPM and RGM in the Angus population were $0.30,0.20,0.32,0.19$ and 0.15 , respectively, and the estimated heritabilities for DMI and WT were 0.39 and 0.41 , respectively.

Genetic correlations between all traits in Angus ranged from -0.44 (between $\mathrm{MI}$ and WT) to 0.98 (between RPM and RGM). Residual phenotypic methane had zero phenotypic correlation with DMI and WT, whereas RGM had 
Table 4.1 Descriptive statistics for methane production (MeP in $\mathrm{g} / \mathrm{d}$ ), methane yield (MeY), methane intensity (MI), residual phenotypic methane (RPM), residual genetic methane (RGM), DMI (in kg/d) and weight at test (WT in $\mathrm{kg}$ ) in Angus beef cattle and MeP, MeY, MI in Holstein population 1 (POP1) and DMI, WT, in Holstein population 2 (POP2).

\begin{tabular}{clclrrrrr}
\hline $\begin{array}{c}\text { Popu- } \\
\text { lation }\end{array}$ & Trait & $\begin{array}{c}\text { Number } \\
\text { animals }\end{array}$ & Unit & Mean & SD & Minimum & Maximum & CV \\
\hline Angus & MeP & 1020 & $\mathrm{~g} / \mathrm{d}$ & 132.6 & 25.5 & 78.9 & 250.9 & 0.19 \\
& MeY & 1020 & $\mathrm{~g} / \mathrm{kg} \mathrm{DMI}$ & 21.9 & 2.3 & 13.1 & 29.5 & 0.10 \\
& MI & 1020 & $\mathrm{~g} / \mathrm{kg} \mathrm{WT}$ & 0.4 & 0.05 & 0.2 & 0.6 & 0.12 \\
& RPM & 1020 & $\mathrm{~kg} / \mathrm{d}$ & 4.9 & 15.9 & -62.4 & 61.4 & - \\
& RGM & 1020 & $\mathrm{~kg} / \mathrm{d}$ & -30.3 & 19.3 & -113.3 & 21.0 & - \\
& DMI & 1020 & $\mathrm{~kg} / \mathrm{d}$ & 6.1 & 1.3 & 3.5 & 9.4 & 0.21 \\
& WT & 1020 & $\mathrm{Kg}$ & 357.7 & 89.5 & 156.0 & 357.7 & 0.25 \\
\cline { 2 - 9 } Holstein & MeP & 205 & $\mathrm{~g} / \mathrm{d}$ & 110.5 & 33.9 & 50.3 & 249.5 & 0.31 \\
POP1 & MeY & 205 & $\mathrm{~g} / \mathrm{kg} \mathrm{DMI}$ & 17.5 & 3.0 & 9.9 & 28.6 & 0.17 \\
& MI & 205 & $\mathrm{~g} / \mathrm{kg}$ milk & 16.1 & 3.2 & 8.9 & 26.6 & 0.24 \\
\cline { 2 - 9 } Holstein $^{1}$ & DMI & 903 & $\mathrm{~kg} / \mathrm{d}$ & 8.3 & 1.3 & 3.6 & 12.5 & 0.16 \\
POP2 $^{1}$ & WT & 903 & $\mathrm{Kg}$ & 215.7 & 42.1 & 107.1 & 352.2 & 0.19 \\
\hline
\end{tabular}

${ }^{1}$ This information is from Pryce et al. (2012) and it is shown here for comparative purposes.

zero genetic correlation with DMI and WT. This result is as expected, because of the definitions of these traits. The estimated genetic correlation between MeP and DMI was 0.83 , while between MeP and WT the estimated genetic correlation was 0.80 .

Estimated genetic variances for $\mathrm{MeP}, \mathrm{MeY}$, and $\mathrm{MI}$ in Holstein POP1 were 170.0, 1.8 and 3.6, respectively, and estimated residual variances were 576.2, 4.9 and 4.4 , respectively. The estimated heritabilities were 0.23 for MeP, 0.30 for MeY and 0.42 for MI, all with high SE ( 0.23).

\subsubsection{Results of Genome Wide Association Studies}

Manhattan plots of the GWAS for DMI, WT, RGM, and RPM in the Angus population are shown in Fig. 4.1. A pairwise comparison between Manhattan plots of $-\log 10$ (p) of the GWAS for MeP, MeY, MI in Angus and in Holstein POP1 are presented in Fig. 4.2. There was no common pattern between the Manhattan plots of MeP, MeY and MI in Angus and Holstein POP1, because with the exception of chromosomes 12 and 26, it seems that there are different significant SNP explaining $\mathrm{CH}_{4}$ traits in each population. However, strong associations $(P<0.001)$ with MeP were found on chromosomes 2, 4, 12, 14, 20, and 30, and, those same chromosomes also had significant SNP for DMI in the Holstein population (POP2). 
Table 4.2 Estimated genetic $\left(\sigma^{2}{ }_{a}\right)$, phenotypic $\sigma_{p}^{2}$ ) variances, heritabilities (on diagonal) and genetic (above diagonal) and phenotypic correlations (below diagonal), with SE (in parenthesis) for methane production (MeP), methane yield (MeY), methane intensity (MI), residual phenotypic methane (RPM), residual genetic methane (RGM), DMI and weight at test (WT) in Angus population from a trivariate analysis using genomic relationship matrix.

\begin{tabular}{lccccccccc}
\hline Trait & $\sigma^{2}{ }_{a}$ & $\sigma^{2}{ }_{p}$ & MeP & MeY & MI & RPM & RGM & DMI & WT \\
\hline MeP & 49.7 & 166.9 & 0.30 & 0.62 & 0.18 & 0.65 & 0.55 & 0.83 & 0.80 \\
& & & $(0.06)$ & $(0.11)$ & $(0.16)$ & $(0.11)$ & $(0.14)$ & $(0.05)$ & $(0.06)$ \\
MeY & 0.4 & \multirow{2}{*}{1.8} & 0.69 & 0.20 & 0.86 & 0.88 & 0.97 & 0.08 & 0.05 \\
& & & $(0.02)$ & $(0.05)$ & $(0.05)$ & $(0.05)$ & $(0.02)$ & $(0.17)$ & $(0.17)$ \\
MI & $0.2^{-03}$ & $0.7^{-03}$ & 0.43 & 0.83 & 0.25 & 0.88 & 0.80 & -0.34 & -0.44 \\
& & & $(0.03)$ & $(0.01)$ & $(0.06)$ & $(0.05)$ & $(0.09)$ & $(0.15)$ & $(0.13)$ \\
\multirow{2}{*}{ RPM } & \multirow{2}{*}{12.9} & \multirow{2}{*}{84.7} & 0.71 & 0.84 & 0.84 & 0.19 & 0.98 & 0.04 & -0.01 \\
& & & $(0.02)$ & $(0.01)$ & $(0.01)$ & $(0.05)$ & $(0.02)$ & $(0.17)$ & $(0.17)$ \\
RGM & \multirow{2}{*}{11.8} & \multirow{2}{*}{96.7} & 0.62 & 0.94 & 0.69 & 0.94 & 0.15 & 0.00 & 0.00 \\
& & & $(0.02)$ & $(0.00)$ & $(0.02)$ & $(0.00)$ & $(0.05)$ & $(0.18)$ & $(0.18)$ \\
DMI & \multirow{2}{*}{0.1} & 0.2 & 0.70 & 0.00 & -0.21 & 0.00 & -0.10 & 0.39 & 0.98 \\
& & & $(0.02)$ & $(0.03)$ & $(0.03)$ & $(0.04)$ & $(0.03)$ & $(0.06)$ & $(0.01)$ \\
WT & 415.4 & \multirow{2}{*}{1010.6} & 0.67 & 0.04 & -0.33 & 0.00 & 0.03 & 0.93 & 0.41 \\
& & & $(0.02)$ & $(0.03)$ & $(0.03)$ & $(0.04)$ & $(0.03)$ & $(0.01)$ & $(0.06)$ \\
\hline
\end{tabular}

Furthermore, the patterns of the peaks in the Manhattan plots for MeP (mainly in chromosomes 4,12 and 14) are more closely related to DMI and WT, than to the residual methane traits (RPM and RGM), which is understandable given that by definition RPM and RGM are adjusted for DMI and WT. Figure 4.3 shows Manhattan plots per chromosome for the 5 chromosomes with most significant SNP (chromosomes 4, 12, 14, 20, and 30) for MeP in the Angus population and for DMI in Holstein POP2. Chromosomes 4 and 14 had a similar pattern for MeP in Angus and DMI in Holstein POP2.

The FDR for Angus traits ranged from 0.74 to 0.97 at $P<0.001$, being 0.78 for MeP, so as result it can be deduced that only $22 \%$ of significant SNP were truly associated with MeP, which is approximately 176 SNP. However, the FDR for Angus traits (excluding RPM and RGM) at $P<0.005$ ranged between 0.93 and 0.96 , being for MeP 0.95, resulting on 165 significant SNP that could be considered as having true associations. For Holstein POP1, the FDR at $\mathrm{P}<0.001$ for MeY was 0.52 and for MI 0.71, meaning there were approximately 583 and 259 SNP that were true findings, respectively, and at $\mathrm{P}<0.005$ for $\mathrm{MeY}$ was 0.72 and for $\mathrm{MI} 0.80$, representing 1231 and 786 SNP. 


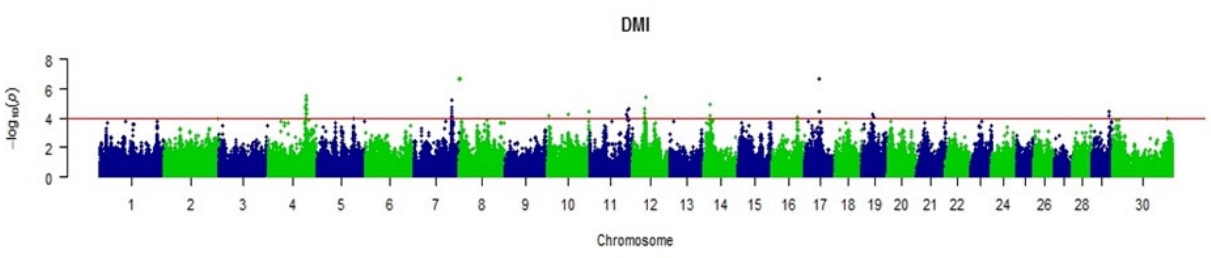

WT

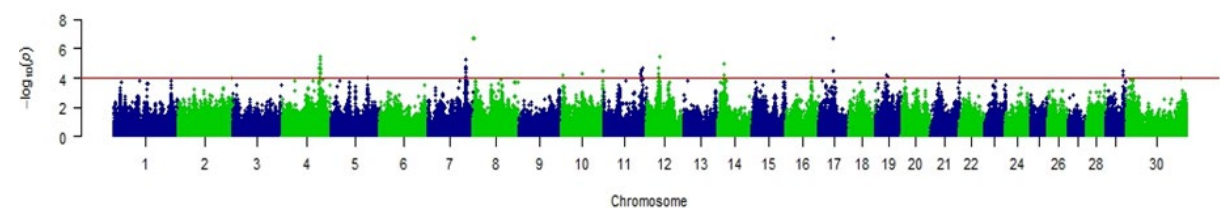

RGM

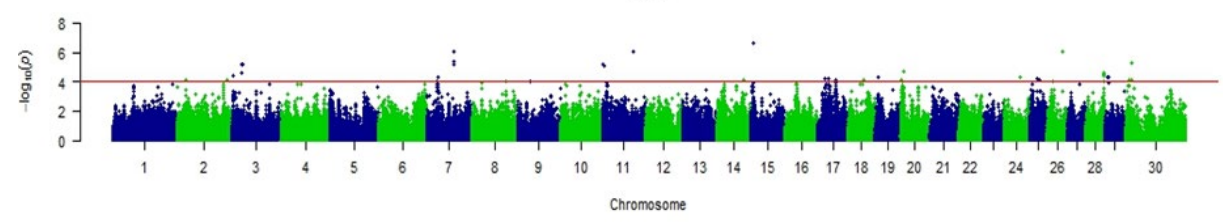

RPM

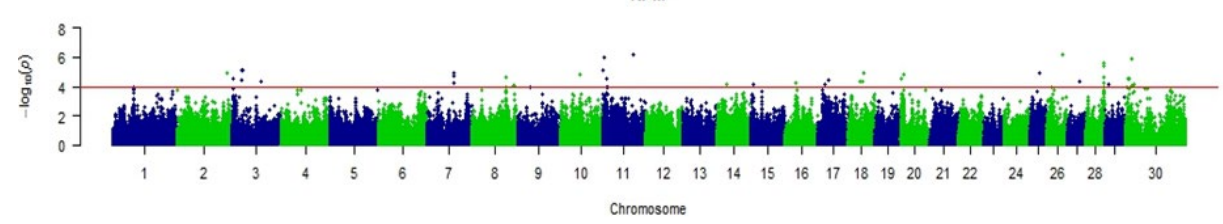

Figure 4.1 Manhattan plots $\left(-\log _{10}(P)\right.$ genome wide association plot) of a genome wide association on DMI, weight at test (WT), residual genetic methane (RGM), and residual phenotypic methane (RPM) in Angus population. The genome wide significance level is set at $10 \times 10^{-5}$ and plotted as the red line.

\subsubsection{Validation}

In Table 4.3, both sets of significant SNP ( $P<0.001$ and 0.005$)$ for all the traits analyzed (MeP, MeY, MI, RGM, RPM, DMI, WT in Angus, MeP, MeY and MI in Holstein POP1, DMI and WT in Holstein POP2) are presented. Also shown (Table 4.3) are the significant SNP in common from a pairwise comparison ( $X^{2}$ test) between all the traits. For example, the number of significant SNP $(P<0.001)$ for MeP was 803 in the Angus population and 568 in Holstein POP2, whereas the number of significant SNP at $P<0.005$ was 3304 in Angus and 2762 in the Holstein 
MeP Angus

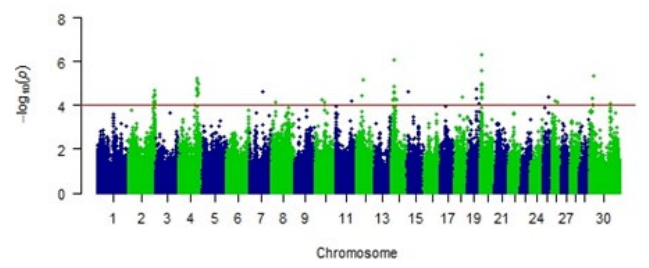

MeY Angus

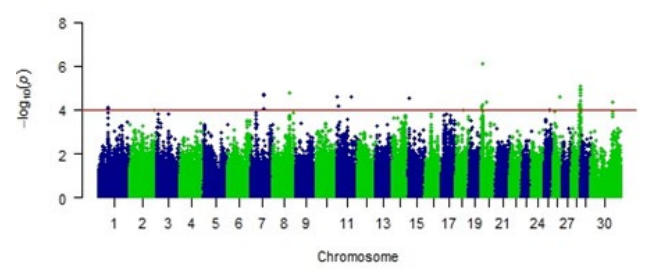

MI Angus

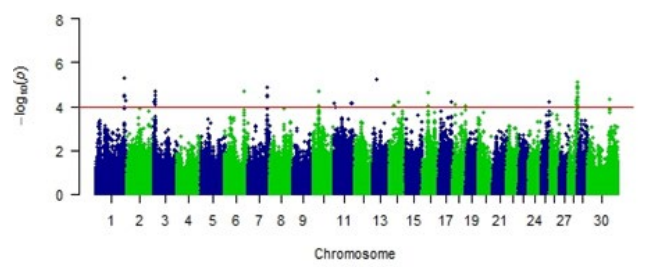

MeP Holstein POP1

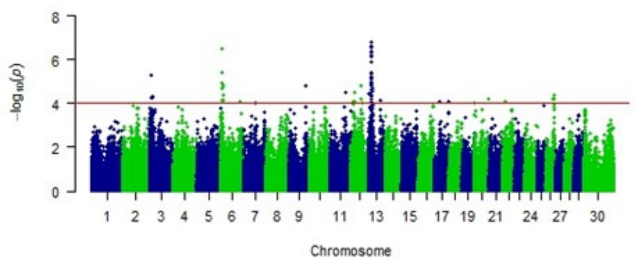

MeY Holstein POP1

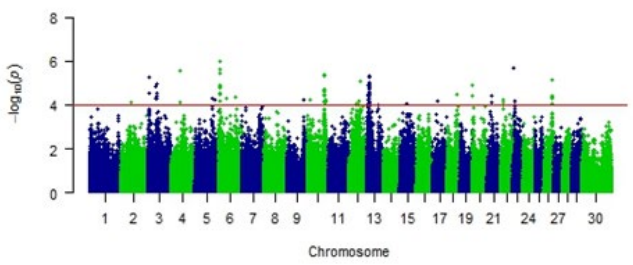

MI Holstein POP1

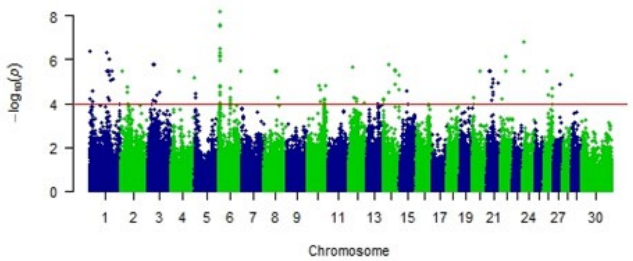

Figure 4.2 Pairwise comparison Manhattan plots $\left(-\log _{10}(P)\right.$ genome wide association plot) of a genome wide association on methane production (MeP), methane yield (MeP), methane intensity (MI) in Angus and Holstein POP1. The genome wide significance level is set at $10 \times$ $10^{-5}$ and plotted as the red line.

POP2. The number of significant SNP at $P<0.001$ for MeY in Holstein POP1 (1216) was twice MeY in Angus (557), likewise, at $P<0.005$ were 4397 significant SNP and in Angus only 2880. Furthermore, the number of significant SNP at $P<0.001$ for DMI in the Angus population was lower (851) than in Holstein POP1 (1796); a similar pattern was observed for WT, with 844 in the Angus population and 1447 in Holstein POP1. Dry matter intake had the highest number (633) of significant SNP $(P<0.005)$ in common with MeP (in Angus), whereas MI had only 138 SNP in common. The number of SNP that were the same for MeP and DMI in Angus were 22 and there were 27 between MeP and WT at $\mathrm{P}<0.005$. Between $\mathrm{CH}_{4}$ traits in the Angus population and $\mathrm{CH}_{4}$ traits in Holstein POP2, the number of SNP in common ranged between 21 and 23 (Table 4.3). The number of SNP in common obtained 
from the $\mathrm{X}^{2}$ test (for all traits) was equal to the number of SNP obtained when significant SNP in the Angus population were used to validate them in Holstein POP1 through the GWAS. This implies that the $X^{2}$ and the GWAS validation show similar results, not just in terms of number of SNP, but also for the SNP identified.

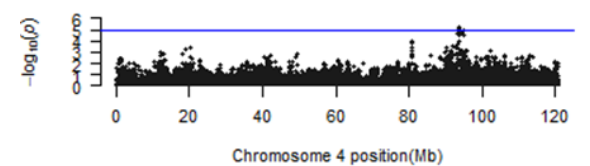

Chromosome 4 position(Mb)
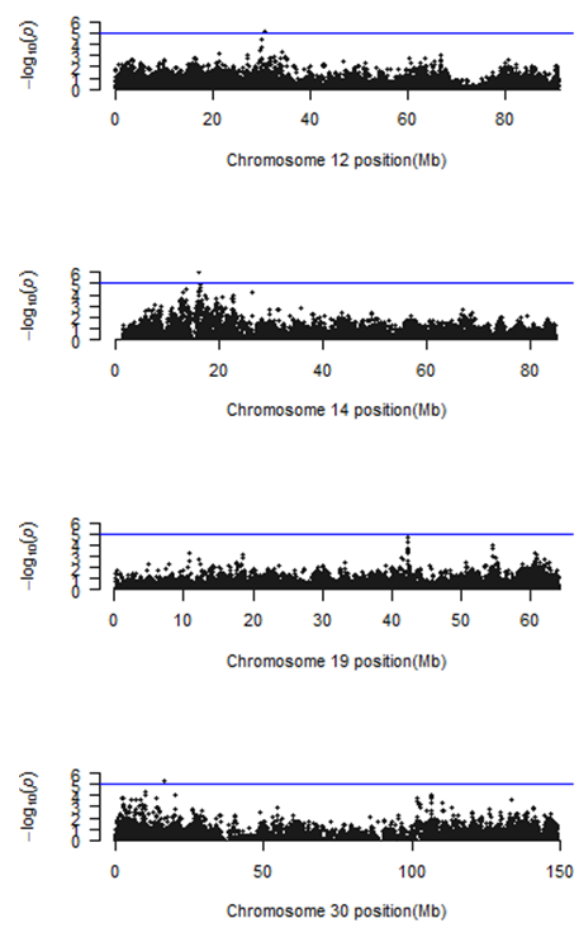
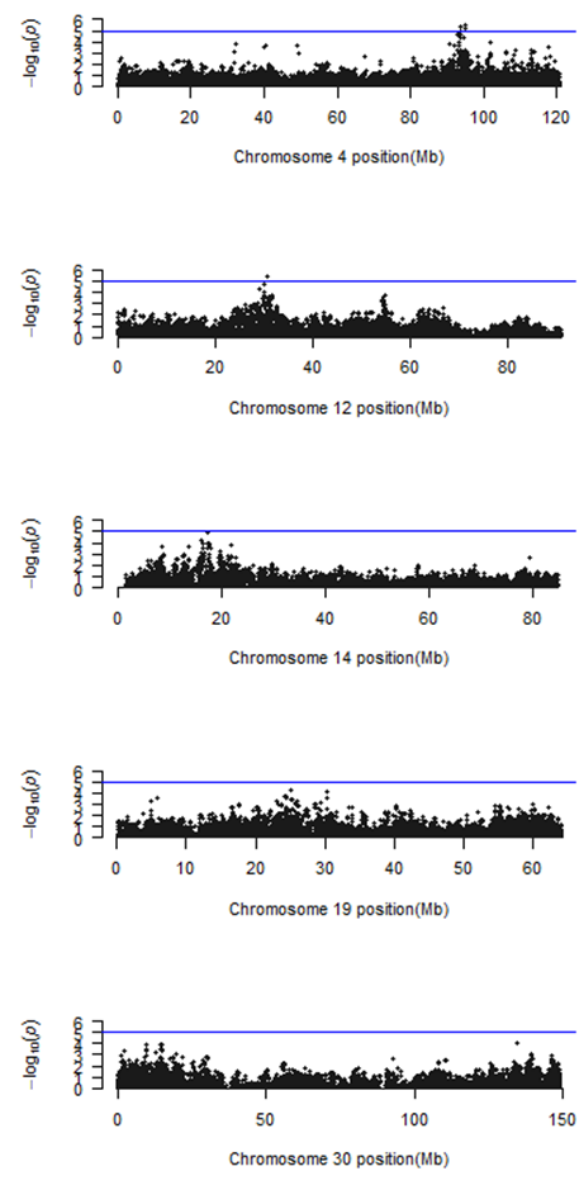

Figure 4.3 Pairwise comparison Manhattan plots for chromosomes 4, 12, 14, 19, and 30 $\left(-\log _{10}(P)\right.$ genome wide association plot) of a genome wide association on methane production (MeP in Angus population, left) and DMI in Holstein POP2 (right). The genome wide significance level is set at $1 \times 10^{-5}$ and plotted as a line. 
Table 4.4 Genetic $\left(\sigma^{2}{ }_{\mathrm{a}}\right)$, residual $\left(\sigma^{2} \mathrm{e}\right)$, and phenotypic variances $\left(\sigma_{\mathrm{p}}{ }_{\mathrm{p}}\right), \mathrm{h}^{2}$, SE of heritabilities and log likelihood for methane production, methane yield and methane intensity in Holstein POP1 at different models including the model with the genomic relationship matrix (GRM) with all the SNP from dairy cattle (gAll; base model) and different GRM built with different subsets of significant SNP $(P<0.005)$ from HD genotypes for methane production (gMeP), $\mathrm{DMI}$ (gDMI) and weight at test (gWT) in Angus population and gMeP and gWT in Holstein POP2.

\begin{tabular}{|c|c|c|c|c|c|c|c|}
\hline GRM based on & Model & \#SNP & Log likelihood & $\sigma_{a}^{2}$ & $\sigma_{e}^{2}$ & $h^{2}$ & SE \\
\hline & & \multicolumn{6}{|c|}{ Methane Production (MeP) } \\
\hline & gAll & 632,003 & -938.80 & 567.9 & 4134.2 & 0.12 & 0.18 \\
\hline & gMeP & 3304 & -938.90 & 299.85 & 4412.68 & 0.06 & 0.12 \\
\hline \multirow[t]{2}{*}{ Angus } & gDMI & 3364 & -938.54 & 594.8 & 4111.2 & 0.13 & 0.13 \\
\hline & gWT & 3284 & -938.05 & 804.8 & 3892.5 & 0.17 & 0.13 \\
\hline Holstein & gDMI & 6559 & -937.57 & 552.5 & 4090.1 & 0.12 & 0.10 \\
\hline \multirow[t]{4}{*}{ POP2 } & gWT & 6139 & -938.18 & 361.5 & 4307.8 & 0.08 & 0.08 \\
\hline & & \multicolumn{6}{|c|}{ Methane yield (MeY) } \\
\hline & gAll & 632,003 & -295.48 & 1.84 & 4.38 & 0.30 & 0.22 \\
\hline & gMeP & 3304 & -295.79 & 1.04 & 5.22 & 0.17 & 0.14 \\
\hline \multirow[t]{2}{*}{ Angus } & gDMI & 3364 & -293.49 & 2.27 & 4.00 & 0.36 & 0.16 \\
\hline & gWT & 3284 & -293.52 & 2.05 & 4.18 & 0.33 & 0.15 \\
\hline Holstein & gDMI & 6559 & -296.55 & 0.03 & 6.25 & 0.00 & 0.08 \\
\hline \multirow[t]{4}{*}{ POP2 } & gWT & 6139 & -296.55 & 0.04 & 6.24 & 0.01 & 0.07 \\
\hline & & \multicolumn{6}{|c|}{ Methane intensity (MI) } \\
\hline & gAll & 632,003 & -325.69 & 2.23 & 6.37 & 0.26 & 0.14 \\
\hline & gMeP & 3304 & -327.10 & 1.48 & 7.17 & 0.17 & 0.15 \\
\hline \multirow[t]{2}{*}{ Angus } & gDMI & 3364 & -325.97 & 2.11 & 6.49 & 0.24 & 0.15 \\
\hline & gWT & 3284 & -325.69 & 2.23 & 6.37 & 0.26 & 0.14 \\
\hline Holstein & gDMI & 6559 & -327.64 & 0.00 & 8.65 & 0.00 & 0.00 \\
\hline POP2 & gWT & 6139 & -327.64 & 0.00 & 8.65 & 0.00 & 0.00 \\
\hline
\end{tabular}

Only results of the validation of Angus SNP (for MeP, DMI and WT at P < 0.005,) in Holstein POP1traits (MeP, MeY and MI) are presented in Table 4.4 together with results from the validation of Holstein POP2 (for DMI and WT) in Holstein POP1, compared with a base model with all the SNP $(632,003)$. When a set of significant SNP from DMI and WT in Angus was used to estimate genetic parameters for $\mathrm{MeP}$ and $\mathrm{MeY}$, the genetic variance increased slightly which 
coincided with a decrease in residual variance. Together these changes in variance estimates resulted in a small increase in the heritability of those traits, compared with the base scenario using all the SNP. However, the reduction in the log likelihood was not significant using this model (< 1 for MeP and 1 for MeY) according to the AIC test. Also, when significant SNP from DMI in Holstein POP2 were used to estimate genetic parameters for MeP, the log likelihood decreased slightly, together with a reduction in all variances, despite the lower SE, the heritability remained the same. However, the number of significant SNP $(\sim 6,500)$ in Holstein POP2 traits, which was used to calculate the GRM was twice the number of SNP $(\sim 3,300)$ in Angus traits.

\subsection{Discussion}

There has been substantial effort from the livestock scientific community in the last decade to reduce $\mathrm{CH}_{4}$ emissions, encompassing different scientific disciplines, such as animal nutrition, physiology, management, and genetics (Alford et al., 2006 ; Hegarty et al., 2007; de Haas et al., 2011; Waghorn and Hegarty, 2011; Garnsworthy et al., 2012; Ross et al., 2013). Several different methodologies and devices to measure $\mathrm{CH}_{4}$ emissions are respiration chambers, sulfur hexafluoride tracer technique, laser methane detector, a micrometeorological technique and more recently mid infrared data obtained from milk samples (Link et al., 2005; Pinares-Patiño et al., 2008; Chagunda et al., 2009; Herd et al, 2014a; Laubach et al., 2014). In cattle, few genetic studies have been published that analyze direct $\mathrm{CH}_{4}$ emissions (Hayes et al., 2016; Lassen and Lovendahl, 2016), which is mainly because most datasets on these phenotypes are currently small in size. However, there are some studies that have predicted methane emissions, either from milk yield and feed intake, or from milk fatty acids and Methyl-coenzyme M (de Haas et al., 2011; Aguinaga Casañas et al., 2015; Pickering et al. 2015; van Engelen et al., 2015; Yin et al., 2015). In sheep, however, there are several published genetic analyses of $\mathrm{CH}_{4}$ (Pinares-Patiño et al., 2013; Robinson et al., 2014), which is likely to be because the animals are easier to handle and it is therefore easier to gather $\mathrm{CH}_{4}$ phenotypes. The heritability of $\mathrm{CH}_{4}$ in sheep is comparable with heritability estimates in cattle in the current study ( 0.29 and 0.30 respectively).

The results of this paper can help improve our understanding of the genetic control of $\mathrm{CH}_{4}$ traits in beef and dairy cattle, and also help to decide on the best selection criteria for $\mathrm{CH}_{4}$. We can conclude that there is genetic variation in 


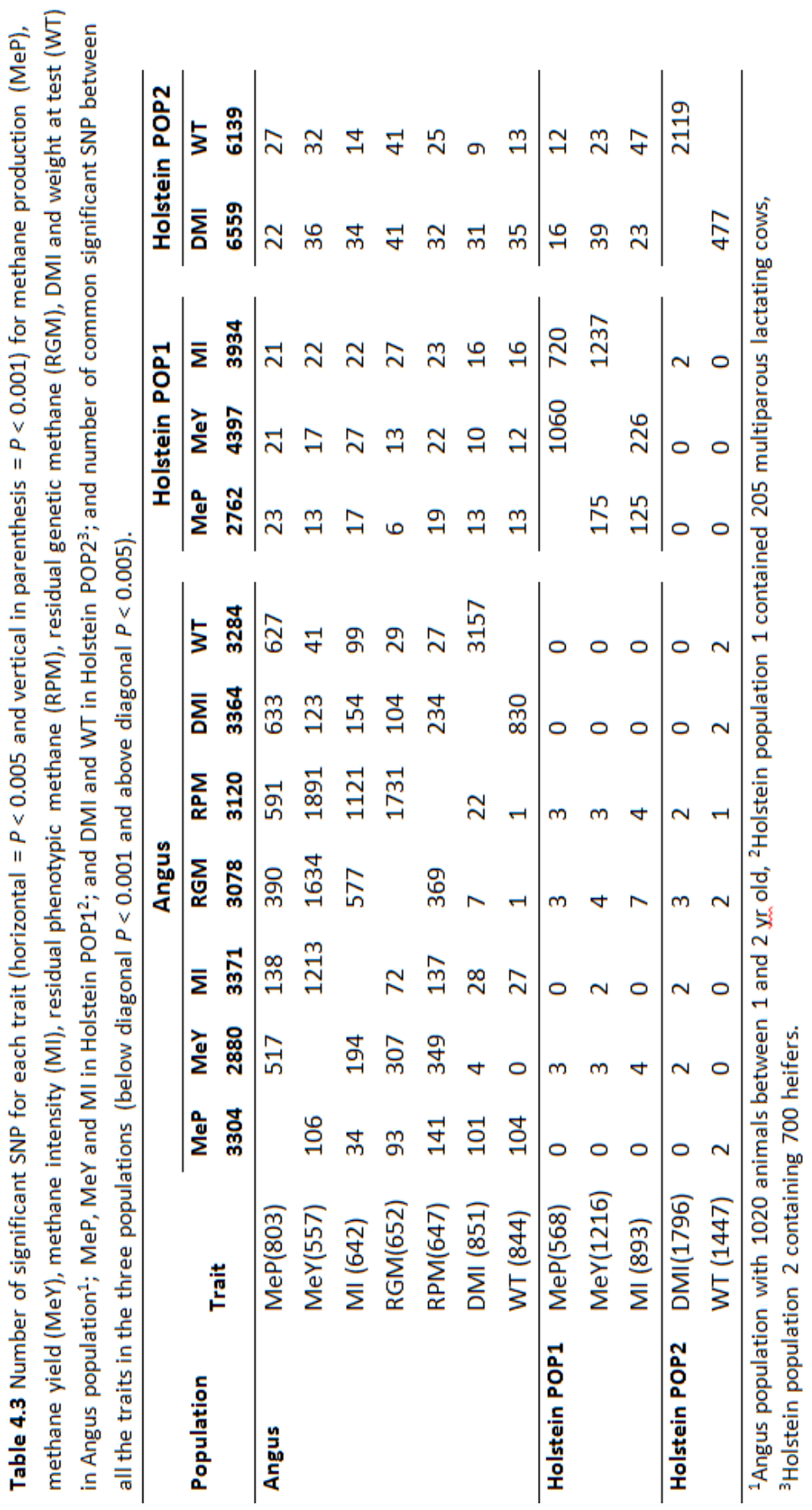


$\mathrm{CH}_{4}$ traits that can be exploited to select for reduced $\mathrm{CH}_{4}$ and to lower the greenhouse gases produced in cattle production systems. In the case of the residual traits, we have quantified the proportion of variation that is independent of DMI and WT, showing zero genetic and phenotypic correlations with these traits. Some chromosomes were identified that can be associated with direct $\mathrm{CH}_{4}$ traits, but they were not the same chromosomes that were identified for the residual $\mathrm{CH}_{4}$ traits. Moreover, the number of significant SNP that were in common between Angus and Holstein populations show that $\mathrm{CH}_{4}$ traits are different traits in beef and dairy cattle, probably due to several reasons, including purpose of the animal (beef or dairy), the age or stage (growing or lactating) and the method used to measure $\mathrm{CH}_{4}$ (respiration chamber or $\mathrm{SF}_{6}$ ). Furthermore, there are obviously limitations in accurately identifying the underlying genetic control in lactating Holsteins, due to the small size of Holstein POP1. However, the main focus of this paper was $\mathrm{CH}_{4}$ traits in Angus cattle, the role of Holstein populations (POP1 and POP2) were mainly used to validate SNP. Moreover, given the difficulty in obtaining $\mathrm{CH}_{4}$ records and the rarity of genetic parameters in the literature, the values and parameters presented in this paper should be considered as a preliminary values for $\mathrm{CH}_{4}$ traits in multiparous lactating Holstein cows.

\subsubsection{Descriptive Statistics}

The means of MeP and $\mathrm{MeY}$ in both populations were different, being $132.6 \mathrm{~g} / \mathrm{d}$ (SD 25.5) and $21.9 \mathrm{~g} / \mathrm{kg}$ (SD 2.3) DMI in Angus and $110.5 \mathrm{~g} / \mathrm{d}$ (SD 33.9) and 17.5 (SD 3.0) in Holstein POP1. The CV for MeP in Angus was 0.19 whereas in Holstein POP1 was 0.31, for MeY in Angus was 0.10 and 0.17 in Holstein. Those differences can be explained by several reasons, for example, the animals in these 2 populations were from different breeds that varied in weight and feeding behavior, which could affect the means estimated (Duthie et al., 2015). Furthermore, the Holstein animals were lactating multiparous cows, whereas, the Angus were growing animals; and the population of Angus was a mixed gender population, as opposed to the Holstein populations that were only females. Additionally, the ration composition of each group could have an impact on the means of methane in Angus and Holstein (Martin et al., 2010), while Angus were offered commercial alfalfa and oaten hay chaff, Holsteins were fed alfalfa supplement and crushed wheat. Also, it is possible that there were some breed by diet interactions in voluntary intake, feed intake and $\mathrm{CH}_{4}$ emissions as Moorby et al. (2015) reported in sheep. Finally, despite these shortcomings, the concordance correlation coefficient between $\mathrm{CH}_{4}$ emissions from the $\mathrm{SF}_{6}$ and the respiration chambers is reported to be 0.83 (Deighton et al., 2013), they mentioned in their 
study that the mean $\mathrm{CH}_{4}$ determined via the two techniques did not differ $(\mathrm{P}=$ 0.265). However, the measurements from the $\mathrm{SF}_{6}$ tracer technique were generally numerically greater than those from the respiration chambers.

Both MeP means (Angus and Holstein POP1) were lower than the ones (180.2 g/d [SD 46.9]) reported by Pickering et al. (2015) and the ones (187 g/d [SD 38]) presented by Herd et al. (2014b). Even though the latter were part of the data from this study, the additional $\sim 300$ animals added to the data since this study could have affected the mean. The means (21.3 to 23.6) reported by van Engelen et al. (2015) for predicted $\mathrm{MeY}$ in Dutch Holstein (defined as $\mathrm{g}$ of $\mathrm{CH} / \mathrm{kg}$ of DMI) were larger than the means for $\mathrm{MeY}(17.5 \mathrm{~g} / \mathrm{d})$ in Australian Holstein. Analyzing the descriptive statistics of RGM, $10 \%$ of the data seemed to be outliers of the normal distribution (i.e., > 4 SD from the mean), however due to the size of the population, they were not removed.

\subsubsection{Genetic Parameters}

The estimated heritabilities for methane traits (MeP, MeY, MI, RPM and RGM) were in agreement $(0.30,0.20,0.25,0.19$ and 0.15$)$ with the heritabilities reported for predicted methane that ranged between 0.12 to 0.44 (de Haas et al., 2011, Pickering et al. (2015), van Engelen et al., 2015). This showed that $\mathrm{CH}_{4}$ is a moderately heritable trait that can be selected for. Pickering et al. (2015) reported, however, lower heritabilities for $\mathrm{CH}_{4}$ recorded with a Laser Methane Detector (0.05 with [SE 0.07]) using a very small data set (57 animals) of dairy cows. In sheep, Pinares-Patiño et al. (2013) reported a heritability of 0.29 for $\mathrm{CH}_{4}$, and 0.13 for $\mathrm{MeY}$, with a repeatability of 0.55 with two records measured $14 \mathrm{~d}$ apart. Given the variation in $\mathrm{CH}_{4}$, as with DMI and WT, it is preferable to have repeated records to determine the repeatability of $\mathrm{CH}_{4}$ in cattle, which could then be taken into account when it is included in the breeding goal (Manzanilla Pech et al., 2014). Finally, the estimated heritability for MeP in Holsteins was lower (0.23) than in the Angus population, whereas MeY was similar (0.30) and $\mathrm{MI}$ was the highest one at 0.42 , but all of them were associated with high SE due to the small amount of records available, and should be interpreted with caution.

The genetic correlation between MeP and DMI was slightly higher $(0.83$ [SE 0.05]) than the genetic correlation between MeP and WT (0.80 [SE 0.06]). This comparatively high correlation makes it difficult to disentangle what part of MeP variance is actually related to $\mathrm{CH}_{4}$ and what part is masking DMI and WT. As Basarab et al. (2013) stated, a large DMI leads to higher $\mathrm{CH}_{4}$ because more substrate is available in the rumen for fermentation, and also more hydrogen is available for methanogens. They also reported lower but moderated correlations 
between $\mathrm{CH}_{4}$ and DMI from an analysis of Australian (0.45) and Canadian (0.68) data.

Given the high positive correlation between MeP and DMI, and between MeP and WT, it seems to be important to have a trait that is still highly correlated with MeP but has zero (or close to zero) genetic correlation with DMI and WT. One alternative could be RGM, as it has zero genetic correlation with DMI and WT and low (-0.10 and 0.03 , respectively) phenotypic correlations. A similar case is seen for RPM, with zero phenotypic correlations with DMI and WT, and small genetic correlations of 0.04 and -0.01 , respectively. Moreover, both traits, RGM and RPM have high-moderate genetic and phenotypic correlations with MeP ranging between 0.55 and 0.71 . Therefore, residual methane traits could be a better option than $\mathrm{CH}_{4}$ to include in the breeding goal to select for lower emitting animals without affecting DMI and WT.

The ratio methane traits ( $\mathrm{MeY}$ and $\mathrm{MI}$ ) presented a moderate to low positive genetic correlation with MeP (0.65 and 0.18), high positive genetic correlations with RPM (0.88) and RGM (0.97 and 0.80). Whereas, MeY and MI had low positive to moderate negative genetic correlations with DMI (0.08 and -0.34) and WT (0.05 and -0.44). This would make it difficult to select for those traits without affecting DMI and WT.

\subsubsection{Are Dry Matter Intake and Weight Genes Affecting Methane Emissions?}

Based on the results of the GWAS, DMI and WT seem to be closely related traits, sharing between 94 and $96 \%$ of the total of number of significant SNP in each trait. Additionally, both traits shared around 19\% of significant SNP with MeP, mainly on chromosome 4,12 , and 14 . In contrast, RGM just shared $3 \%$ of the significant SNP with DMI and less than $1 \%$ with WT, whereas, RPM had $7 \%$ and less than $1 \%$ with DMI and WT, respectively. As expected, RGM and RPM are traits that are more independent of DMI and WT than MeP. The number of SNP in common between RGM and RPM was $\sim 55 \%$ of the total number of SNP for each trait, RPM and RPM were adjusted for DMI and WT phenotypically and genetically respectively and so they are different traits.

The above led us to the question: what SNP are affecting MeP? And the most likely answer is that the same SNP as in DMI and WT affect MeP, based on the high genetic correlations between those traits and the results of the GWAS (Table 4.3). High phenotypic and genetic correlations between $\mathrm{DMI}$ and $\mathrm{CH}_{4}$ have previously reported by de Haas et al. (2011). Pickering et al. (2015) reported 
genetic correlations of 1.00 between predicted methane emissions and DMI and 0.84 with LW.

There were SNP with significant associations for MeP on chromosomes 4, 14, and 20 in Angus and these have also been reported previously in literature for correlated traits. For example, chromosome 4 is associated with average daily feed intake, ADG and RFI (Lindholm-Perry et al., 2012). Chromosome 14 is associated with carcass weight, RFI, post weaning weight and post weaning hip height. Chromosome 20 is associated with weight (Bolormaa et al., 2013). Chromosomes 6, 9, 13, and 26, had SNP that were significant for MeP in Holstein POP1, were reported to be related to post weaning weight and hip height (chromosome 6), with intramuscular fat in beef cattle (chromosome 9; Bolormaa et al. 2013), and with predicted enteric methane emissions in Holsteins (chromosomes 13 and 26; de Haas et al. (2011).

\subsubsection{Single Nucleotide Polymorphisms in Common for Methane Production Between Angus and Holstein}

The number of significant SNP in common between Angus and Holstein populations has illustrated that the genes that control a $\mathrm{CH}_{4}$ trait in beef are not the same as genes that control the equivalent trait in dairy. But more interesting is the fact that the genes in common between $\mathrm{CH}_{4}$ traits and DMI-WT in the two populations of Holstein were also scarce. That can be due to the difference in physiological stage of those two groups (multiparous cows in Holstein POP1 and growing heifers in Holstein POP2) with different energy demands, also related to intake requirements associated with lactation number, correlated with methane production based on diet and animal characteristics (Mangino et al., 2003; Dong et al., 2006), which might affect the $\mathrm{CH}_{4}$ emissions. Finally, it can be also related to the small dataset available for Holstein POP1 that also leads to uncertainty about which SNP are affecting LW and WT in Holstein. Furthermore, the patterns in the Manhattan plots showed that MeP, MeY and $\mathrm{MI}$ are probably not the same traits in Angus and in Holstein, as the most significant SNP were found on different chromosomes in those populations; chromosome 3, 6, and 13 being the most important in Holstein POP1, and chromosomes 12, 14, and 20 are highly important in Angus. This is also likely to be related to the small size of the population in Holstein POP1, and that could be one of the reasons why the same significant SNP were not found in Angus and in Holstein POP1. Therefore, the reader should treat the Manhattan plots for the Holstein POP1 as preliminary.

Results from the validation of significant SNP in DMI and WT from Holstein POP2 in the estimation of genetic parameters for MeP, DMI and WT in Angus 
population were not shown in this study due to their poor performance in all seven scenarios, picking up less than a quarter of the genetic variance and having extremely low heritabilities. This can be explained because the animals were at different stages (lactating multiparous cows in Holstein POP2 versus growing animals in Angus). It has been argued that the age of the animal at measurement can substantially affect phenotypes for methane traits which in turn affects genetic parameter estimation (Hayes et al., 2016; Khansefid et al., 2014). In contrast, when significant SNP in for DMI and WT from Angus were used to build the GRM matrix for calculating genetic parameters in Holstein POP1, the results were encouraging for some traits (MeP and $\mathrm{MeY}$, but not for $\mathrm{MI}$ ), showing that significant SNP for DMI and WT (separately) in Angus can explain most of the variation for MeP and $\mathrm{MeY}$ in Holsteins. Similar results were obtained using significant SNP for DMI in Holstein POP2 to validate in MeP in Holstein POP1, but not for MeY or MI. The estimated genetic variances and heritabilities for MeP in Holstein POP1 using a subset of SNP $(\sim 3,300)$ that were significant for DMI or WT in Angus or DMI in Holstein POP2 ( 6500) were similar to the results obtained using all the SNP $(632,003$; base model). That is also the case when significant SNP for DMI and WT in Angus were used to calculate MeY and MI in Holstein POP1, but not for DMI and WT in Holstein POP2. Despite this finding, the log likelihood tests comparing the models were not significant, leading us to conclude that using only significant SNP is no better than the base model. Based on the increase of the estimated heritabilities (with respective decrease in the SE) and the increase in the log likelihood in the gDMI and the gWT models, compared to the gAll model, we can however conclude that the significant SNP for DMI and WT in Angus cattle are also predictive for MeP and MeY. In this model, $100 \%$ of the genetic variance in MeP in Holstein is captured by only a subset of significant SNP (in Angus). This was not the case for MI, where none of the alternative models (made of subsets of significant SNP in Angus) performed any better than the model using all the 632,003 SNP. However, it should be acknowledged that using only the set of significant SNP in DMI and WT, those traits (MeP and MeY) in Holstein can be overestimated. Similarly, Khansefid et al. (2014) suggested that constructing a GRM for dairy using SNP that are significant in beef is possible, and it can be used as a method to combine information from both sources and increase the accuracies of GEBV. Moreover, we should be cautious in drawing concrete conclusions when using subsets of SNP, except when repeated SNP selection has been done. 


\subsubsection{Methane Emissions: Raw Traits, Ratio Traits or Residual Traits?}

Many ways of defining methane for breeding and management purposes have been proposed, e.g., MeP, MeY, MI, predicted methane, and some residual methane traits. Here, we will discuss the benefits of using residual traits instead of raw (pure) $\mathrm{CH}_{4}$ traits (residual methane vs. methane production) for genetic improvement programs.

The concept of residual traits has been used since RFI and residual daily gain (RDG) were introduced by Koch et al. (1963). Residual feed intake was defined as the difference between actual and predicted feed intake, taking into account variability in growth and maintenance requirement, whereas RDG was the daily gain adjusted by feed. The idea is to have feed adjusted for gain, and gain adjusted for feed, as indicator traits of feed efficiency. In our case, RGM and RPM are proposed as alternative ways to quantify $\mathrm{CH}_{4}$, adjusted genetically (RGM) or phenotypically (RPM) for DMI and WT simultaneously. Due to the high correlation between $\mathrm{CH}_{4}$, DMI and WT in ruminants (Hegarty et al., 2007; Moorby et al., 2015), adjusting DMI and WT isolated the genetic variation of $\mathrm{CH}_{4}$ due to the physiology of the animal, identifying the lower emitting animals from the rest. Thus, one of the objectives of this paper was to evaluate two different residual methane traits and its independence with DMI and WT, and determine if the genes identified to be associated with MeP are also the ones controlling RGM and RPM.

The main advantage of the residual methane traits calculated with the methodology of Kennedy et al. (1993) is that they have zero genetic (RGM) and phenotypic (RPM) correlation with the regressors (DMI and WT). Consequently, the genetic variance and the SNP associated with genes (by GWAS) are not attributable to DMI and WT. However, as Berry and Crowley (2013) stated, the variance is not necessary representing the true trait, this can be due in part to random noise, measurement and prediction error, inaccurate recording, feed losses, or bias in the regression coefficients of the regressors. Direct measurements of $\mathrm{CH}_{4}$ production are more variable, difficult to measure and expensive than DMI measures, especially when respiration chambers are used (Basarab et al., 2013), and they should be expressed as $\mathrm{CH}_{4}$ production ( $\mathrm{g} / \mathrm{d}$ ) adjusted for body size, growth, body composition and DMI or as residual $\mathrm{CH}_{4}$ production.

We analyzed two ratio traits, MeY defined as $\mathrm{CH}_{4}$ production per unit of DMI, and $\mathrm{MI}$ defined as $\mathrm{CH}_{4}$ production per unit of WT in beef and as $\mathrm{CH}_{4}$ production per unit of milk produced in dairy. Methane intensity is a metric often used to assess the amount of methane produced per unit livestock production (Alcock and Hegarty, 2011), whereas, MeY is the amount of $\mathrm{CH}_{4}$ produced per unit 
of input (DMI; Donoghue et al., 2013, Herd et al., 2014a). Those two traits (MeY and $\mathrm{MI}$ ) are expressed as ratios of two component traits while the residual traits are linear indices of three traits. One of the advantages of the ratio traits ( $\mathrm{MeY}$ and $\mathrm{MI}$ ) is the easy calculation and understanding of the trait, but some of the disadvantages are the strong correlation with the denominator trait (in this case DMI and WT), and the difficult interpretation of the selection response because the antagonism between the response in the numerator and the denominator (Berry and Crowley, 2013). Another disadvantage of the use of ratio traits can be problems relating to prediction of the change in the component traits in future generations, due to the selection pressure on the component traits (Arthur et al., 2001). For MI in Angus, the negative correlation with DMI and WT makes it difficult to select for MI without reducing DMI and WT. However, MeY in Angus does not seems to have that limiting factor, given that the genetic correlation with DMI and WT was slightly positive but closer to zero. An interesting observation is the high positive genetic correlation between the ratio methane traits ( $\mathrm{MeY}$ and $\mathrm{MI}$ ) in Angus with the residual methane traits (RPM and RGM; ranging between 0.80 to 0.97 for genetic and from 0.69 to 0.94 for genetic). That could be explained as both (ratio methane traits and residual methane traits) are corrected for DMI and WT (one dividing and the other adjusting by regression).

In trying to answer the question of which type of $\mathrm{CH}_{4}$ trait is best to include in the breeding goal, we analyzed several options: raw traits, residual traits and ratio traits. One important factor is which other traits will be included in the breeding goal. Given that if the component traits (in this case DMI and WT) are already in the breeding goal, it is easier to give them some weight, and the result can be equivalent to include one residual trait (RGM or RPM) that has been adjusted for them previously. However, in considering EBV, it is much easier to understand the EBV for RGM or RPM where negative numbers represent animals than produce less methane than expected. In contrast, for MeP, where an animal with a lower value does not necessarily produce less $\mathrm{CH}_{4}$ than an animal with higher numbers, given that animals producing more milk/meat would have larger associated emissions. Furthermore, according to Arthur et al. (2001), in a linear index the selection, pressure is placed on all the traits and it results in a predictable amount of genetic change. In contrast, to select for animals with lower RGM or RPM can mask in the future to select for some animals with physiological (maybe producing less methane because the poor microbiome) or reproductive problems. Another disadvantage, is that not all animals have DMI or WT (or just one measure in life) and this can be a limit the calculation of RGM and RPM and also MeY and MI. The ideal scenario should be to have repeated measures (MeP, DMI and WT) to 
be able to estimate better residual $\mathrm{CH}_{4}$ through lactation and across lactations, taking into account the stage of the animal, and calculating the repeatability of the trait. This case is similar to what has been happening with feed intake, where it is not a common agreement whether to use residual feed intake (RFI) or DMI (Berry and Crowley, 2013).

We conclude that MeP is a trait that is mainly dependent on DMI and WT based on the results of this study (GWAS results and genetic parameters). Thus, assuming that DMI and WT records are available, residual methane traits (RGM and RPM) seem to be a better choice than ratio traits (MeY or MI) to include in the breeding goal. However, MeP could also be considered as an option to include in the breeding goal if DMI and WT are also included. Finally, there is not a unique solution to reduce $\mathrm{CH}_{4}$ emissions in cattle production systems, and it should be the combined effort of all the disciplines (i.e., genetics, nutrition, management, physiology; Knapp et al., 2014).

\subsection{Acknowledgements}

EU FP7 IRSES SEQSEL (Grant No. 317697) funded the research stay of the first author in Victoria, Australia, where this research was done. Special thanks to the National Council on Science and Technology of Mexico (CONACYT, Mexico) for its financial support for a PhD-study at Wageningen University, and to the National Research Institute of Forestry, Agriculture and Livestock (INIFAP, Mexico) to promote the professional development of their researchers. Mario Calus (Wageningen UR Livestock Research, Wageningen, the Netherlands) is kindly acknowledged for their helpful comments on this paper. 


\subsection{References}

Aguinaga Casanas, M. A., N. Rangkasenee, N. Krattenmacher, G. Thaller, C. C. Metges, and B. Kuhla. 2015. Methyl-coenzyme $\mathrm{M}$ reductase $\mathrm{A}$ as an indicator to estimate methane production from dairy cows. J. Dairy Sci. 98(6):4074-4083.

Alcock, D. J. and R. S. Hegarty. 2011. Potential effects of animal management and genetic improvement on enteric methane emissions, emissions intensity and productivity of sheep enterprises at Cowra, Australia. Anim Feed Sci Tech 16667:749-760.

Alford, A. R., R. S. Hegarty, P. F. Parnell, O. J. Cacho, R. M. Herd, and G. R. Griffith. 2006. The impact of breeding to reduce residual feed intake on enteric methane emissions from the Australian beef industry. Aust J Exp Agr 46(6-7):813-820.

Arthur, P. F., G. Renand, and D. Krauss. 2001. Genetic and phenotypic relationships among different measures of growth and feed efficiency in young Charolais bulls. Livest. Prod. Sci. 68(2-3):131-139.

Basarab, J. A., K. A. Beauchemin, V. S. Baron, K. H. Ominski, L. L. Guan, S. P. Miller, and J. J. Crowley. 2013. Reducing GHG emissions through genetic improvement for feed efficiency: effects on economically important traits and enteric methane production. Animal 7:303-315.

Berry, D. P. and J. J. Crowley. 2013. Cell Biology Symposium: genetics of feed efficiency in dairy and beef cattle. J. Anim. Sci. 91(4):1594-1613.

Bolormaa, S., B. J. Hayes, K. Savin, R. Hawken, W. Barendse, P. F. Arthur, R. M. Herd, and M. E. Goddard. 2011. Genome-wide association studies for feedlot and growth traits in cattle. J. Anim. Sci. 89(6):1684-1697.

Bolormaa, S., J. E. Pryce, K. Kemper, K. Savin, B. J. Hayes, W. Barendse, Y. Zhang, C. M. Reich, B. A. Mason, R. J. Bunch, B. E. Harrison, A. Reverter, R. M. Herd, B. Tier, H. U. Graser, and M. E. Goddard. 2013. Accuracy of prediction of genomic breeding values for residual feed intake and carcass and meat quality traits in Bos taurus, Bos indicus, and composite beef cattle. J. Anim. Sci. 91(7):3088-3104.

Browning, B. L. and S. R. Browning. 2009. A Unified Approach to Genotype Imputation and Haplotype-Phase Inference for Large Data Sets of Trios and Unrelated Individuals. Am J Hum Genet 84(2):210-223.

Chagunda, M. G. G., D. Ross, and D. J. Roberts. 2009. On the use of a laser methane detector in dairy cows. Comput Electron Agr 68(2):157-160.

de Haas, Y., J. J. Windig, M. P. L. Calus, J. Dijkstra, M. de Haan, A. Bannink, and R. F. Veerkamp. 2011. Genetic parameters for predicted methane production and 
potential for reducing enteric emissions through genomic selection. J. Dairy Sci. 94(12):6122-6134.

Deighton, M. H., B. M. O'Loughlin, S. R. O. Williams, P. J. Moate, E. Kennedy, T. M. Boland, and R. J. Eckard. 2013. Declining sulphur hexafluoride permeability of polytetrafluoroethylene membranes causes overestimation of calculated ruminant methane emissions using the tracer technique. Anim Feed Sci Tech 183(3-4):86-95.

Dong, H., J. Mangino, T. A. McAllister, J. L. Hatfield, D. E. Johnson, K. R. Lassey, M. A. de Lima, and A. Romanovskaya. 2006. Chapter 10: Emissions from Livestock and Manure Managment. in IPCC Guidelines for National Greenhouse Gas Inventories. Volume 4: Agriculture, Forestry and Other Land Use. L. B. Eggleston S., K. Miwa, T. Ngara and K. Tanabe, ed. Institute for Global Environmental Strategies (IGES), Hayama, Japan.

Donoghue, K. A., R. M. Herd, S. H. Bird, P. F. Arthur, and R. F. Hegarty. 2013. Preliminary genetic parameters for methane production in Australian beef cattle. Proc. Assoc. Advmt. Anim. Breed. Genet. 20:290-293

Duthie, C. A., J. A. Rooke, J. J. Hyslop, and A. Waterhouse. 2015. Methane emissions from two breeds of beef cows offered diets containing barley straw with either grass silage or brewers' grains. Animal 9(10):1680-1687.

Garnsworthy, P. C., J. Craigon, J. H. Hernandez-Medrano, and N. Saunders. 2012. Variation among individual dairy cows in methane measurements made on farm during milking. J. Dairy Sci. 95(6):3181-3189.

Gilmour, A. R., B. J. Gogel, B. R. Cullis, and R. Thompson. 2009. ASREML User Guide Release 3.0 VSN International Ltd, Hemel Hempstead, UK.

Grainger, C., T. Clarke, S. M. McGinn, M. J. Auldist, K. A. Beauchemin, M. C. Hannah, G. C. Waghorn, H. Clark, and R. J. Eckard. 2007. Methane emissions from dairy cows measured using the sulfur hexafluoride (SF6) tracer and chamber techniques. J Dairy Sci 90(6):2755-2766.

Hayes, B. J., K. A. Donoghue, C. M. Reich, B. A. Mason, T. Bird-Gardiner, R. M. Herd, and P. F. Arthur. 2016. Genomic heritabilities and genomic estimated breeding values for methane traits in Angus cattle. J. Anim. Sci. 94(1):1-7.

Hayes, B. J. and M. E. Goddard. 2008. Technical note: Prediction of breeding values using marker-derived relationship matrices. J. Anim. Sci. 86(9):2089-2092.

Hegarty, R. S. 2013. Applicability of short-term emission measurements for on-farm quantification of enteric methane. Animal 7:401-408.

Hegarty, R. S., J. P. Goopy, R. M. Herd, and B. McCorkell. 2007. Cattle selected for lower residual feed intake have reduced daily methane production. J. Anim. Sci. 85(6):1479-1486. 
Herd, R. M., P. F. Arthur, K. A. Donoghue, S. H. Bird, T. Bird-Gardiner, and R. S. Hegarty. 2014. Measures of methane production and their phenotypic relationships with dry matter intake, growth, and body composition traits in beef cattle. J. Anim. Sci. 92(11):5267-5274.

Herd, R. M., P.F. Arthur, S.H. Bird, K.A. Donoghue, and R.S. Hegarty. 2014. Genetic Variation for Methane Traits in Beef Cattle. in Proc. 10th World Congress of Genetics Applied to Livestock Production, Vancouver, BC, Canada.

Kennedy, B. W., J. H. J. Vanderwerf, and T. H. E. Meuwissen. 1993. Genetic and statistical properties of Residual Feed Intake. J. Anim. Sci. 71(12):3239-3250.

Khansefid, M., J. E. Pryce, S. Bolormaa, S. P. Miller, Z. Wang, C. Li, and M. E. Goddard. 2014. Estimation of genomic breeding values for residual feed intake in a multibreed cattle population. J. Anim. Sci. 92(8):3270-3283.

Knapp, J. R., G. L. Laur, P. A. Vadas, W. P. Weiss, and J. M. Tricarico. 2014. Invited review: Enteric methane in dairy cattle production: Quantifying the opportunities and impact of reducing emissions. J. Dairy Sci. 97(6):3231-3261.

Koch, R. M., K. E. Gregory, D. Chambers, and L. A. Swiger. 1963. Efficiency of Feed Use in Beef Cattle. J. Anim. Sci. 22(2):486-\&.

Laubach, J., S. P. P. Grover, C. S. Pinares-Patino, and G. Molano. 2014. A micrometeorological technique for detecting small differences in methane emissions from two groups of cattle. Atmos Environ 98:599-606.

Lindholm-Perry, A. K., L. A. Kuehn, L. A. Rempel, T. P. Smith, R. A. Cushman, T. G. McDaneld, T. L. Wheeler, S. D. Shackelford, D. A. King, and H. C. Freetly. 2012. Evaluation of Bovine chemerin (RARRES2) Gene Variation on Beef Cattle Production Traits. Frontiers in genetics 3:39.

Link, A., R. Sauter, and U. Haas. 2005. Highly sensitive and mobile TDL-PA spectroscopic measuring device for methane. J Phys Iv 125:841-844.

McDonald, J.H. 2014. Handbook of Biological Statistics (3rd ed.). Sparky House Publishing, Baltimore, Maryland. This web page contains the content of pages 4552 in the printed version. http://www.biostathandbook.com/chigof.html. Accesed: 16 of June of 2016.

Mangino, J., K. Peterson, and H. Jacobs. 2003. Development of an emissions model to estimate methane from enteric fermentation in cattle. doi: http://www.epa.gov/ttn/chief/conference/ei12/green/mangino.pdf. Accesed: 16 of June of 2016.

Manzanilla Pech, C. I. V., R. F. Veerkamp, M. P. L. Calus, J. E. Pryce, and Y. De Haas. 2014. Genetic parameters and accuracy of recording dry matter intake in first parity Holstein-Friesian cows. Pages 1-4 in Proc. Proceedings, 10th World Congress of Genetics Applied to Livestock Production, Vancouver, Canada. 
Martin, C., D. P. Morgavi, and M. Doreau. 2010. Methane mitigation in ruminants: from microbe to the farm scale. Animal 4(3):351-365.

Moorby, J. M., H. R. Fleming, V. J. Theobald, and M. D. Fraser. 2015. Can live weight be used as a proxy for enteric methane emissions from pasture-fed sheep? Sci Rep-Uk 5.

Pickering, N. K., M. G. Chagunda, G. Banos, R. Mrode, J. C. McEwan, and E. Wall. 2015. Genetic parameters for predicted methane production and laser methane detector measurements. J Anim Sci 93(1):11-20.

Pinares-Patino, C. S., S. M. Hickey, E. A. Young, K. G. Dodds, S. MacLean, G. Molano, E. Sandoval, H. Kjestrup, R. Harland, C. Hunt, N. K. Pickering, and J. C. McEwan. 2013. Heritability estimates of methane emissions from sheep. Animal 7:316-321.

Pinares-Patino, C. S., A. Machmuller, G. Molano, A. Smith, J. B. Vlaming, and H. Clark. 2008. The SF6 tracer technique for measurements of methane emission from cattle - effect of tracer permeation rate. Can. J. Anim. Sci. 88(2):309-320.

Pryce, J. E., J. Arias, P. J. Bowman, S. R. Davis, K. A. Macdonald, G. C. Waghorn, W. J. Wales, Y. J. Williams, R. J. Spelman, and B. J. Hayes. 2012. Accuracy of genomic predictions of residual feed intake and 250-day body weight in growing heifers using 625,000 single nucleotide polymorphism markers. J. Dairy Sci. 95(4):21082119.

Pszczola, M., R. F. Veerkamp, Y. de Haas, E. Wall, T. Strabel, and M. P. L. Calus. 2013. Effect of predictor traits on accuracy of genomic breeding values for feed intake based on a limited cow reference population. Animal 7(11):1759-1768.

Robinson, D. L., J. P. Goopy, R. S. Hegarty, V. H. Oddy, A. N. Thompson, A. F. Toovey, C. A. Macleay, J. R. Briegal, R. T. Woodgate, A. J. Donaldson, and P. E. Vercoe. 2014. Genetic and environmental variation in methane emissions of sheep at pasture. J. Anim. Sci. 92(10):4349-4363.

Ross, E. M., P. J. Moate, L. Marett, B. G. Cocks, and B. J. Hayes. 2013. Investigating the effect of two methane-mitigating diets on the rumen microbiome using massively parallel sequencing. J. Dairy Sci. 96(9):6030-6046.

van Engelen, S., H. Bovenhuis, J. Dijkstra, J. A. van Arendonk, and M. H. Visker. 2015. Short communication: Genetic study of methane production predicted from milk fat composition in dairy cows. J Dairy Sci 98(11):8223-8226.

Veerkamp, R. F., H. A. Mulder, R. Thompson, and M. P. Calus. 2011. Genomic and pedigree-based genetic parameters for scarcely recorded traits when some animals are genotyped. J Dairy Sci 94(8):4189-4197.

Waghorn, G. C. and R. S. Hegarty. 2011. Lowering ruminant methane emissions through improved feed conversion efficiency. Anim Feed Sci Tech 166-67:291301. 
Williams, Y. J., J. E. Pryce, C. Grainger, W. J. Wales, N. Linden, M. Porker, and B. J. Hayes. 2011. Variation in residual feed intake in Holstein-Friesian dairy heifers in southern Australia. J Dairy Sci 94(9):4715-4725.

Yang, J., B. Benyamin, B. P. McEvoy, S. Gordon, A. K. Henders, D. R. Nyholt, P. A. Madden, A. C. Heath, N. G. Martin, G. W. Montgomery, M. E. Goddard, and P. M. Visscher. 2010. Common SNPs explain a large proportion of the heritability for human height. Nature genetics 42(7):565-569.

Yin, T., T. Pinent, K. Brugemann, H. Simianer, and S. Konig. 2015. Simulation, prediction, and genetic analyses of daily methane emissions in dairy cattle. J Dairy Sci 98(8):5748-5762. 



\section{Chapter 5}

\section{Accuracies of genomic breeding values for dry matter intake using non-genotyped animals and predictor traits in different lactations}

C. I. V. Manzanilla-Pech ${ }^{1,2,3}$, R. F. Veerkamp ${ }^{1,2}$, Y. de Haas ${ }^{1}$, M. P. L. Calus ${ }^{1,2}$, J. ten Napel ${ }^{1}$

\footnotetext{
${ }^{1}$ Animal Breeding and Genomics Centre, Wageningen Livestock Research, PO Box $338,6700 \mathrm{AH}$ Wageningen, the Netherlands

${ }^{2}$ Animal Breeding and Genomics Centre, Wageningen University, PO Box 338, 6700 $\mathrm{AH}$ Wageningen, the Netherlands

${ }^{3}$ Mococha Research Station, National Institute of Forestry, Agriculture and Livestock Research, 97454 Mococha, Yucatan, Mexico
} 


\section{Abstract}

Given the interest of including DMI in the breeding goal, accurate estimated breeding values (EBV) for dry matter intake (DMI) are needed, preferably for separate lactations. However, due to the limited amount of records available on $\mathrm{DMI}$, two main approaches have been suggested: the inclusion of predictor traits, such as fat and protein corrected milk (FPCM) and live weight (LW), and the addition of genomic information of animals using what is called genomic prediction. Recently, several methodologies to estimate genomic EBV (GEBV) have become available, in particular, a new method known as single-step ridgeregression best linear unbiased prediction (SSRR-BLUP), which allows for the contribution of non-genotyped animals to the estimation of GEBV, with the advantage that non-genotyped data can be used maximally. The objective of this study was to estimate genetic parameters using a relatively large data set with feed intake records, as well as compare the accuracies in the prediction of the GEBV of DMI, which were obtained using three different methods - namely, genomic best linear unbiased prediction (GBLUP), single-step GBLUP (SS-GBLUP) and SSRR-BLUP with records from different lactations, with or without predictor traits (FPCM and LW), in the model. A total of 77,640 weekly records for DMI, 64,443 for FPCM and 73,415 for LW, from three different lactations, were available for 3,188 Dutch Holstein Friesian cows following nutritional experiments conducted in the Netherlands between 1987 and 2015. Genomic EBV were estimated by three methods using MiXBLUP software. The model included experimental treatment, herd, year-month, fraction of Holstein breed by parity, age of cow in months at measurement by parity, and days in milk by parity as fixed effects, with additive genetic, permanent environmental and residual effect as random effects. Accuracies of GEBV for DMI ranged between 0.21 and 0.38 across methods and scenarios. Accuracies of GEBV for DMI were similar in SS-GBLUP and SSRR-BLUP, and lower for the GBLUP method. Hence, SSRR-BLUP could be used when the number of genotyped animals is large, avoiding the construction of the G-matrix. Adding information on DMI from different lactations in the reference population gave higher accuracies in comparison when only Lactation 1 was included. Finally, there was no difference in adding information on predictor traits to the reference population when DMI was already included. However, in the absence of DMI records, having records on FPCM and LW from different lactations is a good way to obtain GEBV with a relatively good accuracy.

Key words: genomic prediction, feed intake, fat and protein corrected milk, live weight 


\subsection{Introduction}

Feed costs represent half of the total costs of dairy production (EU, 2011). Therefore, one way to increase profitability of dairy production is to reduce feed costs by improving feed efficiency (Veerkamp, 1998, de Haas et al., 2012). Optimization of dairy cattle breeding goals for feed efficiency requires the availability of breeding values for DMI, as this is an important component of feed efficiency. In order to estimate accurate DMI breeding values, a large number of records is required; however, DMI is a labor-intensive and expensive-to-measure trait, which is not recorded in relation to commercial herds, meaning that the amount of available data is limited. The difficulty in recording DMI has hampered direct selection for DMI previously, since an insufficient number of records was available on daughters of progeny-tested bulls. This difficulty might be overcome by jointly using predictor traits (Veerkamp and Brotherstone, 1997, Berry and Crowley, 2013, Manzanilla-Pech et al., 2016) and genomic information (Meuwissen et al., 2001). A readily available predictor trait is fat and protein corrected milk (FPCM), while live weight (LW) is another that is easier and cheaper to record than DMI itself. LW can also be very accurately predicted from linear-type traits (Koenen and Veerkamp, 1998, Banos et al., 2012, Haile-Mariam et al., 2014). Both FPCM and LW are known to be highly correlated with DMI (Korver, 1988, Van Arendonk, 1991, Veerkamp and Brotherstone, 1997, Veerkamp, 1998, Liinamo et al., 2012). Ideally, breeding values for feed intake across the whole productive lifetime of cows should be predicted, but historical DMI data in the Netherlands has mainly covered the first lactation. Furthermore, linear-type traits, which are used to predict LW, are only recorded during the first lactation. It is well known that DMI and LW are traits, which vary across lactations (Veerkamp and Thompson, 1999, Berry et al., 2006). For this reason, it is important to investigate the impact of using data for genomic prediction in Lactation 1 alone, or using data combined from multiple lactations when predicting feed intake in Lactation 1 or in the first three lactations.

With genomic prediction, genotypic information, together with phenotypic data and pedigree, can be used to predict more accurate breeding values (Pszczola et al., 2013). A broadly used genomic prediction model is genomic best linear unbiased prediction (GBLUP), which utilizes genomic relationships to estimate the genetic merit of an individual (VanRaden, 2008). The genomic relationship matrix (GRM) reconstructs the relationship between individuals based on genomic information, instead of pedigree information, which means that more accurate predictions can be achieved. However, the main limiting factor of this method is 
that all animals should have phenotypes and genotypes, thereby ignoring important phenotypic information about relatives that are non-genotyped.

Single step GBLUP (SS-GBLUP) (Aguilar et al., 2010, Christensen and Lund, 2010 ) is a method that allows for adding phenotypic information of non-genotyped animals into the GBLUP model. This method combines, in a single step, the GRM $(G)$ with the pedigree relationship matrix $(A)$ into a new relationship matrix $(H)$, whose inverse is used to solve the mixed model equations to obtain the GEBV. Nowadays, SS-GBLUP is a widely-used method due to its simplicity, which has been adopted in several countries for routine evaluations. However, this method has a few limiting factors in common with ordinary GBLUP, as the computation time required to invert the G-matrix quadratically increases with an increasing number of genotyped animals, while computation time to obtain $\mathrm{G}$ linearly increases with the number of SNP per animal.

In this work, a novel method will be evaluated, which combines information about genotyped and non-genotyped animals with phenotypes using SNP estimates, instead of a relationship matrix, using BLUP methodology, namely, ridge-regression best linear unbiased prediction (RR-BLUP) and single-step ridgeregression best linear unbiased prediction (SSRR-BLUP). This methodology is partially based on the theory behind a previously presented Bayesian regression method (Fernando et al., 2014). The Bayesian regression method uses imputed SNP covariates for animals that are not genotyped, together with a residual genetic effect of the deviations between true and imputed genotypes (Fernando et al., 2014). In theory, the accuracy of prediction of SSRR-BLUP is identical to SS-GBLUP, but its advantage is that it does not require the computation of $\mathrm{G}$ or its inverse.

In 2016, a breeding value for DMI was introduced in the Netherlands. As a consequence, more historical feed intake data has been collected and combined for genetic analysis. Therefore, the objective of this study was to estimate genetic parameters using this uniquely large data set with feed intake records, as well as compare accuracies in the prediction of the GEBV of DMI, obtained by applying three different methods, i.e., GBLUP, SS-GBLUP and SSRR-BLUP, using records from different lactations, with or without predictor traits (FPCM and LW), in the model. 


\subsection{Material and methods}

\subsubsection{Phenotypes}

\subsubsection{Data Collection}

A total of 459,096 daily records on DMI were available from 3,954 Dutch dairy cows in 6,820 lactations. These records came from cows that participated in nutritional experiments, which were conducted from 1987 to 2015 on several farms in the Netherlands, e.g.: Aver Heino, Heino; Bosma Zathe, Ureterp; Cranendonck, Soerendonk; 't Gen, Lelystad; Minderhoudhoeve, Swifterbant; Waiboerhoeve Dairy Unit 2, 3, Lelystad; Zegveld farm, Zegveld; Hoorn, Lelystad; and New Wairboerhoeve, Lelystad. A full description of the methodology of most of the experiments and diets has been summarized previously (Veerkamp et al., 2000, Beerda et al., 2007, Zom et al., 2012). Diets primarily included grass silage, fresh grass, dehydrated grass, corn, corn silage, cereal, concentrates or beet pulp. All cows were kept indoors in conventional cubicle housings, offered complete mixed rations ad libitum and milked twice a day, except for $50 \%$ of the cows at Bosma Zathe $(n=50)$, which were milked three times per day.

\subsubsection{Recorded Traits}

Recording frequencies of DMI varied by experiment: it was recorded either one, two, three or five times per week (Veerkamp et al., 2000, Beerda et al., 2007, Zom et al., 2012). An overview of the experiments, treatments and diets is summarized in Manzanilla-Pech et al. (2014). Weighing platforms were used to automatically monitor LW three times a week or daily, depending on the experiment. Fat and protein corrected milk was calculated, using milk yield (MY) and fat and protein content. Milk yield was recorded daily, but averaged per week, because fat and protein contents in milk were measured weekly. The following formula was used to calculate FPCM (FAO, 2010):

$\operatorname{FPCM}(\mathrm{kg})=(0.337 *$ raw milk $\mathrm{kg})+(11.6 *$ fat content $\mathrm{kg})+(5.999 *$ protein content $\mathrm{kg})$.

\subsubsection{Editing DMI Records}

Daily DMI records were averaged to weekly records in order to homogenize the data across experiments, resulting in 109,442 weekly records for DMI. Dry matter intake records for less than $5 \mathrm{~kg}$ per day were deleted, resulting in 109,052 weekly records from 3,954 cows. A second criterion was to select lactations of a cow with at least five weekly DMI records, resulting in 108,625 records from 3,853 cows. A third criterion was to select only experimental 
treatments with at least five animals, which meant that 108,516 records from 3,853 cows were kept. Then, in the next step, only cows with at least $50 \%$ of the Holstein Friesian breed were kept, resulting in 102,561 records from 3,653 cows. Later, data records from some experiments were deleted, since the experiments had extreme residual variances (SD>5) after a model was fitted, which adjusted for DIM, LW, milk, fat and protein yield, experimental treatment, breed, herd and year-month effects in a model, resulting in 98,375 records from 3,606 cows. Finally, only records from the first three lactations were kept, giving a total of 77,640 DMI records from 3,188 cows (4,350 lactations in total). Analysis was performed on DMI, FPCM and LW in the first lactation, referred to as DMI1, FPCM1 and LW1, respectively, and DMI, FPCM and LW with information in three lactations, referred to as DMI3, FPCM3 and LW3, respectively. By considering DMI in Lactations 1-3 as the same trait (DMI3), we assume a genetic correlation of 1 between lactations. A statistical description of the data per trait is summarized in Table 5.1.

Table 5.1 Descriptive statistics of DMI, FPCM and LW in Lactation 1 (DMI1, FPCM1 and LW1, respectively), or averaged over Lactations 1-3 (DMI3, FPCM3 and LW3, respectively)

\begin{tabular}{llllrrrrr}
\hline Trait & $\begin{array}{c}\text { Number } \\
\text { of cows }\end{array}$ & $\begin{array}{c}\text { Number } \\
\text { of } \\
\text { records }\end{array}$ & Unit & Mean & SD & Minimum & Maximum & $\begin{array}{c}\text { CV } \\
\text { (\%) }\end{array}$ \\
\hline DMI1 & 1,936 & 40,298 & $\mathrm{~kg} / \mathrm{d}$ & 18.8 & 3.23 & 5.0 & 34.8 & 17 \\
FPCM1 & 1,718 & 34,701 & $\mathrm{~kg} / \mathrm{d}$ & 28.2 & 5.2 & 2.9 & 53.9 & 18 \\
LW1 & 1,776 & 38,169 & $\mathrm{~kg}$ & 554.7 & 57.6 & 238.4 & 843.2 & 10 \\
DMI3 & 3,188 & 77,640 & $\mathrm{~kg} / \mathrm{d}$ & 20.3 & 3.8 & 5.04 & 39.3 & 19 \\
FPCM3 & 3,131 & 64,443 & $\mathrm{~kg} / \mathrm{d}$ & 31.3 & 7.7 & 1.0 & 69.8 & 24 \\
LW3 & 3,177 & 73,415 & $\mathrm{~kg}$ & 595.3 & 76.7 & 238.4 & 978.8 & 13 \\
\hline
\end{tabular}

\subsubsection{Genotypes}

A total of 1,496 cows were genotyped $(1,421$ of them with records on DMI), either with 50K Illumina, 80K Geneseek, or 15K Eurogenomics SNP chips. The information from these three chips (missing genotypes and animals with $15 \mathrm{~K}$ and 50K) was imputed to a customized set of 76,439 SNP using Beagle 3. After editing based on phenotype records of DMI, in terms of minimum and maximum, and the number of cows per experimental treatment, 1,313 animals were retained (all with DMI records). All 76,439 SNP were used to calculate the GRM, according to Yang et al. (2010), while the inverse H-matrix (Aguilar et al., 2010, Christensen, 2012) was calculated using the Calc_grm program (Calus and Vandenplas, 2015) in combination with MiXBLUP software (ten Napel et al., 2014). 


\subsubsection{Variance Component Estimation}

Two sets of trivariate analyses were performed separately to estimate the variance and covariance components between DMI1, FPCM1 and LW1, and between DMI3, FPCM3 and LW3, using ASReml4 (Gilmour et al., 2009). The model used to estimate the genetic parameters for DMI3, FPCM3 and LW3 was:

$$
\begin{aligned}
\mathbf{Y}_{\mathrm{ijklmnopqr}}= & \mu+\text { EXPTR }_{\mathbf{i}}+\mathbf{H R}_{\mathbf{j}}+\mathbf{Y M}_{\mathbf{k}}+\text { FRAC }_{\mathbf{l}} \cdot \mathbf{P A R}_{\mathbf{m}}+ \\
& \sum_{\mathbf{n}=\mathbf{0}}^{3} \operatorname{AOC}_{\mathbf{n}} \boldsymbol{\Phi}_{\mathbf{n}} \cdot \mathbf{P A R}_{\mathbf{m}}+\sum_{\mathbf{n}=\mathbf{0}}^{5} \operatorname{DIM}_{\mathbf{o}} \boldsymbol{\Phi}_{\mathbf{o}} \cdot \mathbf{P A R}_{\mathbf{m}}+\mathbf{g}_{\mathbf{p}}+ \\
& \mathbf{p e}_{\mathbf{q}}+\mathbf{e}_{\mathbf{i j k l m n o p q r}}
\end{aligned}
$$

where $Y_{-}$ijklmnopqr is the phenotype for DMI3, FPCM3 and LW3; $\mu$ is the mean; EXPTR is the fixed effect for experimental treatment ( $i=515$ classes); HR is the fixed effect for herd ( $j=22)$; YM is the fixed effect for year-month $(k=272)$; FRAC is the fixed effect of fraction of Holstein (defined as a percentage of Holstein $(5 / 8,6 / 8$, $7 / 8$ and $8 / 8 ; 1=$ four classes) by parity (PAR; $m=3$ ); $A O C$ is the fixed regression coefficient of the age of the cow measured in months by PAR; $\Phi_{n}$ is the Legendre polynomial of the third order for AOC; DIM is the fixed regression coefficient of days in terms of milk as measured by PAR; $\Phi_{0}$ is the Legendre polynomial of the fifth order for DIM; $g_{p}$ is the random additive genetic effect distributed as $\mathrm{N}(0$, $\left.\mathbf{G} \sigma^{2}{ }_{a}\right)$, in which $\mathrm{G}$ is the GRM in GBLUP, and as $\mathrm{N}\left(0, \mathbf{H} \sigma^{2}{ }_{\mathrm{a}}\right)$, in which $\mathrm{H}$ is the GRM in SS-GBLUP, where $\sigma^{2}$ is the genetic variance, $p_{\mathbf{q}}$ is the random permanent environmental term (both within and across parities) distributed as $N\left(0,1 \sigma^{2}\right)$, in which $\mathrm{I}$ is an identity matrix and $\sigma^{2}{ }_{\mathrm{c}}$ is the environmental variance, and $\mathrm{e}_{\mathrm{ijklmnopqr}}$ is the residual term of $Y_{i j k l m n o p q r}$ distributed as $N\left(0, I \sigma^{2}\right)$, in which I is an identity matrix and $\sigma_{e}^{2}$ is the residual variance. The same model [1] was used to estimate genetic parameters for DMI1, FPCM1 and LW1, but excluding parity, as this analysis only used information from the first parity.

\subsubsection{Estimation of GEBV}

The GEBV for DMI1 and DMI3 for each animal were estimated using MiXBLUP software (ten Napel et al., 2014) with three different methods: GBLUP, SS-GBLUP and SSRR-BLUP. All three methods were implemented considering the same fixed effects and non-genetic random effects as in [1]. 


\subsubsection{GBLUP and SS-GBLUP}

The GBLUP and SS-GBLUP models were BLUP implementations of the model described in Equation [2], using variance components as estimated with the model in [1], and either relationship matrix $\mathbf{G}^{-\mathbf{1}}$ or $\mathbf{H}^{-\mathbf{1}}$ :

$$
\mathbf{y}=X \beta+\mathbf{Z}_{1} \mathbf{a}+\mathbf{Z}_{2} \mathbf{c}+\mathbf{e}
$$

where $\mathbf{y}$ is the vector of phenotypes; $\mathbf{X}$ and $\mathbf{Z}_{1}, \mathbf{Z}_{\mathbf{2}}$ are incidence matrices relating observations with fixed, direct additive genetic and permanent environmental effects; $\beta$ is the vector of fixed effects; $a$ is the vector of direct additive genetic effects; and $c$ is the vector of permanent environmental effects. Meanwhile, when $\operatorname{var}(\mathrm{a})=\mathbf{G} \sigma^{2}{ }_{\mathrm{u}}$ and $\mathbf{G}$ is the genomic relationship matrix, $\operatorname{var}(\mathrm{c})=\mathbf{I} \sigma^{2}{ }_{\mathrm{c}}$ and $\operatorname{var}(\mathrm{e})=$ $I \sigma^{2}$, where $\mathbf{I}$ is an identity matrix of an order equal to the number of observations.

The G-matrix was built according to Yang et al. (2010) and calculated using Calc_grm (Calus and Vandenplas, 2015):

$$
\mathbf{G}=\frac{\mathbf{w} \mathbf{w}^{\prime}}{\mathbf{N}}
$$

where $\mathrm{N}$ is the number of SNP and $\mathrm{W}$ contains the scaled and centered marker genotypes for all animals at all loci, with elements computed as:

$$
w_{i j}=\frac{\left(x_{i j}-2 p_{i}\right)}{\sqrt{2 p_{i}\left(1-p_{i}\right)}}
$$

Values for $p_{i}$ are calculated from the data. Unbiased estimates of inbreeding coefficients are computed, while diagonal elements of $\mathbf{G}$ are computed as:

$$
\mathrm{G}_{i i}=1+\frac{1}{N} \sum_{i} \frac{x_{i j}{ }^{1}-\left(1-2 p_{i}\right) x_{i j}+2 p_{i}^{2}}{2 p_{i}\left(1-p_{i}\right)}
$$

The inverse of the $\mathrm{H}$-matrix, $\mathbf{H}^{\mathbf{- 1}}$, can be calculated with the following formula (Aguilar et al., 2010, Christensen and Lund, 2010):

$$
\mathbf{H}^{-1}=\mathbf{A}^{-1}+\left[\begin{array}{cc}
\mathbf{0} & \mathbf{0} \\
\mathbf{0} & \lambda\left(\mathbf{G}^{-1}-\mathbf{A}_{22}^{-1}\right)
\end{array}\right]
$$

where $\mathbf{A}^{-\mathbf{1}}$ is the inverse of the pedigree relationship matrix; $\mathbf{G}^{\mathbf{- 1}}$ is the inverse of the genomic relationship matrix; and $\mathbf{A}_{\mathbf{2 2}}^{\mathbf{- 1}}$ is the inverse of the pedigree relationship matrix among genotyped animals. 
It is important to note that, for the GBLUP method, only animals with genotypes and phenotypes were used, meaning that less data were used (Table 5.2) compared to SS-GBLUP, where both genotyped and non-genotyped animals with phenotypes were included.

\subsubsection{SSRR-BLUP}

The SSRR-BLUP model used to calculate the GEBV can be represented as follows:

$$
\mathrm{y}=\mathbf{X} \beta+\left[\begin{array}{l}
\mathbf{W}_{\text {non }} \\
\mathbf{W}_{\text {gen }}
\end{array}\right] \alpha+\delta \mathbf{Z}_{\mathbf{1}} \varepsilon+\mathbf{Z}_{\mathbf{2}} \mathrm{c}+\mathrm{e}
$$

where $\mathbf{y}$ is the vector of phenotypes; $\mathbf{X}$ is the incidence matrix of the fixed effects; $\mathbf{W}_{\text {non }}$ is the regression design matrix with imputed genotypes; $\mathbf{W}_{\text {gen }}$ is the regression design matrix with genotypes; $\mathbf{Z}_{\mathbf{1}}, \mathbf{Z}_{\mathbf{2}}$ are incidence matrices relating observations with genetic and permanent environmental effects; $\boldsymbol{\beta}$ is the vector of fixed effects; $\boldsymbol{\alpha}$ is the vector of SNP regression coefficients; $\boldsymbol{\delta}$ is a vector with 1 for nongenotyped and 0 for genotyped animals; $\mathbf{c}$ is the vector of permanent environmental effects; and $\boldsymbol{\varepsilon}$ is the vector with residual genetic solutions, in addition to the genetic effect explained by the imputed SNP genotypes $\left(\mathbf{W}_{\text {non }}{ }^{*} \boldsymbol{\alpha}\right)$.

The SNP variances were calculated with the following formula for SNP on the original scale:

$$
\mathrm{V}_{\mathrm{SNP}}=\frac{\mathrm{v}_{\mathrm{G}}}{\sum_{\mathrm{i}=1}^{\mathrm{n}_{\mathrm{inf}}} 2 * \mathrm{p}_{\mathrm{i}} *\left(1-\mathrm{p}_{\mathrm{i}}\right)}
$$

where $\mathrm{V}_{\mathrm{SNP}}$ is the SNP variance; $\mathrm{V}_{\mathrm{G}}$ is the genetic variance; $n_{\text {inf }}$ is the number of informative SNP (all three genotypes present); and $p_{i}$ is the allele frequency of SNP i.

For each method, a set of six analyses was performed (Table 5.3), three of which used information about Lactation 1, while the other three used information about Lactations 1-3, each one with three variants depending on the information source used. Thus, the six scenarios were: a) DMI1; b) FPCM1 and LW1; c) DMI1, FPCM1 and LW1; d) DMI3; e) FPCM3 and LW3; and f) DMI3, FPCM3 and LW3.

\subsubsection{Validation}

\subsubsection{Cross-validation}

The models were validated using cross-validation, where the population with genotypes was divided into four subsets, making sure that all paternal half- 
sibs were in the same group. The assignment to the groups was made by sire, using stratified random sampling, which was undertaken in two steps: first, the sires of genotyped animals were sorted from the highest to the lowest number of daughters. Then, from every set of four subsequent sires, one sire was randomly allocated to one of the four groups. Thus, the four validation groups were equivalent in terms of the proportion of sires, cows with genotypes and also the total number of records. The distribution of animals in the cross-validation groups is shown in Table 5.2. To predict GEBV for each validation group, the respective phenotypes were excluded from the analysis, with only information about the other animals with genotypes and phenotypes used.

Table 5.2 Distribution of cows per cross-validation group and total (defined as the total number of cows or records available, not as the sum of the validation groups)

\begin{tabular}{|c|c|c|c|c|c|}
\hline \multirow[b]{2}{*}{ Number of } & \multicolumn{4}{|c|}{ Cross-validation groups } & \multirow[t]{2}{*}{ TOTAL } \\
\hline & 1 & 2 & 3 & 4 & \\
\hline Validation cows & 352 & 303 & 323 & 335 & 1,313 \\
\hline Reference cows & 961 & 1,010 & 990 & 979 & 1,313 \\
\hline \multicolumn{6}{|l|}{ Sires (to divided cross- } \\
\hline validation group) & 68 & 74 & 70 & 73 & 285 \\
\hline \multicolumn{6}{|l|}{ of validation cows } \\
\hline ReferenceDMI1 records ${ }^{1}$ & 14,145 & 16,923 & 16,114 & 14,618 & 20,600 \\
\hline ReferenceDMI3 records ${ }^{1}$ & 23,614 & 25,559 & 24,653 & 24,049 & 32,627 \\
\hline ReferenceDMI1 records ${ }^{2}$ & 33,841 & 36,619 & 35,810 & 34,314 & 40,298 \\
\hline ReferenceDMI3 records ${ }^{2}$ & 68,627 & 70,571 & 69,666 & 69,062 & 77,640 \\
\hline
\end{tabular}

${ }^{1}$ For GBLUP, ${ }^{2}$ for SS-GBLUP and SSRR-BLUP

\subsubsection{Calculation of Accuracies}

The accuracies ( $\mathbf{r}$ ) were calculated via cross-validation per scenario as the correlation between the adjusted phenotype for DMI1 or DMI3 and the GEBV for DMI1 or DMI3. Adjusted phenotypes for DMI1 and DMI3 were calculated per animal in ASReml4 (Gilmour et al., 2009) as the solutions of a model using all fixed effects in the model in [1], but excluding the genetic animal effect. The idea behind this was to have a uniquely adjusted phenotype per animal, instead of multiple adjusted phenotypes. The accuracies were divided by the accuracy of the adjusted phenotypes, computed and approximated with the formula (Falconer and Mackay, 1996):

$$
\sqrt{\frac{n h^{2}}{1+(n-1) r}}
$$


where $n$ is the average number of repeated records per animal per cross-validation group (between 17 and 24 for DMI1 and between 23 and 26 for DMI3); $h^{2}$ is heritability of the trait ( 0.18 for DMI1 and 0.17 for DMI3); and $r$ is the repeatability of the trait (0.48 for DMI1 and 0.44 DMI3). Accuracies were calculated for each validation group $(1,2,3,4)$ and averaged across validation groups. Standard errors of accuracies were defined as the SD of the accuracies divided by the square root of the number of validation groups. Slopes of regression (linear regression coefficients) of adjusted phenotypes (DMI1 and DMI3) on GEBV were calculated per method and per scenario as a measure of the bias in terms of the variance in GEBV.

\subsubsection{Validation Scenarios}

Four validation scenarios were performed: 1) using information sources from Lactation 1 to validate in DMI1; 2) using information sources for all three lactations to validate in DMI1;3) using information sources from Lactation 1 to validate in DMI3; and 4) using information sources from the three lactations to validate in DMI3. To better illustrate this idea, a scheme is presented in Table 5.3.

Table 5.3 Validation traits and scenarios per method used (GBLUP, SS-GBLUP, SSRR-BLUP)

\begin{tabular}{ll}
\hline Validation trait & Reference traits per scenario \\
\hline DMI1/DMI3 & 1a) DMI1 \\
& 1b) FPCM1, LW1 \\
& 1c) DMI1, FPCM1, LW1 \\
& 2a) DMI3 \\
2b) FPCM3, LW3 \\
2c) DMI3, FPCM3, LW3
\end{tabular}

\subsection{Results and Discussion}

Given the interest of the dairy cattle breeding industry in including DMI in the breeding goal, accurate EBV for DMI are needed, preferably reflecting the feed intake throughout the whole productive lifetime of a cow. In light of the limited amount of direct records of feed intake, two main approaches have been suggested to obtain accurate EBV for DMI: inclusion of predictor traits (such as FPCM and LW) and the addition of genomic information about animals.

In recent years, a unique large data set has been generated in the Netherlands, which includes several lactations on DMI. Therefore, the objective of 
this study was to estimate genetic parameters using this relatively large data set with feed intake records, as well as compare the accuracies of estimated GEBV of DMI, obtained using three different methods, i.e., GBLUP, SS-GBLUP and SSRRBLUP, as well as using records from different lactations, with or without predictor traits (FPCM and LW), in the model.

\subsubsection{Estimated Genetic Parameters}

The data set contained 77,640 weekly records, recorded during 4,350 lactations involving 3,188 cows (Table 5.1). Compared to most studies, this is a relative large data set for estimating genetic parameters for DMI (Korver, 1988, Berry and Crowley, 2013). The mean for DMI1 was $18.8 \mathrm{~kg} / \mathrm{d}$, whereas the mean for DMI3 was higher $(22.32 \mathrm{~kg} / \mathrm{d})$. The mean for FPM1 was $28.19 \mathrm{~kg} / \mathrm{d}$ and $31.26 \mathrm{~kg} / \mathrm{d}$ for FPCM3. The mean for LW1 and LW3 was $554.7 \mathrm{~kg}$ and $595.3 \mathrm{~kg}$, respectively. The SD of the traits, including the first three lactations, were always higher than those including only the first lactation.

Genetic variances for DMI1, FPCM1 and LW1 (Table 5.4) were $0.91 \mathrm{~kg}^{2} / \mathrm{d}$, $4.01 \mathrm{~kg}^{2} / \mathrm{d}$ and 1,009 $\mathrm{kg}^{2}$, whereas, for DMI3, FPCM3 and LW3 were $1.06 \mathrm{~kg}^{2} / \mathrm{d}, 5.94$ $\mathrm{kg}^{2} / \mathrm{d}$ and $1254 \mathrm{~kg}^{2}$, respectively. For DMI and FPCM, the permanent environmental variances were higher than the genetic variances, whereas, for LW, the permanent environmental variance was lower than the genetic variance. Estimated heritabilities were 0.18 and 0.17 for DMI1 and DMI3, 0.23 and 0.24 for FPCM1 and FPCM3, and 0.47 and 0.43 for LW1 and LW3, respectively. These estimated heritabilities of DMI1 and DMI3 were well within the range $(0.11$ to 0.35$)$ of previous studies presenting heritabilities (Veerkamp, 1998, Veerkamp and Thompson, 1999, Berry et al., 2007, Vallimont et al., 2010, 2011, Williams et al., 2011, Spurlock et al., 2012). Estimated heritabilities of FPCM in the current study were slightly lower than previously reported heritabilities ranging between 0.27 and 0.47 (Van Arendonk et al., 1991, Veerkamp et al., 2012, Pszczola et al., 2013, Lassen et al., 2016). Estimated heritabilities for LW in the current study were in the range of estimates in the literature ranging from 0.43 to 0.65 (Veerkamp and Brotherstone, 1997, Koenen and Veerkamp, 1998, Berry et al., 2003, Muller et al., 2006, Dechow et al., 2010).

Moderate to high (0.4 to 0.8 ) genetic correlations between feed intake and predictor traits, such as FPCM and LW, have been estimated in several studies (Veerkamp and Brotherstone, 1997, Cooper et al., 2010, Vallimont et al., 2011, Berry and Crowley, 2013). In the current study, the genetic correlations of DMI with predictor traits were also in this range: 0.65 between DMI1 and FPCM1, 0.68 between DMI1 and LW1, 0.59 between DMI3 and FPCM3, and 0.43 between DMI3 
and LW3. With these correlations, we can conclude that it is possible to estimate EBV for DMI by using predictor traits, such as FPCM and LW, and conformation traits, as they explained a large proportion of the variance in DMI.

Table 5.4 Estimated genetic $\left(\sigma^{2}\right)$, permanent environmental $\left(\sigma_{\text {pe }}^{2}\right)$, residual $\left(\sigma^{2}{ }_{e}\right)$ and phenotypic $\left(\sigma_{p}^{2}\right)$ variances, heritabilities (on diagonal, bold), and genetic ( $r_{a}$; below diagonal) and phenotypic correlations ( $r_{p}$; above diagonal) for traits in Lactation 1 (DMI1, FPCM1, LW1), and traits in the three lactations (DMI3, FPCM3, and LW3) used to estimate the GEBV

\begin{tabular}{|c|c|c|c|c|c|c|c|c|}
\hline Lactation & Trait & $\sigma_{a}^{2}$ & $\sigma_{p e}^{2}$ & $\sigma_{e}^{2}$ & $\sigma_{p}^{2}$ & & 2 and $r$ & \\
\hline \multirow{3}{*}{1} & DMI1 & 0.91 & 1.54 & 2.56 & 5.01 & 0.18 & 0.50 & 0.30 \\
\hline & FPCM1 & 4.01 & 7.76 & 5.96 & 17.73 & 0.65 & 0.23 & 0.06 \\
\hline & LW1 & 1009 & 754.6 & 398.1 & 2161.7 & 0.68 & 0.07 & 0.47 \\
\hline \multirow{3}{*}{$1-3$} & DMI3 & 1.06 & 1.61 & 3.42 & 6.09 & 0.17 & 0.48 & 0.24 \\
\hline & FPCM3 & 5.94 & 9.90 & 9.20 & 25.04 & 0.59 & 0.24 & 0.03 \\
\hline & LW3 & 1254 & 1004 & 658.8 & 2916.8 & 0.43 & -0.02 & 0.43 \\
\hline
\end{tabular}

\subsubsection{Accuracies}

Accuracies of estimated GEBV for DMI1 and DMI3 per scenario and method (GBLUP, SS-GBLUP and SSRR-BLUP) are presented in Table 5.5. In general, the accuracies of the GEBV for DMI estimated in this study were in agreement with average accuracies across validation sets in other studies, ranging between 0.20 and 0.45 (Pszczola et al., 2013, Pryce et al., 2014, de Haas et al., 2015). However, when the predictor traits were recorded with regard to the reference population and the validation population, higher accuracies were achieved, ranging from 0.47 to 0.63 (Pszczola et al., 2013).

\subsubsection{Across Methods}

Accuracies of GEBV for DMI1 were lowest with the GBLUP method, ranging between 0.21 and 0.25 , followed by the SS-GBLUP method (between 0.22 and 0.31 ) and the SS-RRBLUP method (between 0.22 and 0.29). Likewise, accuracies of GEBV of DMI were lowest with the GBLUP method, ranging from 0.26 to 0.30 , followed by the SS-GBLUP method (between 0.26 and 0.38) and the SSRR-BLUP method (between 0.26 and 0.35 ). These results are in line with the results of other studies, which concluded that applying the SS-GBLUP method resulted in more accurate GEBV than when applying the GBLUP method, in which 16 economic important traits, such as fertility, milk and longevity in Nordic Red cattle were analyzed 


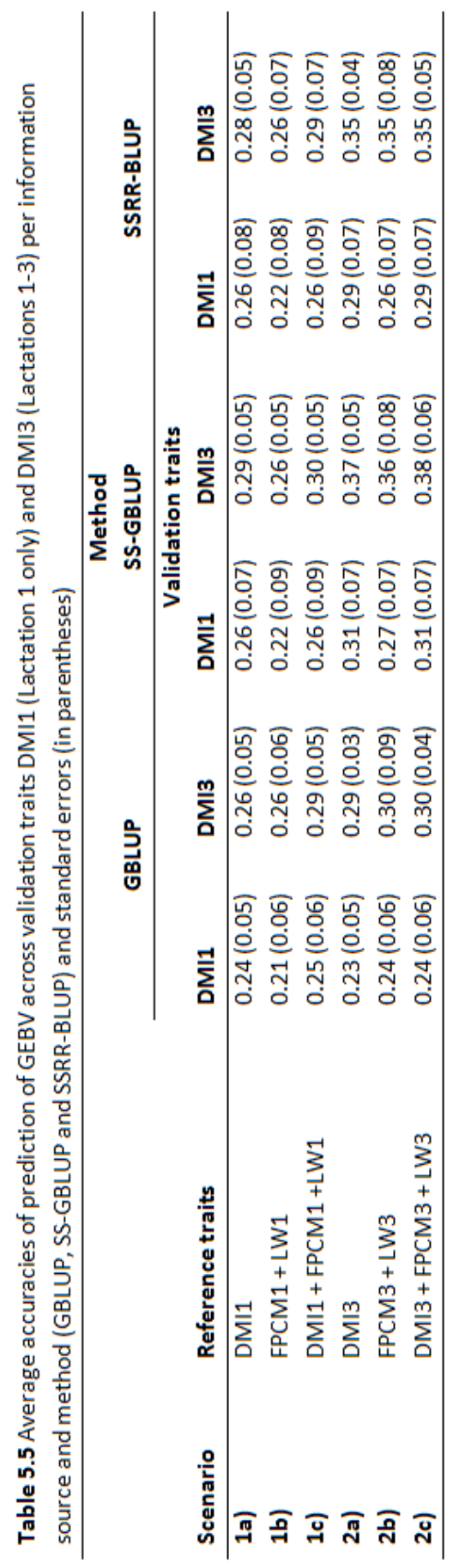


(Gao et al., 2012, Su et al., 2012). Additionally, SS-GBLUP has proven to be more accurate and simpler than multistep methods (Christensen, 2012), as well as broadly used for genetic evaluations in several species. In the current study, applying the SS-GLUP method resulted in similar accuracies for GEBV of DMI1, when information on Lactation 1 was used. However, when information about Lactation 1 was used for the estimation of GEBV for DMI3, or when information about all three lactations was used to estimate GEBV for DMI1 or DMI3, slightly higher accuracies were estimated when applying the SS-GBLUP method, compared to applying the SSRR-BLUP method. The generally similar results between SSGBLUP and SSRR-BLUP are not surprising, as both methods are supposed to be mathematically equivalent. In table 5.6 average correlations between GEBV predicted with SS-GBLUP method and with SSRR-BLUP method are presented. In this table, we can observed that both methods are equivalent and performed similar as the average correlation ranged between 0.94 and 0.98 across scenarios. However, the main advantage of the SSRR-BLUP method, compared to the SSGBLUP method, is that it can handle more genotyped animals, since it avoids the calculation of the inverse H-matrix. In addition, the SSRR-BLUP method may involve SNP-specific variances for multitrait models, unlike SS-GBLUP, meaning that it allows for some SNP to explain a larger fraction of the total genetic variation than other SNP. The SSRR-BLUP method is derived from a Bayesian regression method, which also uses imputed marker covariates for non-genotyped animals, together with a residual genetic effect (Fernando et al., 2014). The current implementation of SSRR-BLUP in the MiXBLUP software (ten Napel et al., 2014) requires a larger number of iterations to converge compared with SS-GBLUP when using the same software, such that SSRR-BLUP requires substantially more computing time than SS-GBLUP for these data. SS-GBLUP is faster for these data because the number of genotyped animals $(1,313)$, which determines the size of the GRM, is relatively small. However, calculating the full $\mathrm{H}$-inverse is impossible in a scenario with hundreds of thousands of animals. Therefore, it is recommended that both methods are tested with a larger number of genotyped animals in order to study the benefits of SSRR-BLUP method. Future developments will likely help to further improve the performance of SSRR-BLUP. Mixed model equations for SSRR-BLUP can be rewritten in order to reduce the number of iterations required. Furthermore, a preconditioned conjugate gradient may not be the most optimal solution for quasisingular systems, such as SSRR-BLUP. 


\subsubsection{Across Lactations}

As DMI varied between lactations (Koenen and Veerkamp, 1998, Veerkamp and Thompson, 1999, Buttchereit et al., 2011), it is of importance to know whether using traits, which containing information about the three lactations in the reference population, would result in higher accuracies than if using traits containing information about Lactation 1 . The accuracies of GEBV for DMI1 and DMI3, as estimated with a reference set with traits containing information on Lactation 1, ranged from 0.21 to 0.30 , whereas the accuracies of GEBV for DMI1 and $\mathrm{DMI} 3$, as estimated with a reference set with traits containing information on all three lactations, varied between 0.22 and 0.38 (Table 5.5). Therefore, the accuracies of GEBV based on a reference set with traits containing information on all three lactations (DMI3, FPCM3 and LW3), independently of the validation trait (DMI1 or DMI3), were higher, compared to reference sets with traits only containing information about Lactation 1 (DMI1, FPCM1 and LW1). In addition, in the current study, the correlation between DMI 1 and DMI3 was 0.6 . These results demonstrate that the assumption about DMI in different lactations being the same trait is at least approximately correct. As reported previously, there is a great difference between DMI in first parity cows and DMI in later parities (Berry et al., 2006).

Table 5.6 Average correlations ( $r$ ) between GEBV estimated with SS-GBLUP method and SSRR-BLUP method per scenario with standard errors (in parentheses)

\begin{tabular}{lll}
\hline Scenario & Reference traits & $\mathbf{r}$ \\
\hline 1a) & DMI1 & $0.98(0.01)$ \\
1b) & FPCM1 + LW1 & $0.94(0.01)$ \\
1c) & DMI1 + FPCM1 +LW1 & $0.96(0.01)$ \\
2a) & DMI3 & $0.98(0.01)$ \\
2b) & FPCM3 + LW3 & $0.96(0.01)$ \\
2c) & DMI3 + FPCM3 + LW3 & $0.96(0.01)$ \\
\hline
\end{tabular}

\subsubsection{Across Scenarios}

Accuracies of estimated GEBV for DMI1 and DMI3 were generally higher when DMI was included as a trait in the reference population (Scenarios a: only DMI; Scenarios c: DMI, FPCM and (W) than when DMI was not included as a reference population trait and when the reference population contained only FPCM and LW (Scenarios b) (Table 5). Additionally, there were either no or slight differences in accuracies between Scenarios a and c, meaning that the value of 


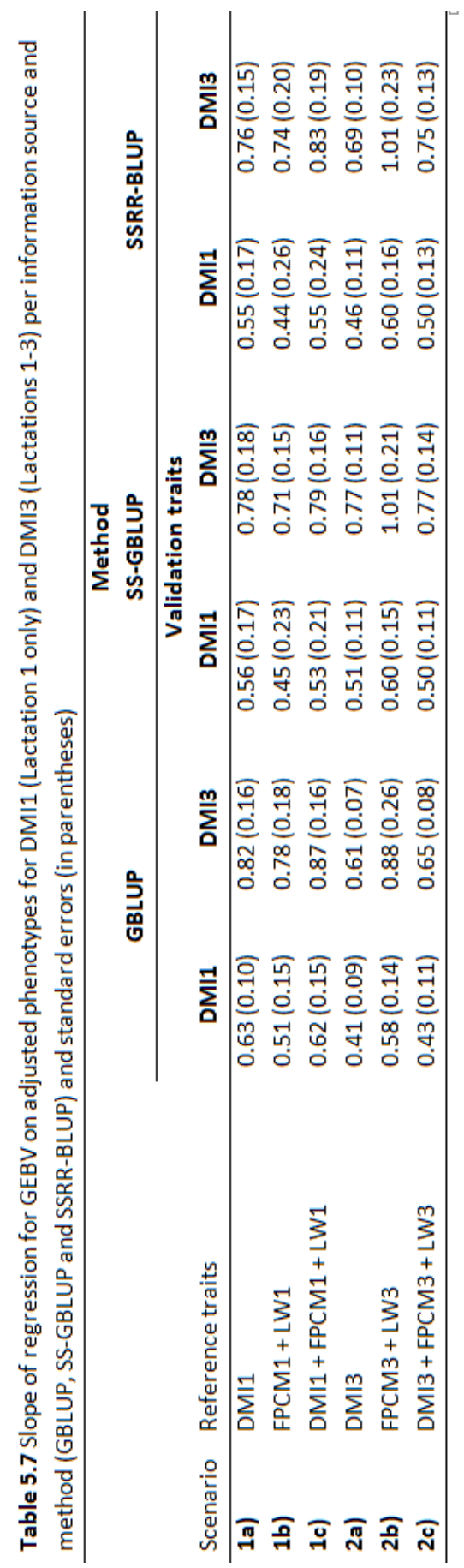


adding additional information about predictor traits, when the DMI is already included in the reference population, is limited. Despite that, in most cases, the accuracies of estimated GEBV for DMI1 and DMI3, when only using predictor traits in the reference population, were lower than in the scenarios using DMI. The difference was not large, indicating that, in absence of records regarding DMI, FPCM and LW could still predict a large and useful percentage of DMI. These results are in agreement with Pszczola et al. (2013), in which no benefit was observed when adding FPCM to DMI in the reference population, while only a slight increase in accuracy (0.02) was observed when adding LW to DMI and FPCM in the reference population.

\subsubsection{Slopes}

Slopes of regression of adjusted phenotypes for DMI1 and DMI3 on GEBV for DMI1 and DMI3 per scenario and method (GBLUP, SS-GBLUP and SSRR-BLUP) and standard errors are presented in Table 5.7. Slopes of regression can be seen as a measure of bias in terms of the variance in GEBV. Slopes smaller than 1 indicate an overestimation of the variance in GEBV, while slopes larger than 1 indicate an underestimation of the variance in GEBV. In general, within the current study, the slopes were smaller than 1 across methods and scenarios, showing some bias towards the variance in GEBV. Slopes were larger for the validation trait DMI3 than for the validation trait DMI1. In addition, for Lactation 1, slopes were larger when DMI1 was included with the predictor traits in the reference population, compared to when only DMI or predictor traits were included. Pszczola et al. (2013) reported larger slopes when all traits (DMI, FPCM and LW) were added to the reference population. Furthermore, despite the fact that SS-GLUP and SSRR-BLUP were expected to have larger slopes, given the extra information added to the reference population, this was only true for Scenario $2 \mathrm{~b}$ when the validation trait was DMI3. The slopes for GBLUP varied between 0.41 and 0.88 , whereas the slopes varied between 0.44 and 1.01 for SS-GBLUP and SSRR-BLUP. Finally, Pszczola et al. (2013) showed that, when information on additional traits was added to both reference and validation animals, the variance in GEBV was unbiased.

\subsection{Conclusions}

In the present study, applying SS-GBLUP and SSRR-BLUP methods to estimate GEBV for DMI resulted in higher accuracies, compared to applying the GBLUP method, because SS-GBLUP and SSRR-BLUP allowed for the incorporation of 
additional information on phenotypic records of non-genotyped animals. The accuracies of GEBV for DMI were similar in the SS-GBLUP and SSRR-BLUP methods, proving that both methods perform in a similar fashion. Thus, SSRR-BLUP could be used instead of SS-GBLUP when the number of genotyped animals is large, avoiding the construction of the H-matrix, while yielding similar results. Furthermore, adding more information about DMI from different lactations in the reference population gave a higher degree of accuracies, compared to when information about Lactation 1 alone was included. In general, adding predictor traits to the reference population did not improve the accuracy concerning DMI when DMI was already included. However, in the absence of DMI records, having records on FPCM and LW from different lactations for reference is an efficient way to obtain GEBV for DMI with a useful degree of accuracy.

\subsection{Acknowledgements}

The data collection was provided by CRV (Arnhem, the Netherlands). The first author would like to thank the National Council on Science and Technology of Mexico (CONACYT, Mexico) for its financial support to study for a PhD at Wageningen University, and to the National Research Institute of Forestry, Agriculture and Livestock (INIFAP, Mexico) in respect of promoting the professional development of the researchers. Mathijs van Pelt, Ina Hulsegge and Ghyslaine Schopen (Wageningen Livestock Research, Wageningen, the Netherlands) are kindly acknowledged for their help regarding the realization of this study. 


\subsection{References}

Aguilar, I., I. Misztal, D. L. Johnson, A. Legarra, S. Tsuruta and T. J. Lawlor. 2010. Hot topic: a unified approach to utilize phenotypic, full pedigree, and genomic information for genetic evaluation of Holstein final score. J. Dairy Sci. 93(2):743752.

Banos, G., M. P. Coffey, R. F. Veerkamp, D. P. Berry and E. Wall. 2012. Merging and characterising phenotypic data on conventional and rare traits from dairy cattle experimental resources in three countries. Animal 6(7):1040-1048.

Beerda, B., W. Ouweltjes, L. B. J. Sebek, J. J. Windig and R. F. Veerkamp. 2007. Effects of genotype by environment interactions on milk yield, energy balance, and protein balance. J. Dairy Sci. 90(1):219-228.

Berry, D. P., F. Buckley, P. Dillon, R. D. Evans, M. Rath and R. F. Veerkamp. 2003. Genetic parameters for body condition score, body weight, milk yield, and fertility estimated using random regression models. J. Dairy Sci. 86(11):37043717.

Berry, D. P. and J. J. Crowley. 2013. Cell Biology Symposium: genetics of feed efficiency in dairy and beef cattle. J. Anim. Sci. 91(4):1594-1613.

Berry, D. P., B. Horan, M. O’Donovan, F. Buckley, E. Kennedy, M. McEvoy and P. Dillon. 2007. Genetics of grass dry matter intake, energy balance, and digestibility in grazing Irish dairy cows. J. Dairy Sci. 90(10):4835-4845.

Berry, D. P., R. F. Veerkamp and P. Dillon. 2006. Phenotypic profiles for body weight, body condition score, energy intake, and energy balance across different parities and concentrate feeding levels. Livest. Sci. 104(1-2):1-12.

Buttchereit, N., E. Stamer, W. Junge and G. Thaller. 2011. Short communication: genetic relationships among daily energy balance, feed intake, body condition score, and fat to protein ratio of milk in dairy cows. J. Dairy Sci. 94(3):1586-1591.

Calus, M. P. L. and J. Vandenplas. 2015. Calc_grm: a program to compute pedigree, genomic, and combined relationship matrices. Wageningen: ABGC, Wageningen UR Livestock Research.

Christensen, O. F. 2012. Compatibility of pedigree-based and marker-based relationship matrices for single-step genetic evaluation. Genet. Sel. Evol. 44.

Christensen, O. F. and M. S. Lund. 2010. Genomic prediction when some animals are not genotyped. Genet. Sel. Evol. 42.

Cooper, A. J., C. L. Ferrell, L. V. Cundiff and L. D. Van Vleck. 2010. Prediction of genetic values for feed intake from individual body weight gain and total feed intake of the pen. J. Anim. Sci. 88(6):1967-1972. 
de Haas, Y., M. P. L. Calus, R. F. Veerkamp, E. Wall, M. P. Coffey, H. D. Daetwyler, B. J. Hayes and J. E. Pryce. 2012. Improved accuracy of genomic prediction for dry matter intake of dairy cattle from combined European and Australian data sets. J. Dairy Sci. 95(10):6103-6112.

de Haas, Y., J. E. Pryce, M. P. L. Calus, E. Wall, D. P. Berry, P. Lovendahl, N. Krattenmacher, F. Miglior, K. Weigel, D. Spurlock, K. A. Macdonald, B. Hulsegge and R. F. Veerkamp. 2015. Genomic prediction of dry matter intake in dairy cattle from an international data set consisting of research herds in Europe, North America, and Australasia. J. Dairy Sci. 98(9):6522-6534.

Dechow, C. D., J. Vallimont, M. D. Dekleva, J. M. Daubert and J. W. Blum. 2010. Genetic correlations of gross feed efficiency with yield, body weight, body condition score, and energy balance in dairy cattle. J. Dairy Sci. 93:184-184.

EU. 2011. European Commission: Agricultural and Rural Development. Farm Economics Brief. No. 2. Production Costs Overview. http://ec.europa.eu/agriculture/rica/pdf/Brief201102.pdf. Accessed: November 7, 2016.

Falconer, D. S. and T. F. C. Mackay. 1996. Introduction to Quantitative Genetics. Fourth Edition. Harlow: Pearson Education Ltd.

Food and Agriculture Organization (FAO) of the United Nations. 2010. Greenhouse Gas Emissions from the Dairy Sector. Rome: FAO.

Fernando, R. L., J. C. M. Dekkers and D. J. Garrick. 2014. A class of Bayesian methods to combine large numbers of genotyped and non-genotyped animals for whole-genome analyses. Genet. Sel. Evol. 46.

Gao, H. D., O. F. Christensen, P. Madsen, U. S. Nielsen, Y. Zhang, M. S. Lund and G. S. Su. 2012. Comparison on genomic predictions using three GBLUP methods and two single-step blending methods in the Nordic Holstein population. Genet. Sel. Evol. 44.

Gilmour, A. R., B. J. Gogel, B. R. Cullis and R. Thompson. 2009. ASREML User Guide Release 3.0. Hemel Hempstead: VSN International Ltd.

Haile-Mariam, M., O. Gonzalez-Recio and J. E. Pryce. 2014. Prediction of liveweight of cows from type traits and its relationship with production and fitness traits. J. Dairy Sci. 97(5):3173-3189.

Koenen, E. P. C. and R. F. Veerkamp. 1998. Genetic covariance functions for live weight, condition score, and dry-matter intake measured at different lactation stages of Holstein Friesian heifers. Livest. Prod. Sci. 57(1):67-77.

Korver, S. 1988. Genetic aspects of feed intake and feed efficiency in dairy cattle: a review. Livest. Prod. Sci. 20(1):1-13. 
Lassen, J., N. A. Poulsen, M. K. Larsen and A. J. Buitenhuis. 2016. Genetic and genomic relationship between methane production measured in breath and fatty acid content in milk samples from Danish Holsteins. Anim. Prod. Sci. 56(2-3):298303.

Liinamo, A. E., P. Mantysaari and E. A. Mantysaari. 2012. Short communication: genetic parameters for feed intake, production, and extent of negative energy balance in Nordic Red dairy cattle. J. Dairy Sci. 95(11):6788-6794.

Manzanilla-Pech, C. I. V., R. F. Veerkamp, M. P. L. Calus, R. Zom, A. van Knegsel, J. E. Pryce and Y. de Haas. 2014. Genetic parameters across lactation for feed intake, fat-and protein-corrected milk, and liveweight in first-parity Holstein cattle. J. Dairy Sci. 97(9):5851-5862.

Manzanilla-Pech, C. I. V., R. F. Veerkamp, R. J. Tempelman, M. L. van Pelt, K. A. Weigel, M. VandeHaar, T. J. Lawlor, D. M. Spurlock, L. E. Armentano, E. E. Connor, C. R. Staples, M. Hanigan and Y. de Haas. 2016. Genetic parameters between feed-intake-related traits and conformation in 2 separate dairy populations: the Netherlands and United States. J. Dairy Sci. 99(5):4095-4095.

Meuwissen, T. H. E., B. J. Hayes and M. E. Goddard. 2001. Prediction of total genetic value using genome-wide dense marker maps. Genetics 157(4):18191829.

Muller, C. J. C., S. W. P. Cloete, J. J. Olivier, J. A. Botha and H. de Waal. 2006. Heritability of live weight and condition score in a Holstein herd and correlations with milk traits: preliminary estimates. S. Afr. J. Anim. Sci. 36(2):79-88.

Pryce, J. E., W. J. Wales, Y. de Haas, R. F. Veerkamp and B. J. Hayes. 2014. Genomic selection for feed efficiency in dairy cattle. Animal 8(1):1-10.

Pszczola, M., R. F. Veerkamp, Y. de Haas, E. Wall, T. Strabel and M. P. L. Calus. 2013. Effect of predictor traits on accuracy of genomic breeding values for feed intake based on a limited cow reference population. Animal 7(11):1759-1768.

Spurlock, D. M., J. C. M. Dekkers, R. Fernando, D. A. Koltes and A. Wolc. 2012. Genetic parameters for energy balance, feed efficiency, and related traits in Holstein cattle. J. Dairy Sci. 95(9):5393-5402.

Su, G., P. Madsen, U. S. Nielsen, E. A. Mantysaari, G. P. Aamand, O. F. Christensen and M. S. Lund. 2012. Genomic prediction for Nordic Red Cattle using one-step and selection index blending. J. Dairy Sci. 95(2):909-917.

ten Napel, J., H. A. Mulder, M. Lidauer, I. Stranden, E. Mäntysaari, M. H. Pool and R. F. Veerkamp. 2014. MiXBLUP: The Mixed-model

Best Linear Unbiased Prediction Software for PCs for Large Genetic Evaluation Systems. Version 1.3.1. Wageningen: Wageningen University. 
Vallimont, J. E., C. D. Dechow, J. M. Daubert, M. W. Dekleva, J. W. Blum, C. M. Barlieb, W. Liu, G. A. Varga, A. J. Heinrichs and C. R. Baumrucker. 2010. Genetic parameters of feed intake, production, body weight, body condition score, and selected type traits of Holstein cows in commercial tie-stall barns. J. Dairy Sci. 93(10):4892-4901.

Vallimont, J. E., C. D. Dechow, J. M. Daubert, M. W. Dekleva, J. W. Blum, C. M. Barlieb, W. Liu, G. A. Varga, A. J. Heinrichs and C. R. Baumrucker. 2011. Heritability of gross feed efficiency and associations with yield, intake, residual intake, body weight, and body condition score in 11 commercial Pennsylvania tie stalls. J. Dairy Sci. 94(4):2108-2113.

Van Arendonk, J. A. M. 1991. Use of profit equations to determine relative economic value of dairy-cattle herd life and production from field data. J. Dairy Sci. 74(3):1101-1107.

Van Arendonk, J. A. M., G. J. Nieuwhof, H. Vos and S. Korver. 1991. Genetic aspects of feed intake and efficiency in lactating dairy heifers. Livest. Prod. Sci. 29(4):263275.

VanRaden, P. M. 2008. Efficient methods to compute genomic predictions. J. Dairy Sci. 91(11):4414-4423.

Veerkamp, R. F. 1998. Selection for economic efficiency of dairy cattle using information on live weight and feed intake: a review. J. Dairy Sci. 81(4):11091119.

Veerkamp, R. F. and S. Brotherstone. 1997. Genetic correlations between linear type traits, food intake, live weight and condition score in Holstein Friesian dairy cattle. Animal Science 64:385-392.

Veerkamp, R. F., M. P. Coffey, D. P. Berry, Y. de Haas, E. Strandberg, H. Bovenhuis, M. P. L. Calus and E. Wall. 2012. Genome-wide associations for feed utilisation complex in primiparous Holstein-Friesian dairy cows from experimental research herds in four European countries. Animal 6(11):1738-1749.

Veerkamp, R. F., J. K. Oldenbroek, H. J. Van Der Gaast and J. H. J. Van Der Werf. 2000. Genetic correlation between days until start of luteal activity and milk yield, energy balance, and live weights. J. Dairy Sci. 83(3):577-583.

Veerkamp, R. F. and R. Thompson. 1999. A covariance function for feed intake, live weight, and milk yield estimated using a random regression model. J. Dairy Sci. 82(7):1565-1573.

Williams, Y. J., J. E. Pryce, C. Grainger, W. J. Wales, N. Linden, M. Porker and B. J. Hayes. 2011. Variation in residual feed intake in Holstein-Friesian dairy heifers in southern Australia. J. Dairy Sci. 94(9):4715-4725. 
Yang, J., B. Benyamin, B. P. McEvoy, S. Gordon, A. K. Henders, D. R. Nyholt, P. A. Madden, A. C. Heath, N. G. Martin, G. W. Montgomery, M. E. Goddard and P. M. Visscher. 2010. Common SNP explain a large proportion of the heritability for human height. Nature Genetics 42(7):565-569.

Zom, R. L. G., G. Andre and A. M. van Vuuren. 2012. Development of a model for the prediction of feed intake by dairy cows: 1 . Prediction of feed intake. Livest. Sci. 143(1):43-57. 




\section{Chapter 6}

General Discussion 



\subsection{Introduction}

Feed costs represent more than half of the total costs of dairy production in Europe (E.U., 2011). Therefore, there is an interest in improving feed efficiency; e.g., by including dry matter intake (DMI) in the breeding goal. As DMI is a trait that varies significantly during and across lactations, it is imperative to understand the underlying genetic architecture of DMI across lactation. Moreover, phenotypes of DMI are scarce, due to the difficulty of recording them (expensive and laborintensive). Some predictor traits have been suggested to help to predict determine DMI. Examples of these predictor traits are those related to production (milk yield [MY] or milk content) or to the maintenance of the cow (body weight or conformation traits). The ability to determine when predictor traits ideally should be measured in order to achieve an accurate prediction of DMI throughout the whole lactation period is thus important. Recently, with the use of single nucleotide polymorphism (SNP) markers' information, together with phenotypic data and pedigree, genomic estimated breeding values (GEBV) of scarcely recorded traits, such as DMI, have become easier to accurately predict. This approach, combined with predictor traits, could contribute to increase accuracy of predictions of DMI.

Methane $\left(\mathrm{CH}_{4}\right)$ is the second largest gas of the greenhouse gases, and enteric $\mathrm{CH}_{4}$ is the largest source of anthropogenic $\mathrm{CH}_{4}$, representing $17 \%$ of global $\mathrm{CH}_{4}$ emissions (Knapp et al., 2014). Furthermore, methane emissions represent 2$12 \%$ of feed energy losses (Johnson et al., 1994). Therefore, the interest in selecting for lower $\mathrm{CH}_{4}$ emitting animals is understandable, as such a move would aid in mitigating global $\mathrm{CH}_{4}$ emissions, and also select for more feed-efficient animals. Further, to identify the impact on $\mathrm{CH}_{4}$ emissions of selecting for lower DMI animals, it is important to determine the correlations between $\mathrm{DMI}$ and $\mathrm{CH}_{4}$ and to identify whether the same genes that control DMI affect $\mathrm{CH}_{4}$.

The objectives of this thesis were as follows: (1) to explore the genetic architecture of DMI during lactation; (2) to study the relationship of DMI to conformation traits, production and other related traits; (3) to investigate the correlations between DMI and methane traits, and determine associated SNP common to both $\mathrm{DMI}$ and $\mathrm{CH}_{4}$ through a genome-wide association study (GWAS); and (4) to investigate the accuracy of GEBV of DMI using predictor traits combined with genomic data. This thesis has provided information about the genetic architecture of $\mathrm{DMI}$ and $\mathrm{CH}_{4}$, together with related traits like fat and protein corrected milk (FPCM), body weight (BW) and conformation traits that can be used as predictor traits. Some results of this thesis have contributed (together with 
other research) to the practical implementation of resource efficiency traits in practice. For example, genetic correlations between BW and conformation traits (Chapter 3) have been used to develop the Body Size Composite Index in Holstein USA (Holstein-USA, 2016). Additionally, in the Netherlands, a breeding value for DMI was introduced in April 2016, and in April 2017 this breeding value will be included in the Dutch index, combined with the returns for the milk yield trait (INET).

At the same time, discussions are still ongoing regarding the optimal way to include (net) feed efficiency in the dairy cattle breeding goal, and the optimal way to record predictor traits in dairy cattle. Therefore, the general discussion will cover two main points: what is needed in order to include feed efficiency in the breeding goal for dairy cattle, and how can the recording of feed intake and its predictors be optimized?

\subsection{Towards including feed efficiency in the breeding goal}

There is growing interest in including feed efficiency in the breeding goal and, in this way, maximizing profitability (Berry and Crowley, 2013; Veerkamp et al., 2013; Berry and Pryce, 2014; Pryce et al., 2014). In this section, I will first discuss whether variation remains in DMI after accounting for maintenance (BW) and production (MY) - i.e., net efficiency. I will also discuss the variation in $\mathrm{CH}_{4}$ associated with BW and DMI. Secondly, the impact on $\mathrm{CH}_{4}$ when selecting for DMI or RFI will be investigated via the correlated response. Thirdly, the advantages and disadvantages of selecting for RFI and DMI will be examined. Later, correlations between feed intake and economically important traits, such as fertility, will be considered, allowing for insight regarding the possible correlated response of these traits when selecting for DMI. Finally, profit indices for DMI and RFI will be reviewed.

\subsubsection{Variation in DMI and $\mathrm{CH}_{4}$ explained by correlated traits, such as MY and BW}

A considerable part of the feed intake is used for milk production, maintenance and body tissue mobilization (Veerkamp, 1998). Therefore, an important question when considering whether or not to include DMI or $\mathrm{CH}_{4}$ in the breeding goal is how much genetic variation in $\mathrm{DMI}$ or $\mathrm{CH}_{4}$ can be explained by reference to traits already considered in selection: milk production and BW. In this respect, estimated genetic correlations between DMI and predictor traits provide information that aids us in disentangling the total variation of DMI. 
Using the results from Chapters 2 and 3, we can say that $64 \%$ of the genetic variation in DMI (calculated as the genetic correlation squared) is attributable to FPCM, with a genetic correlation between those two traits during mid lactation of 0.8 (Figure 2.6). This figure also shows that BW only explained around $9 \%$ of the total variation in DMI in early lactation, but up to $36 \%$ during the rest of the lactation period and $16 \%$ across the entire lactation period (with an average genetic correlation of 0.4 ). Moreover, based on the genetic correlation between DMI and milk energy (MilkE) of 0.63 (Table 3.4) we can infer that MilkE explains around $40 \%$ of the total variation of DMI. In the literature (Veerkamp, 1998), the genetic correlations between DMI and MY varied between 0.44 to 0.84 , and $\mathrm{MY}$ thus explained $19-70 \%$ of the total variation in DMI. Meanwhile, BW explained $5-74 \%$ of the variation in DMI, according to previous studies that reported correlations between DMI and BW of 0.23 (Veerkamp and Brotherstone, 1997) to 0.86 (Svendsen et al., 1994).

The combined effects of MY and BW on DMI can be considered when RFI is used, since RFI is commonly defined as the difference between actual feed intake and predicted feed intake on the basis of requirements for production and maintenance of BW (Kennedy et al., 1993). In Table 3.4, the genetic correlations between DMI and RFI are shown to be 0.70 in the Netherlands and 0.89 in the US, indicating that $49 \%$ and $79 \%$, respectively, of the total variance in DMI is explained by phenotypically adjusting for BW and FPCM. That also implies that $21-51 \%$ of the variance of DMI cannot be explained by reference to predictor traits and, therefore, having records on DMI is still important if we want to select for improved feed efficiency. In Figure 6.1, the energy partitioning in dairy cattle is presented. In this figure, it is possible to observe that the energy used by milk production, maintenance and growth is only a portion of the total available energy that comes from feed intake. Therefore, it is understandable that it is not possible to predict $100 \%$ of the variation of DMI through predictor traits, such as milk and BW.

For methane, fewer genetic parameters are available, but it is expected that $\mathrm{CH}_{4}$ is related to RFI and BW (Hegarty et al., 2007). In Chapter 4, genetic correlations between $\mathrm{CH}_{4}$ and $\mathrm{BW}$ (0.83) and between $\mathrm{CH}_{4}$ and DMI (0.80) were estimated. Based on those genetic correlations, the percentage of the total variation in $\mathrm{CH}_{4}$ explained by $\mathrm{BW}$ and $\mathrm{DMI}$ is $64 \%$ and $69 \%$, respectively. This leaves approximately $30 \%$ of the variation in $\mathrm{CH}_{4}$ to be explained, possibly related to the type of diet and the microbial flora content of each animal (Henderson et al., 2015). 


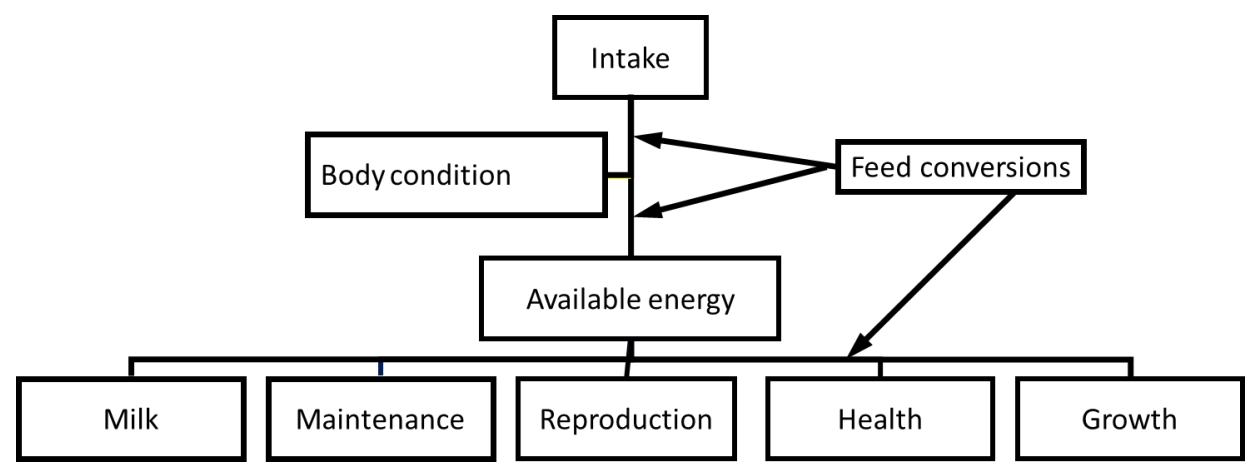

Figure 6.1 Energy partitioning in dairy cattle.

Regardless of the large percentage of the total variation of DMI (around 76\%) and $\mathrm{CH}_{4}$ (around $70 \%$ ) that can be explained by predictor traits that correspond to maintenance and production, there remains a percentage that cannot be explained. This percentage corresponds to the variation that is intrinsic to the net efficiency (or feed conversions, as termed in Figure 6.1) of DMI or $\mathrm{CH}_{4}$, which may be attributable to energy lost in feces, gas, urine or heat for digesting and metabolizing feed. To improve net feed efficiency, DMI breeding values predicted on the basis of MY and BW are not sufficient, and $\mathrm{DMI}$ and $\mathrm{CH}_{4}$ records are required.

\subsubsection{Correlated responses on $\mathrm{CH}_{4}$ when selecting for DMI}

Another important question is how $\mathrm{CH}_{4}$ is affected when selecting for lower DMI animals. Assuming a correlation of 0.8 between $\mathrm{DMI}$ and $\mathrm{CH}_{4}$ and a standard deviation of $7 \mathrm{gr}$ for $\mathrm{CH}_{4}$ (Table 4.2), when selecting for animals with low DMI (reducing DMI by one standard deviation), the correlated response for $\mathrm{CH}_{4}$ is a reduction of $5.64 \mathrm{gr}$ of methane per animal per day. This represents $5 \%$ of the average daily methane production (132 gr; Table 4.1) of growing beef cattle. For a herd of 500 animals, then, that would represent a reduction of $1029 \mathrm{~kg}$ of methane per year from the hypothetical $24,090 \mathrm{~kg}$ otherwise produced per year by that herd, representing a reduction of $4 \%$. However, given that DMI is also highly correlated with BW, this reduction would probably negatively impact growth. Therefore, the solution is not as straightforward as selecting for lower $\mathrm{CH}_{4}$ emitting animals by selecting for lower DMI animals, as BW must be included in the profit equation, and breeding should thus aim for reducing DMI at the same levels of BW.

According to the Australian Bureau of Statistics (2015), there are 13.3 million beef cows in Australia. If we assume an average daily production of $\mathrm{CH}_{4}$ by beef cattle of 179 gr per animal (Hegarty et al., 2007), we would have 872 million 
kilograms of methane produced per year. Selecting for DMI could help to reduce this amount by $5 \%$, corresponding to 43 million kilograms of methane per year. $A$ similar approach with more promising results was taken by Alford et al. (2006), who simulated 25 years of selecting for RFI in commercial herds of beef cattle in Australia, reaching reductions of RFI of $11-21 \%$ and a cumulative reduction of $16 \%$ for enteric methane. Moreover, Hegarty et al. (2007) have suggested that selecting for more efficient animals through RFI in beef cattle not only reduces feed costs but also reduces enteric methane emissions without compromising growth rates or productivity.

In Holstein cows, with a genetic correlation of 0.40 between RFI and predicted $\mathrm{CH}_{4}$ based on De Haas et al. (2011), and a genetic variance for methane of $170 \mathrm{gr}^{2}$ (Chapter 4), the reduction of predicted $\mathrm{CH}_{4}$ as a response correlated with selecting for lower RFI animals by one standard deviation would amount to $5.2 \mathrm{gr}$ per animal per day. With a daily average production of $400 \mathrm{gr} / \mathrm{d}$, this represents a reduction of $1.3 \%$ of daily production of $\mathrm{CH}_{4}$. If we perform the same exercise for dairy cattle in Netherlands, with a 1.7 million population (AHDB, 2015) producing an average of $400 \mathrm{gr} / \mathrm{d}$ per animal - amounting to a total of 233 million kilograms of methane produced in a year - selecting for RFI could achieve a reduction of 3.03 million kilograms of methane. Currently, there is not enough information in the literature about the genetic correlations between $\mathrm{CH}_{4}$ and $\mathrm{DMI}$ in Holstein cattle to calculate their correlated response. However, based on unpublished analyses of Danish Holstein, genetic correlations of 0.75 between DMI and predicted methane have been reported (G. Difford, personal communication, 2016). Using the same genetic variance of $170 \mathrm{gr}^{2}$ and the genetic correlation of 0.75 between DMI and $\mathrm{CH}_{4}$, selecting for lower DMI by one standard deviation would reduce $\mathrm{CH}_{4}$ by $2.44 \%$ (9.77 gr per day).

In sheep, Rose et al. (2016) have reported genetic correlations close to zero (0.05) between $\mathrm{RFI}$ and $\mathrm{CH}_{4}$, but moderately positive genetic correlations between $\mathrm{DMI}$ and $\mathrm{CH}_{4}$ (0.51). This suggests that selecting for animals with lower or negative RFI would not decrease the emissions of $\mathrm{CH}_{4}$ by Merino sheep, but selecting for animals with low DMI would help to reduce $\mathrm{CH}_{4}$ emissions.

These calculations show that selecting for DMI or RFI partially contributes to the mitigation of $\mathrm{CH}_{4}$ emissions in the dairy and beef industry. However, it is important to consider a possible reduction in MY and growth when selecting only for lower DMI animals without properly accounting for MY and BW in the selection index and profit equation. The optimum scenario would be to reduce $\mathrm{CH}_{4}$ while maintaining levels of production ( $M Y$ in dairy cattle) and growth (BW or ADG in 
beef cattle). However, if RFI is not genetically correlated with MY, then in theory there is no risk of lowering production (MY) by selecting for lower RFI animals.

\subsubsection{Advantages and disadvantages of using DMI vs. feed efficiency (RFI or ratio traits)}

There is common agreement that feed efficiency should be included in breeding goals, but there remains considerable debate as to whether selection should include RFI or DMI. Here, I discuss the advantages and disadvantages of including these traits in breeding goals, based on the results of previous chapters and recent literature.

To determine the best feed efficiency phenotype to include in the breeding goal, several questions should be addressed. For example, what is the main purpose of including feed efficiency in the breeding goal - to simply reduce feed intake or to improve feed efficiency? The answer to this question can vary across countries. Moreover, if DMI is selected, which other traits should be included in the breeding goal? Should DMI, MY and BW be included as equivalent to RFI? It is arguably necessary to include a maintenance trait in the breeding goal, so as to avoid secondary negative effects on the body condition of the animal.

Residual feed intake is defined as the difference between actual feed intake and that predicted on the basis of requirements for production and maintenance of BW. Yet there is no standard method by which to calculate RFI (Kennedy et al., 1993). Its calculation varies from study to study, which can be a problem when you want to merge data from several populations/countries. There are several methods of calculating RFI, but perhaps the most accepted is that proposed by Koch et al. (1963) and modified by Berry et al. (2013), which is represented by the residuals from regression of feed intake on various energy sinks. Another method calculates RFI using standard information in the feed tables (nutrient required tables [NRC]) as the energy demand of the energy sinks, subtracted from the energy intake - this method is mainly used for nutritional purposes (Berry and Crowley, 2013). Further, Kennedy et al. (1993) draw a distinction between phenotypic regression and genotypic regression for calculating $\mathrm{RFI}$, according to which phenotypic regression as commonly used would provide an RFI phenotypically independent of its regressors but not necessarily genetically independent of its regressors.

Dry matter intake has the advantage of being clearly defined and simple to understand. As a result, data regarding DMI is easier to combine across countries. In fact, it was possible to bring together DMI data from nine countries through the gDMI project (Veerkamp et al., 2013; Berry et al., 2014), resulting in 
the availability of international EBV and GEBV (de Haas et al., 2015). Further, DMI is a trait with moderate heritability -between 0.20 and 0.50 (Chapter 2 ) - so selection is feasible.

One advantage of RFI is that it is easier to identify efficient animals, as RFI negative numbers represent animals that eat less than expected according to their level of production and weight. By contrast, for DMI, an animal with a lower value is not necessarily more efficient than an animal with a higher value, given that the animal with a lower DMI could be a small animal producing much less milk in comparison to a bigger animal with a higher DMI producing more milk. Another advantage is that RFI is easier to include in a multi-trait selection index that already includes milk production and weight, avoiding the issue of double counting (Pryce et al., 2015).

Heterogeneity in the calculation of RFI could compromise the merging of databases across populations and/or countries, or the estimation of breeding values. Lower heritabilities, of between 0.05 and 0.30 , have been reported for RFI in comparison to DMI, with heritabilities between 0.20 and 0.60 (Berry and Crowley, 2013), in lactating animals. However, de Haas et al. (2011) have reported higher heritabilities for RFI, with an average of 0.47 for the first 30 weeks of lactation. Including RFI in the breeding goal could be akin to having an index within an index. Besides, Herd and Bishop (2000) have mentioned the possibility of ignoring some real variation of DMI by selecting for RFI, due to the correlations between the regressors (traits) used to calculate RFI. Additionally, selecting for RFI could also lead to animals that do not consume enough feed and instead mobilize fat reserves, leading to a negative energy balance and compromising the reproduction and health of the selected animals (Vallimont et al., 2013). Furthermore, although RFI is DMI adjusted by MY and BW, and the expected correlations between DMI and its regressors are zero, there could in fact be some correlations between these factors, rendering RFI inaccurate. In Chapter 3, the genetic correlations between RFI and MY were 0.11 in the Netherlands and 0.35 in the US, while the genetic correlations between RFI and BW were 0.04 in the Netherlands and 0.26 in the US, yet all the phenotypic correlations between RFI and DMI-BW were close to zero in both countries.

Moreover, Van der Werf (2004) states that there is no difference in considering RFI rather than feed intake, production traits and body composition in the breeding objective, assuming no fixed effects in the model. Van der Werf (2004) also mentions that the estimated parameters of RFI could show the genetic variation of feed efficiency, and its genetic parameters and heritability could be informative and help us to understand the biological underpinnings of feed 
efficiency. To summarize, if DMI is included in the breeding goal, BW is not necessary as DMI includes the variation of weight for maintenance and production, but if RFI is included then BW should also be included, as RFI represents only variation in DMI without BW or MY (Pryce et al., 2014).

Traits such as feed conversion efficiency, average daily gain or Kleiber ratio (Berry and Pryce, 2014) can be used in attempts to explain feed efficiency. Despite their popularity, ratio traits come with some disadvantages, such as strong correlation with the denominator trait and difficulty of interpretation of the selection response due to antagonism between the response in the numerator and the denominator (Berry and Crowley, 2013; Veerkamp and Emmans, 1995).

In conclusion, despite there being no fundamental difference between including RFI or DMI and regressors in the breeding goal, DMI does seem to have solid advantages over $\mathrm{RFI}$, such as its simpler definition, the possibility of merging data more easily, its higher heritability and the fact that DMI seems to be more strongly correlated with methane emissions than RFI. Therefore, I suggest including $\mathrm{DMI}$ in the breeding goal instead of RFI. However, that decision can vary across countries, given that some countries have invested years of research in RFI.

\subsubsection{Correlations of DMI and RFI with economically important traits}

Another important aspect when including DMI or RFI in the breeding goals is knowing the possible positive and negative correlations with other economically important traits (e.g., fertility, longevity, calf survival, health traits, etc.). From Figure 6.1 it can be anticipated that selection for feed efficiency could compromise traits like reproduction and fertility (Rauw et al., 1998; Pryce et al., 2004) unless those traits are also included in the breeding goal. Estimates of correlations between DMI and traits like health and fertility are limited because many of these traits are not routinely recorded on commercial farms. However, Vallimont et al. (2013) reported genetic correlations of -0.14 between DMI and open days, and correlations of -0.50 between RFI and open days, with a data set of 970 Holstein cows. They also presented genetic correlations between productive life trait, defined as the sum of the total days in milk (DIM), and both DMI (0.49) and RFI (0.23).

Given that genetic correlations between BW or body condition score (BCS) are available (Pryce et al., 2000; Veerkamp et al., 2001; Berry et al., 2003b; Banos et al., 2004; Bastin and Gengler, 2013) they could help to account for fertility if BW or BCS are represented in the breeding objective. For example, BCS has a genetic correlation with days to first heat/service ranging from 0.4 to 0.6 , and a correlation 
with calving interval of 0.4 (Pryce et al., 2001; Veerkamp et al., 2001; Berry et al., 2003a). Due to the high positive correlations between BCS and DMI, moderate correlations are expected between DMI and those fertility traits.

In pigs, negatively correlated responses in behavior traits, muscle physiology, meat quality and reproductive performance have been reported after selecting for feed efficiency (Fan et al., 2010; Young et al., 2011; Gilbert et al., 2012). Knap and Wang (2012) suggested a series of steps to control these side effects, including routine recording of the correlated traits, estimation of accurate EBV for those traits, monitoring of genetic changes and, finally, inclusion of those EBV traits in the selection index to account for their correlated response. This could also be a good way to account for some other economic traits in dairy cattle.

In poultry, feed conversion has been associated with ascites, sudden death syndrome, reduced immune competence, dyschondroplasia, poor reproductive performance and other metabolic diseases (Emmerson, 1997). Thus, marker assisted selection against these traits, together with growth and feed conversion, has been proposed to ensure the feasibility of sustained genetic improvement of feed conversion (Emmerson, 1997). This could be a promising alternative to implement in dairy cattle - for example, Liefers et al. (2002) reported associations between leptin gene polymorphisms and fertility in Holstein heifers.

As selection in dairy cattle was focused, for more than half a century, primarily on production (Oltenacu and Broom, 2010), thereby compromising health, fertility and longevity, these features should be taken into account before selecting for DMI. These are highly correlated traits, as many health problems cause reproduction disorders or poor fertility, leading to culling decisions. Therefore, a reduction of DMI without taking into account the correlated response of these traits or without including them in the breeding goal could have a negative impact on those traits. In conclusion, to account for traits like fertility or reproduction, health and longevity must also be taken into account.

\subsubsection{Profit indices for DMI and RFI in practice}

In the profit equation index, the economic weights of traits that contribute to the economic merit of the animal are combined with EBV for the component traits into an EBV for economic merit for selection purposes (Van Arendonk et al., 1991). The profit index should include all sources of cost, as well as DMI, as the major contributor. In the Dutch INET and in production indices in many other countries, economic weights for milk, fat and protein are adjusted for normative feed costs, but differences in feed intake are ignored in the profit index. 
Some countries, like New Zealand and the US, have included a type of gross feed efficiency in their profit index equation by including milk production and BW or predicted BW. In the case of the US (Holstein-USA, 2015), they have recently included feed efficiency in their index (called the TPI formula). Feed efficiency is calculated as the value of milk produced (in dollars) minus feed costs for extra milk and extra maintenance costs. The TPI formula also includes production, health, fertility and conformation traits, with respective weights of $48 \%, 28 \%$ and $26 \%$.

Now, with the EBV and GEBV available for DMI and economic evaluations of DMI, it is possible to include DMI in the profit index. In Australia, RFI has been included in the national profit index called the balanced performance index (BPI) (Byrne et al., 2016), resulting in a reduction of feed that represents a saving of half a million Australian dollars (Gonzalez-Recio et al., 2014). Furthermore, Pryce et al. (2015) proposed combining feed required for maintenance (BW) with RFI to calculate a new feed efficiency breeding value called feed saved. The main advantage of this new approach is that animals with the same RFI but higher maintenance requirements can be identified, and selecting for animals with one standard deviation above the mean can save up to $1 \%$ of the annual feed cost.

In the Netherlands and the Flanders area of Belgium, in April 2017, DMI will be added to the INET production index, which combines fat, protein and lactose yield with DMI. Each of these traits have economic values based on farm prices and feed costs. In a pilot trial, adding DMI to the total merit index resulted in lower feed intake and a $2 \%$ higher response in production efficiency and feed usage, having no effects on traits like health and fertility (Jong et al., 2016). By adding the INET to the total index (NVI), genetic responses for traits like fertility, health and longevity are taken into account.

\subsection{Optimizing the recording of feed intake and its predictors}

Given the high cost of recording $\mathrm{DMI}$ and $\mathrm{CH}_{4}$, it is necessary to develop a strategy for recording $\mathrm{DMI}$ and $\mathrm{CH}_{4}$ that optimizes the use of resources. In this section, I will first discuss the lactation curves for DMI, FPCM and BW so as to understand the mechanism behind these traits. Secondly, I will discuss the genetic correlations of DMI during lactation in order to understand the genetic variation within DMI at different DIM values. Later, using a selection index calculation, the best scheme for recording DMI directly will be identified. Then, based on selection index theory and using the genetic correlations between $\mathrm{DMI}, \mathrm{CH}_{4}$ and their predictor traits, the best scheme for recording predictor traits will be suggested. 
Finally, the optimum number of cows in a reference population for predicting accurate DMI will be examined.

\subsubsection{Lactation curves}

Lactation curves are important for understanding how the same trait performs across lactation (DMI, MY and BW), and also how these traits interrelate on average.

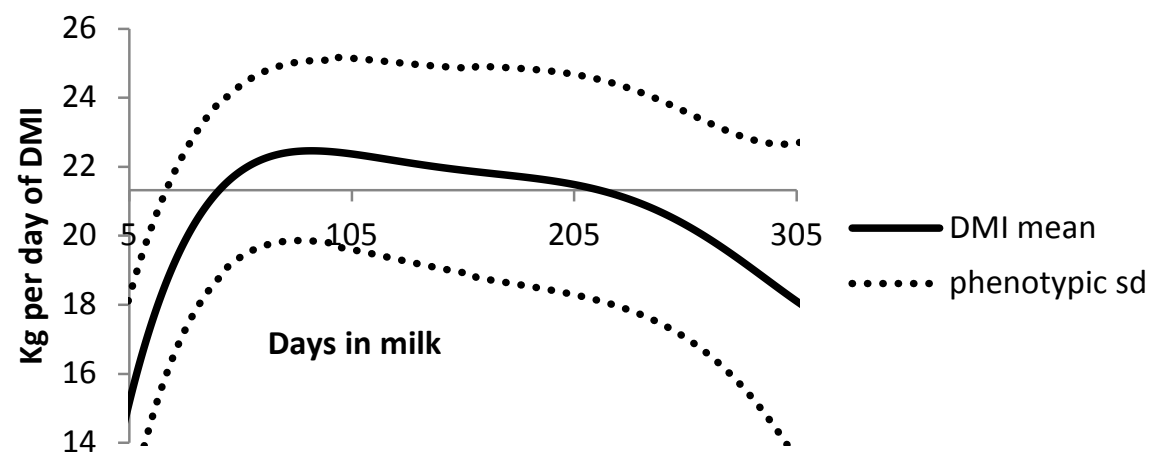

Figure 6.2 Lactation curve of dry matter intake (DMI) adjusted by three lactations using Legendre polynomials with an average consumption of $21.5 \mathrm{~kg}$ per day and an indicated range of plus/minus one phenotypic standard deviation.

When observing and comparing the lactation curves of DMI, FPCM and BW (Figure 6.2, 6.3 and 6.4, respectively), we can appreciate the phenomenon known as negative energy balance. Despite the amount of feed consumed during early lactation (from five to 100 days) and the corresponding amount of milk produced at the beginning of the early lactation period, the BW shows that the animal actually loses weight in this time, using its body fat reserves to produce the milk rather than using the feed digested. During this period, the cow can lose as much as $0.7 \mathrm{~kg} / \mathrm{day}$ (Silvestre et al., 2009). In late lactation, a contrary phenomenon is observed - the animal consumes less feed than in early lactation, produces less milk and gains some weight, accumulating body fat to compensate for the earlier losses. However, at the end of lactation cows are pregnant again, in most cases, so the weight of the calf contributes to this increase in BW. Moreover, cows with excessive body tissue 
mobilization in early lactation can take up to 20 weeks to regain their positive energy balance (Taylor et al., 2003).

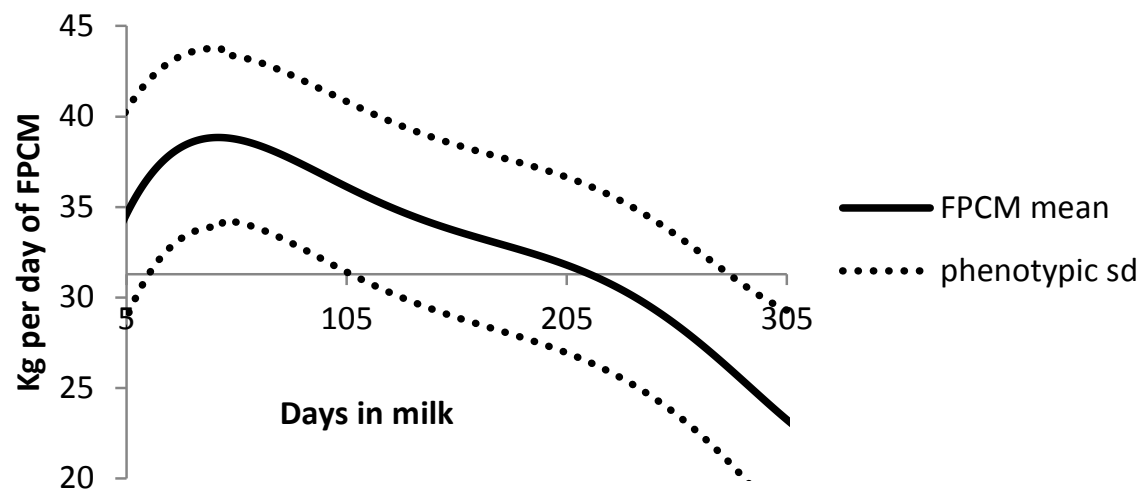

Figure 6.3 Lactation curve of fat and protein corrected milk (FPCM) adjusted by three lactations using Legendre polynomials with an average production of $31.1 \mathrm{~kg}$ per day and an indicated range of plus/minus one phenotypic standard deviation.

To summarize, during early lactation, milk production increases faster than does DMI, since mobilization of body tissues provides the additional energy required for milk production. This is either because the energy demand of milk production is higher than the amount of feed consumed, or because high producing cows are genetically driven towards body tissue mobilization rather than the use of energy provided by the feed (Verbyla et al., 2010). It is unclear which of these two explanations is the most likely, but the consequence is that the cow enters into a negative energy balance, mobilizing body fat reserves and losing weight. Cows reach their production peak in this period, and peak DMI also occurs around the $70^{\text {th }}$ day. During mid lactation, the cows no longer present weight losses - BW starts to increase, DMI remains stable and milk yield starts to decrease. The cow is also inseminated during this period. Finally, during late lactation, milk production and DMI continue to decrease, while BW continues increasing, probably partially due to the new pregnancy.

\subsubsection{Genetic correlation of DMI during lactation}

To optimize the recording of feed intake during lactation, it is important to understand the genetic architecture of DMI. The genetic correlations between DMI recorded on a certain day $(10,80,150$ and 300 DIM) and that recorded on all other 


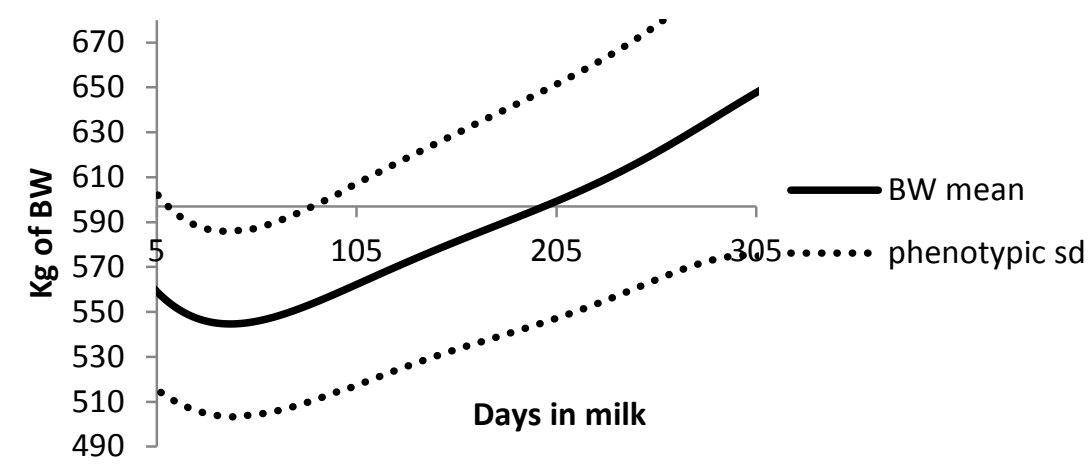

Figure 6.4 Lactation curve of body weight (BW) adjusted by three lactations using Legendre polynomials with an average weight of $605 \mathrm{~kg}$ and an indicated range of plus/minus one phenotypic standard deviation.

DIM (Figure 6.5) were calculated from the genetic parameters reported in Chapter 2. Those days are representative of early, peak, mid and late lactation, so that we can see how DMI on a given day correlates with that on other days during different stages of lactation. The genetic correlation between DMI recorded on 10 DIM and the rest of the lactation period was poor, declining rapidly from 0.97 at day one to 0.38 at day 190. This suggests that early lactation feed intake is not very useful for predicting late lactation feed intake. By contrast, the genetic correlations between DMI recorded at 80, 150 and 300 DIM and the rest of the lactation period varied from moderate (>0.6 for 80 DIM) to highly positive ( $>0.8$ for 150 DIM) for most of the lactation period after 50 DIM.

Similar results have been reported previously (Koenen and Veerkamp, 1998; Huttmann et al., 2009; Buttchereit et al., 2011), with genetic correlations varying from low positive to moderate negative (from 0.29 to -0.55 ) between DMI recorded in early lactation and DMI in mid lactation, while high positive correlations (up to 0.98) are observed for DMI in mid lactation (up to 180 DIM). Furthermore, Karacaoren et al. (2006) reported a slightly negative genetic correlation for DMI (-0.07) for adjacent days after 120 DIM until the end of the lactation period (305 DIM). 


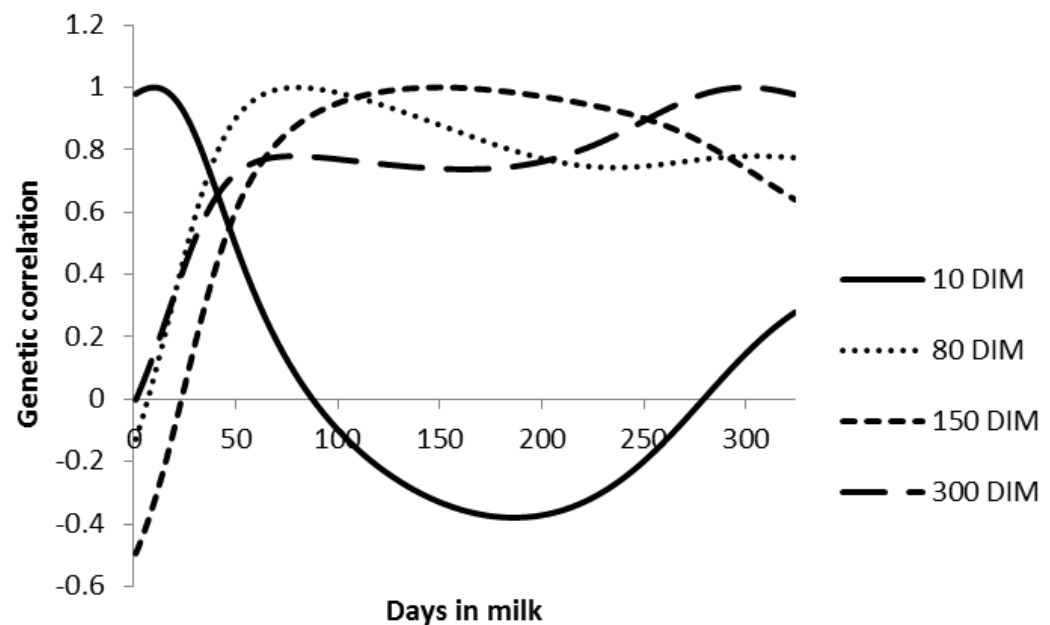

Figure 6.5 Genetic correlation between dry matter intake (DMI) recorded on a certain day $(10,80,150$ and 300 days in milk [DIM]) and DMI recorded on all other DIM.

Genetic correlations within lactation were, as expected, highest between days close to one another, decreasing as time between measurements increased. Figure 6.6 shows the average genetic correlations of DMI when the difference between two DMI recordings is $10,20, \ldots, 300,310$ DIM. The genetic correlations decrease gradually from 0.99 at 10 DIM of difference to 0.5 at 150 DIM of difference, and further down to 0.2 at 310 DIM of difference.

In conclusion, the genetic correlations of DMI during lactation demonstrate that DMI is genetically different across the various stages of lactation, with the main difference being between early and late lactation. These results are important when considering whether to add DMI to a linear selection index. Furthermore, this information is useful to consider when records from different stages of lactations are available, and are relevant to planning the recording strategy for DMI, as will be discussed in the next point.

\subsubsection{Direct recording of DMI}

In order to determine the best scheme for recording DMI, a simulation was performed using selection index theory and genetic parameters obtained from Chapter 2. Selection index theory was used to calculate the accuracy of predicting breeding values of DMI using different recording schemes. 


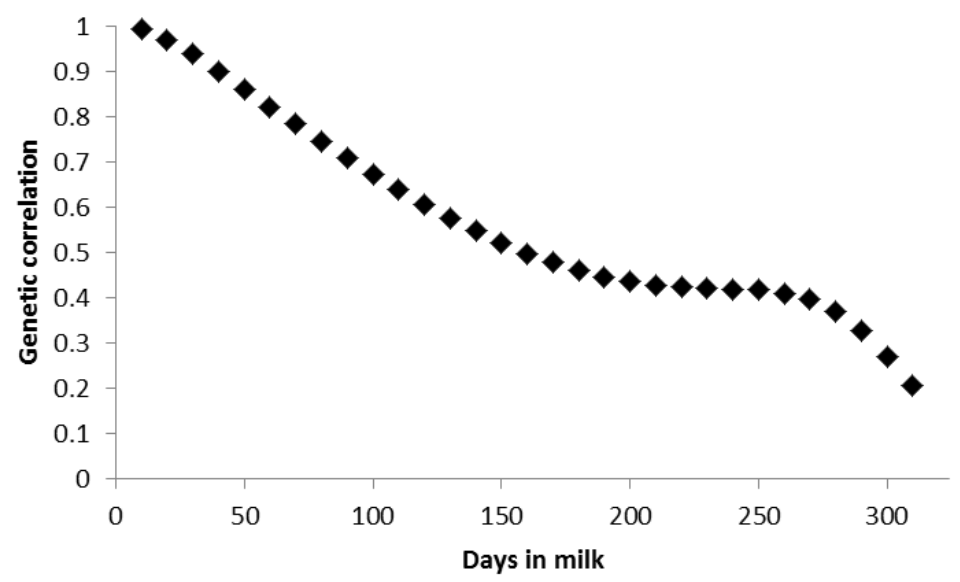

Figure 6.6 Average genetic correlations of dry matter intake (DMI) when the difference between two DMI recordings is $10,20, \ldots, 310$ days in milk (DIM).

Accuracies were calculated for a breeding goal that included DMI across the entire lactation period, and a selection index that included DMI recorded for five, 10, 15 and 20 weeks. Figure 6.7 shows these accuracies when the recording period started in different weeks. As expected, the accuracy is highest when the length of the recording period is longest. Recording DMI for 20 weeks gave an accuracy of 0.67 , which was twice as accurate as the recording of DMI for five weeks. Additionally, beginning the record of DMI in mid or late lactation gave more accurate estimates for the entire lactation period than starting the record in early lactation. When the 15 -week recording period was split into two periods (seven weeks during mid lactation and eight weeks during late lactation), an average accuracy of 0.62 was observed, close to the accuracy obtained via the more intensive 20-week recording scheme. Furthermore, the accuracy of the DMI prediction based on 15 continuous weekly records of early lactation was 0.44 , for mid lactation 0.59 and for late lactation 0.67. This finding further demonstrates that it is more important to measure DMI in mid and late lactation, when the breeding value for the entire lactation is needed.

To summarize, there are two factors that influence the accuracy of prediction of DMI: the length of recording and the stage of lactation recorded. Longer recording periods give better accuracies, yet the costs of recording recommend limiting this variable as much as possible. Therefore, a second recommendation for optimal recording is useful - recording DMI in mid or late lactation gives higher accuracies in comparison to early lactation. 


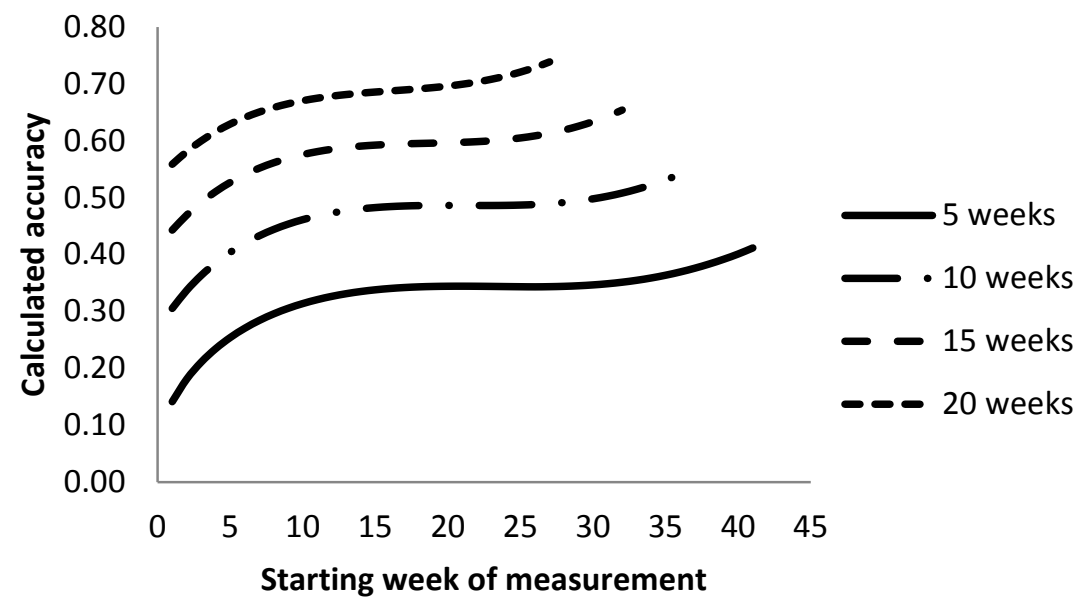

Figure 6.7 Calculated accuracies for dry matter intake (DMI) over the entire lactation period when DMI is recorded for five, 10, 15 or 20 weeks, starting at different weeks of the lactation period.

Furthermore, if the recording period is divided in two, covering both mid and late lactation, the accuracy increases. Thus, the best recording scheme according to the genetic correlations of DMI with lactation and based on the selection index theory is two periods of seven to eight weeks during mid and late lactation. However, in practical terms, it may not be possible to record DMI in two different stages of lactation.

\subsubsection{Indirect recording of DMI through predictor traits}

As in direct recording of DMI, when estimating DMI through predictor traits, the accuracy of prediction can vary according to the lactation stage. In this section, I will discuss the best schemes for recording predictor traits of both DMI and $\mathrm{CH}_{4}$.

\subsubsection{DMI}

In order to determine which trait or combination of traits offers the most accurate prediction of DMI across lactation stages, selection index theory (Falconer and Mackay, 1996) was applied. For this purpose, the genetic correlations between DMI, FPCM and BW were estimated for each week of the lactation (Chapter 2). The accuracy of DMI predictions was calculated with weekly records over the entire lactation period, for FPCM, BW and both traits together across three stages of lactation: early, from one to 15 weeks; mid, from 15 to 30 weeks; and late, from 31 
to 46 weeks. Each scenario had two variants: (1) phenotypic records of cows available for the predictor traits (cow), and (2) highly accurate breeding values available for bulls for all predictors (bull).

The accuracies were, as expected, higher for the scenario with highly accurate breeding values (bull) than for the scenario with phenotypic records (cow) (Table 6.1). Also, accuracies were higher for recording during mid lactation, in comparison to early and late lactation, for FPCM alone, BW alone and FPCM together with BW. The low accuracies recorded during early lactation could be attributable to low or slightly negative correlations between DMI and FPCM/BW during early lactation. These low or negative correlations between DMI and FPCM/BW during early lactation also reflect the fact that the animal is using its own body fat reserves to produce milk, instead of the feed consumed, resulting in a negative energy balance.

Table 6.1 Accuracies of predictions of dry matter intake (DMI) using fat and protein corrected milk (FPCM), body weight (BW) and these two traits combined in an index for three stages of lactation - early (1-15 weeks), mid (16-30 weeks) and late (31-45 weeks) under two variants: cows, with just one phenotypic record available, and bulls, assuming the availability of highly accurate breeding values.

\begin{tabular}{lcccccc}
\hline \multirow{2}{*}{ Predictor traits for DMI } & \multicolumn{2}{c}{ Early } & \multicolumn{2}{c}{$\begin{array}{c}\text { Stage of lactation } \\
\text { Mid }\end{array}$} & \multicolumn{2}{c}{ Late } \\
\hline \multirow{3}{*}{ FPCM } & Bulls & Cows & Bulls & Cows & Bulls & Cows \\
\cline { 2 - 8 } BW & 0.38 & 0.26 & 0.67 & 0.54 & 0.16 & 0.12 \\
FPCM and BW & 0.30 & 0.20 & 0.40 & 0.25 & 0.40 & 0.30 \\
\hline
\end{tabular}

Conformation traits can also be used as predictors of DMI (Chapter 3), as in Figure 3.7, it was shown that DMI can be predicted using stature (ST), chest width (CW) and body depth (BD) with an accuracy of 0.43 (in the Netherlands) for the bull scenario. Adding MilkE (similar to FPCM) to the previous scenario increased the accuracy to 0.74. Furthermore, when BW was added to the index, the accuracies increased to 0.79 , this slight increase being attributable to the fact that variation in DMI due to BW is already captured by the conformation traits (ST, CW and BW together). Thus, when BW is used to predict DMI, the accuracy is 0.47 , similar to that achieved using the conformation traits (0.43).

In conclusion, the best scheme for recording FPCM and BW to predict DMI is to combine both measures in an index with continuous weekly recording during mid lactation (Table 6.1). This recommendation is difficult to follow due to the 
extra costs and labor required, which not many commercial farmers are willing to invest. However, in the near future, this recording scheme could be implemented using new technologies, such as milking robots, that could be adapted to regularly measure BW and inline fat and protein in milk. Such a development could also allow for large amounts of data (records) to be analyzed, thereby further improving accuracy.

\subsubsection{Methane}

Selection for lower methane emitting animals is not yet a daily practice, despite new available techniques to measure such emissions, due to the limited amount of data available and the labor and money investment required (Link et al., 2005; Pinares-Patino et al., 2008; Chagunda et al., 2009; Herd, 2014; Laubach et al., 2014). As an alternative, methane emissions could be one trait positively affected by selection for feed-efficient animals, as currently there are greater records available regarding DMI than $\mathrm{CH}_{4}$.

Thus, there is great interest in the possibility of predicting methane traits using selection index theory [1]. Some scenarios for predicting methane traits in Angus populations are presented using 1) DMI, 2) BW and 3) a combination of both traits. However, in this case, if information by day or by week is not available the whole growth period is assumed to be constant. This study can be regarded as a pilot investigation into the accuracy of predictions of methane production (MeP), methane yield ( $\mathrm{MeY}$, defined as MeP/DMI) and methane intensity ( $\mathrm{MI}$, defined as $\mathrm{MeP} / \mathrm{BW}$ ) using DMI and BW as predictor traits. Furthermore, this study can be used if it is found to be necessary in the future to report daily estimates, as in the case of DMI, to better predict $\mathrm{CH}_{4}$.

In Table 6.2, accuracies of predictions of MeP, MeY and MI using DMI, BW or both traits together in an index for two scenarios - cows and bulls (as previously described) - are presented. As in previous cases, predicting a raw (pure) trait is usually more accurate than predicting a calculated trait (residual or ratio traits), as in the case of DMI vs. RFI. The accuracies of predictions of MeP using DMI and BW traits combined in an index are found to be between 0.71 and 0.84 , while accuracies of predictions of MeY fall between 0.10 and 0.21 . However, using DMI and $\mathrm{BW}$ to predict $\mathrm{MI}$ gave prediction accuracies between 0.30 and 0.74 .

Therefore, in Angus populations, it is possible to predict MeP more accurately from DMI and BW than the other methane traits due to the higher correlations between these traits. This is perhaps not a practical scenario, as DMI is also a scarcely recorded trait, yet if data on DMI and EBV of DMI are available, they could work as proxies for methane. It has been shown that selecting for lower DMI 
Table 6.2 Accuracies of predictions of methane traits: methane production (MeP), methane yield (MeY) and methane intensity ( $\mathrm{MI}$ ) using dry matter intake (DMI) and body weight (BW) for two scenarios: bulls and cows.

\begin{tabular}{llll}
\hline Trait to predict & Predictor traits & Bulls & Cows \\
\hline MeP & DMI & 0.83 & 0.70 \\
& BW & 0.80 & 0.67 \\
& DMI and BW & 0.84 & 0.71 \\
\hline MeY & & \\
& DMI & 0.04 & 0.01 \\
& BW & 0.05 & 0.04 \\
& DMI and BW & 0.21 & 0.10 \\
\hline MI & & & \\
& DMI & 0.33 & 0.20 \\
& BW & 0.44 & 0.33 \\
& DMI and BW & 0.74 & 0.30 \\
\hline
\end{tabular}

cows could offer a favorable correlated response in terms of reducing methane (Hegarty et al., 2007; De Haas et al., 2011). However, additional studies with daily or weekly records on methane and DMI-BW are recommended to capture the correlations between those traits across lactation periods, and determine if DMI and BW can be proxies for methane.

\subsubsection{Optimal number of cows in the reference population}

Genomic selection has been highlighted as having added value in cases of scarcely recorded traits (Pszczola et al., 2012; Pryce et al., 2014), however the size of the reference population needed to achieve competitive accuracies (Daetwyler et al., 2010) must yet be improved. To determine the optimal number of cows with DMI records in the reference population in Holstein, the size of the reference population for genomic prediction according to Daetwyler et al. (2010) has been calculated. With a heritability of 0.32 for DMI (Chapter 3), and an $M_{e}$ (proportion of independent chromosome segments) of 800 for Holstein cows (Wientjes et al., 2013), a reference population of 10,000 cows is needed to reach 0.8 accuracy of prediction of DMI. Consequently, if the reference population size decreased, the accuracy also decreases.

Likewise, Pryce et al. (2015) mention that, for RFI, considering an average heritability of $0.2,30,000$ cows are needed in the reference population to achieve reliabilities of greater than $50 \%$. This exercise demonstrates the importance of the 
number of records in the reference population and the heritability of the trait in the genome-wide evaluation approach for novel traits. For DMI and RFI, such population size requirements represent a challenge.

One viable option for enlarging the size of the reference population in order to achieve accurate GEBV for DMI is to merge reference populations between countries. This is becoming a popular approach, with the creation of consortiums and international groups that share data to get accurate estimates, such as the global Dry Matter Initiative (gDMI), which boasts a membership of nine countries (Veerkamp et al., 2013).

However, some traits (probably due to genotype-environment interaction) perform differently in different countries, as do genetic correlations with related traits. Therefore, it is important to estimate the genetic correlations for DMI and related traits between countries, which requires a good amount of connected bulls/daughters or pedigrees across populations. In Chapter 3, genetic parameters between DMI, production and conformation traits were estimated in two countries. Unfortunately, however, there were not enough bulls in common to link both populations, making it difficult to estimate correlations for DMI between countries. With genomic information, it might be possible to increase the genetic links between populations.

Another aspect to consider when increasing the reference population by merging databases between countries is the level of relatedness within the reference population, as Pszczola et al. (2012) have suggested. According to Pszczola et al. (2012), relatedness within the reference population should be as low as possible, though this may be difficult to achieve if data is pooled between different countries, given that probably closest animals from common bulls will be on this new pooled reference population. The second point suggested by Pszczola et al. (2012) is to maximize the relatedness between the reference population and the validation animals. This would depend on the percentage of the reference population contributed by each country, and countries with small contributions would benefit especially from this approach.

\subsection{Conclusion}

From this discussion, several conclusions have been drawn. In Section 6.2, five main points were made. First, despite the large percentage of DMI explained by predictor traits corresponding to maintenance and production, there is still a percentage that cannot be explained by reference to predictor traits, which corresponds to the variation due to digesting feed or converting it to milk (net 
efficiency). Therefore, to improve net efficiency, records of DMI are always required. Second, by selecting for low DMI or RFI, methane emissions are partially reduced as a correlated response. Third, there is no difference between including all components of RFI (DMI, MY and BW) or RFI alone in the breeding goal. However, including DMI seems to have some practical implications and advantages, such as a simpler definition, the possibility of more easily merging data and greater heritability that could reduce the reference population required by the trait (from 30,000 to 10,000 cows). Fourth, before including DMI in the breeding goal, it is necessary to consider the possible implications of other economic traits, such as health, fertility, reproduction and longevity. DMI (together with milk production and $\mathrm{BW}$ ) or RFI should be included in the profit equation with economic weights. For this to be possible, economic weights must be calculated. Finally, other traits should also be considered for inclusion in the profit equation, such as fertility, health and reproduction.

In Section 6.3, we arrived at six main conclusions. First, in order to design a recording scheme for DMI or its predictor traits (FPCM and BW) it is advisable to determine how each trait performs across different stages of lactation. Second, it is necessary to be aware of genetic correlations within DMI across lactation, given that DMI is a trait that varies across lactation periods. Third, there are two factors that influence the accuracies of predictions of DMI when direct records are used: the length of the recording period (longer periods give higher accuracies) and the stage of lactation (mid and late lactation stages are more accurate than early lactation). Fourth, the best scheme of recording FPCM and BW in order to predict whole lactation DMI is to take weekly records of both traits during mid lactation (between weeks 16 and 30). Fifth, records on DMI at early lactation and FPCM-BW records during mid and late lactation are recommended. Finally, to achieve a prediction accuracy of 0.8 for DMI using genomic prediction, a reference population of 10,000 cows is required. To achieve such a reference population size for phenotypic records on DMI, international collaboration is essential. 


\subsection{References}

ABS (Australian Bureau of Statistics). 2015. Livestock in Australia. http://www.abs.gov.au/ausstats/abs@.nsf/Latestproducts/7121.0Main\%20Featu res52014-15 ?opendocument \&tabname=Summary \&prodno=7121.0\&issue $=2014$ 15\&num=\&view=. Accessed: November 7, 2016.

AHDB. 2015. EU cow numbers. https://dairy.ahdb.org.uk/resources-library/marketinformation/farming-data/eu-cow-numbers/\#.WCCU3FXhCUk.

Accessed: November 7, 2016.

Alford, A. R., R. S. Hegarty, P. F. Parnell, O. J. Cacho, R. M. Herd and G. R. Griffith. 2006. The impact of breeding to reduce residual feed intake on enteric methane emissions from the Australian beef industry. Aust. J. Exp. Agr. 46(6-7):813-820.

Banos, G., S. Brotherstone and M. P. Coffey. 2004. Evaluation of body condition score measured throughout lactation as an indicator of fertility in dairy cattle. J. Dairy Sci. 87(8):2669-2676.

Bastin, C. and N. Gengler. 2013. Genetics of body condition score as an indicator of dairy cattle fertility. A review. Biotechnol. Agron. Soc. 17(1):64-75.

Berry, D. P., F. Buckley, P. Dillon, R. D. Evans, M. Rath and R. F. Veerkamp. 2003a. Genetic parameters for body condition score, body weight, milk yield, and fertility estimated using random regression models. J. Dairy Sci. 86(11):37043717.

Berry, D. P., F. Buckley, P. Dillon, R. D. Evans, M. Rath and R. F. Veerkamp. 2003b. Genetic relationships among body condition score, body weight, milk yield, and fertility in dairy cows. J. Dairy Sci. 86(6):2193-2204.

Berry, D. P. and J. J. Crowley. 2013. Cell biology symposium: genetics of feed efficiency in dairy and beef cattle. J. Anim. Sci. 91(4):1594-1613.

Berry, D. P. and J. E. Pryce. 2014. Feed efficiency in growing and mature animals. pp.1-4. Proceedings, 10th World congress of genetics applied to livestock production. Vancouver, Canada.

Berry, D. P., E. Wall and J. E. Pryce. 2014. Genetics and genomics of reproductive performance in dairy and beef cattle. Animal 8:105-121.

Buttchereit, N., E. Stamer, W. Junge and G. Thaller. 2011. Short communication: genetic relationships among daily energy balance, feed intake, body condition score, and fat to protein ratio of milk in dairy cows. J. Dairy Sci. 94(3):1586-1591.

Byrne, T. J., B. F. S. Santos, P. R. Amer, D. Martin-Collado, J. E. Pryce and M. Axford. 2016. New breeding objectives and selection indices for the Australian dairy industry. J. Dairy Sci. 99(10):8146-8167.

Chagunda, M. G. G., D. Ross and D. J. Roberts. 2009. On the use of a laser methane detector in dairy cows. Comput. Electron. Agr. 68(2):157-160. 
Daetwyler, H. D., R. Pong-Wong, B. Villanueva and J. A. Woolliams. 2010. The impact of genetic architecture on genome-wide evaluation methods. Genetics 185(3):1021-1031.

De Haas, Y., J. E. Pryce, M. P. L. Calus, E. Wall, D. P. Berry, P. Lovendahl, N. Krattenmacher, F. Miglior, K. Weigel, D. Spurlock, K. A. Macdonald, B. Hulsegge and R. F. Veerkamp. 2015. Genomic prediction of dry matter intake in dairy cattle from an international data set consisting of research herds in Europe, North America, and Australasia. J. Dairy Sci. 98(9):6522-6534.

De Haas, Y., J. J. Windig, M. P. L. Calus, J. Dijkstra, M. de Haan, A. Bannink and R. F. Veerkamp. 2011. Genetic parameters for predicted methane production and potential for reducing enteric emissions through genomic selection. J. Dairy Sci. 94(12):6122-6134.

E.U. 2011. European Commission of Agricultural and Rural Development. Farm Economics Brief. No. 2 Production costs overview. http://ec.europa.eu/agriculture/rica/pdf/Brief201102.pdf. Accessed: November 7, 2016.

Emmerson, D. A. 1997. Commercial approaches to genetic selection for growth and feed conversion in domestic poultry. Poultry Sci. 76(8):1121-1125.

Falconer, D. S. and T. F. C. Mackay. 1996. Introduction to Quantitative Genetics. Fourth Edition. Pearson Prentice Hall.

Fan, B., S. Lkhagvadorj, W. Cai, J. Young, R. M. Smith, J. C. M. Dekkers, E. HuffLonergan, S. M. Lonergan and M. F. Rothschild. 2010. Identification of genetic markers associated with residual feed intake and meat quality traits in the pig. Meat Sci. 84(4):645-650.

Gilbert, H., J. P. Bidanel, Y. Billon, H. Lagant, P. Guillouet, P. Sellier, J. Noblet and S. Hermesch. 2012. Correlated responses in sow appetite, residual feed intake, body composition, and reproduction after divergent selection for residual feed intake in the growing pig. J. Anim. Sci. 90(4):1097-U1046.

Gonzalez-Recio, O., J. E. Pryce, M. Haile-Mariam and B. J. Hayes. 2014. Incorporating heifer feed efficiency in the Australian selection index using genomic selection. J. Dairy Sci. 97(6):3883-3893.

Hegarty, R. S., J. P. Goopy, R. M. Herd and B. McCorkell. 2007. Cattle selected for lower residual feed intake have reduced daily methane production. J. Anim. Sci. 85(6):1479-1486.

Henderson, G., F. Cox, S. Ganesh, A. Jonker, W. Young, P. H. Janssen and G. R. C. Collaborators. 2015. Rumen microbial community composition varies with diet and host, but a core microbiome is found across a wide geographical range. Sci. Rep-Uk 5. 
Herd, R. M. and S. C. Bishop. 2000. Genetic variation in residual feed intake and its association with other production traits in British Hereford cattle. Livest. Prod. Sci. 63(2):111-119.

Herd, R. M., P. F. Arthur, S. H. Bird, K. A. Donoghue and R. S. Hegarty. 2014. Genetic Variation for Methane Traits in Beef Cattle. Proc. 10th World Congress of Genetics Applied to Livestock Production, Vancouver, BC, Canada.

Holstein-USA. $2015 . \quad$ TPI formula. http://www.holsteinusa.com/genetic_evaluations/ss_tpi_formula.html. Accessed: November 7, 2016.

Holstein-USA. 2016. New body size composite: an improved way to estimate body weight. http://www.holsteinusa.com/pdf/Body_Size_Composite_New.pdf. Accessed: November 15, 2016.

Huttmann, H., E. Stamer, W. Junge, G. Thaller and E. Kalm. 2009. Analysis of feed intake and energy balance of high-yielding first lactating Holstein cows with fixed and random regression models. Animal 3(2):181-188.

Johnson, K., M. Huyler, H. Westberg, B. Lamb and P. Zimmerman. 1994. Measurement of methane emissions from ruminant livestock using a sulfur hexafluoride tracer technique. Environ. Sci. Technol. 28(2):359-362.

Jong, G., R. van der Linde, Y. de Haas, G. Schopen and R. Veerkamp. 2016. Genetic evaluation for feed intake in the Netherlands and Flanders, impact on efficiency and responses. in Interbull Annual Meeting. Interbull, ed. Interbull Bulletin, Puerto Varas, Chile.

Karacaoren, B., F. Jaffrezic and H. N. Kadarmideen. 2006. Genetic parameters for functional traits in dairy cattle from daily random regression models. J. Dairy Sci. 89(7):2811-2811.

Kennedy, B. W., J. H. J. Vanderwerf and T. H. E. Meuwissen. 1993. Genetic and statistical properties of Residual Feed Intake. J. Anim. Sci. 71(12):3239-3250.

Knap, P. W. and L. Wang. 2012. Feed Efficiency in Swine. pp. 167-181. Springer, ed.

Knapp, J. R., G. L. Laur, P. A. Vadas, W. P. Weiss and J. M. Tricarico. 2014. Invited review: enteric methane in dairy cattle production: quantifying the opportunities and impact of reducing emissions. J. Dairy Sci. 97(6):3231-3261.

Koch, R. M., K. E. Gregory, D. Chambers and L. A. Swiger. 1963. Efficiency of feed use in beef cattle. J. Anim. Sci. 22(2):486-494.

Koenen, E. P. C. and R. F. Veerkamp. 1998. Genetic covariance functions for live weight, condition score, and dry-matter intake measured at different lactation stages of Holstein Friesian heifers. Livest. Prod. Sci. 57(1):67-77. 
Laubach, J., S. P. P. Grover, C. S. Pinares-Patino and G. Molano. 2014. A micrometeorological technique for detecting small differences in methane emissions from two groups of cattle. Atmos. Environ. 98:599-606.

Liefers, S. C., M. F. W. te Pas, R. F. Veerkamp and T. van der Lende. 2002. Associations between leptin gene polymorphisms and production, live weight, energy balance, feed intake, and fertility in Holstein heifers. J. Dairy Sci. 85(6):1633-1638.

Link, A., R. Sauter and U. Haas. 2005. Highly sensitive and mobile TDL-PA spectroscopic measuring device for methane. J. Phys. Iv. 125:841-844.

Oltenacu, P. A. and D. M. Broom. 2010. The impact of genetic selection for increased milk yield on the welfare of dairy cows. Anim. Welfare 19:39-49.

Pinares-Patino, C. S., A. Machmuller, G. Molano, A. Smith, J. B. Vlaming and H. Clark. 2008. The SF6 tracer technique for measurements of methane emission from cattle - effect of tracer permeation rate. Can. J. Anim. Sci. 88(2):309-320.

Pryce, J. E., M. P. Coffey and S. Brotherstone. 2000. The genetic relationship between calving interval, body condition score and linear type and management traits in registered Holsteins. J. Dairy Sci. 83(11):2664-2671.

Pryce, J. E., M. P. Coffey and G. Simm. 2001. The relationship between body condition score and reproductive performance. J. Dairy Sci. 84(6):1508-1515.

Pryce, J. E., O. Gonzalez-Recio, G. Nieuwhof, W. J. Wales, M. P. Coffey, B. J. Hayes and M. E. Goddard. 2015. Hot topic: definition and implementation of a breeding value for feed efficiency in dairy cows. J. Dairy Sci. 98(10):7340-7350.

Pryce, J. E., M. D. Royal, P. C. Garnsworthy and I. L. Mao. 2004. Fertility in the highproducing dairy cow. Livest. Prod. Sci. 86(1-3):125-135.

Pryce, J. E., W. J. Wales, Y. de Haas, R. F. Veerkamp and B. J. Hayes. 2014. Genomic selection for feed efficiency in dairy cattle. Animal 8(1):1-10.

Pszczola, M., T. Strabel, H. A. Mulder and M. P. L. Calus. 2012. Reliability of direct genomic values for animals with different relationships within and to the reference population. J. Dairy Sci. 95(1):389-400.

Rauw, W. M., E. Kanis, E. N. Noordhuizen-Stassen and F. J. Grommers. 1998. Undesirable side effects of selection for high production efficiency in farm animals: a review. Livest. Prod. Sci. 56(1):15-33.

Rose, G., B. Paganoni and A. N. Thompson. 2016. Breeding for feed efficiency does not decrease methane production in growing lambs. Proc. Annual Meeting of the European Federation of Animal Science. p. 451. Wageningen Academy Publishers, Belfast, United Kingdom. 
Silvestre, A. M., A. M. Martins, V. A. Santos, M. M. Ginja and J. A. Colaco. 2009. Lactation curves for milk, fat and protein in dairy cows: a full approach. Livest. Sci. 122(2-3):308-313.

Svendsen, M., P. Skipenes and I. L. Mao. 1994. Genetic correlations in the feed conversion complex of primiparous cows at a recommended and a reduced plane of nutrition. J. Anim. Sci. 72(6):1441-1449.

Taylor, V. J., D. F. Beever and D. C. Wathes. 2003. Physiological adaptations to milk production that affects fertility in high yielding dairy cows. Dairying: using science to meet consumers' needs. Br. Soc. Anim. Sci. 29:37-71.

Vallimont, J. E., C. D. Dechow, J. M. Daubert, M. W. Dekleva, J. W. Blum, W. Liu, G. A. Varga, A. J. Heinrichs and C. R. Baumrucker. 2013. Feed utilization and its associations with fertility and productive life in 11 commercial Pennsylvania tiestall herds. J. Dairy Sci. 96(2):1251-1254.

Van Arendonk, J. A. M., G. J. Nieuwhof, H. Vos and S. Korver. 1991. Genetic aspects of feed intake and efficiency in lactating dairy heifers. Livest. Prod. Sci. 29(4):263275.

Van Der Werf, J. H. J. 2004. Is it useful to define residual feed intake as a trait in animal breeding programs? Aust. J. Agr. Res. 44:405-409.

Veerkamp, R. F. 1998. Selection for economic efficiency of dairy cattle using information on live weight and feed intake: a review. J. Dairy Sci. 81(4):11091119.

Veerkamp, R. F. and S. Brotherstone. 1997. Genetic correlations between linear type traits, food intake, live weight and condition score in Holstein Friesian dairy cattle. Animal Science 64:385-392.

Veerkamp, R. F. and G. C. Emmans. 1995. Sources of genetic variation in energetic efficiency of dairy cows. Livest. Prod. Sci. 44(2):87-97.

Veerkamp, R. F., E. P. C. Koenen and G. De Jong. 2001. Genetic correlations among body condition score, yield, and fertility in first-parity cows estimated by random regression models. J. Dairy Sci. 84(10):2327-2335.

Veerkamp, R. F., J. E. Pryce, D. Spurlock, D. P. Berry, M. P. Coffey, P. Lovendahl, R. van der Linde, J. Bryant, F. Miglior, Z. Wang, M. Winters, N. Krattenmacher, N. Charfeddine, J. Pedersen and Y. de Haas. 2013. Selection of feed intake of feed efficiency: a position paper from gDMI breeding goal discussions. pp. 15-22. Proc. Interbull Bulletin No.47, Nantes, France.

Verbyla, K. L., M. P. L. Calus, H. A. Mulder, Y. de Haas and R. F. Veerkamp. 2010. Predicting energy balance for dairy cows using high-density single nucleotide polymorphism information. J. Dairy Sci. 93(6):2757-2764. 
Wientjes, Y. C. J., R. F. Veerkamp and M. P. L. Calus. 2013. The effect of linkage disequilibrium and family relationships on the reliability of genomic prediction. Genetics 193(2):621-631.

Young, J. M., W. Cai and J. C. M. Dekkers. 2011. Effect of selection for residual feed intake on feeding behavior and daily feed intake patterns in Yorkshire swine. J. Anim. Sci. 89(3):639-647. 

Summary 



\section{Summary}

Feed costs represent half of the total costs of dairy production. One way to increase profitability of dairy production is to reduce feed costs by improving feed efficiency. As DMI is a trait that varies significantly during and across lactations, it is imperative to understand the underlying genetic architecture of DMI across lactation. Moreover, phenotypes of DMI are scarce, due to the difficulty of recording them (expensive and labor-intensive). Some predictor traits have been suggested to predict DMI. Examples of these predictor traits are those related to production (milk yield (MY) or milk content) or to the maintenance of the cow (body weight (BW) or conformation traits). The ability to determine when predictor traits ideally should be measured in order to achieve an accurate prediction of DMI throughout the whole lactation period is thus important. Recently, with the use of information of single nucleotide polymorphism (SNP) markers, together with phenotypic data and pedigree, genomically estimated breeding values (GEBV) of scarcely recorded traits, such as DMI, have become easier to accurately predict. This approach, combined with predictor traits, could contribute to an increased accuracy of predictions of GEBV of DMI.

Methane $\left(\mathrm{CH}_{4}\right)$ is the second important greenhouse gas, and enteric $\mathrm{CH}_{4}$ is the largest source of anthropogenic $\mathrm{CH}_{4}$, representing $17 \%$ of global $\mathrm{CH}_{4}$ emissions (Knapp et al., 2014). Furthermore, methane emissions represent $2-12 \%$ of feed energy losses (Johnson et al., 1994). Selecting for lower $\mathrm{CH}_{4}$ emitting animals and more feed-efficient animals would aid in mitigating global $\mathrm{CH}_{4}$ emissions. To identify the impact on $\mathrm{CH}_{4}$ emissions of selecting for lower DMI animals, it is important to determine the correlations between $\mathrm{DMI}$ and $\mathrm{CH}_{4}$ and to identify whether the same genes that control DMI affect $\mathrm{CH}_{4}$.

Therefore, the general objectives of this thesis were to (1) explore the genetic architecture of DMI during lactation, (2) study the relationship of DMI to conformation, production and other related traits, (3) investigate the correlations between DMI and methane traits, and determine the SNP in common between $\mathrm{DMI}$ and $\mathrm{CH}_{4}$ through a genome-wide association study (GWAS), and (4) investigate the accuracy of predictions of DMI using predictor traits combined with genomic data.

In Chapter 2, genetic parameters were estimated for DMI, fat and protein corrected milk (FPCM), and body weight (BW) across the entire first lactation in order to determine whether those traits are genetically correlated to one another, and whether such correlation varies across lactation periods. The database used 
was a combination of a number of historical nutritional experiments in the Netherlands, resulting in a large amount of data. A total of 30,483 weekly records for DMI, 49,977 for FPCM, and 31,956 for BW from 2,283 Dutch Holstein-Friesian first-parity cows between 1990 and 2011 were available. Genetic correlations between DMI and either FPCM or BW were not symmetric across days in milk (DIM), and differed depending on which trait was measured first. The results of this chapter are useful to understand the genetic relationship of DMI, FPCM, and BW on specific days across lactation.

In Chapter 3, genetic correlations were estimated between six feed intakerelated traits - DMI, residual feed intake (RFI), MY, milk energy (MilkE), BW, and metabolic BW (MBW) - and seven conformation traits - stature (ST), chest width (CW), body depth (BD), angularity (ANG), rump angle (RA), rump width (RW), and body condition score (BCS); reflecting the body conditions and sizes of Holstein cows from two different countries: the Netherlands and the United States. Feed intake data were available for 1,665 cows in NL and for 1,920 cows in US, from 83 nutritional experiments (48 in NL and 35 in US) conducted between 1991 and 2011 in NL and between 2007 and 2013 in US. Additional conformation records from relatives of the animals with $\mathrm{DMI}$ records were added to the database giving a total of 37,241 cows in NL and 28,809 in the US with conformation trait information. As result, feed intake-related traits were moderate to high genetically correlated with conformation traits (ST, CW, BD, and BCS) in both countries, making them potentially useful as predictors of DMI. Feed intake can be predicted with accuracies up to 0.74 in NL and 0.95 in US by combining three conformation traits (ST, CW and BD) and MilkE into an index.

In Chapter 4, genomic wide association studies (GWAS) were performed to identify SNP associated with $\mathrm{CH}_{4}$ traits - methane production (MeP), methane yield (MeY) and methane intensity (MI) - as well as DMI and BW in Australian Angus beef cattle, to validate, a posteriori, the significant SNPs found in beef (for all traits) in two Holstein population. Additionally, two different residual methane traits are evaluated and it is determined whether SNPs associated with $\mathrm{CH}_{4}$ also play a role in controlling residual methane traits. Methane, $\mathrm{DMI}$ and $\mathrm{BW}$ records were available for 1,020 Angus animals. Besides, 205 Holstein multiparous cows with methane records, and 905 Holstein heifers with DMI and BW records were used to validate significant SNP from Angus. Based on SNP in common and genetic correlations, we concluded that MeP is a trait that is mainly dependent on DMI and BW. Besides, methane residual traits could be a good option to include in the breeding goal, as this would facilitate selection for lower emitting animals without compromising DMI and BW. 
In Chapter 5, accuracies of GEBV for DMI from three methods (GBLUP, SSGBLUP and SSRR-BLUP) and several different scenarios (using information from one or three lactations; using FPCM and BW as predictor traits or not) are compared in order to determine which method and scenario provides the most accurate GEBV. A total of 77,640 weekly records for DMI, 64,443 for FPCM and 73,415 for BW from 3,188 Dutch Holstein Friesian cows across 3 different lactations were used from nutritional experiments conducted between 1987 and 2015. Accuracies of GEBV for DMI were similar when applying the SS-GBLUP and SSRR-BLUP method, and lower when applying the GBLUP method. Adding information on DMI from different lactations in the training population gave higher accuracies in comparison when only lactation one is included. Finally, there was no difference in adding predictor traits information to the reference population when DMI is already included. However, in absence of DMI records, having records on FPCM and BW from different lactations enables to obtain GEBV with a considerable accuracy.

In Chapter 6 (General Discussion), two main points are discussed in detail: 1) what is needed in order to include feed efficiency in the breeding goal for dairy cattle, and 2) how to optimize the recording of feed intake and its predictors? Regarding the first point, five main conclusions were drawn: despite the large percentage of DMI explained by predictor traits corresponding to maintenance and production, there is still a percentage that cannot be explained by predictor traits, which corresponds to the variation due to digesting feed or converting it to milk (net efficiency). Therefore, to improve net efficiency, records of DMI are always required. Second, by selecting for low $\mathrm{DMI}$ or $\mathrm{RFI}, \mathrm{CH}_{4}$ emissions are reduced partially as a correlated response. Third, there is no difference between including all components of RFI (DMI, MY and BW) or RFI alone in the breeding goal. However, including DMI seems to have some practical implications and advantages, such as a simpler definition, the possibility of more easily merging data, and greater heritability that could reduce the reference population required for the trait (from 30,000 to 10,000 cows). Fourth, before including DMI in the breeding goal, it is necessary to consider the possible implications of other economic traits, such as health, fertility, reproduction and longevity. DMI (together with milk production and BW) or RFI should be included in the profit equation with economic weights. For this to be possible, economic weights must be calculated. Finally, other traits should also be considered for inclusion in the profit equation, such as fertility, health and reproduction. Regarding the second point, I presented six main conclusions. First, in order to design a recording scheme for DMI or its predictor traits (FPCM and BW) it is advisable to determine how each trait performs across different stages of lactation. Second, it is necessary to be aware of genetic 
correlations within DMI across lactation, given that DMI is a trait that varies across lactation periods. Third, there are two factors that influence the accuracies of predictions of DMI when direct records are used: the length of the recording period (longer periods give higher accuracies) and the stage of lactation (mid and late lactation stages are more accurate than early lactation). Fourth, the best scheme of recording FPCM and BW in order to predict whole lactation DMI is to take weekly records of both traits during mid lactation (between weeks 16 and 30). Fifth, records on DMI at early lactation and FPCM-BW records during mid and late lactation are recommended. Sixth, to achieve a prediction accuracy of 0.8 for DMI using genomic prediction, a reference population of 10,000 cows is required. To achieve such a reference population size for phenotypic records on DMI, international collaboration is essential.

Finally, this thesis has provided information about the genetic architecture of DMI and $\mathrm{CH}_{4}$, together with related traits like FPCM, BW and conformation traits that can be used as predictor traits. Some results of this thesis have contributed to the practical implementation of resource efficiency traits in practice. In particular, genetic correlations between BW and conformation traits (Chapter 3 ) have been used to develop the Body Size Composite Index in Holstein USA (Holstein-USA, 2016). Additionally, in the Netherlands, a breeding value for DMI was introduced in April 2016, and in April 2017 this breeding value will be included in the Dutch index, combined with the returns for the milk yield trait (INET). 


Curriculum vitae 



\section{About the author}

Coralia Ines Valentina Manzanilla Pech, was born on $17^{\text {th }}$ of October of 1979 in Merida, Yucatan, Mexico. She studied her bachelor in Agricultural Engineering with specialty in Tropical Animal Production in the Agricultural Technology of Conkal, located in Yucatan, Mexico during 1997 to 2003. In the same year, she started her master in Animal Genetics in the University of Chihuahua in Chihuahua, Mexico. In 2005 she got her Masters degree diploma with the thesis entitled "Evaluation of Charollais as a terminal breed for lamb production in Northen Mexico". After this, during 3 years, she worked for government agencies to develop productive projects in small rural communities in Mexico. In 2008, during four years, she started to work in the National Research Institute of Forestry, Agriculture and Livestock (INIFAP) in Mexico. In INIFAP, she worked on National Genetic Evaluations for the sheep and beef associations and studied model comparisons and contemporary group definition to estimate growth and fertility traits in several sheep breeds (Katahdin, Hampshire, Suffolk, Dorper). As well, she developed new adjusted factors for beef cattle (Limousine) and sheep (Kathadin). In 2012, Coralia started her PhD in the Animal Breeding and Genetics group of Wageningen UR, investigating how to improve the accuracy of prediction of feed intake through predictor traits and genomic information. During her third year of PhD, she travelled to Australia to work at the Department of Environment and Primary Industries in Melbourne. In this research period, she investigated if SNP that control feed intake also control methane traits in beef and dairy cattle. 


\section{List of publications}

\section{Peer reviewed publications}

Manzanilla-Pech, C.I.V., R.F. Veerkamp, Y de Haas, M.P.L. Calus and J. ten Napel. 2017. Accuracies of genomic breeding values for dry matter intake in Holstein cattle using different methods and scenarios. To be submitted to Journal of Dairy Science.

Manzanilla-Pech, C.I.V., Y de Haas, B.J. Hayes, R.F. Veerkamp, M. Khansefid, K.A. Donoghue, P.F. Arthur and J.E. Pryce. 2016. Genome-side association study of methane emissions in Angus beef cattle with validation in dairy cattle. Journal of Animal Science. 94:4151-4166.

Manzanilla-Pech, C.I.V., R.F. Veerkamp, R.J. Tempelman, M.L. van Pelt, K.A. Weigel, M. VandeHaar, T.J. Lawlor, D.M. Spurlock, L.E. Armentano, C.R. Staples, M. Hanigan and Y. de Haas. 2015. Genetic parameters between feed intake-related traits and conformation in two separate dairy populations: the Netherlands and United States. Journal of Dairy Science. 99:443-457.

Manzanilla Pech, C.I.V., R. F. Veerkamp, M. P. L. Calus, R. Zom, A. van Knegsel, J. E. Pryce, and Y. de Haas. 2014. Genetic parameters across lactation for feed intake, fat-and protein-corrected milk, and liveweight in first-parity Holstein cattle. Journal of Dairy Science. 97:5851-5862.

Manzanilla Pech, C.I.V., J. A. Torres V., A. Borrayo Z., Á. Ríos U., J. J. Baeza R., G. Martínez V., V.E. Vega-Murillo, and M. Montaño B. 2012. Genetic parameter estimates for growth traits in Katahdin sheep using different models. Revista Mexicana de Ciencias Pecuaria. Revista Mexicana de Ciencias Pecuarias Vol 3 (4) 487-500.

Torres Vázquez, J.A., C.I.V. Manzanilla Pech, A. Borrayo Z., Á. Ríos U., J.J. Baeza R., G. Martínez V., V.E. Vega Murillo, and M. Montaño B. 2012. Genetic and phenotypic parameters for yearling weight, scrotal circumference and frame score in Simmental and Simbrah beef cattle from Mexico. Revista Mexicana de Ciencias Pecuarias. Vol 3 (3) 291-298.

\section{Conference proceedings}

Manzanilla Pech, C.I.V., R.F. Veerkamp, J.E. Pryce, M.P.L. Calus and Y. de Haas. 2014. "Genetic Parameters and Accuracy of recording Dry Matter Intake in first parity Holstein-Friesian cows". Proccedings of 10th World Congress of Genetics Applied to Livestock Production. Vancouver, Canada, 17-22 August. 
Manzanilla Pech, C.I.V., A. Torres V., A. Borrayo Z., J.J. Baeza R., A. Ríos U., G. Martínez V., V. E. Vega M., M. Montaño B. 2011. "Genetic Evaluation of traits in Katahdin sheep". Memorias XXXV Congreso Nacional de Buiatría.

Manzanilla Pech, C.I.V., A. Torres V., A. Borrayo Z., J.J. Baeza R., A. Ríos U.G. Martínez V., V.E. Vega M., M. Montaño B. 2011. “Model comparison to estimate variance components for postweaning weight at 120 days in Katahdin sheep" Memorias XXXV Congreso Nacional de Buiatría.

Manzanilla Pech, C.I.V., A. Ríos-Utrera, V.E. Vega-Murillo, G. Martínez-Velázquez and M. Montaño-Bermúdez. 2010. "Genetic analysis of growth traits of Katahdin Sheep". Proceedings of the 9th World Congress on Genetics Applied to Livestock Production.

Manzanilla Pech, C.I.V., F. A. Rodríguez A.., C.O. Ávila C., J.A. Grado A., L. Carlos V., M. Pérez D., J.A. Ortega G. 2006. "Charollais, terminal breed for lamb production in North of Mexico". XXIV Reunión Anual de la Asociación Mexicana de Producción Animal y X Reunión Bienal del Grupo Norte Mexicano de Nutrición Animal.

\section{Conference abstracts}

Manzanilla Pech, C.I.V., Y de Haas, R.F. Veerkamp, K.A. Donoghue, P.F. Arthur, J.E. Pryce. 2016 Genome wide association study of methane emissions in Australian Angus. 67 Anual Meeting of the European Federation of Animal Science. 29 August- 2 September. Belfast, UK.

Manzanilla Pech, C.I.V., R.F. Veerkamp , R.J. Tempelman, K.A. Weigel, Y de Haas. 2015. Genetic associations between feed intake and conformation traits in two populations. 66th Anual Meeting of the European Federation of Animal Science. 31 August- 4 September. Warsaw, Poland.

Manzanilla Pech, C.I.V., R.F Veerkamp, Y. de Haas,. and M.P.L. Calus. 2013. "Genetic associations between DMI and predictor traits in Holstein cattle". 64th Anual Meeting of the European Federation of Animal Science. 26-30 August. Nantes, France.

Manzanilla Pech, C.I.V., A. Torres V., A. Borrayo Z., J.J. Baeza R., A. Ríos U., G. Martínez V., V.E. Vega M., M. Montaño B. 2011. "Variance components and genetic parameters for growth traits in Katahdin sheep under varying definitions of contemporary groups". Memorias de la XLVII Reunión Nacional de Investigación Pecuaria, León, Guanajuato, México.

Manzanilla Pech C.I.V., A. Ríos U., G. Martínez V., V.E. Vega M., M. Montaño B. 2010. "Comparison of models to estimate growth genetic parameters in 
Katahdin sheep". Memorias de la XLVI Reunión Nacional de Investigación Pecuaria, San Francisco de Campeche, Campeche.

Manzanilla Pech, C.I.V., A. Ríos U., G. Martínez V., V.E. Vega M., M. Montaño B. 2010. "Genetic correlations between birth and weaning weight in Katahdin lambs". Memorias de la XLVI Reunión Nacional de Investigación Pecuaria, San Francisco de Campeche, Campeche.

Manzanilla Pech, C.I.V., A. Rios U., G. Martinez V., V.E. Vega Murillo, M. Montano B.. 2010. "Variance components and genetic parameters for growth traits in Katahdin lamb". Segunda Reunión Mesoamericana de Ciencia Animal 2010. Villahermosa Tabasco.

Manzanilla Pech, C.I.V., A. Rios U., G. Martinez V., V.E. Vega M., M.Montaño B. 2009. "Adjustment factors for birth and weaning weight of Limousine cattle". Memorias de la XLV Reunión Nacional de Investigación Pecuaria, Saltillo, Coahuila.

Manzanilla Pech C.I.V., A. Rios U., G. Martinez V., V.E. Vega M., M. Montaño B. 2009. "Adjustment factors for birth and weaning weight in Katahdin sheep". 55 Reunión Anual de la Sociedad del PCCMCA. Cartel. San Francisco de Campeche, México. 



\section{Training and Supervision Plan}

The Basic Package (3 ECTS)

WIAS Introduction Course

Ethics and Philosophy in Life Sciences

\section{Scientific Exposure (12 ECTS)}

\section{International conferences}

Annual meeting of the European Association of Animal

Production (EAAP) 26-30 August Nantes, France

10th World Congress on Genetics Applied to Livestock

Production (WCGALP), Vancouver, Canada

Annual meeting of the European Association of Animal

Production (EAAP) Warsaw, Poland

Annual meeting of the European Association of Animal

Production (EAAP) Belfast, Northern Ireland

Seminars and workshops

New opportunities for conservation genetics with genome wide information

WIAS Science Day, Wageningen, the Netherlands (3x)

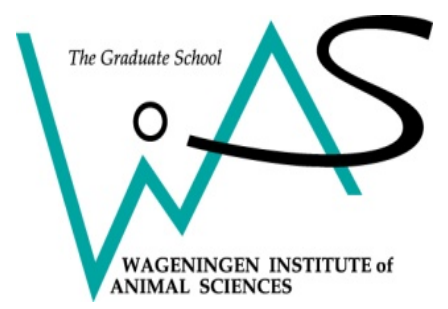

Year

2013

2013

\section{Presentations}

Poster presentation at EAAP, Nantes France

Poster presentation at WCGALP, Vancouver, Canada

Oral presentation at WIAS Science, Wageningen, the

Netherlands

Oral presentation at EAAP, Warsaw, Poland ORAL

Oral presentation at EAAP, Belfast, Northern Ireland

\section{In-Depth Studies (22 ECTS)}

Disciplinary and interdisciplinary courses

Genetic Analyses using AsReml, Wageningen, the Netherlands 
Introduction to theory and implementation of Genomic

2014

Selection, Wageningen the Netherlands

From sequence data to Genomic Prediction, Wroclaw,

2015

Poland

Genotype by environment interaction, Wageningen, the

2015

Netherlands

Feed Efficiency in Dairy Cattle,

2016

Hafjell, Norway

Advanced statistics courses

Modern Statistics, Wageningen, the Netherlands

PhD students' discussion groups

Quantitative Genetics Discussion Group (QDG)

2012-2016

$\mathrm{R}$ users meeting

2013-2015

MSc level courses

Genetic Improvement Livestock

2012

Professional Skills Support Courses (8 ECTS)

Academic Writing III, Wageningen, the Netherlands

2012-2013

Course Techniques for Scientific Writing, Wageningen, the

2013

Netherlands

Social Dutch I, Wageningen, the

2013

Netherlands

Information Literacy including Endnote Introduction,

2014

Wageningen the Netherlands

Social Dutch II, Wageningen, the Netherlands

2015

\section{Research Skills Training (10 ECTS)}

Preparing own PhD research proposal

Introduction to R for Statistical Analysis, Wageningen, the

Netherlands

Getting started in AsReml, Wageningen, the Netherlands

2013

External training period abroad (3 months) La Trobe

2015

University, Melbourne, Australia

Fortran for Scientific computer, Stuttgart, Germany

2016

\section{Education and Training Total 55 ECTS}



Acknowledgments 



\section{Acknowledgments / Agradecimientos}

I would like to thank every person that has contributed to accomplish this project, it was not easy and it took twelve years after I finished my Master to achieve, many years that I invested looking for funding, institution that support me, supervisor and a nice project to work with. In many occasions I almost give up, thinking it wouldn't happen, but at the end it was something telling "You can do it! You will do it!". It has been a long trip but finally I'm getting to the end. For the ones that know me from so long, they know this has been always my dream, and today I can say I'm almost there! I will conquer it! And it has been thanks to all of you!

I would like to first thank my parents, for encouraging me since young to reach my goals in life. I would not be able to reach this moment without you, you supported me emotionally, mentally, economically and morally during all those years. I hope to have you for many more years. Olga, I can tell you that you did a great job as mother and now you are among my best friends, thanks for always been there for me. Felipe, you have always inspired me to be a better person and act selflessly, thank you for loving me so much. Erick, my brother, thanks for being there supporting our parents when I was far from them. Byron, my dog that I love so much, for giving me so many joys during those years, beside my absence you have always been there for me, it has been really hard to be without you! Thanks also to my maternal and paternal family that have supported me those years from the distance.

Antes que nada me gustaría agradecerles a mis padres, por incentivarme desde pequeña a alcanzar mis metas. No hubiera sido capaz de llegar hasta aquí sin ustedes, ustedes me han apoyado emocional, ,moral y económicamente en todos estos años. Olga, déjame decirte que has hecho un increíble trabajo como madre y ahora eres una de mis mejores amigas, gracias por siempre estar ahí para mi. Felipe, tu siempre me has inspirado a ser mejor persona y actuar desinteresadamente, gracias por quererme tanto. Erick, hermano, gracias por estar ahí con nuestros padres mientras yo he estado lejos todo este tiempo. Byron, mi perro que amo tanto, por darme muchas alegrías durante todos estos años a pesar de la distancia siempre has estado ahí para mi y me demuestras tu amor cada vez que regreso, ha sido muy difícil estar lejos de ustedes todo este tiempo. 
Gracias también a mi familia paterna y materna que me han apoyado en estos años desde la distancia.

Also, I would like to thank my supervision committee for their guidance throughout the process of becoming a Doctor, thank you truly. Yvette, it has been a pleasure to work with you and get to know you as a person, you have always encouraged me to keep going. Roel you have promoted my professional development in your particular way and helped me to become a more tolerant person. Mario, thank you for all the times that you help me, I cannot count them, you were always available to answer a question, help me with a problem or give a nice suggestion, thanks! Jennie, I really enjoyed to work with you during these years, but particularly I enjoyed my time in Australia, working under your supervision and also getting to know you a bit better, I think we made a great team! Further, I would like to thank all my co-authors from Netherlands, Australia and United States, that gave me helpful comments and feedback for the papers, without you it would not be possible to achieve 4 quality papers in 4 years, 3 of them already published and with several citations.

Further, I want to thank all my colleagues: first the ones from Triton building: Andres, Eef, Rianne, Marcin, Ina, Amabel, Sonia, Aniek, Mario, etc, we had great times in our cafeteria and in the patio, chatting, having lunch, celebrating etc. Many thanks to my colleagues in DEPI, Melbourne: Hassan, Majid, Hans, Ben and Deirdre for making my stay over there so special and interesting and also for helping me with my research. I also want to thank my colleagues, staff and secretaries from $A B G$ in Radix building during those almost 3 years we spend together: Hadi, Marcos, Andre, Gabriel, Jeremie, Sandrine, Pascal, Floor, Kasper, Mandy, Sanne, Juan, Piter, Lucia, Maya, Lisette, Henk among others, with special attention to my officemates (new and former) Hamed, Mathieu, Charles, Merina, Sonia, Maria, Garreth and Zih Hua, you guys rule! That is why we are the best office! Aren't we? You guys helped me so much during my PhD, sharing knowledge, solving problems and questions together, chatting and having so much fun and party when I needed it the most. A special thanks for your support during my stress period before handing in the thesis, you made my days easier, and I will always thank you for that. Finally, Sonia, Yvonne, Amabel, Claudia, Merina and Maria, it was so much fun to travel with you, people say that you really know somebody when you travel together, and it is indeed true, travelling with you girls was so much fun and I enjoyed it a lot, I really hope we travel together again somehow, 
somewhere (in Mexico perhaps?), girls: thanks for make those 4 years fun, crazy and joyful. Special thank for my paranymphs: Yvonne and Maria, you rock girls!

I would like to thank to my mentors from INIFAP, that always believed in me and supported me from the start of my career encouraging me to take this adventure: Moises and Vicente. And special acknowledgment for Juan Magaña from UADY, for being my counselor for many years and always give me the best advices. Also I would like to thank Angel Sierra for his friendship and advice in several moments of my life. To my former colleagues, which I spent so many nice days with: Omar, Diana, Gello, Lino, Claudia, Emiliano, Alma thank you so much guys! I also would like to thank all my friends in Mexico, that despite the distance were always there to cheer me up with nice words: Zelmy, Marytere, Karla, Laura, Gina, Claudia, Joel, Marco, and many others. Gracias amigos por estar ahí para mi siempre con un mensaje de aliento y siempre apoyándome en mis locas aventuras, los quiero mucho! A special thank to my Mexican friends here in Wageningen: Edgar, Francisco, Edith, Oscar, Lupita, Teresa, Lilo, Erika, Pamela (para mi eres como si fueras mexicana); ustedes me han ayudado muchísimo a hacer llevaderos estos años, con sus platicas, sus consejos, su compañía pero sobretodo su amistad. Chicas, compartir con ustedes ha sido hermoso, viajar juntas, celebrar juntas y crecer juntas ha sido muy gratificante. Estoy segura de que nos encontraremos de nuevo en algún lugar planeado o no.

I would like to thank Ellie, Leen, Gertjan and Viola for being a second family for me, we have spent together nice evenings and I hope you will visit me soon in Mexico. Finally, I would like to thank you, Mathijs, for all your support during those years, especially in the last stretch, without it this achievement would be impossible, you have been always there for me, encouraging me every day to keep going and to be a better person. Thank you my love.

\section{Caralia}




\section{Colophon}

This PhD program was financially supported by the National Council on Science and Technology of Mexico (CONACYT, Mexico) with the scholarship number 177181 (year 2012) and the National Research Institute of Forestry, Agriculture and Livestock (INIFAP).

The data used was collected and brought together in projects previously financed by the Dutch Dairy Board (Zoetermeer, the Netherlands), the Dutch Product Board Animal Feed (Zoetermeer, the Netherlands) and CRV (Arnhem, the Netherlands). The data used in Chapter 3 was provided by Agriculture and Food Research Initiative Competitive Grant \# 2011-68004-30340 from the USDA National Institute of Food and Agriculture. EU FP7 IRSES SEQSEL (Grant No. 317697) funded the research stay of the first author in Victoria, Australia, where the research presented in Chapter 4 was performed.

The cover of this thesis was made by Ana Ramayo based on a paint from Manuel Mena Avila.

This thesis was printed by Digiforce, Vianen, the Netherlands

ISBN 978-94-6343-069-2

DOI: $10.18174 / 403342$ 